ISSN: 0719-2150

Revista Chilena de

\title{
DERECHO Y CIENCIA POLÍTICA
}

Facultad de Ciencias Jurídicas, Económicas y Administrativas

\section{UNIVERSIDAD \\ CATÓLICA DE \\ TEMUCO}




\section{REVISTA CHILENA}

\section{DE DERECHO Y CIENCIA POLÍTICA}

FACULTAD DE CIENCIAS JURÍDICAS, ECONÓMICAS Y ADMINISTRATIVAS 


\title{
REPRESENTANTE LEGAL
}

Dr. Aliro Bórquez Ramírez, Rector

\author{
Director EDITOR \\ Dr. David Almagro Castro, Universidad Católica de Temuco, Chile
}

\section{COMité Editorial Área JurídicA}

Dr. Mártin Haeberlin, Centro Universitario UniRitter, Brasil

Dr Augusto Martin de la Vega, Universidad de Salamanca, España

Dr Ingo Wolfgang Sarlet, Pontificia Universidad Católica de Rio Grande do Sul., Brasil

Dr. Víctor Javier Vázquez Alonso, Universidad de Sevilla, España

Dr. Felipe Paredes, Universidad Austral de Chile

Dra. Patricia Toledo Zúñiga, Universidad Austral de Chile, Chile

Dr. Manuel Carrasco Durán, Universidad de Sevilla, España

Dr. David Martín Herrera, Universidad Nacional de Educación a Distancia, España

\section{Comité Editorial Área Ciencia Política}

Dr. Christopher Martínez Nourdin, Universidad Católica de Temuco, Chile

Dra. Gabriela Tarouco, Universidad Federal de Pernambuco, Brasil

Dr. Leiv Marsteintredet, University of Bergen, Noruega

Dr. Eduardo Carreño Lara, Universidad de Chile, Chile

Dra. Jessica Mecellem, Sewanee: The University of the South, Estados Unidos

Dra. María Cristina Escudero Illanes, Universidad de Chile, Chile

Dra. Ana Isabel López García, German Institute of Global and Area Studies GIGA, Alemania

Dr. Carlos Miguel Rico Motos, Universidad Pontificia de Comillas, España 


\section{Comité Científico Editorial}

Dr. Jorge Del Palacio Martín, Universidad Rey Juan Carlos, España

Dr. Jhon Polga-Hecimovich, United States Naval Academy, Estados Unidos

Dr. Ivan Mauricio Obando Camino, Universidad de Talca, Chile

Dr. Pablo Eduardo Slavin, Universidad Nacional de Mar del Plata, Argentina

Dr. Enrique Pastor Seller, Universidad de Múrcia, España

Dr. Gabriel Negretto, Columbia University, México

Dr Ginés Marco Perles, Universidad Católica de Valencia San Vicente Mártir, España

Dr Miguel Azpitarte Sánchez, Universidad de Granada, España

Dr. Mauricio Morales Quiroga, Universidad de Talca, Chile

Dra. Claudia Heiss, Universidad de Chile, Chile

Dr. Pablo Nicolás Biderbost, Universidad Pontificia Comillas, España

Dr. Alfredo Di Pietro, Universidad Católica de Temuco, Chile

Dr. Juan Carlos Gómez Leyton, FLACSO Chile, Chile

Dr. Sergio Toro Maureira, Universidad Católica de Temuco, Chile

Dra. Agustina Palacios Rizzo, Universidad Nacional de Mar del Plata, Argentina

Dr. Jordi Delgado Castro, Universidad de Talca, Chile

Dr. David Vallespín Pérez, Universidad de Barcelona, España

Dr. Paolo Comanducci, Universidad de Génova, Italia

Dr. Vladimir Aguilar Castro, Universidad de Los Andes, Venezuela

Dra. Yennesit Palacios, Universidad Pablo de Olavide, España

Dr. Leslie Wehner, Universidad de Bath, Alemania

Dr. Lorenzo Bujosa Vadell, Universidad De Salamanca, España

Dr. David Cienfuegos, Universidad Nacional Autónoma de México, México

Dr. Ariel Mantecón Ramos, Universidad de Valencia, Cuba

Dr. Jean Pierre Matus Acuña, Universidad De Chile, Chile

Dr. Rodrigo Coloma, Universidad Alberto Hurtado, Chile

Dr. Jaime Baeza, Universidad de Chile, Chile

Dra. Judith Schönsteiner, Universidad Diego Portales, Chile

CoOrdinadora Editorial

Claudia Campos Letelier, Universidad Católica de Temuco, Chile

Asistente de Coordinación

Hernán Sandoval Alarcón, Universidad Católica de Temuco, Chile

Corrector de Estilo y Diseñador

Angélica Vera Sagredo, Universidad Católica de Temuco, Chile 


\title{
REVISTA CHILENA DE DERECHO Y CIENCIA POLÍTICA
}

\author{
ISSN 0718-9389 | E-ISSN 0719-2150 | VOL. 10 | NÚM. 1 | 15 DE JUNIO DE 2019
}

La Revista Chilena de Derecho y Ciencia Política es una publicación científica editada por la Facultad de Ciencias Jurídicas, Económicas y Administrativas, fundada en el año 2010. Su sello distintivo se basa en la existencia de dos secciones permanentes sobre el Derecho y la Ciencia Política entendidas como campos interdisciplinares. Su objetivo principal es la creación de espacios especializado que se beneficie de las sinergias que pueden y deben establecerse entre ambas especialidades.

La Revista publica trabajos de investigación originales que versen sobre las diferentes ramas del Derecho, manifestando especial interés en materia de derechos fundamentales y su proyección en el ordenamiento jurídico en su conjunto. En el campo de la Ciencia Política, recibe trabajos de investigación originales que aborden el estudio de las relaciones entre instituciones, actores y procesos políticos desde una perspectiva comparada, con especial preferencia en el ámbito Iberoamericano.

Revista Chilena de Derecho y Ciencia Política es una publicación semestral y está indexada en Latindex, Dialnet, Rebiun, CLASE UNAM, BCN (Biblioteca Congreso Nacional), Cisne (UCM), Al día (Universidad de Chile),V-Lex, El Mercurio Legal, EZB, WorldCat, MacEwan University, Academic Journal Database. Los números se publican en los meses de junio y diciembre de cada año.

\author{
Revista Chilena de Derecho y Ciencia Política \\ Casilla $15 \mathrm{D}$, Temuco. \\ Teléfono: (56-45) 2205317 \\ derechoycienciapolitica@uct.cl•www.derechoycienciapolitica.cl
}

Revista Chilena de Derecho y Ciencia Política es distribuida bajo una Licencia

Creative Commons Atribución-NoComercial-NoComercial 4.0. 


\section{REVISTA CHILENA DE DERECHO Y CIENCIA POLÍTICA}

ISSN 0718-9389 | E-ISSN 0719-2150 | VOL. 10 | NÚM. 1 | 15 DE JUNIO DE 2019

\section{Contenidos}

Editorial

\section{ARtíCUlos DE INVESTIGACIÓN}

\section{Constanza Pamela Basoalto Riveros}

Alcances de la adopción homoparental a la luz del interés superior del niño.

\section{José Reynel Cristancho Díaz}

Capacidad jurídica de las personas con discapacidad: ¿Derecho fundamental absoluto?

\section{Lisandra Suárez Fernández y Luis Pérez Orozco}

Estudio doctrinal, legal y jurisprudencial de los efectos de la fertilización invitro heteróloga en la filiación.

\section{Gabriel Budnik Ojeda}

Indemnización de perjuicios por infracciones a la libre competencia

\section{Lina Maritza Camacho Lucio}

Los diputados chilenos y la despenalización del aborto: una aproximación desde el análisis crítico del discurso.

\section{José Miguel González Zapata y Luciano Simonetti Izquierdo}

Propiedad y caridad en Locke. Un análisis crítico a la propuesta interpretativa de Juliana Udi

\section{Patrícia Perrone Campos Mello}

Comportamiento judicial estratégico: el caso del supremo tribunal federal de Brasil ....

\section{Thiago Augusto de Oliveira Marinho Ferreira}

A Atuação dos Tribunais de Contas Estaduais Brasileiros em prol da Qualidade das Políticas Públicas 
RESEÑA

Camilo Garber Fuentes

Recensión How Democracies Die...... 


\title{
EDIT ORI AL
}

\section{El Derecho de Partidos, un campo de estudio necesiado de INTERDISCIPLINARIEDAD}

\section{David Almagro Castro}

Director

\author{
Revista Chilena de Derecho y Ciencia Política
}

Facultad de Ciencias Jurídicas y Administrativas

Universidad Católica de Temuco

La elección de este tema para el editorial de nuestro número 10.1 no es, ni mucho menos, fruto de la casualidad. Muy al contrario: cualquier lector familiarizado con los contenidos de nuestra Revista sabrá que la principal seña de identidad de nuestra publicación es la apuesta decidida por la consolidación de una cultura de trabajo e investigación que fomente la interdisciplinariedad entre el Derecho y la Ciencia Política.

Si tuviéramos que elegir un área necesitada de las sinergias que la metodología interdisciplinar puede aportar, no sería descabellado apostar por los partidos políticos y su discurrir vital, a medio camino entre la Ciencia Política y el Derecho. A nadie escapa hoy día que estas organizaciones se han convertido en instituciones centrales del sistema político. Esta trascendencia les ha hecho acreedores de reconocimiento constitucional y ha hecho necesario el desarrollo de un buen número de leyes con la intención - no siempre acompañada de buenos resultados - de regular satisfactoriamente los diferentes aspectos de su organización y funcionamiento. A este hecho ha contribuido, sin duda, un apetito desmedido por ocupar y controlar los diferentes resortes decisorios del Estado.

La Ciencia Política viene discutiendo desde finales del siglo pasado acerca del decepcionante presente e incierto futuro de la democracia de partidos. No son pocos los autores - como Peter Mair - que afirman que la era de la democracia de partidos, como la hemos conocido, ha pasado; según el insigne autor, nos encontramos en una situación de reorganización del espacio político que abrirá espacio a nuevos actores decisivos al margen de los partidos. Esta situación es consecuencia de la transformación de los partidos en entidades autorreferenciales, desideologizadas y preocupadas únicamente por la satisfacción de sus intereses y al margen de las expectativas ciudadanas.

Este diagnóstico es, no hay como dudarlo, bien preocupante y exige responder satisfactoriamente una pregunta urgente: ¿Qué puede hacer el Derecho para contribuir a revertir la desafección y crisis en la democracia de partidos? 
Es bien sabido que para la Ciencia Jurídica los partidos son concebidos como asociaciones privadas que desarrollan funciones públicas de especial trascendencia para el sistema democrático. Su centralidad sistémica choca, sin embargo, con una paradoja preocupante que conviene no minusvalorar: la desproporción existente entre su condición de agente principal del sistema democrático y la persistencia de un régimen jurídico que no corrige las deformaciones y vicios anteriormente denunciados.

El sistema político y el Derecho de partidos chileno no es ajeno a este diagnóstico. Los estudios y análisis de una parte expresiva de politólogos, que advierten de la probable insostenibilidad del sistema político a largo plazo si persisten las notorias deficiencias del funcionamiento de los partidos, no se ven acompañados de la generación de un Derecho de partidos que permita presionar a los actores estatales para consolidar unas reglas del juego que permita recuperar la credibilidad en la democracia de partidos. El riesgo, parafraseando a Ortega y Gasset, es que la realidad por tanto tiempo ignorada traiga consigo su venganza. 


\author{
ARTÍCULO DE INVESTIGACIÓN
}

\title{
Alcances de la adopción homoparental a la luz del interés superior del niño
}

\author{
Effects of homoparental adoption in the light of the best interests of the child
}

\section{Constanza Pamela Basoalto Riveros ${ }^{1}$ \\ Universidad de Talca, Chile}

\begin{abstract}
RESUMEN Si la adopción busca propiciar al adoptado el mejor entorno posible para su crianza, educación y cuidado, la real pregunta sobre la admisibilidad de la adopción homoparental es si esta perjudica o no el resguardo del interés superior del niño. Por ello, este trabajo brinda diversas razones jurídicas y no jurídicas para arribar a una conclusión, examinando algunos de los conceptos involucrados en la problematización, como también las inconsistencias de los argumentos que rechazan la procedencia de la misma. Se sostiene, por tanto, que tales razonamientos fracasan en formular objeciones persuasivas a la crianza homoparental.
\end{abstract}

PALABRAS CLAVE Familia, Adopción, Interés Superior del Niño.

ABSTRACT If adoption seeks to provide adopted children with the best possible environment for their upbringing, education and care, the real question about the admissibility of homoparental adoption is whether or not it harms the best interests of the child. This work proposes several legal and non-legal arguments from which to draw a conclusion, examining some of the concepts involved in the problematization, as well as the inconsistencies of the arguments that reject homoparental adoption. It is argued that such reasoning fails to formulate persuasive objections to homoparental parenting.

1. Abogada. Licenciada en Ciencias Jurídicas y Sociales de la Universidad de Talca. Magíster en Derecho, de la misma casa de estudios. Profesora de la Facultad de Derecho, Universidad Santo Tomás, Chile. Mail: cbasoalto@utalca.cl 
KEYWORDS Family, Adoption, Interest of the child.

\section{Delimitación introductoria}

Actualmente, la Ley $\mathrm{N}^{\circ} 19.620$ sobre Adopción de Menores propone un sistema de adopción que repercute directamente en las parejas del mismo sexo. La ley imposibilita que estas accedan a la adopción conjunta, situación ligada esencialmente a la exigencia del vínculo matrimonial de la cual dichas parejas se encuentran todavía excluidas. Aquel escenario ha propiciado la difusión del debate sobre la procedencia o el rechazo de la adopción homoparental, el cual se ha visto renovado por la discusión parlamentaria del actual Proyecto de Ley sobre Matrimonio Igualitario ${ }^{2}$, del que seguramente se derivarán importantes consecuencias legales en la redefinición de aquella histórica institución.

Por su parte, pese a las legítimas exigencias de las minorías sexuales, en general se olvida que la adopción busca como objetivo primordial el interés superior del niño, por lo que en estricto rigor, para nadie existe algo así como un "derecho a la adopción". En base a lo anterior, es que la problemática debe girar en torno a la idoneidad más que a la igualdad, y por ello es que la homoparentalidad, como elemento característico de la pareja adoptante, no debe ser considerada un factor condicionante del interés superior del niño. Para evidenciar esta proposición primeramente se desarrollarán algunos conceptos jurídicos involucrados, luego se expondrá el marco legal imperante en Chile, y finalmente se analizarán las inconsistencias de las tesis que rechazan dicha posibilidad.

\section{Conceptos involucrados en la problematización}

\subsection{Adopción y familia}

La adopción no es un fenómeno reciente. La condición de desamparo generada por el abandono, por la muerte o incapacidad de los progenitores se ha producido a lo largo de la historia de la humanidad, por ello es que para hacer frente a la circunstancia de niños carentes de familias idóneas, es que desde antaño esta institución ha pretendido crear, en general, una relación similar a la de padre e hijo ${ }^{3}$.

Pese a que esta idea ha contado con cierta permanencia en el tiempo, lo cierto es que originalmente la adopción contaba con objetivos muy diferentes a los actuales. Esta, tal como ocurre con otras instituciones, ha experimentado importantes cam

2. Boletín 11.422-07 de 2017 .

3. GARRIDO (2011) p. 16. 
bios según las normas y valores de cada una de las sociedades en las que ha encontrado aceptación ${ }^{4}$.

De esta manera, en el primitivo Derecho romano, la institución nació como una forma de incorporar a un varón bajo la patria potestad de un pater familias ${ }^{5}$. En aquel contexto se solía distinguir entre diferentes modalidades de adopción, la adoptio y la adrogatio, las cuales si bien, contaban con diferentes requisitos formales ${ }^{6}$, en la práctica servían para facilitar la continuidad de apellidos ilustres ${ }^{7}$, así como también la transmisión de ciertos patrimonios ${ }^{8}$.

Esta situación, que pone el acento en el adoptante antes que en el adoptado, no necesariamente cambió en el siguiente período, pues efectivamente, la edad media tampoco fue una época precisamente próspera en lo que a la protección jurídica de la niñez se refiere ${ }^{9}$. Ciertamente, durante el medioevo la nueva organización religiosa y la moral cristiana resultaron fundamentales en la concepción que se tuvo sobre la familia, razón por la cual, la adfiliatio, un remedo de la adoptio romana ${ }^{10}$, permitía que un ser humano sea acogido por otro, siempre y cuando fuera por razones caritativas y asistenciales, y sin dar lugar al nacimiento de vínculos familiares ${ }^{11}$.

Por el contrario, el propósito protector que hoy atribuimos a la adopción se hizo patente recién entrando el siglo $\mathrm{XX}^{12}$, donde con ocasión de diversos factores, tales como los efectos de las guerras mundiales, la transformación de ciertos valores y normas culturales, así como los avances en el reconocimiento de la infancia y sus derechos, fueron influenciando en gran medida la práctica de la adopción, hasta llegar a la fisionomía que hoy le podemos atribuir.

Conforme con lo anterior, es cierto que el acento de la filiación adoptiva ha cambiado de acuerdo con la mutación de las costumbres, la organización social y la conciencia que las comunidades tienen respecto a realidades como el matrimonio y la

4. Sin ir más lejos, la adopción ocupa un lugar distintivo en varias historias mitológicas de la antigüedad clásica: hijos que son abandonados por sus padres, normalmente dioses, para ser encontrados por una familia humilde o un animal salvaje. Vemos ejemplos de aquello en las historias de Edipo, en la cultura griega, y la de Rómulo y Remo, en la romana.

5. CORRAL (2001) p. 9.

6. Conforme con lo expresado por GUZMÁN (2012) p. 360, la adrogatio se celebraba ante los comicios curiados en presencia de un Pontífice, mientras que la adoptio no exigía la misma intervención.

7. En relación a sus efectos, en ambos tipos de adopción el adoptado salía de una familia para entrar en la del adoptante. Para un análisis más a fondo véase a RODRÍGUEZ (1973) p. 235.

8. SALAS (2013) p. 193.

9. Para REA-GRANADOS (2016) pp. 151 y ss, las razones radican en el interés excluyente del Estado en fortalecer su soberanía, lo cual dejaba a un lado la protección de los derechos humanos.

10. VALLVERDÚ (2004) pp. 37 y 38.

11. DEL PICÓ et al (2016) p. 541.

12. BARROSO (2012) p. 60. 
infancia ${ }^{13}$. Por ello, indudablemente el origen y la aceptación paulatina de la adopción homoparental tiene directa conexidad con los cambios en las concepciones imperantes sobre lo que es y no es la familia, fundamentalmente porque el objetivo, $\mathrm{o}$ al menos el que hoy se tiene, es reestablecer el derecho del niño a formar parte de una.

Es más, si la adopción homoparental genera tantas interrogantes, es porque redefine el tradicional triángulo padre-madre-niño que ha constituido hasta ahora el modelo familiar tradicional. En esa línea cobra importancia el proceso evolutivo que ha experimentado esta institución, con la consecuente aparición de algunas tipologías de familia, incluida la homoparental.

En este sentido, primeramente debe establecerse que la familia es siempre una categoría activa ${ }^{14}$, y de acuerdo con ello, la noción nunca permanecerá estática, por la misma razón que ha sobrevivido a todas las transformaciones que han ocurrido a lo largo de la historia, desde las etapas primitivas recién descritas hasta la sociedad actual.

Del mismo modo, y si se quisiera emprender la difícil tarea conceptual, podrían ser muchas las nociones que pueden acuñarse sobre la institución ${ }^{15}$, pero en general, el significado jurídico de familia no constituye un concepto que concite unanimidad en la doctrina, realidad que tradicionalmente se ha derivado a la ley con las mismas características elusivas y vagas del debate público sobre la materia.

Así, desde el punto de vista del Derecho Internacional, el Pacto Internacional de Derechos Civiles y Políticos, en su artículo 23, y la Convención Americana de Derechos Humanos, en su artículo 17, propenden a la protección de la familia sin dar una definición concreta, pues en general, los tratados sobre derechos humanos no consagran un modelo único de la misma ${ }^{16}$.

De igual forma, el Código Civil chileno, en conjunto con otras leyes complementarias internas, mencionan a la familia en diversas disposiciones, definiéndola para efectos precisos, cuyos alcances son bastante restringidos atendidas las materias que pretenden regular $^{17}$.

\section{CORRAL (2002) p. 57.}

14. PLACERES et al (2017) p. 362.

15. Para OLIVA Y VILLA (2014) p. 20, la definición de familia nunca será simple, por cuanto su estudio debe ser abordado desde una perspectiva integradora que permita observarla bajo una comprensión incluyente de todas las disciplinas que la tienen como objeto de análisis.

16. GARCÍA Y CONTRERAS (2014) p. 460.

17. De esta manera, el artículo 815 del Código Civil emplea una definición de familia bastante amplia al hacer referencia a las necesidades personales del usuario y habitador. En igual sentido, la Ley $\mathrm{N}^{\circ} 19.620$ entiende por familia de origen a "los parientes consanguíneos a que se refiere el artículo 14 , y a falta de ellos, a quienes tengan bajo su cuidado al menor de edad". 
Por su parte, una definición que se ha tornado clásica es la referida por la Constitución Política de la República, cuyo artículo primero precisa que la familia es el núcleo fundamental de la sociedad, idea que repite la Ley de Matrimonio Civil. Estos textos, de manera similar a lo recogido por los instrumentos internacionales antes mencionados, no precisan el concepto de familia que el Estado debe proteger, sin embargo, el Tribunal Constitucional ha señalado a propósito de dichas normas, que el modelo de matrimonio heterosexual y monogámico consagrado en la legislación es compatible con la idea de familia como núcleo fundamental de la sociedad, aunque tal consagración no descarta que otras formas de familia sean igualmente compatibles ${ }^{18}$.

Esta amplitud conceptual nos permite transitar desde la familia nuclear, en su consideración más clásica, pasando por las familias monoparentales, hasta llegar a las familias mixtas o ensambladas ${ }^{19}$. De la misma forma, puede pensarse en la familia poligámica, propia de la tradición islámica, como también en los modelos familiares que reportan algunas comunidades indígenas ${ }^{20}$.

Según Espinoza Collao ${ }^{21}$, este cambio de paradigma en el tratamiento jurídico de la familia y la consecuente ampliación de su estructura ha sido el resultado de una confluencia de factores que pueden resumirse en el vacío de los elementos basales del Derecho de Familia. En este sentido, basta observar la actual institución matrimonial como contrato disoluble, el amplio reconocimiento a la autonomía de la voluntad, la eliminación de las distinciones entre hijos, y lógicamente, el avance en el reconocimiento legal de las uniones homosexuales ${ }^{22}$.

18. Requerimiento de inaplicabilidad por inconstitucionalidad (2013).

19. MARTÍNEZ (2015) p. 526 define a la familia nuclear como la unidad familiar básica que se compone de padre, madre e hijos, y a la familia monoparental como aquella constituida por uno de los padres y sus hijos. Por su parte, GROSMAN Y MARTÍNEZ (2000) p. 35, definen a las familias mixtas como aquellas originadas en el matrimonio o unión de hecho en la cual uno o ambos de sus integrantes tiene hijos provenientes de una relación previa.

20. En este sentido, véase a ESPINOZA (2016) pp. 119 y ss, quien realiza un análisis de los modelos familiares originarios de las comunidades indígenas del norte de Chile.

21. ESPINOZA (2017) pp. 226 y ss.

22. Ciertamente, es posible aseverar que dichas transformaciones conceptuales no han sido más que el resultado de un profundo proceso de cambio en varias ideas determinantes del Derecho de Familia. En este sentido, sobre los nuevos principios que inspiran esta área legal, véase LEPÍN (2014) pp. 9 y siguientes. 
Bajo esa dirección pueden encuadrarse las múltiples reformas legales que han reemplazado la visión unívoca que el Código Civil asume de la familia, por una regulación que permite abrir espacios para diferentes proyectos de vida. Así se observa en la Ley $\mathrm{N}^{\circ} 20.066$ sobre Violencia Intrafamiliar y la Ley $\mathrm{N}^{\circ} 20.830$ que creó el Acuerdo de Unión Civil. La primera reconoce como objeto de protección incluso a los ex convivientes, mientras que la segunda posibilita la unión civil de parejas de hecho sean o no del mismo sexo.

Finalmente, es dable destacar la influencia de ciertas corrientes del pensamiento jurídico en la concepción familiar. De esta manera se ha hablado del pluralismo jurídico aplicable a las relaciones familiares y de la constitucionalización del Derecho de Familia.

El paradigma del pluralismo jurídico conlleva un reconocimiento de la convergencia en un mismo espacio geográfico de dos o más sistemas jurídicos diversos ${ }^{23}$. Dentro de aquella línea el Derecho de Familia promueve la apertura de nuevos modelos familiares, pues bajo tal idea es posible el reconocimiento de grupos minoritarios cuyas maneras de estructurar su vida familiar muchas veces difieren del patrón generalmente aceptado. En este sentido, mucho se ha debatido sobre el reconocimiento del derecho de los pueblos originarios al control de sus propias instituciones, donde precisamente, para algunas de estas culturas, sus miembros son parte de una familia nuclear, pero también de una familia ampliada y de una patrilocalidad ${ }^{24}$.

Por otro lado, la constitucionalización es un fenómeno generalizado en diversas áreas del Derecho, en virtud del cual se produce la extensión de la fuerza normativa de la Constitución a las distintas ramas legales ${ }^{25}$, vale decir, un proceso de transformación en que el ordenamiento jurídico resulta totalmente impregnado por las normas de la Carta Fundamental ${ }^{26}$.

Para la profesora Fabiola Lathrop ${ }^{27}$, la normativa constitucional incidiría directamente en las relaciones privadas entre particulares, y en especial, en cuestiones de carácter extrapatrimonial, como el Derecho de la Persona (protección de la vida,

22. Ciertamente, es posible aseverar que dichas transformaciones conceptuales no han sido más que el resultado de un profundo proceso de cambio en varias ideas determinantes del Derecho de Familia. En este sentido, sobre los nuevos principios que inspiran esta área legal, véase LEPÍN (2014) pp. 9 y siguientes.

23. LLANO (2016) pp. 54 y ss.

24. RUÍZ Y SÁNCHEZ (2011) p. 27.

25. ALVITES (2018) p. 362.

26. FAVOREU (2001) p. 40

27. LATHROP (2017) pp. 330 y ss. 
derecho a la honra, intimidad, entre otros) y por supuesto en el Derecho de Familia. De esta manera, inspirados en el proceso de constitucionalización, los juristas han comenzado a cuestionar las bases de la regulación de la vida familiar, así como también han comenzado a buscar el reconocimiento igualitario de los derechos de familia. Precisamente, entre tales derechos, se puede mencionar el libre desarrollo de la personalidad, garantía reconocida a nivel constitucional que comprende también el derecho fundamental a elegir el modelo de familia en que los sujetos desean perfeccionar su proyecto de vida ${ }^{28}$.

Siguiendo a Zúñiga y Turner ${ }^{29}$, el fenómeno supone además la existencia de normas jerárquicas provenientes de diferentes cuerpos normativos ligados a la Constitución, (por ejemplo, el Derecho Fiscal y el Derecho Administrativo), lo cual evidencia que la regulación de la familia no puede ser privativa de las leyes civiles, porque dichos cuerpos normativos solo la tratan de manera parcelada. En consecuencia, todas estas disposiciones jurídicas, tanto legales como constitucionales, buscan por un lado, describir un conglomerado de relaciones típicas que socialmente son entendidas como una familia y, por el otro, prescribir, dentro de estas últimas, solo "algunos modelos" especialmente deseables, más no imperativos, todos dignos de protección.

\subsection{Interés superior del niño: Interés superior del adoptado}

Cabe iniciar este apartado puntualizando qué es y cómo se debe entender un "principio", término clave a los fines de las presentes líneas.

Siguiendo a Dworkin, un principio es un estándar que ha de ser observado no porque favorezca una situación económica, política o social deseable, sino porque es una exigencia de la justicia, la equidad o alguna otra dimensión de la moralidad ${ }^{30}$. Conforme con esta afirmación, la teoría supone que el principio se impone a la autoridad, y en consecuencia, nada más lejano al sentido de lo que se llama principio del interés superior del niño, creer que debe sólo "inspirar" las decisiones de las autoridades. Muy por el contrario, este dispone una limitación, obligación o prescripción de carácter imperativo hacia las mismas ${ }^{31}$.

El interés superior del niño es un principio fundamental de la legislación que rige el Derecho de la Infancia y Adolescencia, y a su vez una expresión de uso frecuente en el Derecho de Familia, a pesar de que, aunque suene de Perogrullo, sea un término

28. ESBORRAZ (2015) pp. 26 y ss.

29. ZÚÑIGA Y TURNER (2013) p. 273.

30. DWORKIN (1989) p. 72.

31. RODRÍGUEZ (2013) p. 12. 
indefinido tanto en nuestra legislación ${ }^{32}$ como en la Convención sobre los Derechos del $\mathrm{Niño}^{33}$. Con dicha advertencia, cabe señalar que el mencionado instrumento en su artículo 3 dispone que debe atenderse siempre a este interés superior en todas las medidas concernientes a los niños, niñas y adolescentes, lo cual concuerda con lo señalado por el Comité de los Derechos del Niño, que en su Observación General Número 14 lo ha catalogado como un principio rector ${ }^{34}$.

Ya en lo que se refiere al contenido preciso del interés superior, se debe primero señalar que el término se enmarca en aquella clase de nociones que la lingüística jurídica califica de abiertas, las cuales hacen necesaria una definición funcional, siempre atenta con la circunstancialidad casuística ${ }^{35}$. Esto quiere decir que el interés superior del niño debe ser concretado en cada situación específica ${ }^{36}$.

Pese a lo anterior, en general, hay cierta unanimidad en cuanto a entender que aquel interés consiste en la plena satisfacción de todos los derechos que surgen de su calidad de persona humana ${ }^{37}$. En este sentido, la Corte Suprema ha señalado que el principio "alude al pleno respeto de los derechos esenciales del niño, niña o adolescente, buscándose a través del mismo, el asegurar el ejercicio y protección de los derechos fundamentales de los menores y posibilitar la mayor satisfacción de todos los aspectos de su vida, orientados al desarrollo de su personalidad"38.

Más allá del alcance conceptual, es indudable que aquel principio se encuentra involucrado en la problemática de la presente investigación, y en consecuencia, el interés superior del niño pasará a ser el del adoptado, lo que hará necesario explicitar su aplicación en la presente materia.

32. No obstante, los profesores Pinochet y Ravetllat aseguran que, si inicialmente esta cláusula se configuró en Chile como un concepto jurídico indeterminado, posteriormente el legislador parece haberse decantado, en particular tras la reforma introducida en el Código Civil por la Ley $\mathrm{N}^{\circ} 20.680$, hacia un mayor nivel de concreción positiva del término, lo que se ha logrado por medio de la introducción de ciertos indicadores que facilitan al intérprete su aplicación. Los autores señalan que tales indicadores aparecen, por ejemplo, en los artículos 225-2 y 229 del Código Civil, relativos al establecimiento del régimen y ejercicio del cuidado personal de los hijos y a la fijación del régimen de relación directa y regular con el progenitor que no tenga el cuidado personal. PINOCHET Y RAVETLLAT (2015) pp. 918 y 919.

33. GÓMEZ (2000) p. 23.

34. Comité de los Derechos del Niño (2013) pp. 3 y 4.

35. Melín con Alarcón (2017).

36. TURNER (2012) p. 262.

37. CILLERO (1999) p. 26. En el mismo sentido GÓMEZ (2007) p. 46.

38. Martínez con Pavez (2014). 
En general, cuando se habla de adopción, el interés superior se entrelaza con lo que algunos autores llaman "el binomio control-garantía"39. Conforme con este elemento, la autoridad competente será responsable de llevar a cabo un doble examen.

En primer lugar, se deberá examinar la situación particular del niño de manera que pueda ser "declarado" adoptable. En la práctica, este examen se verifica mediante el proceso de susceptibilidad de adopción, el que constata la situación del niño en relación con su familia de origen, contemplando la posibilidad de que esta se oponga al proceso.

Desde el punto de vista teórico, la situación anterior se vincula con el resguardo del principio de subsidiariedad de la adopción, conforme al cual, la adopción será admitida solo cuando la familia de origen no esté en condiciones de proporcionar al niño el afecto y los cuidados necesarios ${ }^{40}$. En esa línea, la Corte Suprema ha señalado que "sólo se puede decretar la susceptibilidad de adopción cuando se haya establecido que es imposible mantener al menor en su familia de origen, habiendo realizado los organismos del Estado todas las acciones tendientes a mantener al niño en su familia ${ }^{41}$ ".

Por otro lado, el interés superior del niño implicará un análisis de los futuros padres o posibles candidatos, en el sentido de si son o no aptos para adoptar. Bajo este examen deberá evaluarse si la familia adoptiva es idónea en cuanto capacidad para satisfacer las necesidades espirituales y materiales del niño, como también el respeto de sus derechos esenciales ${ }^{42}$.

En este sentido, y tomando en cuenta la segunda arista del mencionado examen, privar a niños de la posibilidad de hacer parte de una familia, con el único argumento de que esta está integrada por una pareja del mismo sexo, implica generar un déficit de protección que compromete su derecho a tener una familia y con ello el principio de interés superior, que es precisamente el criterio que debe imperar en esta clase de decisiones $^{43}$.

De esta manera, considerando sólo el principio en análisis no existe un criterio objetivo para restringir a niños en situación de orfandad el derecho a tener una familia, o limitarlo únicamente a aquellas integradas por un hombre y una mujer. Esto significa que una decisión que a priori descarta la idoneidad de una pareja fundándose en su orientación sexual, nunca lo será en búsqueda del interés superior del niño. Por el contrario, un criterio que atiende a dicho interés es aquel que sólo tendrá en cuenta las cualidades de crianza de los padres.

39. GARCÍA (2003) p. 67.

40. GOÑI (2016) p. 4.

41. I.S.V. con SENAME (2017).

42. GÓMEZ (2007) p. 227.

43. DE FELICE (2016) p. 402. 
Finalmente, las consideraciones basadas en preconceptos relativos a las personas homosexuales o su presunto impacto negativo en la vida de los niños y niñas, no son de recibo a la hora de decidir sobre la adopción ${ }^{44}$.

\section{Situación actual de la adopción homoparental en Chile}

La Ley $\mathrm{N}^{\circ} 19.620$ sobre Adopción de Menores en sus artículos 20, 21 y 31 determina las personas que pueden considerarse como posibles adoptantes, los requisitos que deben cumplir y la preferencia que debe hacerse entre ellas cuando concurra más de una respecto del mismo niño. La adopción es una medida excepcional, y como se señaló, se funda en el interés superior del adoptado, por lo que sólo puede ser autorizada a dichas personas y en los casos que la ley expresamente ha dispuesto ${ }^{45}$.

La ley contempla dos grandes modalidades o formas de adopción: La adopción conjunta o conyugal, que admite la pluralidad de adoptantes, y la adopción individual.

La adopción conjunta, esto es, por padre y madre a la vez, es desarrollada en el artículo 20 del mencionado cuerpo normativo ${ }^{46}$. De acuerdo con esta disposición, podrá otorgarse la adopción a los cónyuges que cumplan con los requisitos establecidos en la norma, de manera que sólo es admitida cuando medie entre ambos un vínculo matrimonial. Por otro lado, la adopción individual se encuentra regulada en el artículo $21^{47}$. Esta figura permite que una persona cuyo estado civil es el de soltera, viuda o divorciada, con residencia permanente en el país, pueda también optar por la adopción.

Como se puede observar, la normativa no niega de manera expresa la posibilidad de que parejas homosexuales puedan adoptar, sin embargo, conforme la redacción

44. BOLAÑOS Y CHARRY (2018) p. 414.

45. CORRAL (2002) p. 195.

46. Ley N¹9.620, artículo 20: "Podrá otorgarse la adopción a los cónyuges chilenos o extranjeros, con residencia permanente en el país, que tengan dos o más años de matrimonio, que hayan sido evaluados como física, mental, psicológica y moralmente idóneos por alguna de las instituciones a que se refiere el artículo $6^{\circ}$, que sean mayores de veinticinco años y menores de sesenta, y con veinte años o más de diferencia de edad con el menor adoptado. Los cónyuges deberán actuar siempre de consuno en las gestiones que requieran de expresión de voluntad de los adoptantes (...)".

47. Ley $\mathrm{N}^{\circ}$ 19.620, artículo 21: "En caso de que no existan cónyuges interesados en adoptar a un menor que cumplan con todos los requisitos legales o que sólo les falte el de residencia permanente en Chile, podrá optar como adoptante una persona soltera, divorciada o viuda, con residencia permanente en el país, respecto de quien se haya realizado la misma evaluación y que cumpla con los mismos rangos de edad y de diferencia de edad con el menor que se pretende adoptar." 
de la misma se impide esa posibilidad. Ello en cuanto la adopción conjunta exige el vínculo matrimonial, y en Chile el matrimonio es concebido por el Código Civil como una unión exclusiva entre un hombre y una mujer. Asimismo, en lo relativo a la adopción individual, el artículo 21 habla de "una" persona soltera, divorciada o viuda, precisión que cobra relevancia ya que según la historia de la Ley $\mathrm{N}^{\circ} 19.620$, en un principio el artículo hablaba en plural refiriéndose a "las" personas solteras, divorciadas o viudas, cuestión que fue modificada, toda vez que se pensó que la norma podría ser interpretada de manera que permitiera que dos personas solteras solicitaran adoptar conjuntamente a un mismo niño, lo que legitimaría la adopción por convivientes que carecen del vínculo conyugal o de parejas compuestas por personas del mismo sexo ${ }^{48}$.

Por su parte, y en cuanto al reconocimiento de otras organizaciones familiares, la ley también deja fuera a los convivientes civiles unidos por medio del Acuerdo de Unión Civil. Los motivos para su exclusión, según la Historia de la Ley $\mathrm{N}^{\circ} 20.830^{49}$ radican en que dicha figura aparentemente carece de la estabilidad que el matrimonio ofrece, principalmente por la facilidad legal con la que puede terminar.

Hechas las precisiones anteriores, es importante mencionar que la imposibilidad se encuentra en la "pareja" homosexual, y no así en la "persona" homosexual, que como tal puede iniciar de manera individual el proceso de adopción, ya que la ley no establece inhabilidad alguna en razón de la orientación sexual del adoptante ${ }^{50}$.

Actualmente existe un Proyecto de Ley iniciado en mensaje presidencial que propone la modificación del Código Civil permitiendo el matrimonio igualitario ${ }^{51}$. $\mathrm{Al}$ respecto, y sin tratar de abordar aquel proyecto que escapa a los fines de esta investigación, sólo cabe señalar que por medio de la sustitución conceptual del artículo 102, este permitiría que dichos matrimonios accedan a la adopción ya sea por integración o a través de la adopción propiamente tal.

48. Historia de la Ley $\mathrm{N}^{\circ} 19.620$, p. 479.

49. Historia de la Ley $\mathrm{N}^{\circ} 20.830$, p. 980.

50. A este respecto puede mencionarse el caso de Cristina Poblete y Catalina Franco que fueron conocidas en Chile como la primera pareja lésbica declarada idónea para adoptar. Sin embargo, la verdad de los hechos es que se trató de una adopción individual, ya que como ha quedado establecido, la ley no contempla la adopción por parejas de hecho, sean heterosexuales u homosexuales. MOVILH (2016) pp. 177 y178.

51. Boletín N¹1.422-07 de 2017. 


\section{La homosexualidad de los adoptantes no condiciona el resguardo del interés superior del niño}

Es ya conocida la lucha que los movimientos por la liberación homosexual han emprendido desde hace tiempo. Esta lucha ha pasado por distintos niveles de conquista, desde la descriminalización de las relaciones homosexuales, hasta el reconocimiento del matrimonio igualitario ${ }^{52}$.

Es del caso mencionar que en este debate la consigna y defensa de un supuesto derecho de las personas homosexuales a adoptar se hace pesar más que el interés del niño, por lo que la adopción homoparental se ha ido imponiendo en diversas partes del mundo como consecuencia de una argumentación igualitarista de que "todos" poseen el mismo derecho, ignorando completamente que ninguna legislación contempla el derecho a adoptar ${ }^{53}$.

El papel de las leyes, en este sentido, es sólo el de establecer los requisitos que se consideran necesarios para garantizar que un sujeto es idóneo. La voluntad de quien pretende adoptar en ningún caso responde al ejercicio activo de un derecho, es más que nada una manifestación de su disponibilidad en orden a que los organismos encargados del proceso los acrediten como tales. Es más, ni siquiera la declaración de idoneidad de los solicitantes constituye el fundamento de un eventual derecho, puesto que la concreción de la adopción dependerá siempre de la existencia o no de otros solicitantes mejor capacitados.

La Corte Suprema también lo ha entendido así: "la finalidad de la adopción se centra principalmente en el beneficio del menor que va a ser adoptado más allá del de los adoptantes, pues lo que se pretende es proporcionarle a éste una familia que lo proteja y le brinde las condiciones para su adecuado desarrollo ${ }^{54}$. En el mismo sentido, el artículo 10 del Reglamento de la Ley $\mathrm{N}^{\circ} 19.620$ indica que en todo proceso de adopción debe primar el beneficio del adoptado por encima del interés del adoptante.

Tomando en cuenta lo anterior, en ningún caso la defensa de la adopción homoparental debe encaminarse en esa dirección: ni homosexuales ni heterosexuales tienen el derecho a adoptar, por lo mismo, los siguientes argumentos en caso alguno deben ser vistos como parte de la lucha contra la discriminación que legítimamente han iniciado las minorías sexuales.

Hecha esta advertencia, corresponde determinar si la orientación sexual de las personas es un elemento sine qua non para excluir a una pareja del proceso de adopción.

52. DE OLIVEIRA Y DE SALLES (2009) p. 82.

53. MOLINER (2012) p. 108.

54. SENAME con V.I.K.S. (2012). 
En primer lugar, conforme lo expuesto en el segundo apartado de esta investigación, el interés superior del niño carece de una significación jurídica explícita, y ello puede facilitar graves abusos invocando su resguardo.

En general, quienes deciden sobre el contenido de este principio rector no operan de manera aséptica, sino que en la mayoría de las ocasiones no logran sustraerse a sus propias convicciones, y consciente o inconscientemente, valoran ese interés desde su propia óptica ${ }^{55}$. La complejidad antes mencionada se pone en evidencia cuando se presentan casos límite como el de la adopción homoparental, pues tanto detractores como defensores sustentan su postura en el mismo principio ${ }^{56}$. Sin embargo, la diferencia está en que los primeros enfocan su posición hacia un proteccionismo exacerbado $^{57}$, que más que nada restringe el derecho del niño a tener una familia.

Precisamente porque se trata de encontrar el mejor entorno para la protección de los derechos del niño, la adopción, a diferencia de la filiación biológica, permite elegir a quien mejor puede cumplir la misión de custodiar esos intereses, de manera que la idoneidad debe tomar en cuenta las virtudes y cualidades del solicitante para brindarle al adoptado una familia en donde se desarrolle integralmente ${ }^{58}$. Como ya quedó establecido, la orientación sexual no debe ser parte de esa idoneidad, porque la heterosexualidad tampoco garantiza que el adoptado vivirá en condiciones óptimas para su desarrollo 59 .

En segundo lugar, como ya se examinó, la aceptación de la adopción homoparental tiene directa relación con la concepción de familia y de matrimonio, siendo este último la base argumentativa de quienes la rechazan, alegando una presunta vulneración del interés superior cuando se le "quita" al niño el derecho a crecer en un ambiente familiar calificado como tradicional.

Al respecto, no es posible sostener que la protección de los derechos de los niños sea exclusivamente resguardada bajo un único modelo familiar, pues tal como se constató, existen otras tipologías y el Derecho no puede reconocerlas sólo para algunos efectos legales ${ }^{60}$.

Por otro lado, tal como acontece en la mayoría de los conflictos que involucran el Derecho de Familia, las voces interdisciplinarias no pueden quedar fuera so pena de incurrirse en un estudio parcial, y la adopción homoparental no escapa a este principio $^{61}$.

55. RAVETLLAT (2012) p. 91.

56. SILVA Y VALLS (2014) p. 183.

57. DÍAZ (2017) p. 13.

58. FLORES (2017) p. 284.

59.GUZMÁN (2017) p. 145.

60. DÍAZ (2017) pp. 13-15.

61. HERRERA (2010) p. 187. 
En general, existe un temor sobre los posibles impactos negativos generados en el desarrollo psíquico y emocional de los niños que crecen bajo una crianza homoparental. Precisamente esa línea argumentativa fue seguida por la Corte Suprema en el caso de Karen Atala el año $2004^{62}$, sin embargo, cabe señalar que en la literatura científica existen varios estudios que demuestran que la crianza por parejas del mismo sexo no influye de manera negativa en el bienestar y el desarrollo emocional del adoptado.

El Instituto Colombiano de Bienestar Familiar ha dicho a este respecto que no existe evidencia de que la adopción por parejas del mismo sexo genere riesgo para la salud física o mental de los niños, niñas o adolescentes, y que por el contrario, aquel bienestar se ve más afectado por aspectos como la ausencia de soporte social y económico en la familia o la existencia de malas relaciones entre los hijos y sus padres, las cuales nada tienen que ver con la orientación sexual de los mismos ${ }^{63}$.

Igualmente, en un estudio llamado "(How) Does the Sexual Orientation of Parents Matter?" realizado por la American Sociological Association, dos profesores de la Universidad de California del Sur y de la Universidad de Nueva York, concluyeron que no hay diferencias notorias entre niños criados por parejas heterosexuales y aquellos criados por parejas homosexuales, y que los padres homosexuales son tan competentes y efectivos como los primeros ${ }^{64}$.

En esta misma línea, el año 2002 también se presentaron los resultados de un estudio realizado por el Departamento de Psicología Evolutiva de la Universidad de Sevilla donde se analizó el desarrollo infantil y adolescente de quienes viven en hogares homoparentales. Aquí se confirmó que la orientación sexual de los progenitores, en sí misma, no parecer ser una variable relevante a la hora de determinar el modo en que se construye el ajuste psicológico de hijos e hijas ${ }^{65}$.

También destaca de manera crítica la idea que sostiene una posible confusión de roles sexuales que podría producirse en el adoptado al contar con dos padres o dos madres, pasando a llevar la necesidad de brindarle a los niños dos modelos de identificación: materno por parte de una mujer y paterno por parte de un hombre ${ }^{66}$.

62. En este caso, los jueces de la mayoría evidenciaron que "el padre de las menores dedujo su demanda dirigida a obtener la tuición de sus hijas, sobre la base de argumentar que la decisión adoptada por la madre siguiendo su tendencia homosexual, provoca daños en el desarrollo integral psíquico de las menores". López con Atala (2004).

63. ICBF (2014) p. 2.

64. STACEY Y BIBLARZ (2001) p. 160.

65. DEL MAR (2005) p. 17.

66. HERRERA (2010) p. 188. 
Frente a esta posición, hay una incompatibilidad argumentativa que se evidencia cuando por un lado, se defiende la igualdad de trato, el respeto y la prohibición de discriminación frente a las distintas manifestaciones de orientación sexual, y paralelamente se niega la adopción homoparental por la probabilidad de que el adoptado adquiera esa condición ${ }^{67}$. Ello más que nada visibiliza el sentir de que la homosexualidad es un fenómeno indeseable y evitable en las futuras generaciones. Sin embargo, y por sobre esa contrariedad, existen estudios que indican que los hijos de padres homosexuales tienen claro que la orientación sexual de sus progenitores es una posibilidad, pero estadísticamente no son más propensos a ser homosexuales que sus pares criados por heterosexuales ${ }^{68}$.

Si no es ese el temor detrás de dicha argumentación, sino que más bien, la preocupación legítima en torno a la necesidad de contar con un padre de cada género para tener una crianza integral, lo cierto es que ningún género es dueño de la paternidad exitosa, lo que puede ser demostrado también por el aumento en los últimos años de los hogares monoparentales, quienes de hecho también son reconocidos en la Ley de Adopción en su artículo 21.

Ahora bien, también es posible pensar que los hijos de familias homoparentales son sometidos a un estado de vulnerabilidad por el juzgamiento que la sociedad hace de este tipo de modelos familiares. En este sentido, no siendo posible desconocer los prejuicios sociales que envuelven a las familias homoparentales, esta consideración se traduce en dos situaciones que están lejos de ser coherentes con los fines constitucionales ${ }^{69}$. Primero, que es la sociedad la que en medio de su incapacidad para aceptar la diferencia decide que es mejor tener a un niño huérfano, víctima del fenómeno de la institucionalización (prolongación excesiva de la internación en hogares de acogida), que someterlo a la discriminación social. Y segundo, que es la misma sociedad la que afirma su compromiso con la defensa de los derechos de los niños, pero al mismo tiempo niega su derecho fundamental a tener una familia ${ }^{70}$.

Por tanto, no es válido este argumento como justificación para perpetuar tratos discriminatorios, especialmente cuando Chile está llamado a adoptar las medidas necesarias a fin de que los ciudadanos puedan ejercer sus derechos, y garantizar la eliminación de cualquier manifestación discriminatoria o excluyente.

67. Quizás eso responde al hecho de que un 59\% de los chilenos respalda el matrimonio igualitario, pero sólo un 42\% apoya la adopción homoparental. MOVILH (2016) p. 20.

68. MUÑOZ (2013) p. 24.

69. La no discriminación en su calidad de valor jurídico constitucional enraíza profundamente en la noción de dignidad de la persona, y la Constitución lo confirma en su primer artículo. DÍAZ (2013) pp. 635-636.

70. ESTRADA (2011) p. 33. 


\section{Palabras finales}

Los objetivos de la adopción han ido cambiado a través del tiempo. Hoy no cabe duda que la guía o propósito preponderante e invariable en ella es el interés superior del niño, sin embargo, la invocación sociocultural de la familia heterosexual, ha encontrado en la flexibilidad propia de este principio la posibilidad de que a través de cierta interpretación restrictiva, y por cierto, errónea de su contenido, se perpetúen actos de discriminación que no buscan el bienestar del adoptado. Con ello se pasa por alto que primar la heterosexualidad de la pareja adoptante sobre el interés del adoptado, supone desfigurar la propia finalidad de la adopción.

Volviendo a los argumentos entregados al final de la sección anterior, si la evidencia ofrecida por la ciencia de la psicología demuestra que no hay diferencias entre los hogares heteroparentales y homoparentales en cuanto al cumplimiento de funciones encuadradas bajo el concepto de crianza, o el bienestar físico y psíquico de los niños, entonces el deber de protección de la familia que constitucionalmente recae sobre los hombros del Estado exige una política activa de validación de los hogares homoparentales, no excluyendo a las parejas homosexuales a priori y en abstracto como posibles adoptantes. Naturalmente, la Administración competente debe examinar con el mayor rigor posible toda solicitud de adopción antes de concederla, y debe velar en todo momento por el interés y derechos del niño adoptado.

Aun cuando las deficiencias argumentativas de las posturas contrarias a la adopción homoparental son evidentes, el proceso de reivindicación de los derechos de los niños a crecer en una familia con independencia de la orientación sexual de sus padres es un proceso que debe generarse desde distintos escenarios. Desde el punto de vista legal, las soluciones que pueden ofrecerse deben ir dirigidas a todas las situaciones fácticas que vinculan a la pareja del mismo sexo con la adopción, distinguiendo, por un lado, la adopción por parte de una persona homosexual (de lege lata, en la medida que la ley actualmente no descarta al solicitante soltero, divorciado o viudo por su orientación sexual), por otro, la adopción de un matrimonio integrado por dos mujeres o dos hombres (de lege ferenda, en la medida que la reforma de matrimonio igualitario permitiría que dichas parejas adopten), la adopción integrativa del hijo biológico o adoptivo del otro cónyuge en el marco de un matrimonio homosexual y la adopción conjunta por parte de una pareja compuesta por "convivientes civiles", sean o no del mismo sexo. 


\section{Referencias bibliográficas}

ALVITES, Elena (2018): “La constitucionalización del ordenamiento jurídico peruano: avances y obstáculos del proceso". En Revista de Derecho, Pontificia Universidad Católica del Perú, año 2018, N8o, pp. 361-39o.

BARROSO FIGUEROA, José (2012): “La adopción efectuada por matrimonio homosexual”. En Revista Cultura, año 2012, N³, pp. 53-72.

BOLAÑOS ENRÍQUEZ, Tania y CHARRY MORALES, Ariel (2018): "Prejuicios y homosexualidad, el largo camino hacia la adopción homoparental. Especial atención al caso colombiano”. En revista Estudios Constitucionales, año 16, №1, pp. 395-424.

CILLERO BRUÑOL, Miguel (1999): “El interés superior del niño en el marco de la Convención Internacional sobre los Derechos del Niño". En Revista Justicia y Derechos del Niño, año 1999, primera edición, pp. 46-62.

CORRAL TALCIANI, Hernán (2001): "El nuevo régimen jurídico de la adopción en Chile”. En Revista Chilena de Derecho, año 28, $\mathrm{N}^{\circ} 1$, pp. 9-46.

CORRAL TALCIANI, Hernán (2002): Adopción y filiación adoptiva (Santiago de Chile, Editorial Jurídica de Chile).

DE FELICE, Roberto (2016): “El interés superior del menor prohíbe la restricción del derecho de adopción a las solas parejas de personas heterosexuales". En Revista de Derecho Privado, año 2016, N³1, pp. 385-408.

DEL MAR GONZÁLEZ, María (2005): “Homosexualidad y Adopción. Entre la ciencia y el prejuicio". En Revista Del Consejo General de Colegios Oficiales de Psicólogos, año 2005, $\mathrm{N}^{\circ} 24$, pp. 16-19.

DEL PICÓ RUBIO, Jorge; ACUÑA SAN MARTÍN, Marcela; AEDO BARRENA, Cristián; JARUFE CONTRERAS, Daniela; MONDACA MIRANDA, Alexis y RIVEROS FERRADA, Carolina (2016): Derecho de Familia (Santiago de Chile, Editorial Thomson Reuters).

DE OLIVEIRA NUSDEO, Ana María y DE SALLES, Carlos Alberto (2009): Adopción por homosexuales. El discurso jurídico (Buenos Aires, Editorial Libraria).

DÍAZ GARCÍA, Iván (2013): "Ley chilena contra la discriminación. Una evaluación desde los Derechos Internacional y Constitucional”. En Revista Chilena de Derecho, año 40, $\mathrm{N}^{\circ}$ 2, pp. 635-668.

DÍAZ PANTOJA, Juliana (2017): “Adopción homoparental: Un desafío entre la heteronormatividad y la lucha por la igualdad". En Revista digital Derecho y cambio social, año 2017, pp. 1-19.

DWORKIN, Ronald (1989): Los Derechos en Serio (Barcelona, Editorial Ariel). 
ESBORRAZ, David (2015): "El concepto constitucional de familia en América Latina. Tendencias y proyecciones". En Revista de Derecho Privado, año 2015, N²9, pp. 15-55.

ESPINOZA COLLAO, Álvaro (2016): “La invisibilidad jurídica de la familia andina en el norte de Chile". En Revista de Derecho, año volumen XXIX, N ${ }^{\circ}$, pp. 119-140

ESPINOZA COLLAO, Álvaro (2017): “En qué está la familia en el derecho del siglo $x x i$ ? El camino hacia un pluralismo jurídico familiar". En Revista Nueva Época, Año 10, $\mathrm{N}^{\circ} 41$, pp. 223-240.

ESTRADA VÉLEZ, Sergio (2011): “Dos ejercicios de ponderación a propósito del matrimonio y la adopción en parejas del mismo sexo". En Revista de Opinión Jurídica, año 10, $\mathrm{N}^{\circ}$ 19, pp. 21-40.

FAVOREAU, Louis Joseph (2001): “La constitucionalización del Derecho”. En Revista de Derecho, año 2001, volumen XII, pp. 31-43.

FLORES OSORIO, Isabel (2017): "La adopción por las familias homoparentales en México: análisis del interés superior del niño”. En Revista Perfiles de las Ciencias Sociales, año 5, $\mathrm{N}^{\circ}$ 2, pp. 257-291.

GARCÍA CANO, Sandra (2003): Protección del menor y cooperación internacional entre autoridades (Madrid, Editorial Colex).

GARCÍA PINO, Gonzalo y CONTRERAS VÁSQUEZ, Pablo (2014): Diccionario Constitucional Chileno (Santiago de Chile, Cuadernos del Tribunal Constitucional).

GARRIDO CHACANA, Carlos (2011): Los procedimientos de adopción. Análisis práctico (Santiago, Editorial Metropolitana).

GÓMEZ DE LA TORRE VARGAS, Maricruz (200o): “El interés superior del niño”. En Gaceta Jurídica, año 200o, $\mathrm{N}^{\circ}$ 238, pp. 23-26.

GÓMEZ DE LA TORRE VARGAS, Maricruz (2007): El sistema filiativo chileno (Santiago, Editorial Jurídica de Chile).

GOÑI HUARTE, Elena (2016): "El problema de la homosexualidad y la filiación en Chile”. En Revista Electrónica Iberoamericana, año1o, N², pp. 1-18.

GROSSMAN, Cecilia y MARTÍNEZ, Inés (200o): Familias Ensambladas, Nuevas Uniones después del Matrimonio (Buenos Aires, Editorial Universidad).

GUZMÁN ÁVALOS, Aníbal (2017): “La doble maternidad y la doble paternidad”. En Revista del Instituto de Ciencias Jurídicas de Puebla, año11, $\mathrm{N}^{\circ}$ 39, pp. 9-23.

GUZMÁN BRITO, Alejandro (2012): Derecho Privado Romano (Santiago, Editorial Jurídica de Chile). 
HERRERA, Marisa (2010): “Adopción y ¿Homoparentalidad u Homofobia? Cuando el principio de igualdad manda". En Revista del Instituto de Ciencias Jurídicas de Puebla, año IV, $\mathrm{N}^{\circ}$ 26, pp. 180-221.

LATHROP GÓMEZ, Fabiola (2017): “Constitucionalización y Jurisprudencia Constitucional en el Derecho de Familia chileno". En Revista de Estudios Constitucionales, año $15, \mathrm{~N}^{\circ} 1$, pp. 329-372.

LEPÍN MOLINA, Cristián (2014): “Los nuevos principios del Derecho de Familia”. En Revista Chilena de Derecho Privado, año 2014, $\mathrm{N}^{\circ}$ 23, pp. 9-55.

LLANO FRANCO, Jairo (2016): "Pluralismo jurídico, diversidad cultural, identidades, globalización y multiculturalismo: perspectiva desde la ciencia jurídica". En Revista Novum Jus, año 10, $\mathrm{N}^{\circ} 1$, pp. 49-92.

MARTÍNEZ VASALLO, Haydee (2015): "La familia: una visión interdisciplinaria”. En Revista Médica Electrón, año 37, $\mathrm{N}^{\circ}$, pp. 523-534.

MOLINER NAVARRO, Rosa (2012): “Adopción, Familia y Derecho”. En Revista Bolivariana de Derecho, año 2012, $\mathrm{N}^{\circ}$ 14, pp. 98-121

MUÑOZ LEÓN, Fernando (2013): "El núcleo fundamental de la sociedad: Los argumentos contra la crianza homoparental en los casos Atala y Peralta". En Revista Ius Et Praxis, año 19, $\mathrm{N}^{\circ}$ 1, pp. 7-34.

OLIVA GÓMEZ, Eduardo y VILLA GUARDIOLA, Vera (2014): "Hacia un concepto interdisciplinario de la familia en la globalización”. En Revista Justicia Juris, año 10, $\mathrm{N}^{\circ}$ 1, pp. 11-20.

PINOCHET OLAVE, Ruperto y RAVETLLAT BALLESTÉ, Isaac (2015): “El interés superior del niño en el marco de la Convención Internacional sobre los Derechos del niño y su configuración en el Derecho Civil chileno". En Revista Chilena de Derecho, año 42, $\mathrm{N}^{\circ}$ 3, pp. 903-934.

PLACERES HERNÁNDEZ, José; OLVER MONCAYO, Diego y ROSERO MORA, Germania (2017): "La familia homoparental en la realidad y la diversidad familiar actual”. En Revista Médica Electrón, año39, N², pp. 361-369.

RAVETLLAT BALLESTÉ, Isaac (2012): "El interés superior del niño: concepto y delimitación del término”. En Revista Educatio Siglo XXI, año 30, º 2, pp. 89-108.

REA-GRANADOS, Sergio (2016): “Evolución del Derecho Internacional sobre la infancia”. En Revista Colombiana de Derecho Internacional, No 29, pp. 147-192.

RODRÍGUEZ CARRETERO, José Alberto (1973): La persona adoptada (Madrid, Editorial Montecorvo).

RODRÍGUEZ JIMÉNEZ, Sonia (2013): "El principio del Interés Superior del Menor". En Revista Letras Jurídicas, año 2013, $\mathrm{N}^{\circ} 16$, pp. 1-71. 
RUIZ MOLLEDA, Juan Carlos y SÁNCHEZ BOTERO, Esther (2011): “El pluralismo jurídico en América Latina: del reconocimiento legal a la democracia intercultural”. En GADEA, Elisa. El pluralismo jurídico y normativo ¿Una vía para refundar la gobernanza? (Lima, Instituto de investigación y debate sobre la gobernanza), pp. 21-28.

SALAS DOMÍNGUEZ, Ana Daysu (2013): “Tendencia nacional en relación a la adopción entre personas del mismo sexo". En Revista de Derecho Privado del Instituto de Investigaciones Jurídicas de la Universidad Nacional Autónoma de México, año 2, $\mathrm{N}^{\circ}$ 3, pp. 189-216.

SILVA MEZA, Juan y VALLS HERNÁNDEZ, Sergio (2014): Transexualidad y Matrimonio y Adopción por parejas del mismo sexo. (Ciudad de México, Editorial Porrúa).

STACEY, Judith y BIBLARZ, Timothy (2001): "(How) Does the Sexual Orientation of Parents Matter?”. En American Sociological Review, año66, N² 2, pp. 159-183.

TURNER SAELZER, Susan (2012): “Sentencia sobre adopción: ¿Y el interés superior del adoptado en el caso concreto? (Corte Suprema)". En Revista de Derecho, año $\mathrm{XXV}, \mathrm{N}^{\circ}$ 1, pp. 253-263.

VALLVERDÚ, Jordi (2004): “Reflexiones históricas sobre la adopción”. En Revista de psiquiatría y Psicología del Niño y del Adolescente, año 2004, Nº 1, pp. 28-53.

ZÚNIGA, Yanira y TURNER, Susan (2013): "Sistematización comparativa de la regulación de la familia en las constituciones latinoamericanas". En Revista de Derecho de la Universidad Católica del Norte, año 20, $\mathrm{N}^{\circ}$ 2, pp. 269-301.

\section{Jurisprudencia citada}

I.S.V. con Sename (2017): Corte Suprema, 22 de marzo de 2017 (Recurso De Casación en el Fondo, rol N94884-16).

Melín con Alarcón (2017): Corte Suprema, 10 de abril de 2017 (Recurso de Casación en el Fondo, rol N $47842-16)$.

Martínez con Pávez (2014): Corte Suprema, 6 de octubre 2014 (Recurso de Casación en el Fondo, rol N $3666-14)$.

Sergio Larraín Sáez (2014): Tribunal Constitucional, 10 de abril de 2014 (Recurso de inaplicabilidad por inconstitucionalidad, rol N $2435-13)$.

Sename con V.I.K.S (2012): Corte Suprema, 28 febrero 2012 (Recurso de Casación en el Fondo, rol N9o88-11).

López con Atala (2004): Corte Suprema, 31 de mayo de 2004 (Recurso de Queja, rol N¹193-03). 


\section{Otros documentos citados}

Boletín $\mathrm{N}^{\circ}$ 11.422-07 que modifica diversos cuerpos legales para regular, en igualdad de condiciones, el matrimonio de parejas del mismo sexo.

Comité de los Derechos del Niño, Observación General № 14 (2013): Sobre el derecho del niño a que su interés superior sea una consideración primordial.

Historia de la Ley $\mathrm{N}^{\circ} 19.620$ sobre Adopción de Menores.

Historia de la Ley $\mathrm{N}^{\circ} 20.830$ sobre Acuerdo de Unión Civil.

Informe Anual de Derechos Humanos de la Diversidad Sexual y de Género en Chile número XV emitido por MOVILH.

Informe Instituto Colombiano de Bienestar Familiar, 25 de septiembre de 2014. 


\title{
Capacidad jurídica de las personas con discapacidad: ¿Derecho fundamental absoluto?
}

\author{
Legal capacity of people with disabilities: An absolute basic right?
}

\author{
José Reynel Cristancho Díaz ${ }^{1}$ \\ Investigador Independiente, Colombia
}

\begin{abstract}
RESUMEN En el derecho internacional de los derechos humanos, el reconocimiento y protección de los derechos de las personas con discapacidad ha surtido una interesante evolución, pasando de ser un tema marginal a uno de la agenda central en las Naciones Unidas, en especial luego de la entrada en vigor de la Convención sobre los Derechos de las Personas con Discapacidad. Este instrumento internacional consagra la capacidad jurídica como un derecho fundamental de carácter absoluto, pues, de acuerdo a la interpretación de su contenido y alcance, este derecho no puede ser limitado de ninguna forma. En este orden, el presente artículo pone en evidencia lo equivocado de esta postura al demostrar la existencia de casos en los que la limitación de este derecho se constituye en una medida de protección necesaria para un grupo muy reducido de personas con discapacidad, sin que esto denote discriminación alguna.
\end{abstract}

PALABRAS CLAVE Persona con discapacidad, capacidad jurídica, derecho fundamental, interdicción, margen de apreciación.

ABSTRACT In international human rights law, the recognition and protection of the rights of persons with disabilities has presented an interesting evolution, from a marginal issue to a central agenda issue in the United Nations, especially after the entry in force of the Convention on the Rights of Persons with

1. Abogado, diplomado en Políticas Públicas para las víctimas y Construcción de Paz por el Instituto Interamericano de Derechos Humanos en conjunto con la Unidad para la Atención y Reparación Integral a las Víctimas. Tecnólogo en Criminalística y Ciencias Forenses. Mail: jcristanchod@gmail. com 
Disabilities. This international instrument establishes legal capacity as a basic right of an absolute nature, since, according to the interpretation of its content and scope, this right cannot be limited in any way. In this context, the present article shows the wrongness of this position by demonstrating the existence of cases in which the limitation of this right constitutes a necessary protection measure for a very small group of people with disabilities, without this denoting any form of discrimination.

KEYWORDS Persons with disability, legal capacity, basic right, interdiction, margin of appreciation.

\section{Introducción}

La discriminación en contra de las personas con discapacidad ha tenido muchas manifestaciones a lo largo de la historia ${ }^{2}$, tanto por parte del Estado como por parte de la sociedad en general ${ }^{3}$, pues durante un largo periodo se asumió la discapacidad como sinónimo de daño, imperfección e incluso de minusvalía, hecho que motivó sentimientos de compasión, lástima o indiferencia por parte de la comunidad y olvido por parte del Estado. Pero este olvido no provino exclusivamente de los países, sino que también se presentó en el derecho internacional, pues, a pesar de que las personas con discapacidad se constituyen como uno de los grupos de minorías más grande del mundo, las Naciones Unidas optaron por ignorarlas durante sus tres primeras décadas de existencia, lo que se observa al analizar los primeros tratados de derechos humanos originados en esta organización internacional, dado que ninguno de ellos incluye a las personas con discapacidad como un grupo vulnerable a las violaciones de derechos humanos ${ }^{4}$.

Ahora bien, dentro de las personas con discapacidad se observa que aquellas que tienen patologías que comprometen su salud mental ${ }^{5}$ se constituyen en un grupo especialmente vulnerable, pues los Estados han demostrado en muchas ocasiones su resistencia a realizar reformas a sus normas y políticas en materia de salud mental y los funcionarios judiciales no siempre implementan los cambios necesarios para mejorar los derechos y el bienestar de las personas con discapacidad mental ${ }^{6}$. Así,

2. GARCÍA (2015), p. 155.

3. HÉRNANDEZ y CRUZ (2006), pp. 13-14

4. DEGENER (2000), p. 187.

5. De acuerdo a la OMS (2004), al tratar el tema de la salud mental se deben tomar en consideración aspectos como el bienestar subjetivo, autonomía, competencia, dependencia integracional y reconocimiento de la habilidad de realizarse intelectual y emocionalmente; de ahí que, la salud mental se defina como un estado de bienestar a través del cual la persona reconoce sus habilidades, siendo capaz de hacer frente al estrés normal de la vida y contribuir a la comunidad. (p. 7)

6. GOSTIN y GABLE (2004), p. 20 
dentro de estas normas destacan aquellas que consideran que por el solo hecho de tener una discapacidad mental la persona automáticamente es incapaz de comprender lo que ocurre a su alrededor y, como consecuencia, debe ser sometida a un proceso tendiente a limitar su derecho a tomar decisiones libremente, para que sea un tercero quien tome las decisiones en lugar de la persona con discapacidad. Esta práctica generalizada motivó a que en la discusión de la Convención sobre los Derechos de las Personas con Discapacidad se incluyera una norma con la cual se compeliera a los Estados a derogar toda figura normativa que tuviera como propósito la limitación de la capacidad jurídica de las personas con discapacidad mental.

Así las cosas, ¿efectivamente se puede considerar a la capacidad jurídica de las personas con discapacidad como un derecho de carácter absoluto que no admite limitación bajo ninguna circunstancia o, por el contrario, es posible afirmar que este derecho, al igual que otros derechos fundamentales, es susceptible de restricciones de carácter excepcional que atiendan las especiales necesidades de las personas con discapacidad?

\section{Las personas con discapacidad como grupo históricamente excluido}

La discapacidad ha sido abordada desde diversas perspectivas a lo largo de la historia, tanto por parte de la sociedad como del mismo Estado. Así, la primera de ellas es la conocida como el modelo de prescindencia, según el cual la discapacidad tiene connotaciones religiosas, pues esta se ve como un castigo divino, esto, sumado a la situación particular de la persona, creó un imaginario colectivo consistente en que las personas con discapacidad no aportaban nada a la sociedad y, por lo tanto, se debía prescindir de ellas ${ }^{7}$, para lo cual se adoptaron dos submodelos; el primero de ellos se caracterizaba por recurrir a prácticas eugenésicas, lo cual se puede observar en la antigüedad, época en la cual había una práctica generalizada y, por lo tanto, aceptada del infanticidio por razones de discapacidad ${ }^{8}$; por su parte, el segundo submodelo, característico de la edad media, optaba por la marginación de las personas con discapacidad, por lo que la regla impuesta era la exclusión de este grupo poblacional, lo que ocasionó que quienes hacían parte de él se dedicaran a tareas como la mendicidad, la apelación a la caridad e incluso ser objeto de diversión con el propósito de subsistir ${ }^{9}$.

Otra de las perspectivas desde las que se abordó la discapacidad fue la del modelo médico o rehabilitador, caracterizado por una atención de carácter individual, centrada exclusivamente en la persona y la cual veía en la discapacidad una desviación, deficiencia o enfermedad que impide que el individuo alcance estándares de normali$\operatorname{dad}^{10}$. El objetivo que perseguía este modelo era el de rehabilitar a la persona sin que

7. GONZÁLEZ (2010), p. 14

8. DE VICENTE (2001), p. 11.

9. PALACIOS y BARIFFI (2007), p. 15.

10. RIOUX y CARBET (2003), p. 1. 
fuera de mayor importancia el origen de la discapacidad; en adición, se adoptaron una serie de beneficios sociales encaminados a ayudar al individuo, pues se consideraba que este era incapaz de enfrentarse por sí solo a la sociedad ${ }^{11}$; así, la adopción de este tipo de medidas generaba en la sociedad en general un sentimiento de preocupación y no uno de aceptación e igualdad, lo que contribuyó a reforzar la estigmatización de las personas con discapacidad ${ }^{12}$, pues se llegó a considerarlas como improductivas, inútiles, dependientes, pasivas e incluso problemáticas ${ }^{13}$.

Estos enfoques propiciaron la exclusión de las personas con discapacidad, pues la reacción ante ellas, tanto por parte de las autoridades, como de la comunidad en general, se limitaba a la compasión o a la repugnancia ${ }^{14} \mathrm{y}$, si bien hubo una atenuación en la forma de percibir a este grupo poblacional, la discriminación de la cual históricamente han sido objeto se mantuvo, dado que, como lo expresa González:

Las sociedades han sido construidas teniendo en cuenta solo a las personas sin discapacidad, lo que ha producido que las personas con discapacidad sean segregadas de todas las actividades cotidianas. Incluso la invisibilidad se ha llegado a aceptar como algo natural. Las diferencias de la discapacidad han sido percibidas como causa para la exclusión.

Debido a esta relativa invisibilidad las personas con discapacidad han sido marginadas de las actividades cotidianas en la sociedad, incluso de las protecciones legales que las personas sin discapacidad dan por sentadas. La marginación ha provocado que las personas con discapacidad vean vulnerados sus derechos de muy distintas maneras ${ }^{15}$.

En este orden, es evidente la segregación a la que históricamente fueron sometidas las personas con discapacidad ${ }^{16}$, principalmente debido a la manera en que se abordaba su situación por parte de los Estados y la sociedad, hecho que demuestra la situación de vulnerabilidad en que se encuentran quienes hacen parte de este grupo poblacional y que motivó un importante movimiento en favor de la protección y garantía de sus derechos, el cual se ve reflejado en los instrumentos internacionales que abarcan esta temática, los cuales, como se analizará, surtieron una interesante evolución.

\footnotetext{
11. PALACIOS y BARIFFI (2007), p. 16.

12. JIMÉNEZ (2008a), p. 11.

13. JIMÉNEZ (2008b), p. 7.

14. QUINN y DEGENER (2002), p. 23.

15. GONZÁLEZ (2010), p. 30.

16. OMS (2011), p. 3.
} 


\subsection{Primeros instrumentos internacionales sobre derechos de personas con dis- capacidad}

Lo primero que se destaca al analizar la normativa internacional relacionada con los derechos de las personas con discapacidad es que, inicialmente, la atención específica sobre el tema se dio con ocasión al gran número de personas que, como consecuencia de los enfrentamientos en la Segunda Guerra Mundial, adquirieron algún tipo de discapacidad. A raíz de esto, la Asamblea General, el Consejo Económico y Social, al igual que la Comisión Social (órgano subsidiario de este último) tuvieron como propósito promover el bienestar y la asistencia social de las personas con discapacidad, esto a través de la cooperación técnica, la rehabilitación y programas de formación profesional $^{17}$, fue así como en 1950 se emitieron los informes titulados "The social rehabilitation of the handicapped" $\mathrm{y}$ "The social rehabilitation of the blind", emitidos difundidos y analizados durante la sexta sesión de la Comisión Social.

No obstante, lo anterior, el abordaje de esta temática por parte de Naciones Unidas era limitado, dado que el mismo no trascendía más allá de la ayuda asistencial y rehabilitadora a través de la asistencia técnica a los Estados parte, los cuales calificaban de caridad o beneficencia las políticas públicas dirigidas a este grupo poblacional, motivo por el cual las personas con discapacidad no jugaban un rol activo en el diseño e implementación de las políticas de las que eran beneficiarios en razón a su situación $\operatorname{particular}^{18}$.

En 1969, se proclamó la "Declaración sobre el progreso y el desarrollo social”, constituyéndose en el primer instrumento internacional en el que se hacía mención expresa de las personas con discapacidad; desafortunadamente, se refería a este grupo poblacional en términos peyorativos, lo que puede observarse en sus artículos 11 (c) y 19 (d), en los que se hace uso de los términos "impedidos" y "desfavorecidos", hecho que deja en evidencia el concepto que se tenía sobre las personas con discapacidad en ese momento, el cual se mantuvo durante mucho tiempo.

Como se advierte, hasta ese momento no existía ningún instrumento que se centrara de manera exclusiva en la temática de la discapacidad, hecho que cambió en la década de los setenta cuando en el seno de las Naciones Unidas se adoptaron la "Declaración de los Derechos del Retrasado Mental" y la "Declaración de los Derechos de los Impedidos", declaraciones que mantenían un enfoque de prevención y rehabilitación, pero que, en la práctica, carecían de efectividad, pues las mismas no son jurídicamente vinculantes, dado que no tenían el propósito de establecer obligaciones, sino el dar a conocer las aspiraciones que se tenían en su momento.

17. ONU (2015), p. 18.

18. BIEL (2009), p. 39. 
La siguiente acción por parte de las Naciones Unidas fue la de proclamar, a través de la Resolución 31/123 de 16 de diciembre de 1976, el año de 1981 como el año internacional de los impedidos, esto con el fin de facilitar la inclusión de las personas con discapacidad a través de la prestación de asistencia, atención, capacitación y orientación apropiada. Por su parte, en 1982 se adoptó el "Programa de Acción Mundial para los Impedidos", consistente en una declaración de principios y directrices en favor de las personas con discapacidad, cuyo cumplimiento se inscribió en un marco temporal con la proclamación del periodo 1983-1992 como el "Decenio Mundial de las Naciones Unidas para los Impedidos”. Esto produjo una reafirmación de la importancia de los derechos de las personas con discapacidad y dio lugar a la adopción de las "Directrices de Tallin para el Desarrollo de los Recursos Humanos en la Esfera de los Impedidos", al igual que los "Principios para la protección de los enfermos mentales y el mejoramiento de la atención de la salud mental”.

Uno de los resultados del Decenio Mundial fue el considerar la temática de los derechos de las personas con discapacidad como un problema de derechos humanos y para su solución era necesaria la participación de todos los órganos de vigilancia, lo cual se vio reflejado en los pronunciamientos que siguieron a la culminación del Decenio Mundial, como son: Convención Interamericana para la Eliminación de todas las Formas de Discriminación contra las Personas con Discapacidad, la Observación General N ${ }^{\circ} 5$ del Comité de Derechos Económicos, Sociales y Culturales; las resoluciones 1998/31, 2000/51, 2002/61, 2003/49, 2004/52 y 2005/65 de la Comisión de Derechos Humanos ${ }^{19}$ y la adopción de las Normas Uniformes sobre la Igualdad de Oportunidades para las Personas con Discapacidad. La importancia de este último radica en que, pese a su falta de fuerza jurídica vinculante, fue, durante mucho tiempo, el instrumento internacional por excelencia para el estudio de la regulación jurídica de la discapacidad, esto teniendo en cuenta que su contenido material propendía por la aplicación del modelo social de la discapacidad en la esfera del derecho internacional $^{20}$.

Hasta este punto, en el orden internacional se había surtido un proceso que significó un gran avance en materia de reconocimiento de los derechos humanos de las personas con discapacidad, aun cuando los instrumentos internacionales adoptados al respecto carecían de vinculatoriedad.

19. Esta Comisión hacía parte del Consejo Económico y Social, asistiendo además en funciones a la Oficina del Alto Comisionado de las Naciones Unidas para los Derechos Humanos. Sin embargo, la misma cumplió sus funciones dentro del periodo comprendido entre el 12 de agosto de 1947 y el 27 de marzo de 2006, fecha de su última sesión, esto debido a la creación del Consejo de Derechos Humanos como organismo de la Naciones unidas.

20. LINDQVIST (2002), párr. 29. 


\section{El modelo social de la discapacidad y su incidencia en la Convención sobre los Derechos de las Personas con Discapacidad}

La adopción del modelo social para abordar la temática de la discapacidad se constituye en un significativo avance en el reconocimiento, garantía y protección de los derechos de las personas con discapacidad, pues este tiene como propósito "potenciar el respeto por la dignidad humana, la igualdad y la libertad personal, propiciando la inclusión social, y sentándose sobre la base de determinados principios: vida independiente, no discriminación, accesibilidad universal, normalización del entorno, diálogo civil, entre otros" ${ }^{21}$. Además, se da un cambio drástico en la manera en que se analizaba la discapacidad, pues en lugar de explicar la misma partiendo de la "deficiencia" de la persona se pasa a hacerlo desde las "deficiencias" de la sociedad misma, dado que son estas las que se constituyen en barreras discapacitantes ${ }^{22}$. Esto se ve reflejado en una definición más dinámica e integral de la discapacidad, dado que bajo este modelo se la analiza "como un complejo proceso de salud, económico, sociocultural y también político, un fenómeno diverso en el que la discapacidad se conforma en la interacción entre las capacidades funcionales de la persona y su entorno físico y social" 23 .

Así, el enfoque del modelo social radica en la dignidad de la persona, siendo la discapacidad de la misma algo de carácter secundario, esto con el propósito de construir sociedades realmente inclusivas que reconozcan y valoren las diferencias de sus integrantes ${ }^{24}$, pues esto contribuiría a que el imaginario general se caracterizara por entender que "las personas con discapacidad pueden aportar a las necesidades de la comunidad en igual medida que el resto de personas, pero siempre desde la valoración y el respeto de su condición de personas, en ciertos aspectos, diferentes" ${ }^{25}$.

En este sentido, este modelo configuró un cambio de paradigma frente a la manera en que se abordaba la discapacidad, cambio que contribuyó a que en el orden internacional se viera la necesidad de contar con un tratado de derechos humanos que enfocara su atención en las personas con discapacidad, lo que se vio reflejado en la discusión y posterior adopción de la Convención sobre los Derechos de las Personas con Discapacidad ${ }^{26}$, la cual no busca sustituir los demás tratados existentes, sino que

21. PALACIOS y BARIFFI (2007), p. 19.

22. PALACIOS (2015), p. 14.

23. STANG (2011), p. 7.

24. GONZÁLEZ (2010), p. 16.

25. PALACIOS y BARIFFI (2007), p. 19.

26. La Convención entró en vigor el 3 de mayo de 2008 al haber sido ratificada por 25 Estados. 
complementa el sistema internacional de derechos humanos al regular situaciones concretas de discriminación y desigualdad a las que se ven enfrentadas a diario personas con discapacidad en todo el mundo ${ }^{27}$.

Aunque la Convención sobre los Derechos de las Personas con Discapacidad contiene una gran cantidad de disposiciones en que desarrolla el contenido y alcance de los derechos de las personas con discapacidad, siendo uno de los más importantes el de igual reconocimiento como persona ante la ley, contenido en el artículo 12, no en vano el CDPD decidió dedicar su primera observación general sobre la Convención a explicar el contenido y alcance real de esta disposición. Este artículo establece una serie de directrices frente al ejercicio del derecho a la capacidad jurídica por parte de las personas con discapacidad y cómo el Estado debe adoptar determinadas medidas en procura de hacer efectivo este derecho, prohibiendo cualquier modelo o disposición normativa que tenga como consecuencia la limitación de la capacidad jurídica de las personas que hacen parte de este grupo poblacional, lo que, en principio, significa que, de acuerdo a esta Convención, este derecho es absoluto.

\section{La capacidad jurídica como derecho fundamental y su importancia para las personas con discapacidad}

La capacidad jurídica hace referencia a la posibilidad con que cuenta la persona de adoptar decisiones de manera libre, sin estar sujeta a limitantes, sin imposición alguna y "ejerciendo la voluntad de realizar o no realizar un acto" ${ }^{28}$; igualmente, se ha establecido una relación directa entre esta y el derecho al reconocimiento de la personalidad jurídica, al considerarlo un parámetro para determinar si una persona puede ejercer los derechos de los que es titular ${ }^{29}$, lo que implica que la capacidad jurídica se constituye como un atributo de la personalidad y, por lo tanto, debe ser considerada como un derecho fundamental en los ordenamientos jurídicos internos ${ }^{30}$, así como en el Derecho Internacional de los Derechos Humanos ${ }^{31}$. En lo que atañe a las personas con discapacidad, este derecho tiene una importancia trascendental, pues la capacidad de ejercer sus derechos y de tomar decisiones propias contribuye al desarrollo de capacidades humanas que le permiten a la persona emprender las acciones y funciones necesarias para tener una vida completa, en igualdad de condiciones con las demás personas ${ }^{32}$.

27. SULLIVAN (2012), p. 19.

28. COMISIÓN DE DERECHOS HUMANOS DEL DISTRITO FEDERAL (2008), p. 96.

29. O'DONNELL (2004), p. 584.

30. VALLEJO et al. (2017), p. 4.

31. CORTE IDH (2005), párr. 177

32. DHANDA (2007), p. 436. 


\subsection{La interdicción de personas con discapacidad mental}

La interdicción se constituye en una figura jurídica a través de la cual, mediante sentencia judicial, se somete a una persona mayor de edad a la guarda de un tercero, denominado tutor o curador, siendo este el encargado del cuidado de aquella, función que incluye la administración de sus bienes y su representación en todos los actos jurídicos que se requiera ${ }^{33}$. Bajo esta perspectiva, puede considerarse a la interdicción como una medida de protección, pero lo cierto es que es una figura que se ha prestado para que se vulneren los derechos de las personas con discapacidad sometidas al régimen de representación o curatela que de aquella se desprende, dado que este modelo:

... suele ser aplicado con demasiada amplitud; que en la mayoría de los casos el alcance de la restricción fijada en la sentencia es indeterminado; que el procedimiento judicial es extenso, oneroso y no ofrece en todos los casos garantía a una tutela judicial efectiva (habida cuenta de que no siempre se dispone de intérpretes o instrumentos probatorios en formatos accesibles); que predomina la ausencia de mecanismos de control de curatelas ya impuestas, entre otras cuestiones ${ }^{34}$.

Además de los defectos que caracterizan el proceso judicial a través del cual se limita la capacidad jurídica de la persona con discapacidad, la figura de la interdicción en sí misma es fuertemente criticada ${ }^{35}$ debido al impacto que tiene sobre la persona al negarle la oportunidad de cumplir con ciertas actividades de la vida, pues esto ocasiona que el individuo afectado por este tipo de medida sea considerado como incompetente, que sus decisiones y preferencias personales no sean tenidas en cuenta, que asuman que varios eventos de su vida se encuentran fuera de su control, lo que, en su conjunto, tiene efectos realmente negativos en la forma en que la persona se ve a sí misma, así como en el comportamiento de dependencia que puede adoptar en un futuro ${ }^{36}$. Es bajo estas consideraciones que la Convención sobre los Derechos de

33. PÉREZ (2014), p. 235.

34. ROSALES (2015), p. 1.

35. Al respecto, CELS Argentina et al (2014) realizan un análisis de la manera en que se regula la interdicción de personas con discapacidad, indicando que la misma responde al modelo rehabilitador y no al social, motivo por el cual la medida se torna en discriminatoria al desconocer la incidencia que tienen las barreras que el Estado y la sociedad le imponen a las personas con discapacidad para el pleno ejercicio de sus derechos.

36. DHANDA (2007), p. 436. 
las Personas con Discapacidad consagró en su artículo 12.2 el derecho a la capacidad jurídica como un componente vital para este grupo poblacional, especificando que su garantía se debe brindar en igualdad de condiciones con las demás personas y en todos los aspectos de la vida.

Al respecto, la Oficina del Alto Comisionado de las Naciones Unidas para los Derechos Humanos sostuvo que:

Toda ley que prevea que la existencia de una discapacidad es motivo directo o indirecto para declarar la incapacidad jurídica entra en conflicto con el reconocimiento de la capacidad jurídica de las personas con discapacidad consagrado en el párrafo 2 del artículo 12. Además de derogar las normas que violan el deber de los Estados de respetar el derecho humano a la capacidad jurídica de las personas con discapacidad, es igualmente importante que se adopten medidas que protejan y hagan efectivo ese derecho, de conformidad con los párrafos 3, 4 y 5 del artículo $12^{37}$.

En adición, respecto al alcance de esta prerrogativa, se ha indicado que la garantía de la capacidad jurídica se extiende incluso a los casos en que la persona no pueda ser comprendida por terceros, pues en ellos al Estado le asiste la obligación de realizar un razonamiento fundado en el interés superior, propendiendo por averiguar lo que la persona hubiera querido si fuera posible entenderle ${ }^{38}$. Así las cosas, es posible afirmar que la prohibición de privar de la capacidad jurídica a las personas con discapacidad mental se mantiene sin importar las circunstancias particulares de la patología que padezca la persona y cómo esta afecta su proceso de toma de decisiones.

\subsection{La Observación General No. 1 del Comité sobre los Derechos de las Personas con Discapacidad}

A raíz de la tarea de supervisión encomendada por la Convención sobre los Derechos de las Personas con Discapacidad, el CDPD evidenció que existía un malentendido general de los Estados partes respecto del alcance concreto de las obligaciones derivadas del artículo 12 de la Convención, esto teniendo en cuenta que el modelo de discapacidad basado en derechos humanos impone "pasar del paradigma de la sustitución en la adopción de decisiones a uno basado en el apoyo para tomarlas" ${ }^{39}$. Igualmente, hizo énfasis en que este cambio se constituía en una deuda con este grupo poblacional que históricamente había sido discriminado a través de la imposición de medidas que limitaban su capacidad jurídica por el solo hecho de contar con una discapaci$\mathrm{dad}^{40}$, lo cual impactaba de manera negativa en el ejercicio de otros derechos funda

37. OACNUDH (2009), párr. 45.

38. QUINN (2010), p. 13.

39. CDPD (2014), párr. 3.

40. Ibidem, párr. 7. 
mentales ${ }^{41}$; de ahí la necesidad de abolir todas aquellas practicas que atenten contra los presupuestos del artículo 12 de la Convención ${ }^{42}$.

En este orden, el CDPD precisó que la capacidad jurídica se constituye en un derecho con el cual se "reconoce que la persona es un actor jurídico que puede realizar actos con efectos jurídicos"43. Esto implica que no sean de recibo las equiparaciones efectuadas por los ordenamientos jurídicos entre capacidad jurídica y capacidad mental, dado que esto ha facilitado la limitación, e incluso la pérdida total, de la capacidad jurídica de personas que tienen una discapacidad mental, sustentando tal práctica en criterios como la condición de la persona (el diagnóstico de una enfermedad mental), los resultados de sus decisiones (cuando se considera que las decisiones que adopta la persona tiene consecuencias negativas) y el funcional (consistente en considerar que la aptitud que tiene el individuo para adoptar decisiones es deficiente) ${ }^{44}$.

En este sentido, el CDPD recalcó la obligación que le asiste a los Estados parte de proporcionar el apoyo que las personas con discapacidad requieran para tomar decisiones que tengan efectos jurídicos ${ }^{45}$, el cual debe desarrollarse bajo la premisa de la diversidad de las personas con discapacidad, es decir, el apoyo debe variar en cuanto al tipo e intensidad en atención a las condiciones particulares de la persona que lo requiera ${ }^{46}$. No obstante, lo anterior, esta obligación no se ve agotada con la sola existencia de las medidas tendientes a otorgar apoyo en la toma de decisiones, pues si se decide mantener vigentes, de manera paralela, normas que limitan la capacidad jurídica de las personas con discapacidad el Estado no estaría dando un cabal cumplimiento a lo estipulado por el artículo 12 de la Convención ${ }^{47}$.

Así las cosas, de acuerdo a lo dispuesto por la Convención sobre los Derechos de las Personas con Discapacidad y la interpretación que se ha realizado de su artículo 12, es claro que el derecho a la capacidad jurídica de una persona con discapacidad se erige como un derecho de carácter absoluto, pues no es permitido que se le limite bajo ninguna circunstancia. Esto demuestra una posición bastante garantista frente a un grupo poblacional que históricamente ha sido discriminado por la sociedad y por el mismo Estado; sin embargo, como se analiza a continuación, esta postura puede llegar a tornar ineficaz la garantía del derecho a la capacidad jurídica de algunas personas con discapacidad.
41. Ibidem, párr. 8.
42. Ibidem, párr. 9.
43. Ibidem, párr. 11.
44. Ibidem, párr. 13.
45. Ibidem, párr. 14.
46. Ibidem, párr. 16.
47. Ibidem, párr. 24. 


\section{4. ¿La capacidad jurídica de las personas con discapacidad es un derecho funda- mental absoluto?}

Los derechos fundamentales, al igual que los principios, ostentan una especial relevancia dentro de los ordenamientos jurídicos estatales, pero, en atención a las múltiples situaciones que se pueden presentar en una sociedad determinada, existen ocasiones en las que la garantía de alguno de estos derechos entra en colisión con otro de la misma categoría, eventos en los que se requiere hacer un ejercicio de ponderación en el cual se determine cuál de los derechos debe ser garantizado y cuál limitado con ocasión de dicha garantía ${ }^{48}$. En este sentido, el afirmar que un derecho fundamental es absoluto y que, por lo tanto, no admite limitación alguna, implica asumir que no existen, ni existirán nunca circunstancias que tengan mayor peso que la garantía de ese derecho fundamental, lo que se constituye en una teoría difícil de defender ${ }^{49}$ y de entender, máxime si se tiene en cuenta que en el estudio de los derechos fundamentales se ha afirmado que la postura según la cual "los derechos están sujetos a restricciones y pueden ser delimitados o limitados parece ser un conocimiento evidente y hasta trivial" ${ }^{\circ}$. Bajo esta perspectiva, es claro que la capacidad jurídica, como derecho fundamental, también puede ser objeto de limitaciones, tal y como se pasa a explicar.

\subsection{La interdicción en el Tribunal Europeo de Derechos Humanos}

Aunque el máximo tribunal en el Sistema Interamericano de Derechos Humanos es la Corte IDH, una vez revisada su jurisprudencia queda en evidencia que, hasta el momento, no se ha tratado ningún caso en el que se analice la interdicción de personas con discapacidad y si dicha figura jurídica vulnera o no los derechos humanos de este grupo poblacional, motivo por el cual, en procura de analizar esta temática desde la perspectiva de la garantía y protección de los derechos humanos se requiere acudir a otros tribunales internacionales que sí se hayan pronunciado sobre esta materia. En este sentido, se advierte que el Tribunal Europeo de Derechos Humanos (en adelante TEDH) se caracteriza por contar con múltiples pronunciamientos en los que analiza la vulneración de derechos de personas con discapacidad a quienes les fue limitada su capacidad jurídica a través de procesos de interdicción, motivo por el cual se procede a efectuar una relación de las precisiones realizadas en algunos de estos casos.

En uno de sus primeros pronunciamientos sobre la materia ${ }^{51}$, el TEDH determinó que un hecho que, en principio, se considere vulneratorio de un derecho humano puede ser permitido siempre que se haya realizado conforme a la ley, persiga un obje

48. ALEXY (2009), p. 6.

49. ÁLVAREZ (2014), p. 72.

50. ALEXY (1993), p. 267.

51. TEDH. (1999). Caso Matter Vs. Eslovaquia 
tivo legítimo en virtud de lo consagrado en un tratado internacional de derechos humanos y que pueda considerarse como necesario en una sociedad democrática ${ }^{52}$. Así, el Tribunal concluyó que la interdicción, en ese caso en particular, no vulneraba los derechos de la persona con discapacidad dado que esta figura jurídica se encontraba consagrada en la legislación del Estado demandado, el objetivo que perseguía era la protección eficaz de los demás derechos de la persona y, respecto a la necesidad, se aplicó la teoría del margen de apreciación del Estado, pues este podía estar en contacto directo con la persona y determinar la real necesidad de la medida en el caso ${ }^{53}$.

En caso posterior ${ }^{54}$, el TEDH efectuó un importante análisis del procedimiento a través del cual se limitaba la capacidad jurídica a las personas con discapacidad en ese Estado, evidenciando hechos vulneratorios del derecho a un proceso equitativo, pues no se le notificó a la persona con discapacidad mental que se adelantaba en su contra un proceso de interdicción, por lo que no estuvo presente en la audiencia en que se decidió limitar su capacidad jurídica; además, se vulneraron los principios de inmediación de la prueba y de contradicción al fundamentar la decisión solamente en pruebas documentales, sin tener contacto alguno con el afectado con la medida. Igualmente, el TEDH realizó las siguientes precisiones: i) la privación legal de la capacidad jurídica asciende a una injerencia en la vida privada de la persona ${ }^{55}$; ii) la existencia de un trastorno mental, aunque sea grave, no puede ser la única razón para justificar la limitación total de la capacidad jurídica de la persona ${ }^{56}$; iii) el que una persona no cuente legalmente con capacidad jurídica no implica que la misma sea de facto incapaz de comprender su situación ${ }^{57}$; iv) las autoridades deben encontrar un equilibrio justo entre los intereses de la persona y los derechos que se verían afectados con la limitación de su capacidad jurídica ${ }^{58}$; v) las decisiones de las autoridades estatales están abiertas a crítica en sede internacional cuando el procedimiento en el que sustenta la decisión fue deficiente de acuerdo a las exigencias de un tratado internacional de derechos humanos suscrito por el Estado ${ }^{59}$.

52. Ibidem, párr.66.

53. Ibidem, párr. 72.

54. TEDH. (2008). Caso Shtukaturov Vs. Russia.

55. Ibidem, párr. 83.

56. Ibidem, párr. 94.

57. Ibidem, párr. 108.

58. Ibidem, párr. 87.

59. Ibidem, párr. 89. 
Luego de esto, el TEDH analizó un $\operatorname{caso}^{60}$ en el que se alegaba la vulneración de los derechos políticos de una persona con discapacidad mental al no haber podido participar como elector dentro de las elecciones legislativas debido a que se encontraba sujeto a una medida que limitaba su capacidad jurídica. En esta oportunidad, además de considerar vulnerados los derechos del ciudadano, el Tribunal Internacional determinó que: i) al aplicar una restricción a los derechos fundamentales de un grupo particularmente vulnerable, que ha sufrido una discriminación considerable en el pasado, como es el caso de las personas con discapacidad mental, el margen de apreciación del Estado se reduce y debe motivar debidamente las restricciones en cuestión $^{61}$; ii) encasillar a una persona directamente dentro de determinado grupo puede tener como consecuencia el surgimiento de estereotipos legislativos que prohíban la evaluación individualizada de sus capacidades y necesidades ${ }^{62}$; iii) la restricción de los derechos de las personas con discapacidad mental debe estar sujeta a un estricto escrutinio ${ }^{63}$.

El siguiente pronunciamiento del TEDH sobre la materia fue en el de Stanev Vs. Bulgaria ${ }^{64}$, siendo un caso emblemático, dado que se analizó la figura de la interdicción tomando como referencia normatividad europea e internacional aplicable a la materia, incluyendo lo establecido por el artículo 12 de la Convención sobre los Derechos de las Personas con Discapacidad, concluyendo que la limitación de la capacidad jurídica, sea esta total o parcial, no es una figura que por sí sola vulnere los derechos de las personas con discapacidad mental, dado que la misma puede ser necesaria en algunos casos; por el contrario, la vulneración se encuentra relacionada con la falta de garantías procesales en el marco de los procesos de interdicción. En este sentido, recalcó las premisas desarrolladas hasta el momento frente a las actuaciones judiciales tendientes a limitar la capacidad jurídica de las personas con discapacidad, agregando que:

En particular, el derecho a solicitar a un tribunal que revise una declaración de incapacidad es uno de los derechos más importantes para la persona en cuestión ya que un procedimiento de este tipo, una vez iniciado, será determinante para el ejercicio de todos los derechos y libertades afectados por la declaración de incapacidad, sobre todo en relación con las restricciones de las que puede ser objeto la libertad de la persona ${ }^{65}$.

60. TEDH. (2010). Caso Alajos Kiss Vs. Hungría.

61. Ibidem, párr. 42.

62. Ídem.

63. Ibidem, párr. 44.

64. TEDH. (2012). Caso Stanev Vs. Bulgaria

65. Ibidem, párr. 241. 
En fallo posterior ${ }^{66}$, el TEDH se refirió a los exámenes médicos, reconociendo la importancia de los mismos en materia probatoria para la determinación de la procedencia o no de una medida de limitación de la capacidad jurídica de una persona con discapacidad mental ${ }^{67}$; no obstante, lo anterior, aclaró que es el juez, y no el médico, quien debe evaluar circunstancias particulares de la persona ${ }^{68}$. Esto implica que el juez está llamado a comprobar el estado real de la persona, para lo cual, de requerirse, puede solicitar una opinión de un profesional diferente a quien efectuó la valoración inicial de aquella; agregando que, si bien el juez no cuenta con los estudios necesarios para determinar si la misma sufre de una enfermedad mental, si puede verificar si la misma está en la capacidad de manifestar su voluntad ${ }^{69}$.

En sus últimos pronunciamientos sobre la interdicción de personas con discapacidad, el TEDH aceptó que pueden presentarse casos en los que la persona con discapacidad no pueda expresar su opinión de manera coherente, lo que implica que la existencia de una grave discapacidad mental puede afectar seriamente la forma en que el individuo ejerce sus derechos, evento en el cual una restricción o modificación en la manera en que se ejerce el derecho a la capacidad jurídica es permitida, dado que se trata de una circunstancia excepcional ${ }^{70}$. Por otro lado, determinó que la limitación de la capacidad jurídica de la persona con discapacidad es admisible cuando cuenta con un equilibrio entre el respeto por la dignidad y la autodeterminación de la persona y la necesidad de protegerla y salvaguardar sus intereses; este equilibrio se puede ver reflejado en aquellos casos en que los procedimientos internos contemplen salvaguardias efectivas que prevengan el abuso, asegurando, en la medida de lo posible, que los derechos, la voluntad y las preferencias de la persona se tengan en cuenta; además, es necesario que en el procedimiento de interdicción que se adelante la persona esté involucrada en cada una de sus etapas, teniendo la oportunidad de ser escuchado en persona para expresar sus deseos y opiniones; igualmente, se requiere que la limitación de la capacidad jurídica sea proporcional y adaptada a las circunstancias particulares de la persona y tiene que estar sujeta a revisión por parte de tribunales nacionales competentes, independientes e imparciales ${ }^{71}$.

Como se advierte, el TEDH ha dejado claro que la interdicción se erige como una medida de protección de la persona con discapacidad, pero que solamente es admisible, a la luz del derecho internacional de los derechos humanos, si la misma es apli

66. TEDH. (2014). Caso Ivinović Vs. Croacia

67. Ibidem, párr. 40.

68. Ídem

69. Ibidem, párr. 45.

70. TEDH. (2016). Caso A.N. Vs. Lituania, párr. 90.

71. TEDH. (2017). Caso A.-M. V. Vs. Finlandia, párr. 90. 
cada de manera estrictamente excepcional y obedeciendo una serie de parámetros tendientes a brindar una protección real de la persona en situación de discapacidad; así, es claro que los Estados cuentan con un margen de apreciación para limitar la capacidad jurídica de las personas con discapacidad, margen que, a pesar de ser estrecho al tratarse de una medida que afecta a un grupo vulnerable, demuestra que este derecho fundamental no es absoluto.

\subsection{La expresión de la voluntad de la persona con discapacidad}

Tal como lo señala el CDPD, la voluntad de la persona con discapacidad siempre debe ser respetada en la adopción de las decisiones que inciden en su vida, lo que implica que el modelo de apoyo en la toma de decisiones propuesto por la Convención sobre los Derechos de las Personas con Discapacidad en procura de garantizar el derecho a la capacidad jurídica debe obedecer a la voluntad y preferencias de la persona y nunca se debe prestar para que se decida por ella ${ }^{72}$. Igualmente, se ha precisado que cualquier medida de apoyo en la toma de decisiones, sin importar la intensidad de la misma, debe estar basada "en la voluntad y las preferencias de la persona, no en lo que se suponga que es su interés superior objetivo"73, esto teniendo en cuenta que, de acuerdo a las exigencias del artículo 12 de este instrumento internacional de derechos humanos, las personas con discapacidad deben contar con "oportunidades de formar y expresar su voluntad y preferencias, a fin de ejercer su capacidad jurídica en igualdad de condiciones con las demás"74.

A pesar de lo garantista de esta postura, la misma tiene un efecto similar a la interdicción, pues esta asume que por el solo hecho de tener una discapacidad mental es necesario limitar la capacidad jurídica de la persona, mientras que el modelo de apoyo en la toma de decisiones asume que todas las personas pueden expresar su voluntad sin importar el tipo o grado de discapacidad que tengan. Al respecto, es importante que se tenga en cuenta que "la medición de la discapacidad constituye una experiencia pluridimensional compleja”75, tarea que se dificulta aún más respecto de la discapacidad mental en atención a sus múltiples manifestaciones ${ }^{76}$ y a su gravedad $^{77}$, esto implica que establecer, como regla general, que todas las personas con discapacidad mental pueden manifestar su voluntad desconoce las particulari

72. CDPD (2014), párr. 15.

73. Ibidem, párr. 25.b.

74. Ibidem, párr. 40.

75. OMS (2011), p. 23.

76. CONSEJO NACIONAL PARA PREVENIR LA DISCRIMINACIÓN (2010), pp. 17-18.

77. NOVELL et al (2003), p. 40. 
dades que entrañan algunas afectaciones a la salud mental de las personas; tal es el caso de la discapacidad intelectual, caracterizada por un retraso en el desarrollo del funcionamiento intelectual, dificultades en el funcionamiento social adaptativo y por manifestarse en diferentes niveles de gravedad, uno de los cuales es el profundo, que representa del $1 \%$ al $2 \%$ de todos los $\operatorname{casos}^{78}$. Dentro de este nivel, se destacan los casos de personas con discapacidades intelectuales y de desarrollo severas y profundas (SPIDD por sus siglas en inglés), quienes, desde una perspectiva clínica, tienen limitaciones en todas las áreas de su vida y, con ocasión a la naturaleza de sus necesidades, no es posible establecer de manera cierta y concreta un limite máximo para el grado de discapacidad o la extensión del apoyo que requieren, pues se trata de personas con una amplia gama y nivel de necesidades caracterizadas por su complejidad en atención a profundas discapacidades intelectuales, sensoriales y físicas ${ }^{79}$.

En atención a esto, es evidente que, aunque pocas, existen personas con una discapacidad tan severa que requieren un apoyo en todas las esferas de su vida debido a la naturaleza y grado de la discapacidad que padecen. Algunas de estas personas, debido a la magnitud de su discapacidad, no se encuentran en la capacidad de manifestar su voluntad por ningún medio de comunicación ${ }^{80}$ que sea comprensible por un tercero, así que frente a este grupo reducido no es posible aplicar el modelo de apoyo en la toma de decisiones, pues, como lo expresó el CDPD, las medidas "de apoyo en el ejercicio de la capacidad jurídica (incluidas las formas de apoyo más intenso) deben estar basadas en la voluntad y las preferencias de la persona, no en lo que se suponga que es su interés superior objetivo" ${ }^{81}$.

En este orden, pretender aplicar el modelo de apoyo en la toma de decisiones a personas con discapacidad que no puedan expresar su voluntad a través de ningún medio de comunicación tiene como consecuencia que, en la práctica, sean terceros los que terminen adoptando las decisiones relacionadas con el ejercicio de los derechos de estas personas, es decir, en estos eventos el concepto de "modelo de apoyo en la toma de decisiones" se constituye en un eufemismo, pues se estaría frente a una interdicción de la persona con discapacidad. Es bajo estas consideraciones que se

78. KE y LIU (2017), p. 5.

79. COIFFAIT y LEEDHAM (2016), p. 1403.

80. Para delimitar los medios de comunicación se acude a lo descrito en el artículo 2 de la Convención sobre los Derechos de las Personas con Discapacidad, teniéndose por estos "los lenguajes, la visualización de textos, el Braille, la comunicación táctil, los macrotipos, los dispositivos multimedia de fácil acceso, así como el lenguaje escrito, los sistemas auditivos, el lenguaje sencillo, los medios de voz digitalizada y otros modos, medios y formatos aumentativos o alternativos de comunicación, incluida la tecnología de la información y las comunicaciones de fácil acceso".

81. CDPD (2014), párr. 25.b. 
plantea la necesidad de contar con una figura jurídica, debidamente reglamentada, con la cual se pueda garantizar que personas con un grado severo de discapacidad puedan ejercer su derecho a la capacidad jurídica a través de un tercero, dado que de nada sirve que se garantice de manera absoluta un derecho si existen personas que, debido a sus condiciones particulares, no pueden ejercerlo, pues en estos eventos ese derecho se torna ineficaz.

\subsection{Limitación de la capacidad jurídica de personas con discapacidad como fi- gura estrictamente excepcional}

En primera instancia, es necesario aclarar que la limitación del derecho fundamental a la capacidad jurídica no implica una infracción al Derecho Internacional de los Derechos Humanos, dado que el máximo Tribunal del Sistema Interamericano de Derechos Humanos ha sostenido que una medida que limite o restrinja un derecho humano, como lo es la capacidad jurídica debido a su conexión con el derecho al reconocimiento de la personalidad jurídica, carece de arbitrariedad, y por lo tanto es convencionalmente permitida, siempre que esté debidamente fundamentada ${ }^{82}$.

Ahora bien, como se explicó con antelación, existen personas que debido al tipo y magnitud de su discapacidad no pueden expresar su voluntad y, en consecuencia, requieren de una figura que vaya más allá que el apoyo en la toma de decisiones; de ahí que, al encontrarse en una situación particularmente vulnerable, se requiere que frente a estas personas prevalezca la adopción de la medida más favorable, motivo por el cual es necesario que se aplique el principio pro homine, frente al cual se ha explicado que:

Sin perjuicio de las reglas tradicionales de interpretación y aplicación de las fuentes de derecho tanto de orden interno como internacional enunciadas sucintamente, conviene subrayar que en el ámbito del derecho internacional de los derechos humanos importa tener en cuenta una regla que está orientada a privilegiar, preferir, seleccionar, favorecer, tutelar y, por lo tanto, a adoptar la aplicación de la norma que mejor proteja los derechos fundamentales del ser humano ${ }^{83}$.

En este sentido, es evidente que plantear la limitación de un derecho fundamental con el propósito de garantizar otros supone un conflicto entre derechos de una misma categoría y, por lo tanto, sea procedente la aplicación del test de proporcionalidad ${ }^{84}$, para esto se deben analizar la finalidad, la idoneidad, la necesidad y la proporcionali

82. CORTE IDH (2013), párr. 224.

83. HENDERSON (2004), p. 87

84. Sentencia C-022 (1996). 
dad en sentido estricto ${ }^{85}$ de la medida con la que se limitaría, en este caso, la capacidad jurídica. En lo que respecta a la finalidad, se requiere que esta sea legítima ${ }^{86}$, es decir, que la medida analizada propenda por la garantía de un derecho fundamental ${ }^{87}$, en el presente caso la limitación de la capacidad jurídica del grupo poblacional señalado para que esta sea ejercida por un tercero busca hacer efectivos los demás derechos de los que es titular la persona con ese tipo y grado particular de discapacidad.

Frente a la idoneidad, es preciso que la medida se constituya en un medio a través del cual la finalidad perseguida se alcance en la mayor medida posible ${ }^{88}$, hecho que se logra con una figura que limite la capacidad jurídica, pues, como se explicó, la opción alterna, el apoyo en la toma de decisiones, no es procedente ante la imposibilidad que tiene la persona de manifestar su voluntad. Sobre la necesidad, se ha explicado que se debe verificar la posibilidad de que sea implementada una medida menos gravosa, pero que también conduzca al propósito esperado ${ }^{89}$, lo que no es procedente en esta oportunidad debido a las especiales características y necesidades de las personas con discapacidad a quienes estaría dirigida la limitación de su capacidad jurídica.

Con relación a la proporcionalidad en sentido estricto, es necesario demostrar, cualitativamente, que el beneficio obtenido con la implementación de la medida es mayor o igual a la restricción que se efectúa del derecho fundamental ${ }^{90}$, esto requiere llevar a cabo una ponderación con el propósito de determinar: i) el grado de afectación de uno de los derechos analizados, estableciendo si la intensidad de la afectación es grave, intermedia o moderada; ii) la importancia que reviste la satisfacción del bien contrario, y iii) si la satisfacción de este justifica la restricción de aquel ${ }^{91}$. Con relación al grado de afectación, es claro que el hecho de que un tercero tome las decisiones por la persona con el tipo y grado de discapacidad referenciadas tiene como consecuencia una afectación grave al derecho a la capacidad jurídica; no obstante, lo anterior, al analizar, objetivamente, el segundo elemento se tiene que el bien contrario que se pretende satisfacer es el efectivo ejercicio de todos los demás derechos de los que es titular la persona a quien le sería aplicada la figura de la representación, motivo por el cual, en lo que se refiere al tercer elemento, se encuentra que una medida que limite la capacidad jurídica de las personas con discapacidad en estos eventos se encuentra justificada.

85. Sentencia C-470 (2011).

86. Sentencia C-584 (1997).

87. Sentencia C-623 (2015).

88. CLÉRICO (2008), p. 131.

89. Sentencia C-470 (2011).

90. SÁNCHEZ (2008), p. 251.

91. CORTE IDH (2008), párr. 84. 
En este orden de ideas, la limitación de la capacidad jurídica de las personas con discapacidad puede verse desde la perspectiva del paternalismo jurídico, pues este se refiere a aquellas interferencias en la libertad de acción de una persona que encuentran su justificación en razones relacionadas con el bienestar, el bien, la felicidad, las necesidades, los intereses o los valores de la persona coaccionada ${ }^{92}$. Bajo esta óptica, la medida tendiente a limitar la capacidad jurídica que se propone no se aplicaría sobre la base de la discriminación de la persona en atención a su condición de discapacidad, sino que se adoptaría con el propósito de protegerla y que sea posible que, a través de un tercero, ejerza los demás derechos de los que es titular al verse imposibilitada de hacerlo personalmente por el hecho de no poder expresar su voluntad a través de ningún medio de comunicación comprensible por otra persona, lo que implica que la procedencia de la medida sería estrictamente excepcional, pues son muy pocas las personas que se encuentran en esa situación.

Sin embargo, no basta con que la medida sea de procedencia excepcional, sino que también se requiere que la misma esté debidamente regulada, especialmente en lo concerniente al procedimiento para su imposición, motivo por el cual se considera pertinente hacer uso de los parámetros que al respecto ha establecido el TEDH en su jurisprudencia en materia de interdicción. Así las cosas, el proceso debe adelantarse ante una autoridad judicial, en él se debe propender porque la persona con discapacidad haga parte de cada una de las etapas, esto teniendo en cuenta que el juez tiene que corroborar, de manera personal, que efectivamente la persona no puede manifestar su voluntad a través de ningún medio de comunicación comprensible por un tercero; además, la medida debe estar sujeta a revisión periódica por parte del juez, pero puede solicitarse su revocatoria en cualquier momento por parte de un tercero o de la misma persona sometida a la restricción en caso de que su condición mejore. Finalmente, con el propósito de evitar abusos en el ejercicio de la capacidad jurídica de la persona con discapacidad, el tercero que se nombre para su representación debe tener limitantes para el ejercicio de los derechos de la persona, en especial los relacionados con la administración de bienes, la libertad e integridad personal y los sexuales y reproductivos. Estas limitantes consistirían en la necesidad de contar con la aprobación del juez para adoptar una decisión que comprometa alguno de estos derechos y, con relación a otro tipo de decisiones, se considera conveniente que también se cuente con otras personas que supervisen la actuación de quien ha sido nombrado como representante de la persona con discapacidad, función que puede ser asignada a los familiares cercanos de esta última, quienes podrían informar al juez cualquier irregularidad en el ejercicio de las facultades otorgadas al tercero que representa a la persona con discapacidad.

92. DWORKIN (1971), p. 107. 


\section{Conclusiones}

Es innegable la importancia y necesidad del cambio de paradigma frente al reconocimiento, garantía y protección de los derechos de las personas con discapacidad, pues se trata de un grupo especialmente vulnerable debido a la discriminación de la cual ha sido objeto históricamente a través de la imposición de barreras; sin embargo, no es admisible que, con el propósito de atacar figuras discriminatorias como la interdicción, se adopten modelos que asignen la categoría de absoluto a derechos que, en la práctica, no pueden ser ejercidos por todas las personas con discapacidad. En este sentido, el modelo de "apoyo en la toma de decisiones" propuesto por Naciones Unidas asume que todas las personas con discapacidad pueden expresar su voluntad al momento de adoptar cualquier decisión y, por lo tanto, la capacidad jurídica no puede ser limitada bajo ninguna circunstancia, pero esta postura desconoce la existencia de un pequeño grupo de personas cuya discapacidad es de tal grado que no pueden expresar su voluntad a través de ningún medio de comunicación, por lo que el modelo en comento es ineficaz para ellos.

Así las cosas, es evidente que Naciones Unidas debe reevaluar la postura que hasta el momento ha mantenido frente al derecho a la capacidad jurídica de las personas con discapacidad y admitir que, frente a casos excepcionales, la limitación de este derecho fundamental se torna en una medida de protección al propender por el ejercicio de los demás derechos de la persona con discapacidad que no puede hacerlo por sí misma. Igualmente, es necesario que la medida o modelo a través del cual se realice tal limitación sea debidamente reglamentada con el fin de evitar que su imposición sea arbitraria o que su ejercicio permita la vulneración de otros derechos fundamentales, para lo cual es posible acudir a las precisiones que el TEDH ha realizado sobre la materia y que se fundan en la especial protección que requieren las personas con discapacidad por parte de la sociedad, el Estado y la comunidad internacional.

\section{Referencias bibliográficas}

ALEXY, Robert (1993): Teoría de los derechos fundamentales (Traducción de GARZÓN, Ernesto), (Madrid, Centro de Estudios Constitucionales).

ALEXY, Robert (2009): "Derechos fundamentales, ponderación y racionalidad” (Traducción de SÁNCHEZ, Rubén). En Revista Iberoamericana de Derecho Procesal Constitucional, No. 11, pp. 3-13.

ÁLVAREZ, Íñigo (2014): “Universales, absolutos e inalienables: los derechos indestructibles". En Revista de Humanidades de Valparaíso, año 2, $\mathrm{N}^{\circ}$ 4, 2do semestre, pp. 63-8o. 
BIEL, Israel (2009): Los Derechos de las Personas con Discapacidad en el Marco Jurídico Internacional Universal y Europeo (Tesis doctoral). Universitat Jaume I, Castellón, España.

CELS Argentina; EQUAL Asociación para la promoción y protección de los derechos de las personas en situación de vulnerabilidad; Centro de Investigación y Docencia en Derechos Humanos "Alicia Moreau”, Faculta de Derecho, Universidad Nacional de Mar del Plata; Fundamental Colombia; Programa de Acción por la Igualdad y la Inclusión Social; Fundamental Costa Rica; Instituto Interamericano sobre Discapacidad y Desarrollo Inclusivo; Documenta, análisis y acción para la justicia social; Id(h)eas, Litigio Estratégico en Derechos Humanos; Centro Estratégico de Impacto Social; Colectivo Chuhcan; Instituto de Democracia y Derechos Humanos Pontificia Universidad Católica; Instituto Interamericano sobre Discapacidad y Desarrollo Inclusivo; y Disability Rights International (2014): "Informe sobre la situación de los derechos de las personas con discapacidad en América Latina: capacidad jurídica y acceso a la justicia". Disponible en: <http://documenta.org. $\mathrm{mx} /$ layout/publicaciones/informes-justicia-discapacidad-psicosocial/informederechos-personas-discapacidad-america-latina-2014.pdf $>$. [Fecha de consulta: 21 de marzo de 2019].

CLÉRICO, Laura (2008): "El examen de proporcionalidad: entre el exceso por acción y la insuficiencia por omisión o defecto”. En CARBONELL, Miguel. El principio de proporcionalidad y la interpretación constitucional. (Quito, Ministerio de Justicia y Derechos Humanos), pp. 125-174.

COIFFAIT, Fleur-Michelle y LEEDHAM, Alexandra (2016): "Psychological WellBeing of Children and Adults with Severe and Profound Intellectual and Developmental Disabilities". En I.L., Rubin, J., Merrick, D.E., Greydanus y D.R., Patel. Health Care for People with Intellectual and Developmental Disabilities across the Lifespan. (Ginebra, Springer International Publishing Switzerland), pp. 1401-1419.

COMISIÓN DE DERECHOS HUMANOS DEL DISTRITO FEDERAL (2008): Informe especial sobre la situación de los derechos humanos de las personas con discapacidad en el Distrito Federal 2007-2008 (México D.F., Comisión de Derechos Humanos del Distrito Federal).

CONSEJO NACIONAL PARA PREVENIR LA DISCRIMINACIÓN (2010): Estudio sobre discriminación y discapacidad mental e intelectual (México D.F., Consejo Nacional para Prevenir la Discriminación).

Convención Interamericana para la Eliminación de todas las Formas de Discriminación contra las Personas con Discapacidad. Aprobada por la Organización de Estados Americanos y suscrita el 7 de junio de 1999. 
DHANDA, Amita (2007): "Legal capacity in the disability rights convention: Stranglehold of the past or lodestar for the future?". En Syracuse J. Int'l L. E Com., Año34 $\mathrm{N}^{\circ} 429$, pp. 429-462.

DEGENER, Theresia (200o): "International Disability Law-A New Legal Subject on the Rise: The Interregional Experts' Meeting in Hong Kong, December 13-17, 1999". En Berkeley Journal of International Law, Año18, pp. 180-195.

DE VICENTE, María (2001): "Precedentes históricos de la educación infantil: de la antigüedad hasta Roma”. En Anales de Pedagogía, N 19, pp. 9-17.

DWORKIN, Gerald (1971): “Paternalism”. En WASSERSTROM, Richard. Morality and the Law. (Belmont, Wadsworth Publishing Company), pp. 107-126.

GARCÍA, Eduardo (2015): "La discriminación por discapacidad como tema emergente en el contexto de los movimientos sociales contemporáneos". En Rev. Fac. Med., Año 63, No. 1, pp. 155-16o.

GONZÁLEZ, Alonso (2010): Capacidad jurídica de las personas con discapacidad (México D.F., Comisión Nacional de los Derechos Humanos).

GOSTIN, Lawrence y GABLE, Lance (2004): “The human rights of persons with mental disabilities: a global perspective on the application of human rights principles to mental health". En Maryland Law Review, Año 63, pp. 20-121.

HENDERSON, Humberto (2004): "Los tratados internacionales de derechos humanos en el orden interno: la importancia del principio pro homine". En Revista IIDH, Año39, pp. 71-99.

HÉRNANDEZ, Janeth y CRUZ, Israel (2006): Exclusión social y discapacidad (Bogotá D.C., Editorial Universidad del Rosario).

JIMÉNEZ, Rodrigo (2008a): Derechos de las personas con Discapacidad (San José, Instituto Interamericano de Derechos Humanos).

JIMÉNEZ, Rodrigo (20o8b): Derecho y discapacidad (San José, Universidad Nacional de Costa Rica).

KE, Xiaoyan y LIU Jing (2017): “Discapacidad Intelectual” (Traducción de IRARRÁZAVAL, M., MARTIN, A., PRIETO-TAGLE, F. y FUERTES, O.). En REY, Joseph. Manual de Salud Mental Infantil y Adolescente de la IACAPAP. (Ginebra, Asociación Internacional de Psiquiatría del Niño y el Adolescente y Profesiones Afines), pp. 1-28.

LINDQVIST, Bengt. (2002). Informe sobre las actividades de vigilancia de la aplicación de las Normas Uniformes sobre la igualdad de oportunidades para las personas con discapacidad realizadas durante su tercer mandato, 2000-2002. Rendido en el $40^{\circ}$ periodo de sesiones de la Comisión de Desarrollo Social. (E/ CN.5/2002/4). 
Naciones Unidas. (1969). Declaración sobre el progreso y el desarrollo social. Proclamada por la Asamblea General en su resolución 2542 (XXIV), de 11 de diciembre de 1969.

Naciones Unidas. (1971). Declaración de los Derechos del Retrasado Mental. Proclamada por la Asamblea General en su resolución 2856 (XXVI), de 20 de diciembre de 1971.

Naciones Unidas. (1975). Declaración de los Derechos de los Impedidos. Proclamada por la Asamblea General en su resolución 34.47 (XXX) de 9 de diciembre de 1975.

Naciones Unidas. (1989). Directrices de Tallin para el Desarrollo de los Recursos Humanos en la Esfera de los Impedidos. Adoptadas por la Asamblea General en su resolución 44/70 de 8 de diciembre de 1989.

Naciones Unidas. (1991). Principios para la protección de los enfermos mentales y el mejoramiento de la atención de la salud mental. Adoptados por la Asamblea General en su resolución 46/119 de 17 de diciembre de 1991.

Naciones Unidas. (1993). Normas Uniformes sobre la Igualdad de Oportunidades para las Personas con Discapacidad. Aprobadas por la Asamblea General en su resolución 48/96 de 20 de diciembre de 1993.

NOVELL, Ramón, RUEDA, Pere, SALVADOR, Luis y FORGAS, Eulalia (2003): Salud mental y alteraciones de la conducta en las personas con discapacidad intelectual Guía práctica para técnicos y cuidadores (Madrid, Confederación Española de Organizaciones en favor de las Personas con Discapacidad Intelectual - FEAPS).

OACNUDH (2009): Informe anual del alto comisionado de las naciones unidas para los derechos humanos e informes de la oficina del alto comisionado y del secretario general. Estudio temático preparado por la Oficina del Alto Comisionado de las Naciones Unidas para los Derechos Humanos para mejorar el conocimiento y la comprensión de la Convención sobre los derechos de las personas con discapacidad (U.N. Doc.A/HRC/10/48, 26 de enero de 2009).

O'DONNELL, Daniel (2004): Derecho internacional de los derechos humanos - Normativa, jurisprudencia y doctrina de los sistemas universal e interamericano (Bogotá D.C., Oficina en Colombia del Alto Comisionado de las Naciones Unidas para los Derechos Humanos).

OMS (2004): Informe mundial sobre la discapacidad (Malta, Organización Mundial de la Salud).

OMS (2011): Invertir en salud mental (Ginebra, Organización Mundial de la Salud).

ONU (2015): Global Status Report on Disability and Development Prototype 2015 (New York, United Nations). 
PALACIOS, Agustina (2015): "Una introducción al modelo social de discapacidad y su reflejo en la convención internacional sobre los derechos de las personas con discapacidad". En Pontificia Universidad Católica del Perú. Nueve conceptos claves para entender la Convención sobre los derechos de las personas con discapacidad. (Lima, Instituto de Democracia y Derechos Humanos de la Pontificia Universidad Católica del Perú), pp. 9-33.

PALACIOS, Agustina y BARIFFI, Francisco (2007): La discapacidad como una cuestión de derechos humanos. Una aproximación a la Convención Internacional sobre los Derechos de las Personas con Discapacidad (Madrid, Grupo Editorial Cinca).

PÉREZ, Hilda (2014): "Análisis crítico y constructivo de la declaración del estado de interdicción”. En DOMÍNGUEZ, Jorge y SÁNCHEZ, José. Homenaje al maestro José Barroso Figueroa. (México, Colegio de Profesores de Derecho Civil Facultad de Derecho-UNAM), pp. 235-250.

QUINN, Gerard y DEGENER, Theresia (2002): Human Rights and Disability. The current use and future potential of United Nations human rights instruments in the context of disability (New York, United Nations).

QUINN, Gerard (2010), "Personhood E Legal Capacity: Perspectives on the Paradigm Shift of Article 12 CRPD" (Paper presented at Conference on Disability and Legal Capacity under the CRPD, Harvard Law School, Boston). Disponible en: <http:// www.inclusionireland.ie/sites/default/files/attach/basic-page/846/harvardlegalcapacitygqdraft2.doc $>$. [Fecha de consulta: 18 de marzo de 2019].

RIOUX, Marcia y CARBET Anne (2003): "Human Rights and Disability: The International Context”. En Journal on Developmental Disabilities, Año1o No2, pp. 1-13.

ROSALES, Pablo (2015): Diagnóstico regional sobre el ejercicio de la capacidad jurídica de las personas con discapacidad (Washington D.C., Organización de los Estados Americanos).

SÁNCHEZ, Rubén (2008): "El principio de proporcionalidad en la jurisprudencia mexicana”. En CARBONELL, Miguel. El principio de proporcionalidad y la interpretación constitucional. (Quito, Ministerio de Justicia y Derechos Humanos), pp. 221-268.

STANG, María (2011): Las personas con discapacidad en América Latina: del reconocimiento jurídico a la desigualdad real (Santiago de Chile, Centro Latinoamericano y Caribeño de Demografía).

SULLIVAN, Chris (2012): "A manera de introducción: hacia un instrumento internacional para proteger los derechos de las personas con discapacidad". En LARA, Diana. La Convención sobre los Derechos de las Personas con Discapacidad (fascículo 10). (México D.F., Comisión Nacional de los Derechos Humanos), pp. 13-20. 
VALLEJO, Geovana, HERNÁNDEZ, Mónica y POSSO, Adriana (2017): "La capacidad jurídica de las personas con discapacidad en Colombia y los nuevos retos normativos". En CES Derecho, 8 (1), pp. 3-21.

\section{Jurisprudencia citada}

a) Tribunales nacionales

Sentencia C-o22 (1996). Corte Constitucional de Colombia. Sentencia del 23 de enero, M.P. Carlos Gaviria Díaz.

Sentencia C-584 (1997). Corte Constitucional de Colombia. Sentencia del 13 de noviembre, M.P. Eduardo Cifuentes Muñoz.

Sentencia C-47o (2011). Corte Constitucional de Colombia. Sentencia del 13 de junio, M.P. Nilson Pinilla Pinilla.

Sentencia C-623 (2015). Corte Constitucional de Colombia. Sentencia del 30 de septiembre, M.P. Alberto Rojas Ríos.

b) Tribunales internacionales

CORTE IDH (2005), Caso de las Niñas Yean y Bosico Vs. República Dominicana. Excepciones Preliminares, Fondo, Reparaciones y Costas. Sentencia de 8 de septiembre de 2005. Serie C No. 130.

CORTE IDH (2008), Caso Kimel Vs. Argentina. Fondo, Reparaciones y Costas. Sentencia de 2 de mayo de 2008. Serie C No. 177.

CORTE IDH (2013), Caso J. Vs. Perú. Excepción Preliminar, Fondo, Reparaciones y Costas. Sentencia de 27 de noviembre de 2013. Serie C No. 275.

TEDH. (1999). Caso Matter Vs. Eslovaquia, N³1534/96, julio 5 de 1999.

TEDH. (2008). Caso Shtukaturov Vs. Russia, N44009/05, 27 de marzo de 2008.

TEDH. (2010). Caso Alajos Kiss Vs. Hungría, N³8832/o6, mayo 20 de 2010.

TEDH. (2012). Caso Stanev Vs. Bulgaria, $\mathrm{N}^{\circ}$ 3676o/o6, 17 de enero de 2012.

TEDH. (2014). Caso Ivinović Vs. Croacia, No 13006/13, 18 de septiembre de 2014.

TEDH. (2016). Caso A.N. Vs. Lituania, No 17280/o8, 31 de agosto de 2016.

TEDH. (2017). Caso A.-M. V. Vs. Finlandia, No 53251/13, 23 de junio de 2017. 


\title{
Debates en torno a los efectos de la fertilización in vitro heteróloga en la filiación
}

\author{
Debates about the effects of heterologous in vitro fertilization on filiation
}

\section{LisANdRa SuÁrez Fernández ${ }^{* 1}$ \\ Luis Pérez Orozco \\ Universidad de Matanzas, Cuba}

\begin{abstract}
"Ser padre o madre es mucho más que un vínculo genético o biológico: es querer ser padre o querer ser madre."

Eleonora Lamm
\end{abstract}

\begin{abstract}
RESUMEN Los avances logrados en la Biotecnología, especialmente en el ámbito de las técnicas de reproducción humana asistida, han provocado transformaciones en la forma en que actualmente se conciben algunas instituciones jurídicas. La fertilización in vitro heteróloga de modo particular, a razón de la intervención de donantes de material genético, trastoca los fundamentos en los cuales se ha sostenido la filiación como categoría del Derecho de Familia, dando lugar a que se contemple la posibilidad de existencia de una tercera tipicidad filiatoria. Las polémicas teóricas y doctrinales que genera su implementación para los usuarios en relación a las presunciones filiatorias y la dimensión del consentimiento informado trascienden a los ordenamientos foráneos en solu
\end{abstract}

\footnotetext{
* El presente trabajo es resultado de la actividad científica desarrollada por los autores en el marco del Grupo de Investigación: "El Derecho frente a los nuevos retos sociales", del Departamento de Derecho de la Universidad de Matanzas; 2016.

1. Lisandra Suárez Fernández es profesora universitaria auxiliar y notario público en Universidad de Matanzas, Cuba. Mail: lisisf85@gmail.com. Luis Pérez Orozco trabaja en el Departamento Legal y es profesor de Derecho de la Universidad de Matanzas "Camilo Cienfuegos", Cuba. Mail: luisperezorozco1994@gmail.com
} 
ciones diversas que son reflejadas de modo igualmente variado en el plano a jurisprudencial. Aún existen ordenamientos ajenos a estos cambios, generando una desprotección a los derechos de los sujetos involucrados en su utilización, cuestión que amerita una construcción normativa que atempere los basamentos teóricos de la filiación a la realidad social y la ciencia en evolución.

PALABRAS CLAVE fertilización in vitro heteróloga, filiación, familia.

ABSTRACT The advances achieved in Biotechnology, especially in the field of assisted human reproduction techniques, have led to changes in the way in which some legal institutions are currently conceived. Due to the intervention of donors of genetic material, heterologous in vitro fertilization overturns the foundations on which filiation has been maintained as a category of Family Law, giving rise to the possibility of a third type of filiation. The theoretical and doctrinal controversies generated for users by implementation of this technique in relation to filiatory presumptions and the dimension of informed consent transcend foreign systems in diverse solutions that are reflected in an equally varied manner in jurisprudence. Orders still exist which do not take these changes into account, generating a lack of protection of the rights of the subjects involved in their use; this situation merits the construction of norms to adapt the theoretical foundations of filiation to the reality of our society and evolving science.

KEYWORDS Heterologous in vitro fertilization, filiation, family.

\section{Introducción}

Ante la imposibilidad de obtener descendencia de manera natural, es necesario acudir al desarrollo científico y tecnológico para poder alcanzar el proyecto familiar. Con las técnicas de reproducción humana asistida pueden ser padres o madres quienes no podían, separando la reproducción humana de la sexualidad, permitiendo que modelos familiares en ascenso hoy día puedan tener descendencia. De forma general entre las principales alternativas terapéuticas para tratar la infertilidad, se ubican la inseminación artificial, la donación de ovocitos, la criopreservación de gametos y embriones, el diagnóstico genético preimplantacional, la maternidad subrogada y la fertilización in vitro ${ }^{2}$, siendo esta última en su variante heteróloga, objeto de estudio de la presente disertación, excluyendo por su carácter abarcador y controvertido las

2. En lo adelante el término será identificado con las siglas FIV. 
cuestiones asociadas al derecho a la vida del concepturus y a la fecundación postmortem ${ }^{3}$.

Sin embargo, la imposibilidad de concebir un hijo trasciende las fronteras médicas o psicológicas para convertirse en un problema social y jurídico, acarreando una serie de dificultades en el seno de la familia que está conformándose, sobre todo cuando a filiación se refiere.

La polémica desatada por la FIV en relación a la filiación no trasciende homogéneamente al ámbito normativo, resaltando un desentendimiento al respecto en varias naciones donde las porfías se han solventado en sede judicial, quedando a la espera de una interpretación tribunalicia favorable y un desarrollo progresivo en el orden social y jurídico, advirtiendo que si bien, la vía judicial pudiera funcionar como temporal solución, no ofrece-a criterio de los investigadores- un tratamiento uniforme, quebrantando en definitiva el principio de seguridad jurídica. Lo anteriormente expuesto pone en evidencia la necesidad de reestructurar el sistema jurídico en materia de filiación atendiendo los más recientes avances científicos y la reconfiguración de sus pilares teóricos.

Son precisamente tales inquietudes científicas pie forzado para el estudio a desarrollar con el objetivo de sistematizar las tendencias doctrinales, jurisprudenciales y legales respecto a la fertilización in vitro heteróloga, y su impacto en los basamentos de la filiación. A razón de lo planteado se define como problema científico de esta investigación el siguiente: La ausencia de presupuestos doctrinales, legales y jurisprudenciales en el orden sustantivo familiar que delimiten los efectos filiatorios derivados de la técnica de fertilización in vitro heteróloga impiden la protección adecuada de las relaciones paterno-filiales. No constituye pretensión hacer un estudio de Derecho Comparado, sino sistematizar los principales cambios en la filiación provocados por la FIV heteróloga desde una perspectiva integradora.

En Cuba, la temática de investigación cobra singular importancia toda vez que la nueva Constitución de la República de 2019 reconoce el ejercicio de los derechos sexuales y reproductivos y propicia la consolidación de todos los modelos familiares. La propia Carta Magna dispone el proceso a seguir con vistas a la promulgación de un Código de Familia que deberá desarrollar los postulados constitucionales y pronunciarse inevitablemente sobre las técnicas de reproducción humana asistida.

\section{Fecundación natural y técnicas médicamente asistidas de reproducción hu- mana}

La salud reproductiva está conformada por la capacidad de disfrutar una vida sexual satisfactoria y sin riesgos, la libertad para decidir fecundar o no hacerlo, cuándo y con qué frecuencia y por la procreación en sí misma, entendida esta última como una

3. En lo adelante el término será identificado con las siglas FIV. 
consecuencia y no como derecho. Esta gama de potestades lleva implícito el derecho a obtener información sobre planificación familiar, así como de los métodos para la regulación de la fecundidad y su acceso, el derecho a recibir servicios adecuados de atención de la salud que permitan embarazos y partos sin riesgos y den a las parejas las máximas posibilidades de tener hijos sanos. Todo ello se encuentra estrechamente relacionado con el ejercicio de los derechos sexuales y reproductivos que aunque comúnmente se utilizan en calidad de sinónimos, realmente no lo son ${ }^{4}$. Los investigadores son conscientes del debate sobre género que se suscita en torno a las técnicas de reproducción humana asistida, pero el mismo no será objeto de atención en el presente trabajo pues excede el marco metodológico pretendido.

La reproducción sexual consiste en el proceso creador de un nuevo organismo a partir de la combinación de material genético de dos seres de una misma especie. Como parte de esa simbiosis en los humanos ocurre la fecundación de los gametos masculino y femenino, dando lugar posteriormente al embrión. Cuando este proceso no puede llevarse a cabo de forma natural en una o varias de sus fases, se recurre a la Biotecnología, permitiendo mediante el uso de un conjunto de técnicas poner en contacto los elementos germinales del hombre y la mujer mediante la manipulación del material genético. Las distinciones y coincidencias entre ambas se aluden en la jurisprudencia colombiana cuando dice que:

"la diferencia entre la reproducción "natural" y la "artificial" consiste en que la primera se da por la cópula de los órganos sexuales masculino y femenino; mientras que en la segunda la fecundación del óvulo se hace sin unión sexual o ayuntamiento, aunque tales conceptos no son del todo precisos porque ambos procesos son biológicos y siguen las leyes naturales de la reproducción celular." 5

4. VALDÉS (2012) pp. 229-230 ; BLENGIO (2018) pp. 121-128.

5. Sentencia 6359 de 10 de mayo de 2017 de la Sala de Casación Civil de la Corte Suprema de Justicia colombiana, Disponible en: http://legal.legis.com.co/document/index?obra=jurcol\&document= jurcol_d19419719bf34f5a8863c69fdb4fb900>. [Fecha de consulta: 24 de mayo de 2018]. Al respecto, los autores explican que se han seleccionado fragmentos de Sentencias de diversos países de Iberoamérica por ser más afín cultural y jurídicamente a la sociedad y sistema legal cubanos. Estas resoluciones judiciales, a pesar de que no constituyen fuente de derecho en Cuba, son representativas de lo mejor de los pronunciamientos sobre reproducción asistida que han hecho algunos tribunales. Por tanto, se convierten en un referente casi obligado como orientador de futuras transformaciones en el ordenamiento jurídico nacional. 
Estos avances científicos y posibilidades tecnológicas generan análisis desde la Bioética, en busca de concienciar las consecuencias de estos progresos, ocasionando en la sociedad sentimientos encontrados, pues por un lado los nuevos descubrimientos actúan como mecanismos idóneos para conseguir una mejor calidad de vida, y, por otra parte, ocasionan un temor hacia lo inexplorado, debido a los efectos poco conocidos y en algunas ocasiones incontrolables aún. Su carácter pluridisciplinar, la relaciona con la Sociología, la Antropología, las ciencias biomédicas, la Ética y el Derecho. La relación entre la bioética y la ciencia jurídica está caracterizada por un permanente diálogo, por lo que estas últimas pueden integrarla en su marco de análisis, tomando como fundamento y límite, el respeto a los derechos humanos refrendados en instrumentos internacionales.

En el área propiamente de la reproducción humana asistida se ha originado un replanteamiento del fenómeno de la paternidad, primordialmente por el uso en la fecundación de material genético de terceras personas, generando un cierto grado de conflicto entre lo técnicamente posible, lo que la sociedad está dispuesta a aceptar y los valores que son necesarios tutelar jurídicamente atendiendo al interés social.

\subsection{La fertilización in vitro heteróloga: breve reseña de las cuestiones medulares}

Las técnicas de reproducción asistida serán entendidas, a los efectos de esta investigación, como los tratamientos o procedimientos que incluyen la manipulación tanto de ovocitos como de espermatozoides o embriones humanos para el logro de un embarazo. Dado el adelanto científico alcanzado en este campo, se utilizan diferentes variantes dentro de las cuales pueden mencionarse la inseminación artificial, la fecundación in vitro, y la transferencia intratubárica de gametos ${ }^{6}$. Las mismas se agrupan según la tecnología utilizada, de baja o alta complejidad, y en heterólogas u homólogas en atención al empleo o no de material genético de terceras personas ${ }^{7}$.

Dentro de las técnicas más utilizadas destaca la fertilización in vitro la cual reconoce su existencia tanto en la variante homóloga como en la heteróloga, siendo esta última controversial dado que, el material genético utilizado para lograr engendrar una nueva vida deviene de la donación de terceras personas, lo cual se devela como un verdadero reto para el Derecho de Familia.

El término in vitro, significa literalmente "en vidrio", lo cual se asocia a la cápsula de este material donde originariamente se realizaba este proceder, que por regla se efectúa de modo extracorpóreo, cuestión distintiva respecto a la inseminación artificial, pues esta última ocurre dentro del vientre materno. El procedimiento implica la fecundación del óvulo en un medio artificialmente creado; para luego proceder a la transferencia de embriones a la cavidad uterina. Su empleo en un principio se centró

6. BERNAL (2013) p. 137.

7. DORÍN y GIACCHETTA (2017) p. 9. 
en el tratamiento de la infertilidad femenina, pero su espectro fue ampliándose y se incorporó a todos aquellos casos en los que existe dificultad en el encuentro entre los espermatozoides y el óvulo ${ }^{8}$.

En ese contexto la fecundación in vitro heteróloga continúa estableciéndose generando para el gremio jurídico una realidad que debe ser objeto de un tratamiento técnico-legal adecuado. Tales aseveraciones se resumen magistralmente en una resolución judicial salvadoreña:

"algunas de esas técnicas de reproducción eran casi inimaginables hasta hace muy poco tiempo, ya que los campos de la Biomedicina, Biogenética y la Biotecnología, han tenido avances y descubrimientos científicos, que han abierto expectativas y esperanzas en el tratamiento de la esterilidad o infertilidad masculina o femenina, cuando otros métodos fueron inadecuados o ineficaces, existiendo una impostergable necesidad para que los Estados decreten leyes que regulen dicho status, ya que por lo general, los avances científicos van por delante del Derecho, retrasando su acomodación y este asincronismo entre la Ciencia y el Derecho, origina un vacío jurídico respecto de problemas concretos que lógicamente deben solucionarse jurídicamente, no pudiendo evadir o dejar a estas personas, los menores nacidos bajo estas circunstancias, en situaciones de abandono o indefensión." 9

En el ámbito de la reproducción asistida ocurre la coexistencia, no siendo excluyentes entre sí, de dos tipos de relaciones: administrativas y familiares. Las primeras se constituyen entre los individuos que formen parte de algún tratamiento y el centro hospitalario que lo practica; mientras que las segundas se circunscriben a los vínculos jurídico familiares entre las personas que se benefician con el tratamiento médico.

Sobre los sujetos y parafraseando a Roca Trías ${ }^{10}$ existen como mínimo dos grupos implicados: usuarios y donantes de material genético, cuando la filiación sea la consecuencia de la utilización de gametos ajenos a los padres formales. Pese a su validez, los autores de esta disertación académica desean emplear otra nomenclatura, por entender que es más comprensible para delinear el rol de los involucrados en atención a la técnica. A partir de ello se decide distinguir entre sujetos activos, que pueden ser también denominados indistintamente, beneficiarios, usuarios o destinatarios, y

8. ENGUER y RAMÓN (2018) p. 107.

9. Recurso de apelación de la Cámara de Familia de la Sección del Centro, San Salvador, El Salvador de fecha 13 de julio de 1995. Disponible en: <http://www.jurisprudencia.gob.sv/DocumentosBoveda/ D/1/1990-1999/1995/07/6EB5.PDF>. [Fecha de consulta: 20 de mayo de 2018].

10. ROCA (2017) p.1. 
sujetos pasivos, reconocidos en las personas de los donantes, ya que en strictu sensu no realizan ningún uso o manejo de las técnicas, solo tributan a ellas, para la consecución de su fin.

En relación al equipo médico especializado a cargo de dicha técnica se sigue el criterio de no enmarcarlo en ninguna de las categorías anteriores, pues este sólo constituye un mero facilitador del procedimiento, aunque es cierto que el acto procreador deja de ser íntimo, exclusivo, personal e intransferible de la pareja, para pasar a ser un acto pluripersonal en que intervienen en condición de terceros, quedando su actuar vinculado a valoraciones éticas y profesionales referentes al Derecho Administrativo y Laboral.

Con la fecundación asistida heteróloga la causalidad biológica de la procreación no es razón suficiente para establecer entre los beneficiarios y los concebidos un vínculo jurídico de filiación. Todo ello aboca a reflexionar sobre la valía reconocida a la voluntad individual, cuestión sobre la que se reflexiona al formular que "la trascendencia de la voluntad [...] supondrá que, cuando en una misma persona no coincidan el elemento genético y el volitivo, se debe dar preponderancia al último. Se está ante nuevas realidades que importan una "desbiologización y/o desgenetización de la filiación”, y en cuya virtud el concepto de filiación gana nuevos contornos comenzándose a hablar de "parentalidad voluntaria" o "voluntad procreacional".

"Ciertamente, la ausencia de relaciones sexuales en el origen de la procreación, la intervención de terceros (incluido aquí el equipo médico) en la generación de nuevos seres humanos, la certeza sobre la procedencia de los gametos que han generado ese nuevo ser humano, la ruptura de numerosos condicionamientos puestos por la naturaleza y la biología, la conversión en posibles de supuestos imposibles, hace sólo unas décadas, han afectado directísimamente los pilares sobre los que se asienta la vigente regulación de la filiación y, más allá, los propios conceptos de filiación, paternidad y maternidad, y el papel de hombre y mujer en la procreación, todo lo cual resulta puesto en duda." ${ }^{11}$

En este ámbito el consentimiento constituye tanto requisito necesario y habilitante para la aplicación de la técnica, como fundamento para la constitución de una relación de filiación, hasta el punto de que se ha llegado a decir que "sustituye a la relación sexual como causa iuris." ${ }^{12}$ Su empleo es frecuente en el ámbito de las ciencias médicas, adoptando matices diferentes conforme a la disciplina donde opera, pero en todo caso, puede decirse que la teoría del consentimiento informado está basada en principios éticos, regulados por normas legales y ejecutadas por los galenos en el marco de la relación médico-paciente ${ }^{13}$.

11. MARTÍNEZ (2013) p.98.

12. JIMÉNEZ (2012) p.47.

13. TABOADA (2017) p.90. 
En la procreación médica asistida el consentimiento informado es la declaración de voluntad suficiente efectuada por los beneficiarios y donantes. En cuanto a los primeros, es un elemento base e integrador de la filiación y presupuesto indispensable para la práctica tendente a este tipo de fecundación; y para los segundos, el mecanismo excluyente de cualquier sujeción filiatoria con el hijo procreado con su material genético.

En esencia se trata de un acto jurídico que trasciende la esfera del documento administrativo, en tanto repercute en el ámbito del Derecho de Familia, pues la aceptación de la fecundación in vitro, es la fuente creadora del vínculo de filiación, independiente de la verdad biológica, generando un verdadero status filii, aún más, un status familiae.

Para someterse a la FIV y a cualquier tratamiento de reproducción asistida, el personal médico previamente debe observar y recabar en el documento contentivo del consentimiento informado algunos requisitos como la capacidad, el estado civil y hacer referencia al status filiatorio de la criatura que pueda concebirse. Sin embargo, la trascendencia del acto sugiere que sean operadores del Derecho, por su sapiencia en el tema, los que tramiten esta fase del procedimiento y más específicamente los Notarios. Siendo estos por envestidura de la ley funcionarios autorizantes de instrumentos que rigen las relaciones jurídicas entre las personas, y receptores de sus inquietudes sobre las relaciones de derecho que detentan o establezcan en un futuro, parece inadecuado que sea el personal médico el competente para recibir, interpretar, validar y dar certeza de esos hechos, toda vez, que su formación profesional no abarca esas aristas de la realidad ni está investido de dichas funciones.

En los casos de la fecundación asistida heteróloga, el hijo nacido como consecuencia de ella, tendrá la filiación de las personas beneficiarias de la técnica, siempre y cuando hayan prestado su consentimiento conforme a lo estipulado en el orden legal, no pudiendo impugnar la filiación legalmente determinada. La voluntad de los padres sería suficiente para bloquear el emplazamiento filial concordante con la realidad biológica de los niños concebidos. En sentido esclarecedor la Corte Suprema de Justicia de Colombia ha fundamentado que:

“(...) la realización de un tratamiento de fecundación artificial a una mujer casada está precedido de la obtención del consentimiento de su marido, manifestación que, por una parte, es el fundamento de una relación de filiación entre el hijo así concebido y el esposo de quien es su madre (...) y, por otra, impide que aquél posteriormente pueda entablar acción de impugnación de la paternidad así determinada, pues se considera que quien así actúa con 
tradice los parámetros de la buena fe objetiva al comportarse en forma incoherente con sus precedentes determinaciones, restricción con la cual, además, se protegen de mejor manera los intereses del menor y de la familia. ${ }^{14}$

Las brechas teóricas que la reproducción asistida heteróloga deja al descubierto la disciplina familiar y abren el camino a replantear los modelos históricos sobre los que descansa la institución de la filiación, imponiendo a tales fines una remisión a sus elementos doctrinales. Además, la familia y el interés superior del niño como bienes jurídicos a proteger llegan a confrontarse con otros como el derecho a la intimidad y el derecho a la identidad; un conflicto en el que algunos cederán frente a otros.

\section{La heterología como nudo gordiano de la reproducción asistida}

Cuando en las técnicas de reproducción humana asistida se emplea el material genético de un donante ajeno a la pareja o proyecto familiar, se habla de técnicas heterólogas. Se define como donante aquella persona que dispone de su material genético para que pueda ser utilizado en centros autorizados y bajo un control riguroso, por terceras personas cuando estas encuentran limitaciones para poder procrear de manera natural. Son donantes tanto los hombres respecto a su semen, como las mujeres que autorizan la utilización de sus óvulos ${ }^{15}$. El carácter de anónimo que requiere este acto de donación está estrechamente vinculado con el derecho a la intimidad de las personas, que como dice Albadalejo, consiste en el poder concedido a la persona sobre el conjunto de actividades que forman su círculo íntimo, poder que le permite excluir a los extraños de entrometerse en él y de darle una publicidad que no desee el interesado". ${ }^{16}$

Es la facultad que tiene cada persona de disponer de una esfera de espacio privado, el cual no puede ser invadido por terceros, y presupone que cada individuo se reserva la potestad de planificar su vida y tener los métodos y medios adecuados para poder concretar aquellas decisiones personales sobre las que sostiene el desarrollo de su personalidad. En ese mismo sentido Díaz Magrans expone que la intimidad es la esfera o conjunto de actividades de la persona que esta precisa mantener en secreto o fuera del alcance de otras personas y que como es una necesidad del individuo, el ordenamiento jurídico se ha visto compelido a brindarle protección ${ }^{17}$.

14. Sentencia de 28 de febrero de 2013 de la Sala de Casación Civil de la Corte Suprema de Justicia de Colombia. Disponible en: <https://www.icbf.gov.co/cargues/avance/docs/csj_scc_s-_28-02-2013_ [1100131100022006-00537-01]_2013.htm>. [Fecha de consulta: 19 de mayo de 2018].

15. ISLA (2014) p.38.

16. VALDÉS (2005) p.143.

17. Ídem. 
Sin embargo, en el ámbito de la FIV heteróloga, la noción de secreto no puede definirse exclusivamente en términos jurídicos, porque la decisión de comunicar o no la utilización de gametos donados depende (generalmente) de las condiciones en que la/s persona/s hayan llevado adelante el proyecto procreacional y, más específicamente, de su subjetividad durante el proceso. En definitiva, si se mantiene o no el secreto depende del proceso de subjetivación del proyecto parental ${ }^{18}$.

Sobre el manejo de la información de índole personal de los donantes, se consideran diversos bienes jurídicos como: derecho a la intimidad, derecho a la privacidad, derecho a la autodeterminación informativa, y derecho a la protección de datos personales. "El planteo del anonimato es, no obstante, objeto de importantes reflexiones en los últimos tiempos. Por un lado, ha tenido en consideración que tanto la dación de gametos, como su recepción, integrarían el ámbito de la intimidad y que, en consecuencia, debe preservarse toda intrusión que quiebre el secreto o la reserva, si se prefiere, que dadores y receptores tienen derecho a pretender. Pero por otro lado, se ha advertido que el anonimato, llevado al extremo, en vez de defender los intereses de la persona más directamente implicada -el hijo, y su derecho a la intimidad- lo que busca fundamentalmente es la realización de las apetencias y la eliminación de las responsabilidades de las restantes personas implicadas en la operación, y, en definitiva, a la instrumentalización del hijo, que puede ver cercenado su derecho a conocer quién fue su progenitor biológico, o a contar con ese dato para la defensa de intereses morales o materiales". 19

Al hablar de anonimato del donante, y si se deja por sentado que este no es el padre jurídico-formal del ser nacido mediante la FIV heteróloga, se debe cuestionar qué papel desempeña este sujeto en cuanto transmisor de tal herencia genética, y cuál es su relación con el así nacido.

De un resumen de los planteamientos doctrinales al respecto se pueden distinguir varios criterios. Uno maximalista, apoyado por quienes consideran que el nacido ha de conocer al donante de quien procede, y podrá reclamarle la paternidad; existiendo esta posibilidad en todos los supuestos (concepción eminentemente genetista de la filiación y de la paternidad), o limitada a determinados casos (fundamentalmente, cuando el nacido no tenga otra posibilidad de tener padre). También está la postura minimalista de quienes defienden el anonimato del donante en todo caso, considerándose que es la mejor forma de defender la ausencia de relación jurídica entre donante y nacido. Por último, se encuentra la posición ecléctica: la de los que preconi

18. GONZÁLEZ (2016) pp. 221-227.

19. Comisión Wamock del Reino Unido. GARZÓN (2007) pp.105-106. 
zan que el nacido sólo puede conocer los datos biogenéticos del donante en cuanto transmisor de una rica herencia genética con importante repercusión en la vida y salud de aquel, datos que no se le pueden negar, bien con base en un derecho a la salud de la persona, o en un derecho a conocer la propia identidad biológica, de la que tales datos forman parte (conocido como anonimato relativo) y la perspectiva de quienes defienden el derecho a conocer la identidad personal del donante de gametos, mas sin otra consecuencia jurídica ni derechos ${ }^{20}$.

"Una actitud prudente en la cuestión, al menos por ahora, aconseja adoptar una solución intermedia: ni el anonimato impuesto a ultranza, ni la obligación legal de informar al hijo acerca de los datos del donante y la forma de su concepción. Quizás esa solución intermedia --que respetará el derecho y el deber que tienen los padres de hablar con verdad al hijo, y el derecho de éste de acceder a la información indispensable- implica la obligación del establecimiento o del facultativo de recoger y conservar todos los datos relativos al donante y de la pareja, los que deben ser secretos y sólo podrán ser exhibidos por orden judicial o a requerimientos de la pareja o del hijo, para información de éste, cuando fuese mayor de edad. Respecto del donante, en principio no sería informado de la pareja receptora, salvo conformidad expresa de ésta"21.

De tal forma es la posición intermedia la más equilibrada basada en "la existencia de donantes y, consecuentemente, la satisfacción del derecho a formar una familia, a gozar de los beneficios del progreso científico, a la vida familiar, a la igualdad, a la autonomía personal, a la libre elección del plan de vida y a la dignidad; así como el derecho del niño nacido a conocer su origen genético" ${ }^{22}$, pero sin llegar a crear vínculos filiatorios.

Aunque el Tribunal Supremo Popular de Cuba hasta el momento de la redacción de esta investigación no ha recibido casos vinculados a técnicas de reproducción asistida, sí se pueden citar algunas sentencias en materia de filiación que consiguen arrojar algunas luces sobre el tema, o al menos invitan al debate ${ }^{23}$. Dichas sentencias son soluciones casuísticas ofrecidas en recurso de casación de lo dispuesto por los diferentes Tribunales Provinciales del país, no tienen como finalidad armonizar la legislación existente a las situaciones fácticas, y por tanto no deben asumirse con carácter generalizador, en tanto esa función la cumplen las disposiciones del Consejo de Gobierno del propio órgano de justicia. La primera resolución judicial que se comen

20. CÁRDENAS (2015) pp. 47-65.

21. Comisión Wamock del Reino Unido. GARZÓN (2007) pp.105-106.

22. RODRÍGUEZ (2015) p. 145.

23. Sobre la temática de la filiación en Cuba, y muy escuetamente sobre su relación con la reproducción asistida. PÉREZ (2011) pp. 395-440; VALDÉS (2012) pp. 216-239; VALDÉS (2017) pp. 9-23; RODRÍGUEZ (2009) pp. 5-19; MESA (1998) y MESA (2013) pp. 5-18. 
ta es la Sentencia No. 249 de 30 de junio de 2011, y de ella resalta la importancia del dictamen pericial de un equipo multidisciplinario al declarar la inexistencia de una confusión de filiación ante un caso de adopción. En esa resolución judicial destaca el hecho de que el adolescente del cual se pretendía su adopción era capaz de identificar plenamente las figuras de sus padres biológicos respecto a las de las personas que le habían proporcionado amor filial, además de desenvolverse adecuadamente como una persona de ese grupo etáreo y alcanzado los logros propios de las diferentes etapas de su vida. Cabría preguntarse si ante el supuesto de un niño producto de fecundación asistida con material genético de una tercera persona, el pronunciamiento del equipo multidisciplinario hubiera sido el mismo. ¿En una familia como la cubana, generalmente de fuertes lazos afectivos entre sus miembros, se podría convivir comunicándole al niño su origen genético? Si en el caso que resolvió el Tribunal, el menor de edad podía distinguir el rol de sus progenitores y el de quienes fungieron como padres ("personas que le habían proporcionado amor filial"), el autor de esta tesis se inclina a pensar que sí es posible en los casos de técnicas heteróloga. Sin embargo, siempre dejando claro que no existirá vínculo filiatorio con el donante de gametos ${ }^{24}$.

\section{Fundamentos de la filiación como institución del Derecho de Familia}

Según Scotti "el vocablo filiación encierra diversos significados. En una primera acepción, implica el vínculo biológico entre una persona y sus progenitores. En un segundo sentido, desde una noción jurídica, entraña la relación entre el hijo con sus padres, lo que supone el emplazamiento de una persona en un estado civil y el establecimiento de un conjunto de derechos y deberes que nacen como consecuencia." ${ }^{25}$

Su enunciación en voz de la jurisprudencia patria se resume:

"la filiación es la relación jurídica que une a ciertas personas que pueden ser progenitores o no con otras que pueden ser procreados o no y que determina en los primeros un conjunto de deberes y derechos encaminados en esencia al cuidado, protección, alimentación y educación de los últimos, [...]." ${ }^{26}$

24. Sentencia No. 249 de 30 de junio de 2011 del Tribunal Supremo Popular, Sala de lo Civil y lo Administrativo, Juez Ponente: Isabel Arredondo Suárez, Segundo Considerando, en Boletín del Tribunal Supremo Popular, La Habana, 2011, p. 219.

25. SCOTTI (2015) pp. 77-104.

26. Sentencia No 862 de 30 de diciembre de 2005 de la Sala de lo Civil y de lo Administrativo del Tribunal Supremo Popular de la República de Cuba. Vid. Boletín del Tribunal Supremo Popular de Cuba, La Habana, 2006, p.92. 
El término filiación es correlativo a las palabras paternidad y maternidad, expresiones que designan indistintamente el vínculo que une al padre o a la madre con su hijo. Las interacciones sociales que entre sus protagonistas se catalogan como relaciones paterno-filiales encaminadas a establecer y definir los vínculos entre padres e hijos, regularizando en lo jurídico, político y social parte del estado civil del procreado.

Doctrinalmente se sistematizan dos tipos de filiación: la dada por naturaleza, tendente a asegurar la identidad personal en referencia a la realidad biológica y la de tipo civil creadora de una relación jurídica de filiación entre dos personas que no son biológicamente, ni por afinidad, progenitor e hijo entre sí. Consiste en un vínculo que, sin base biológica, tiene lugar mediante un acto jurídico administrativo o judicial, creando entre los sujetos involucrados, relaciones de derechos y deberes semejantes a los existentes en la familia consanguínea.

\subsection{El sistema de presunciones de la maternidad y paternidad}

Tanto maternidad como paternidad se han entendido históricamente a partir del hecho biológico de la procreación, asumiendo este como un hecho presumible.

La maternidad ancestralmente se establece por el parto, presunción que hasta hace no mucho tiempo se consideraba iure et de iure, en función de que no había otra forma de concebir que no fuera la natural. "El principio tradicional que sigue el derecho in genus es el mater semper certa est, puesto que el parto debidamente acreditado es el hecho que atribuye de pleno derecho la maternidad. El parto sigue al vientre, partus sequitur venter, razón por la cual, la maternidad en sentido biológico es siempre cierta. Esto, [...], se sustenta en la suposición de que el parto culmina con el proceso iniciado con la fecundación del óvulo y desarrollado sin interrupción alguna." ${ }^{27}$

La paternidad, en otro sentido, se trata de un hecho que no es posible constatar por simple observación, por lo que la ley ha recurrido a las presunciones, permitiendo que por medio de antecedentes conocidos se deduzcan cuestiones desconocidas, como la paternidad. Esta se ha inferido recurrentemente de la existencia cierta del matrimonio y la maternidad, tal y como se alega al referir que "la presunción derivada del Derecho Romano consiste en reputar padre al marido de la mujer que ha dado a luz al hijo." ${ }^{28}$

Lo que hoy se conoce más brevemente como pater is est, lleva a determinar un hecho que ocurre en la privacidad y, comprende a los hijos nacidos después de la celebración del matrimonio y hasta un número de días, determinados por ley, después de decretado su disolución. El reconocimiento de paternidad es el resultado de la ma

27. VARSI (2017) p.127.

28. DERUGGIERO (1978) p. 197. 
nifestación expresa o tácita del pretendido padre de su relación sexual con la madre en el periodo de la concepción, generando una presunción iuris tantum, sobre la que cabe prueba en contrario por conducto de las acciones filiatorias previstas por ley ${ }^{29}$.

Estas presunciones devienen en incongruentes con el advenimiento de la fecundación asistida heteróloga, pues se apoyan en una realidad biológica circunscripta al hecho de que en "las relaciones sexuales mantenidas por un hombre y una mujer es habitual que nazcan niños", y no pueden subsistir sin ella. A partir de ahí, marido y mujer tienen relaciones sexuales con el principio de exclusividad de tales relaciones, para concluir que lo normal es que los hijos de la mujer sean también (biológicamente) del marido.

29. Muy interesantes resultan dos sentencias del máximo órgano judicial cubano. En ambos casos, el Tribunal le otorgó mayor credibilidad a la prueba testifical frente a la documental que acreditaba la imposibilidad para procrear como causa para impugnar la filiación ya establecida. Sentencia No. 510 de 31 de octubre del 2013 del Tribunal Supremo Popular de la República de Cuba, Sala de lo Civil y lo Administrativo, Ponente: Isabel Arredondo Suárez, Tercer Considerando: "el impugnante sustenta la inconformidad que relata, en inequívoco criterio personal valorativo de los elementos de prueba obrantes en las actuaciones, de manera que sobreestima el resultado de las pruebas de documentos consistentes en resultas de espermograma que se le practicara por el Departamento de Biología Reproductiva del Hospital "Eusebio Hernández" y certificado médico emitido por facultativa, cuando por su contenido no resultan contundentes, en tanto no determinan su imposibilidad física para procrear, constatándose como las pruebas de testigos y de reconocimiento de personas practicada a instancia de su contraria en el pleito, aportan elementos de juicio diametralmente opuestos a los que pretende hacer valer". Sentencia No. 895 de 23 de diciembre de 2014, Ponente: Marta Acosta Ricart, Segundo Considerando: El inconforme "sostiene el infundado criterio de que se han valorado erróneamente las documentales que oportunamente presentó en relación con el resultado de un estudio que se le realizó, denominado espermograma, lo que en realidad no acontece, pues en los razonamientos en que se sustenta la decisión impugnada, si se evalúa dicho extremo, pero no se le concede virtualidad suficiente para descartar la probabilidad de la procreación, debido a la fecha posterior en que se realizó, fuera del periodo en que tuvo lugar la fecundación, pero además, porque resultaron de mayor peso y credibilidad, las pruebas de testigos y la pericial consistente en examen antropológico comparativo". 
Ello descarta el reconocimiento de la paternidad fuera del ámbito de la consanguinidad, cuestión a repensar en clave de expansión al comentar que, "a quien de manera persistente ha ostentado con firmeza y sin interrupción un comportamiento como padre, deberá serle respetada dicha posesión de estado acreditada por un tractatus y reputatio ininterrumpida en su condición o función social (...). La relación de filiación hay que disociarla de su componente genético; es o debe ser ante todo, una relación socializante, de suerte que el vínculo biológico debe quedar desnaturalizado en favor de un nexum de integración cultural." ${ }^{\circ}$

En igual línea de pensamiento resultan categóricas las palabras de Benavente Moreda quien refiriéndose al actual sistema de presunciones señala que "es evidente el conflicto que se produce y aventuro que se seguirá produciendo, derivado de la aplicación "forzada" de las citadas reglas cuando la filiación tiene su origen en el uso de dichas técnicas de reproducción asistida y básicamente en los casos de fecundación heteróloga, fundamental y básicamente porque, salvo en los casos en los que la biología manda, es la voluntad y no la biología la que determina legalmente la atribución de la paternidad o maternidad. A partir de tal dato, resulta insostenible utilizar las mismas reglas de juego," ${ }^{31}$ convocando a reelaborar las presunciones en un sentido de evolución.

\section{La fertilización in vitro heteróloga y sus efectos jurídicos en la filiación}

\subsection{El elemento subjetivo en la fertilización in vitro heteróloga}

El término sujeto de Derecho hace referencia al elemento subjetivo de una relación jurídica concreta, siendo esta última categoría "una situación en la que se encuentran dos o más personas, que aparece regulada como una unidad por el ordenamiento jurídico, organizándola con arreglo a determinados principios, y que la considera, además, como cauce idóneo para la realización de una función merecedora de la tutela jurídica." ${ }^{32}$

En el orden de los sujetos beneficiarios resalta la restricción de acceso a esta técnica de nuevas estructuras familiares, cuestión -a juicio de los autores- niega la evolución de esta institución y conlleva un cambio de ideología ${ }^{33}$. La porfía de su implementación a mujeres solteras se esclarece por parte de la Corte Interamericana de Derechos Humanos, institución que se ha pronunciado favorablemente respecto a la familia monoparental al razonar:

30. LLEDÓ (1988) pp.73-75.

31. BENAVENTE (2017) pp. 1-36.

32. VALDÉS (2005) pp.79-80.

33. FERNÁNDEZ (2016) pp. 119-146. 
"[...] la decisión de tener hijos biológicos a través del acceso a técnicas de reproducción asistida forma parte del ámbito de los derechos a la integridad personal, libertad personal y a la vida privada y familiar. Además, la forma como se construye dicha decisión es parte de la autonomía y de la identidad de una persona tanto en su dimensión individual como de pareja." ${ }^{34}$

En similar situación de inadmisión se encuentran las parejas del mismo sexo, quienes bajo juicios naturales y morales, asociados a la reproducción y la sexualidad, encuentran sólidos obstáculos para identificarse como una válida familia, con plenos derechos a realizarse como padres. Ello, como parte del reconocimiento de pluralidades familiares al margen de su orientación sexual ${ }^{35}$, el derecho a formar una familia consagrado universalmente ${ }^{36}$ y la definición amplia del derecho a la salud, debería desencadenar en una permisibilidad a las alianzas del mismo sexo de acogerse a los beneficios de la reproducción asistida, tal y como se asevera al concluir que es perentorio "plantearse alternativas que supongan una mejora para la crianza de las hijas/ os, sin distinción de la forma en la que han sido concebidos o gestados, o del tipo de familia de la que forman parte." ${ }^{37}$

Lo anteriormente expuesto conduce a abrir el horizonte en cuanto a los beneficiarios de la técnica, en tanto, su determinación no debe desligarse de los nacientes modelos familiares, que en definitiva, sólo contemplan una gama más amplia de formas de constitución de la filiación.

\subsection{El otorgamiento de la voluntad mediante el consentimiento informado: sur- gimiento de una tercera fuente de filiación}

Acorde con el principio de verdad formal, el rol jurídicamente relevante en la heterología es, por tanto, el de padre y no el de progenitor. Lo que provoca que terminológicamente se comiencen a diferenciar esos términos, atribuyéndose a la paternidad un específico contenido jurídico, sociológico y cultural. ${ }^{38}$ En relación a su jerarquía también se ha pronunciado la jurisprudencia española al colegir que si uno de los cónyuges:

34. Sentencia de 28 de noviembre de 2012 de la Corte Interamericana de Derechos Humanos, relativa al caso Artavia Murillo y otros. vs Costa Rica. Cfr. punto 272, p.86.

35. ESBORRAZ, (2015) pp. 30-31.

36. Cfr. precepto 24 de los Principios sobre la aplicación de la legislación internacional de Derechos Humanos en relación con la orientación sexual y la identidad de género, Yogyakarta, Indonesia, 2006.

37. CATALÁ (2015) p.238.

38. LAMM (2012) pp.76-91. 
“(...) tuvo la voluntad procreacional por haberse constatado que era estéril y descartado por tanto la procreación por naturaleza, aceptó la donación de semen de donante anónimo consintió el uso de la técnica que se implementó a su esposa en el momento en que tuvo lugar la concepción y por tanto debe asumir las consecuencias jurídicas de tal decisión." ${ }^{39}$

Ello sugiere que además de la filiación natural y adoptiva, se debería comenzar a concebir con mayor amplitud una tercera tipicidad, teniendo en cuenta el desarrollo de estas técnicas, su situación actual, y la imposibilidad de comprenderla en alguna de las dos clases de filiación existentes, ya que, en la derivada de las técnicas de reproducción asistida heterólogas no coincide, por la voluntaria aportación de material genético empleado en la concepción de la nueva vida, la paternidad/maternidad genética o biológica con la formal. Los autores aclaran que cualquier diferenciación en cuanto a las fuentes filiatorias debe tener carácter puramente académico y metodológico.

De la Torre explica que, a pesar de existir características compartidas entre las tres fuentes filiales, también se advierten diferencias. La práctica de la reproducción asistida heteróloga carece de la relación sexual como presupuesto inmediato, disociándose el elemento biológico, el genético y el volitivo, cobrando éste último primacía; siendo posible realizar los deseos de paternidad/maternidad ${ }^{40}$.

Tomando en líneas generales los criterios de Eleonora Lamm ${ }^{41}$, puede referirse que en la filiación por naturaleza el vínculo se funda en el elemento biológico (que comprende el genético), en la reproducción asistida heteróloga no es así y hace que sea diferente su determinación y el régimen de impugnación. En la adopción el niño ya existe cuando surge la voluntad de adoptarlo, mientras que en la FIV el elemento volitivo está presente desde el mismo origen de la persona, es decir, el niño nace y existe como consecuencia de esa voluntad.

39. Sentencia No 28 de 27 de septiembre 2007 de la Sala de lo Civil y Penal del Tribunal Supremo de Justicia de Cataluña. Disponible en: https://www.iberley.es/jurisprudencia/sentencia-civil-n28-2007-tsj-cataluna-sala-civil-penal-sec-1-rec-135-2006-27-09-2007-5733341?term=Sentencia+ Civil $+\mathrm{N} \% \mathrm{C} 2 \% \mathrm{BA}+28 \% 2 \mathrm{~F} 2007 \% 2 \mathrm{C}+$ Tribunal + Superior $+\mathrm{de}+\mathrm{Justicia}+\mathrm{de}+\mathrm{Catalu} \% \mathrm{C} 3 \% \mathrm{~B} 1 \mathrm{a} \% 2 \mathrm{C}+\mathrm{Sa}$ $\mathrm{la}+\mathrm{de}+\mathrm{lo}+\mathrm{Civil}+\mathrm{y}+$ Penal $\% 2 \mathrm{C}+$ Secci $\% \mathrm{C} 3 \% \mathrm{~B} 3 \mathrm{n}+1 \% 2 \mathrm{C}+\mathrm{Rec}+135 \% 2 \mathrm{~F} 2006+\mathrm{de}+27+\mathrm{de}+$ Septiembre + $\mathrm{de}+2007 \&$ query $=$ Sentencia + Civil $+\mathrm{N} \% \mathrm{C} 2 \% \mathrm{BA}+28 \% 2 \mathrm{~F} 2007 \% 2 \mathrm{C}+$ Tribunal + Superior $+\mathrm{de}+$ Justicia + $\mathrm{de}+$ Catalu $\% \mathrm{C} 3 \% \mathrm{~B} 1 \mathrm{a} \% 2 \mathrm{C}+\mathrm{Sala}+\mathrm{de}+\mathrm{lo}+\mathrm{Civil}+\mathrm{y}+$ Penal $\% 2 \mathrm{C}+\mathrm{Secci} \% \mathrm{C} 3 \% \mathrm{~B} 3 \mathrm{n}+1 \% 2 \mathrm{C}+\mathrm{Rec}+135 \% 2 \mathrm{~F} 20$ 06+de+27+de+Septiembre+de+2007\&noIndex. [Fecha de consulta: 23 de mayo de 2018].

40. RODRÍGUEZ et al (2017) p.7.

41. LAMM (2012) pp.87-89. 
"Cuando el nacimiento se produce mediante técnicas de reproducción asistida el principio de veracidad paterno-filial carece de toda relevancia, protegiéndose de forma lógica la estabilidad de la relación paterno-filial constituida [...] De este modo, además del orden familiar natural y de la filiación por adopción, tradicionalmente admitida en nuestro derecho, se introduce la regulación de la filiación mediante el empleo de esta ciencia separando los conceptos de progenitor y padre legal (...). Consecuencia de esta legislación es que existan dos planos de regulación de la filiación: el realista basado en el principio de veracidad que pretende la total correspondencia entre la verdad biológica y la jurídica que posibilita la investigación de la paternidad y el de la ficción legal o voluntarista que basa en la voluntad y en el consentimiento del empleo de técnicas de fecundación artificial y consecuentemente la asunción de una paternidad no biológica resultado de las técnicas, con los mismos efectos jurídicos que la filiación por naturaleza." ${ }^{42}$

\subsection{El ejercicio de la función notarial en el contexto de la reproducción asistida}

La manifestación de la voluntad para someterse a la FIV y a cualquier tratamiento de reproducción asistida es un requisito esencial respecto al despliegue de sus efectos médicos y jurídicos. Con solo hacer público el deseo de ser beneficiario de las técnicas, no es suficiente para crear una relación a la que el orden legal le otorgue tutela. En tal sentido, el elemento volitivo debe quedar registrado en un documento al que se le denomina consentimiento informado, y que generalmente es administrado por el personal médico. En ese instrumento se recaba información como la capacidad, el estado civil y el status filiatorio de la criatura que pueda concebirse.

Sin embargo, la trascendencia del acto sugiere que sean operadores del Derecho, por su sapiencia en el tema, los que tramiten esta fase del procedimiento y más específicamente los Notarios. Siendo estos por envestidura de la ley funcionarios autorizantes de instrumentos que rigen las relaciones jurídicas entre las personas, y receptores de sus inquietudes sobre las relaciones de derecho que detentan o establezcan en un futuro, parece inadecuado que sea el personal médico el competente para recibir, interpretar, validar y dar certeza de esos hechos, toda vez, que su formación profesional no abarca esas aristas de la realidad ni está investido de dichas funciones.

42. Sentencia No 44 de 22 de diciembre de 2008 de la Sala de lo Civil y Penal del Tribunal Supremo de Justicia de Cataluña. Disponible en: <https://www.iberley.es/jurisprudencia/sentencia-civil-n44-2008-tsj-cataluna-sala-civil-penal-sec-1-rec-30-2007-22-12-2008-11565341?term=Reproducci $\% \mathrm{C} 3 \% \mathrm{~B} 3 \mathrm{n}+$ asistida + Filiaci\%C3\%B3n\&query $=$ Reproducci\%C3\%B3n+asistida+Filiaci\%C3\%B3n\&no Index>. [Fecha de consulta: 23 de mayo de 2018]. 
De manera que es el Notario - a juicio de los autores- el operador del Derecho idóneo para participar en la creación del documento donde se consienta participar de la técnica de reproducción asistida con sus correspondientes consecuencias jurídicas. Con su intervención se interpreta la voluntad de las partes y adecúa la misma a las exigencias legales, dando fe de la identidad, la capacidad y la legitimación de los otorgantes en relación con el acto o negocio jurídico concreto que pretenden realizar, controlando la legalidad y asegurándose de que la voluntad de las partes sea libremente declarada.

Posee al tiempo la pericia necesaria para apreciar esa capacidad volitiva de los sujetos, que le permita autorizar el instrumento público, que en este caso en estricta técnica debe ser la escritura notarial, en tanto son el reservorio de los actos y negocios jurídicos, en el que la voluntad es presupuesto mismo de su existencia ${ }^{43}$. Como operador del Derecho, actúa con la responsabilidad que su quehacer requiere y, de manera integral, genera un medio de prueba que es plenamente válido para producir un vínculo jurídico tan relevante como lo es la filiación, gracias a su labor de información, asesoramiento y la imparcialidad, independencia, legalidad y dación de fe que ejercita con su actuar. El valor probatorio del instrumento público está dado por el principio de indubitabilidad, y contiene una presunción de autenticidad que lo legitima en el tráfico jurídico e impide que sea desvirtuado, a no ser judicialmente. Las cuestiones en debate se esclarecen magistralmente por el Tribunal Supremo de Justicia de Cataluña quien ha dicho que:

"no cabe duda que la legislación catalana exige un plus de seguridad juridica al establecer que el consentimiento del marido se preste en escritura pública. Es igualmente claro que el instrumento público garantiza en principio la libertad, la consciencia, el carácter expreso y escrito del consentimiento prestado para asumir la paternidad resultante de la inseminación. La intervención del Notario que asesora, indaga la voluntad del compareciente y comprueba la capacidad natural del otorgante, atribuye al acto una presunción de legalidad." 4

\section{PÉREZ (2014) p.168.}

44. Sentencia No 28 de 27 de septiembre 2007 de la Sala de lo Civil y Penal del Tribunal Supremo de Justicia de Cataluña. Disponible en: https://www.iberley.es/jurisprudencia/sentencia-civil-n28-2007-tsj-cataluna-sala-civil-penal-sec-1-rec-135-2006-27-09-2007-5733341?term=Sentencia+ Civil $+\mathrm{N} \% \mathrm{C} 2 \% \mathrm{BA}+28 \% 2 \mathrm{~F} 2007 \% 2 \mathrm{C}+$ Tribunal + Superior $+\mathrm{de}+$ Justicia $+\mathrm{de}+\mathrm{Catalu} \% \mathrm{C} 3 \% \mathrm{~B} 1 \mathrm{a} \% 2 \mathrm{C}+\mathrm{Sa}$ $\mathrm{la}+\mathrm{de}+\mathrm{lo}+\mathrm{Civil}+\mathrm{y}+$ Penal\%2C+Secci\%C3\%B3n+1\%2C+Rec+135\%2F2006+de+27+de+Septiembre+ $\mathrm{de}+2007 \&$ query $=$ Sentencia + Civil $+\mathrm{N} \% \mathrm{C} 2 \% \mathrm{BA}+28 \% 2 \mathrm{~F} 2007 \% 2 \mathrm{C}+$ Tribunal + Superior $+\mathrm{de}+$ Justicia +

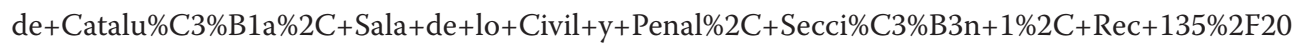
06+de+27+de+Septiembre+de+2007\&noIndex $>$. [Fecha de consulta: 23 de mayo de 2018] . 
La autenticidad que confiere la intervención del notario en los actos de los particulares y el estado en sus relaciones juridicas, constituye un valor agregado para la prevención de litigios, siendo consustancial a su actividad, su carácter tutelar, de forma que se eviten contiendas que en algún momento pudieran generarse acerca de las instituciones familiares, especialmente la filiatoria. A diferencia del médico, tiene profesionalidad en actuaciones que se encuadren en el Derecho de Familia y que estén exentas de toda contienda o litigio lo cual "garantiza la protección de los derechos, libertades e intereses particulares en las relaciones personales, familiares, patrimoniales y extrapatrimoniales." 45

A este profesional del Derecho se le ha encomendado la misión de custodiar los intereses involucrados en los actos de los particulares en calidad de depositario de la fe del Estado; asesorando a las partes y adaptando la verdadera voluntad de estos a la ley; o sea, diseñando una forma propia de regular el acto conforme a la autonomía de la voluntad y en el marco de la ley, de manera tal que, el documento redactado se convierte en una obra de ingeniería jurídica.

De conformidad con los elementos vertidos, los autores consideran que la declaración del consentimiento informado para la aplicación de la FIV debe ser instrumentada mediante escritura pública. Así, se da una respuesta acabada a las cuestiones de lugar y fecha cierta, al momento del otorgamiento, a la conservación en el tiempo a través del sustento de la matriz del protocolo, a la capacidad del otorgante, tal como al pronunciamiento de los sujetos sobre la impugnabilidad de la filiación del niño que pueda nacer, devenido del asesoramiento integral respecto al tema, generando, además, un basamento certero a su validez probatoria en caso de conflicto sobrevenido.

\subsection{El ejercicio de acciones filiatorias a la luz de la FIV}

Estas acciones tienen por objeto obtener de los órganos jurisdiccionales competentes un pronunciamiento relativo a la filiación, ya declarándola, si no ha sido determinada de otra manera, o bien refutando la establecida formalmente. Las mismas se catalogan como acciones de estado, por cuanto, a través de ellas se persigue un pronunciamiento judicial que cree, modifique o extinga un estado de familia. Gesurmino Massaccesi citando a Belluscio expone que las mismas "son inalienables, irrenunciables, imprescriptibles e inherentes a las personas. Pueden ser: constitutivas de estado: aquellas que tienden a obtener un estado de familia nuevo o extinga o modifique el existente; declarativas de estado: se limita a reconocer una situación jurídica anteriormente existente; de reclamación: que se reconozca un estado existente o de impugnación: que se destruya un vínculo existente." ${ }^{46}$ 
Tanto las acciones de reclamación como las de impugnación conllevan un análisis a partir de las transformaciones operadas en la filiación, por la implementación de las nuevas técnicas de reproducción asistida. Tales razonamientos se establecen sobre la base del consentimiento prestado para la realización de ellas, donde el donante queda excluido de que se le reclame el status filii, ya que él no externa su voluntad en ese sentido, tal como de que impugnar la filiación reconocida al tercero, ya que no puede ir contra sus propios actos ${ }^{47}$.

No obstante, podría ser impugnada si se considera la existencia vicios del consentimiento al momento de otorgarlo, cuestión que comenta Guzmán Ávalos y Valdés Martínez al reseñar que "quien haya dado su consentimiento para un tratamiento de asistencia médica para la procreación no podrá impugnar la filiación, a no ser que la pretensión se base en que el hijo(a) no nació como consecuencia del tratamiento o que el consentimiento fue privado de efecto." ${ }^{48}$

Si bien es cierto, existe una aparente contraposición con respecto al anonimato del donante y al derecho a conocer el origen del niño como interés superior ${ }^{49}$, en la legislación cubana se determina el anonimato de donante como regla general. La solución adoptada es meritoria porque respeta las precauciones de anonimato que son necesarias para realizar las técnicas, pero ante un conflicto de intereses da primacía a la salud del hijo. Con lo cual, se logra un equilibrio que posibilita la continuidad de donantes y garantiza las necesidades del hijo, estableciendo que ni el anonimato es iure et de iure, ni el derecho a conocer al donante de gametos es absoluto.

Sin embargo, la regla que apunta a distanciar a donante y concebido en el orden de la filiación no impide rotundamente que existan determinados nexos entre ellos, sobre todo cuando el hijo procreado con material genético de una tercera persona desea conocer su origen. A su favor en líneas generales se afilia la Convención de Nacio

47. Sobre la teoría de los actos propios BELLUSCIO (2004) p.266.

48. GUZMÁN y VALDÉS (2018) p.16

49. "El concepto de interés superior significa reconocerle derechos al niño en su condición de persona en desarrollo. En efecto, resultará de su interés toda acción o medida que tienda a respetar de manera efectiva sus derechos, y se constituirá en pauta de decisión ante un conflicto de intereses, y en criterio para la intervención institucional destinada a proteger al niño". MONTEJO RIVERO y HERNÁNDEZ SOSA (2011) p.83. 
nes Unidas sobre los derechos del $\mathrm{Niño}^{50}$, pese a que, el derecho a conocer el propio origen en caso de fecundación heteróloga debe matizarse con los límites que vienen dados, sobre todo, por el derecho a la intimidad del donante que quiere permanecer en el anonimato; pero también por el derecho a la intimidad personal y familiar de los padres jurídicos del hijo en el sentido de la afectación que para la convivencia familiar y la intimidad de los padres puede suponer que el hijo conozca la forma en que se ha engendrado. Pese a ello, se ha considerado que el anonimato del donante de material genético, debe ceder ante circunstancias extraordinarias como en aquellos casos en que exista peligro cierto para la vida o la salud del hijo, haber arribado el hijo a la mayoría de edad o emancipación y contar con el consentimiento del donante o por haber sido dispuesto por resolución judicial ${ }^{51}$. Sin embargo ello no genera alteración alguna en la determinación filiatoria, ni involucra acciones judiciales al respecto, quedando tales intenciones y vínculos en consensuadas relaciones privadas.

\subsection{Los efectos que origina la FIV en las relaciones paterno-filiales desde la óp- tica normativa de legislaciones latinoamericanas y europeas}

Con el afán de exponer de modo sucinto los efectos en materia filiatoria de la fecundación asistida heteróloga en ordenamientos jurídicos foráneos, y sin llegar a realizar un verdadero estudio de Derecho Comparado, se desarrolla este apartado, a los fines de valorar su factibilidad ante una posible reforma de la normativa familiar en Cuba, aunque sin ánimo de exportar modelos jurídicos. Se consideraron como parámetros de comparación: la participación de los donantes y su anonimato, beneficiarios, el sistema de presunciones, así como el consentimiento y su instrumentación.

Entre las similitudes se pueden encontrar naciones que cuentan con legislación específica de tipo administrativo o recomendaciones de tipo médico-ético, que normalmente orientan la modificación de Códigos Civiles o de Familia ${ }^{52}$, según corresponda, en lo pertinente a la institución filiatoria. Otros países como Paraguay, Colombia y

50. La Convención de Naciones Unidas sobre Derecho del Niño en su Artículo 7, apartado 1 expresa que "El niño será inscripto inmediatamente después de su nacimiento y tendrá derecho desde que nace a un nombre, a adquirir una nacionalidad y, en la medida de lo posible, a conocer a sus padres y a ser cuidado por ellos". La Convención no utiliza el término "biológicos" para referirse a los padres del niño, por tanto, no existe un derecho expreso a "conocer los padres biológicos", lo que se atempera plenamente con la realidad que implica la reproducción asistida heteróloga donde los donantes no tienen ningún vínculo parental con los procreados con su material genético.

51. CÁRDENAS (2015) pp. 47-65 ; MUÑOZ y VÍTTOLA (2017) pp.208-228.

52. Bélgica, Grecia, Holanda, Portugal, Suiza, Francia, España, Reino Unido, Italia, Austria, República Checa, Brasil, Colombia, Uruguay, Argentina. 
Venezuela abordan puntualmente la temática desde normativas sobre la niñez y adolescencia.

En la generalidad se reconoce la posibilidad de utilizar donantes de material genético cuando así se requiera, no siendo así en Italia y Noruega donde es posible únicamente el empleo de gametos provenientes de la pareja, pese a que, la jurisprudencia italiana en voz de su Tribunal Constitucional en sentencia No.162 de 2014 declaró inconstitucional la prohibición de fecundación heteróloga.

En relación al anonimato del donante se sistematizan cuatro sistemas. En uno de los extremos se encuentran aquellas legislaciones que aseguran el derecho de los niños a conocer sus orígenes al revelar la identidad del donante a toda costa, de la cual son exponentes Reino Unido, Holanda, Austria, Suecia, Suiza, Finlandia, haciendo valer el aforismo latino vincit omnia verita. En otro extremo se encuentran normas donde el anonimato es absoluto, siendo exponentes Francia y Dinamarca.

Otra forma de regulación es la denominada de "doble ventanilla", acogida por las legislaciones de Bulgaria, Bélgica, Islandia y Argentina ${ }^{53}$, permitiendo que la elección sea llevada adelante por los donantes o receptores, es decir, que la decisión escapa al niño y es tomada por los padres previo a su nacimiento.

También existe una postura ecléctica o de anonimato relativo que permite conocer la identidad del donante en determinadas circunstancias. En este sentido se inclinan las legislaciones de Portugal ${ }^{54}$, República Checa, Grecia, España ${ }^{55}$, Uruguay ${ }^{56}$ y Brasil.

53. En el caso resuelto por la Cámara Nacional de Apelaciones en lo Contencioso Administrativo Federal de Argentina, sala V, del 29 de abril de 2014, los padres de dos personas menores de edad concebidas en virtud de técnicas de reproducción humana asistida heterólogas, promovieron recurso a fin de que el Estado Nacional creara un registro con toda la información de los centros de fertilidad y bancos de gametos respecto de sus donantes. El recurso fue admitido parcialmente a fin de garantizar la posibilidad de ejercicio efectivo del derecho a la identidad reconocido en el art. 8 de la Convención sobre los Derechos del Niño, e instó al Estado a asegurar que el centro médico y/o el banco de gametos que posibilitaron la realización del tratamiento de fertilización asistida con material heterólogo respecto de la persona menor de edad que motivó el amparo, salvaguardara la información relativa a la identidad del donante en forma reservada y sin dar acceso a ella. RODRÍGUEZ (2015) pp. 159-160.

54. Cfr. artículo 15 apartados 2, 3 y 4 de la Ley No 32 de 26 de julio de 2006 sobre reproducción asistida en Portugal.

55. Cfr. artículo 5 apartado 5, tercer párrafo, de la Ley 14/2006, de 26 de mayo, sobre técnicas de reproducción humana asistida en España.

56. Cfr. artículo 21 de la Ley No 19.167 de 2013 sobre técnicas de reproducción asistida en Uruguay. 
A pesar de la multiplicidad de sistemas, todos coinciden que en ninguna circunstancia conocer la identidad del donante implicaría la creación de vínculo filiatorio con los hijos procreados mediante su material genético ${ }^{57}$. De esa forma prevalece el status filii a favor de quien otorgó su voluntad procreacional en el documento contentivo del consentimiento informado.

En el ámbito de los beneficiarios no existe consenso, advirtiéndose en naciones como Noruega y Francia la exigencia de su implementación sólo a favor de los miembros de un matrimonio heterosexual, mientras que Suecia, Italia, Chile y España ${ }^{58}$ lo extienden a las uniones de hecho. Países como Francia, Suiza e Italia ${ }^{59}$ admiten su acceso sólo para personas con problemas de esterilidad en contraposición a España, Argentina ${ }^{60}$ y Uruguay ${ }^{61}$ que asumen una postura más de avanzada y permisiva, de lo que se colige que las técnicas de reproducción humana asistida son métodos alternativos.

Sin llegar a adentrarse a fondo, en el debate iusfilosófico sobre las leyes permisivas y restrictivas, particularmente en el ámbito de la reproducción asistida heteróloga, los autores consideran que las primeras contribuyen mejor al bien común de consolidación de la familia como célula fundamental de la sociedad. La norma permisiva, como su nombre lo indica, es la que permite, concede o autoriza hacer o no hacer algo, realiza una acción o una abstención, debiendo el otro sujeto o los otros sujetos tolerar que la persona beneficiada con el permiso haga o no haga lo que expresamente se le ha permitido. La imperatividad de la norma permisiva estaría, pues, en la imposición

57. "La acción de reclamación o de investigación de la paternidad se orienta a constituir, entre los sujetos afectados, un vínculo jurídico comprensivo de derechos y obligaciones recíprocos, integrante de la denominada relación paterno-filial, siendo así que la revelación de la identidad de quien es progenitor a través de las técnicas de procreación artificial no se ordena en modo alguno a la constitución de tal vínculo jurídico, sino a una mera determinación identificativa del sujeto donante de los gametos origen de la generación, lo que sitúa la eventual reclamación, con este concreto y limitado alcance, en un ámbito distinto." Tribunal Constitucional de España, Sentencia No. 116 del 17 de junio de 1999 en BARBER (2010), p. 34.

58. Cfr. artículo 3 apartado 1 y artículo 6 apartado 1, de la Ley 14/2006, de 26 de mayo, sobre técnicas de reproducción humana asistida en España.

59. La jurisprudencia italiana con una decisión innovadora, ha admitido la posibilidad de utilización de la reproducción artificial a una pareja, cuyos miembros no eran ni estériles ni infértiles, pero que, no obstante, eran portadores sanos de enfermedad trasmisible genéticamente al hijo. A pesar de la norma, el Juez realizó una lectura constitucional de la Ley y dedujo el derecho de los padres a tener un hijo que no estuviera afectado por esta enfermedad y de autodeterminarse en las elecciones atinentes a la esfera de la procreación. BERTI (2015) pp. 761-776.

60. Cfr. artículo 8 de la Ley No 26.862 de 2013 sobre técnicas de reproducción asistida en Argentina.

61. Cfr. artículo 2 de la Ley No 19.167 de 2013 sobre técnicas de reproducción asistida en Uruguay. 
a los sujetos pasivos de tolerar una acción u omisión de otra persona, por lo que devienen en disposiciones más incluyentes a la vez que provee una mayor protección a los más vulnerables o en riesgo de exclusión social ${ }^{62}$.

Refiriéndose a las leyes permisivas Schwember expresa que "son esenciales para el derecho privado $y$, en realidad, lo constituyen, pues prácticamente todas las normas de derecho privado son leyes permisivas o descansan o remiten a leyes permisivas. Las leyes sobre los bienes, las leyes sobre familia y las leyes sobre contratos, que constituyen el núcleo del derecho privado, descansan, en último término, en la suposición de que estamos autorizados, bajo ciertas condiciones, para realizar según nuestro arbitrio ciertas cosas que son relevantes jurídicamente y que, por lo mismo, el derecho reconoce y ampara". ${ }^{3}$

A pesar de la permisividad, se ha establecido como regla que la filiación de los hijos nacidos mediante técnicas de reproducción humana asistida se determina por el consentimiento previo, informado y libre de quienes se someten a esta técnicas, con independencia de quién hubiera aportado los gametos, regla que se reproduce en las distintas normas que regulan la determinación de la filiación (matrimonial y extramatrimonial) y subyace en la legislación de las acciones de filiación, cuando se dispone la improcedencia de la acción de reclamación y se desestima la posibilidad de desplazar la filiación en los casos de fertilización "heteróloga", si ha mediado consentimiento previo e informado de quien asumió la maternidad o paternidad ${ }^{64}$.

En cuanto a las presunciones existe una generalización de establecer un rango de tiempo (30o días) para presumir la filiación de un hijo después de extinguido el vínculo matrimonial. Sin embargo, esta figura no se ajusta a la realidad biológica y científica que caracteriza a la FIV sea homóloga o heteróloga. Se ha podido observar que en este procedimiento médico es muy frecuente que el nacimiento fruto de métodos artificiales se produzca como resultado de una gestación inferior a 180 o superior a 300 días. Si se aplicara en forma tan estricta dicho mecanismo de presunción, podría pensarse que en la mayoría de los casos de reproducción asistida que terminan satisfactoriamente, es decir con el nacimiento de un nuevo ser, pero que no se produjo dentro del término establecido, daría lugar a que el marido de la mujer impugnara su paternidad, por la simple y única razón de que el nacimiento fue extemporáneo; dejándose de lado la realidad biológica en éste tipo de procedimientos ${ }^{65}$.

62. Cfr. ISLER (2010) pp. 147-162.

63. SCHWEMBER (2014) p. 397.

64. Cfr. artículo 8 apartado 1 de la Ley 14/2006, de 26 de mayo, sobre técnicas de reproducción humana asistida en España.

65. GESURMINO (2018) p.47. 
Muy asociado a ello está la superación de los límites naturales de la procreación, propiciada por la posibilidad de conservación de embriones congelados ${ }^{66}$, que hacen, por ejemplo, que los tiempos de un embarazo normal puedan verse superados, y desde la concepción en el laboratorio hasta el nacimiento puede llegar a tardar mucho más tiempo que el establecido por la presunción. Únicamente el Código Civil argentino establece una solución salomónica al respecto, pues excluye esta presunción del ámbito de las técnicas de reproducción humana asistida ${ }^{67}$.

De las legislaciones consultadas, solo Francia y Argentina ${ }^{68}$ requieren la instrumentación del consentimiento mediante la protocolización ante Notario o Escribano público. Así el Código civil francés dispone que los cónyuges o la pareja de hecho que recurran a un donante deberán dar su consentimiento al juez o notario ${ }^{69}$.

A continuación, se explica la forma en que legislativamente se ha regulado la reproducción asistida en Códigos de Familia. Los autores de esta investigación han decidido deslindar este análisis del resto de normas jurídicas que previamente se expusieron, teniendo en cuenta que en Cuba el Derecho familiar se ha codificado de manera autónoma. Fueron considerados los Códigos de Bulgaria, Costa Rica, Bolivia, Panamá y los Estados mexicanos Sonora, Michoacán de Ocampo, Morelos y San Luis Potosí, pero se citan aquellos preceptos representativos para evitar reiteraciones innecesarias.

66. En el caso Evans contra el Reino Unido (asunto 6339/05, Sec. $4^{\text {a }}$ de 7 de marzo de 2006, confirmado Gran Sala 10 de abril de 2007) dos ex convivientes litigaron respecto a los embriones que habían sido conservados durante su relación de pareja y que se destinarían a su posterior implantación en la mujer. Luego a ella le fueron extirpados los ovarios por una enfermedad y solicitó que los embriones pudieran ser implantados con el argumento de que constituían su última oportunidad de tener un hijo genético. El hombre, por su parte, se opuso a la petición de la mujer, con el argumento de que no podía ser forzado a procrear. Ante tal situación, el Tribunal Europeo de Derechos Humanos declara que se afecta el derecho al respeto de la vida privada del demandante, un concepto amplio que comprende la decisión de ser o no padre. El Tribunal basándose en la normativa británica declaró que sí era posible que cualquier parte revocara su consentimiento al tratamiento en cualquier momento previo a la implantación del embrión. FARNÓS (2016) pp. 93-111.

67. Cfr. artículo 565 del Código Civil y Comercial de la Nación Argentina modificado en el 2014.

68. Cfr. artículo 566 del Código Civil y Comercial de la Nación Argentina modificado en el 2014 y artículo 2 de la Ley № 26.862 de 2013 sobre técnicas de reproducción asistida en Argentina.

69. Cfr. artículo 311-20, párrafo primero del Código Civil francés, modificado por la Ley No 94-653, de 29 de junio de 1994, Sección III De la asistencia médica a la reproducción. 
En los Códigos examinados existe consenso en admitir solo la práctica de técnicas de reproducción humana asistida en personas casadas o en los casos de uniones de hecho, siempre heterosexuales. No se permite el uso alternativo de estas técnicas, por lo que otros modelos familiares están vedados de acceder a ellas ${ }^{70}$. Los donantes de material genético no adquieren derechos de ningún tipo respecto al hijo procreado ${ }^{71}$.

En cuanto al sistema de presunciones solo el código búlgaro presenta novedades al regular que madre es quien da a luz, de ese modo la presunción de maternidad queda fundamentada en el hecho del parto y no en el de la concepción ${ }^{72}$. En los casos que se haya dado el consentimiento este funcionará como presunción de filiación y mediante ficción jurídica será semejante a la cohabitación para efectos de la paternidad. Se hace la salvedad de que en la reproducción asistida no podrá alegarse la imposibilidad de procreación para impugnar el status filii ${ }^{73}$.

En ese mismo sentido todos los Códigos concuerdan en establecer al consentimiento informado como base para el establecimiento del vínculo filiatorio entre el hijo procreado mediante técnicas de reproducción humana asistiday los sujetos que expresaron su voluntad procreacional ${ }^{74}$. En lo que se refiere a la intervención notarial solo se pronuncia el Código del Estado de Sonora al señalar que "la autorización de los cónyuges para recurrir a la reproducción asistida, admitiendo la paternidad o maternidad del producto, deberá hacerse ante el Director de la Clínica o Centro Hospitalario, ante notario público o por acuerdo privado suscrito ante testigos", para dejar constancia de esta nueva fuente de la paternidad o la maternidad ${ }^{75}$.

Las normas sustantivas familiares de Bolivia y del Estado mexicano San Luis Potosí tienen preceptos sui géneris en relación con las otras legislaciones de su tipo. El Código de las Familias boliviano impide establecer vínculo conyugal, entre la madre o el padre, con la hija o hijo nacida o nacido, mediante técnicas de reproducción

70. Cfr. artículos 149 Código Familiar para el Estado de Michoacán de Ocampo última reforma publicada en el periódico oficial del Estado, el 12 de abril de 2017, Tomo: CLXVII, número: 5, octava sección.

71. Cfr. artículo 207 del Código de Familia del Estado de Sonora.

72. Cfr. Código de Familia de Bulgaria de 1 de octubre de 2009, artículos 60 apartados 2 y 5, 61, 62 apartado 5 .

73. Cfr. artículo 72 último párrafo de la Ley No. 5476 de 7 de noviembre de 1973 Código de Familia de Costa Rica.

74. Cfr. artículo 244 del Código Familiar para el Estado de San Luis Potosí última reforma publicada en el periódico oficial el 17 de septiembre de 2015.

75. Cfr. artículo 208 del Código de Familia del Estado de Sonora. 
asistida con gametos ajenos ${ }^{76}$. Por su parte el ordenamiento familiar de San Luis Potosí es bastante minucioso al regular esta temática ${ }^{77}$, especificidades que a juicio de los autores resultan más apropiadas de una ley especial que de una codificación en materia de familia.

A grandes rasgos, y luego de analizar el comportamiento de las legislaciones foráneas, los autores determinan que cualquier análisis de una regulación en Cuba de las técnicas de reproducción asistida, comienza con la inevitable promulgación de una norma jurídica especial que reglamente e integre el conjunto de dichas técnicas y sus efectos. No es suficiente con Resoluciones del Ministerio de Salud Pública con tal propósito. Una norma que ampare con fundamentos bioéticos, aquellos aspectos que exceden el ámbito de la filiación, tales como: los derechos y deberes de los sujetos beneficiarios y de los donantes, las responsabilidades de las instituciones o centros de salud, el rol de los comités de bioética, el estatuto del embrión y todo cuanto le concierne en el marco de la fertilización in vitro.

Esa futura legislación especial debería estar fundamentada en la posibilidad que actualmente la Constitución da al reconocimiento de los modelos de familia, para que así el procedimiento médico de fertilización in vitro permita a todas las tipicidades acceder a él. Particularmente en los casos de parejas del mismo sexo y maternidad en solitario por elección, la fertilización in vitro se presenta de facto como una de las alternativas para alcanzar la casi siempre ansiada descendencia. De ahí que, en un país como Cuba, con vocación humanista y alto nivel de desarrollo y accesibilidad del sistema de salud, las técnicas de reproducción asistida sean legitimadas como forma alternativa de alcanzar el proyecto familiar.

Los problemas que surgen del uso de las técnicas no se identifican con las otras formas de filiación, en particular cuando se utiliza material genético externo al proyecto familiar, sea de un donante anónimo o no. El Código de Familia debería regular en una Sección denominada "De la Reproducción Asistida", los efectos de un tercer tipo de filiación: la inducida o por voluntad procreacional, como quiera nombrársele, pero sin llegar a la taxatividad. Cualquier enumeración de las tipicidades de filiación devendría inconstitucional según el Artículo 83 de la Ley de leyes. En esa Sección dedicada a este tipo filial uno de sus pilares debería ser el consentimiento otorgado de forma previa, informada y libre, pues constituye el núcleo duro del régimen filial derivado de la reproducción asistida: la voluntad procreacional.

\footnotetext{
76. Cfr. artículo 144, apartado I, inciso e de la Ley No. 603 de 19 de noviembre de 2014 Código de las Familias y del Proceso Familiar de Bolivia.

77. Cfr. artículos del 236 al 239 del Código Familiar para el Estado de San Luis Potosí última reforma publicada en el periódico oficial el 17 de septiembre de 2015.
} 
Además, ese consentimiento debe recabarse por el centro hospitalario y protocolizado por el Notario, así como ser renovado antes de iniciar cada tratamiento. Es así, que el notario cubano se convierte en un agente colaborador eficiente del logro de seguridad jurídica a las partes que ante él acuden. El notario certifica o da fe de que hay legitimidad en el derecho que se ejerce, legalidad en el acto de voluntad, licitud en los hechos observados, capacidad en los sujetos que pretenden beneficiarse de la fertilización in vitro, idoneidad en el objeto materia del acto, de que se tiene o no un régimen conyugal, se otorga una voluntad verdadera e identidad de los sujetos que actúan e intervienen.

En Cuba ya se tiene experiencia de la participación notarial en asuntos médicos. La donación de órganos y tejidos, actualmente requiere su formalización mediante escritura pública notarial ${ }^{78}$, haciendo más arduo y delicado el quehacer de este funcionario. "La atribución al notario, cada día, de nuevas competencias por razón de la materia es viva expresión de la confianza que depositan las instituciones públicas, estatales y gubernamentales en el cometido que le viene dado por ley (...). Las autoridades gubernativas recaban la presencia notarial. Confían en la mesura y prudencia de su actuar, en el cavere, en ese perfil de la labor del notario, dirigido esencialmente a la prevención (...). Nuevamente resulta la pieza clave en la seguridad jurídica preventiva que reclama un Estado de derecho. Se acude a él por la confianza que éste deposita, por su solvencia intelectual, por su probidad y por ser baluarte de la legalidad en todo acto jurídico en el que interviene. Los ojos del notario lo ven a él mismo y a los de cada miembro de la sociedad en donde se desenvuelve y por la cual ha nacido la institución que representa." 79

Por otra parte, el sistema actual de presunciones para atribuir la maternidad y la paternidad no puede ser aplicable a la reproducción asistida, pues se sustenta en el hecho biológico de la relación sexual y la cohabitación, por tanto, de mantenerse su redacción actual se tendría que dejar claro su excepcionalidad en la fecundación asistida heteróloga. La legislación especial debe establecer el periodo de tiempo en que los embriones pueden estar en conservación porque de ello dependerá la futura validez de la presunción matrimonial del Artículo 74 incisos a y b.

\footnotetext{
78. Cfr. artículos 4 y 15 de la Resolución No. 857 de 2015 del Ministerio de Salud Pública, e Indicación Metodológica No. 5 de 2015 a todos los Notarios del país por conducto de los Jefes de Departamentos o secciones de notarías provinciales, del municipio especial Isla de la Juventud, y de los Directores generales de Consultoría Jurídica Internacional, Bufete Internacional, CONABI, LEX, y la notaría adscrita al MINJUS.
}

79. PÉREZ (2015) pp.201-202. 
En interés a la relación familiar en la que queda insertado el hijo, se hace merecedor de una efectiva protección, la cual debe materializarse en la limitación de la investigación de la paternidad o maternidad genéticas, con la intención de que se le imputen así al donante obligaciones o responsabilidades paterno-filiales por el mero hecho de ser progenitor, y considerarse preferente el mantenimiento de la relación familiar en que formalmente queda insertado el hijo. La revelación identidad del donante de material genético no conllevará en ningún caso el establecimiento del status filii hacia él. Su publicidad estará supeditada a un interés superior previamente apreciado por autoridad competente.

Por último, cabe destacar otra consecuencia inexcusable y propia de la filiación derivada de fecundación asistida heteróloga, inherente al consentimiento como exteriorización de la voluntad procreacional, el autor se refiere a la imposibilidad de interponer acción de impugnación cuando se trata de filiación por esta técnica y se ha prestado el debido consentimiento informado, según los requisitos que serán fijados por la ley especial. Así lo hace el Code catalán: "Si la filiación se deriva de la fecundación asistida de la madre, la acción de impugnación no puede prosperar si la persona cuya paternidad o maternidad se impugna consintió la fecundación, y tampoco, en ningún caso, si es progenitor biológico del hijo". ${ }^{\circ}$

Ese consentimiento solo podría ser rebatido cuando se evidenciase alguno de los supuestos de ineficacia del acto jurídico que establece el Código Civil en su Título IV, Capítulo III, Sección Quinta. De conformidad con ese precepto, la imposibilidad de impugnar la filiación fundamentándose en la imposibilidad de procrear del Artículo 78 no es causa coherente para los casos de reproducción asistida.

En resumen, los autores reconocen que es necesaria una mención a la fertilización in vitro heteróloga en el Código, aunque también debería existir un precepto que permita incluir otras técnicas que el propio desarrollo de la Biotecnología pueda alcanzar.

\section{Conclusiones}

- Entre los sujetos beneficiarios de la fertilización in vitro heteróloga deberían ser incluidos otros modelos familiares, pues los mismos son parte de la realidad social, y en ocasiones quedan excluidos de dicho tratamiento. La fecundación asistida heteróloga da lugar al surgimiento de una tercera tipicidad de filiación: la voluntad procreacional, que se diferencia de la originada por naturaleza y adopción. El otorgamiento de esa voluntad debe hacerse siguiendo determinados requisitos para evitar que el

80. Cfr. artículo 235-27 apartado 2 de Ley 25/2010, de 29 de julio, Libro Segundo del Código civil de Cataluña relativo a la persona y la familia, BOE No. 203, 21 de agosto de 2010 Sección I, p. 73429 
documento que la contenga sea refutado. En este sentido la participación del Notario o Escribano Público, según sea conocido en cada país, resulta de extrema importancia pues es el funcionario por excelencia para intervenir en este procedimiento. Los pronunciamientos que las personas involucradas hagan sobre esta última, determina la existencia de derechos, deberes y facultades, incluyendo la imposibilidad de impugnar la filiación ya establecida por esta vía.

- Además, se debe preservar el anonimato del donante y este solo podrá ser develado mientras sea excepcionalmente permitido. El ejercicio de acciones filiatorias podría ser viable en los casos en que el documento que contiene el consentimiento carezca de los requisitos legalmente exigidos. A propósito, el sistema de presunciones sustentado en el hecho de la concepción resulta caduco, pues desde ese momento y hasta la implantación del embrión puede transcurrir un tiempo considerable según sea dispuesto por ley o acordado por voluntad de las personas beneficiarias.

- La regulación de las técnicas de reproducción humana asistida no es uniforme en los ordenamientos jurídicos universales, encontrando posiciones que marchan desde las más tradicionales o restrictivas hasta las miradas y enfoques más contemporáneos y audaces. Estas últimas ofrecen un reconocimiento loable a los efectos diversos que en las relaciones paterno-filiales provoca la fertilización in vitro heteróloga por lo que puede afirmarse que existe un tratamiento normativo heterogéneo. Las legislaciones foráneas sirven de orientación a las futuras modificaciones que deberá hacer el legislador del Código de las Familias cubano.

\section{Referencias bibliográficas}

BARBER CÁRCAMO, Roncesvalles (2010): "Reproducción asistida y determinación de la filiación”. En REDUR, No 8, 2010, pp. 25-37.

BELLUSCIO, Augusto César (2004): Manual de Derecho de Familia. (Buenos Aires, Editorial Astrea, Tomo II, Séptima Edición actualizada y ampliada).

BERNAL CRESPO, Julia Sandra (2013): "Reproducción asistida y filiación. Tres casos". En Opinión Jurídica, vol. 12, No 24, pp.135-150.

BERTI DE MARINIS, Giovanni (2015): "La jurisprudencia italiana en materia de reproducción asistida". En Actualidad Jurídica Iberoamericana, № 2, pp. 761-776.

BENAVENTE MOREDA, Pilar (2017): "Los errores de legislar en paralelo: la problemática aplicación de las reglas sobre filiación (determinación, acciones de reclamación e impugnación) en la filiación derivada del uso de técnicas de reproducción humana asistida”. En Oñati Socio-legal Series, vol. 7, No 1, pp. 1-36.

BLENGIO VALDÉS, Mariana (2018): "Principio de progresividad en relación al derecho a la salud y sus consideraciones desde la ética y el derecho". En Revista de Derecho Público, Año 27, No 54, pp. 121-128. 
CÁRDENAS KRENZ, Ronald (2015): "El derecho a la identidad biológica de las personas nacidas mediante reproducción asistida en la doctrina, jurisprudencia y legislación peruana". En Persona y Familia, Revista del Instituto de la familia, vol. 1, $\mathrm{N}^{\circ}$ 4, pp. 47-65.

CATALÁ PÉREZ, Consuelo (2015): "La maternización de la sociedad: derechos reproductivos y salud primal". En Revista Dilemata, año 7, No 18, pp. 225-240.

DERUGGIERO, Roberto (1978): Instituciones de derecho civil (Madrid, Instituto Editorial Reus S.A, tomo II, volumen II).

DI CASTELNUOVO, Franco (2016): "La tridimensionalidad del fenómeno notarial en materia de familia". En Revista Notarial, No 94, pp.31-204.

DORÍN, Giselle y GIACCHETTA, Paula Jimena (2017): "La Biotecnología aplicada a la reproducción humana y su influencia en las relaciones filiales". Disponible en: <http://www.derecho.uba.ar/institucional/deinteres/ponencias-congreso-derecho-privado/familia-y-sucesiones-paula-giacchetta-noelia-giselle-dorin.pdf $>$. [Fecha de consulta: 17 de diciembre de 2017].

ENGUER GOSÁLBEZ, Pablo y RAMÓN FERNÁNDEZ, Francisca (2018): "Dilemas bioéticos y jurídicos de la reproducción asistida en la sociedad actual en España”. En Revista Latinoamericana de Bioética, vol. 18, № 1, pp.104-135.

ESBORRAZ, David Fabio (2015): "El concepto constitucional de familia en América Latina. Tendencias y proyecciones". En Revista de Derecho Privado, No 29, pp. 1555 .

FARNÓS AMORÓS, Esther (2016): "La reproducción asistida ante el Tribunal Europeo de Derechos Humanos: De Evans c. Reino Unido a Parrillo c. Italia". En Revista Bioética y Derecho, No 36, pp. 93-111.

FERNÁNDEZ JIMENO, Natalia (2016): "Desafiando la institución de la maternidad: reapropiaciones subversivas de tecnologías de reproducción asistida". En Revista CTS, vol. 11, No 31, pp. 119-146.

GARZÓN JIMÉNEZ, Roberto (2007): "Reproducción asistida". En Revista Mexicana de Derecho, No. 9, pp. 97-116.

GESURMINO MASSACCESI, María de los Ángeles (2018): "Las técnicas de reproducción humana asistida y las relaciones de familia". Disponible en: <https://repositorio.uesiglo21.edu.ar/bitstream/handle/ues21/11982/Tesis_T\%C3\%A9cnicas_ de_Reproducci\% $\mathrm{C}_{3} \% \mathrm{~B} 3 \mathrm{n} \_$Asistidaa.pdf?sequence $=1>$. [Fecha de consulta: $20 \mathrm{de}$ marzo de 2018].

GONZÁLEZ, Ana Cecilia (2016): “Técnicas de reproducción humana asistida heterólogas: el derecho a conocer los orígenes. ¿legislación versus subjetividad?”. En Acta Bioethica, vol. 22, № 1, pp. 221-227. 
GUZMÁN ÁVALOS, Aníbal y VALDÉS MARTÍNEZ, María del Carmen (2018) "Voluntad procreacional”. Disponible en: <http://www.colectivoderechofamilia.com/ wp-content/uploads/2015/o4/Avalos-y-Valdes-Voluntad-procreacional.pdf $>$. [Fecha de consulta: 20 de marzo de 2018].

ISLER SOTO, Carlos (2010): “Es el derecho un sistema de mandatos? La crítica de Hart a la teoría imperativista del derecho". En Revista de Derecho Universidad Católica del Norte, año 17, No 1, pp. 147-162

JIMÉNEZ MUÑOZ, Francisco Javier (2012): La reproducción asistida y su régimen jurídico (Madrid, Editorial Reus).

LAMM, Eleonora (2012): "La importancia de la voluntad procreacional en la nueva categoría de filiación derivada de las técnicas de reproducción asistida". En Revista Bioética y Derecho, No 24, pp.76-91.

LLEDÓ YAGÜE, Francisco (1988): Fecundación artificial y derecho (Madrid, Editorial Tecnos S. A.).

MARTÍNEZ DE AGUIRRE ALDAZ, Carlos (2013): "La filiación, entre Biología y Derecho". En Prudentia Iuris, No 76, p.117-133.

MESA CASTILLO, Olga (2013): "La experiencia de una justicia familiar en Cuba: validación de la naturaleza social y el enfoque interdisciplinario del Derecho de Familia". En Revista Cubana de Derecho, IV Época, No 41, pp. 5-18.

MESA CASTILlO, Olga; et. al. (1998): Temas de Derecho de Familia, (La Habana, 1998).

MONTEJO RIVERO, Jetzabel M. y HERNÁNDEZ SOSA, Luz M. (2011): “Aproximación a la definición de interés superior del niño". En Justicia y Derecho Revista del Tribunal Supremo Popular de la República de Cuba, año 9, No. 16, pp. 82-87.

MUÑOZ GENESTOUX, Rosalía y VÍTTOLA, Leonardo Raúl (2017): “El derecho a conocer el origen genético de las personas nacidas mediante técnicas de reproducción humana asistida con donante anónimo". En IUS Revista del Instituto de Ciencias Jurídicas de Puebla, México, vol. 11, No 39, pp.208-228.

PÉREZ GALLARDO, Leonardo Bernardino (2015): “Dación de órganos y tejidos humanos entre vivos y función notarial". En IUS Revista del Instituto de Ciencias Jurídicas de Puebla, México, Nueva Época, No. 36, pp. 179-202.

PÉREZ GALLARDO, Leonardo Bernardino (2014): "Diez interrogantes sobre el juicio notarial de capacidad: Un intento de posibles respuestas". En Revista de Derecho, No 17, pp.153-183.

PÉREZ GALLARDO, Leonardo Bernardino (2011): “Luces y sombras en torno a la regulación jurídica de la filiación en Cuba". En Revista Universitas, No 122, pp. 395-440. 
ROCA TRÍAS, Encarna (2017): Filiación asistida y protección de derechos fundamentales. Disponible en: <http://www.ajs.es/downloads/volo701.pdf >. [Fecha de consulta: 17 de diciembre de 2017].

RODRÍGUEZ CORRÍA, Reinerio (2009): "La filiación y sus acciones. Algunas reflexiones sobre su regulación y aplicación práctica". En Revista Cubana de Derecho, IV Época, No 34, pp. 5-19.

RODRÍGUEZ ITURBURU, Mariana (2015): "La regulación de las técnicas de reproducción humana asistida en la actualidad". En Reproducción, vol. 30, № 4, pp. 143-160

RODRÍGUEZ ITURBURU, Mariana; SALITURI AMEZCUA, María Martina y VÁZQUEZ ACATTO, Mariana (2017): "La regulación de la filiación derivada de las técnicas de reproducción asistida en la Argentina: voluntad procreacional y consentimiento informado". En IUS Revista del Instituto de Ciencias Jurídicas de Puebla, México, vol. 11, No 39, pp.1-31.

SCHWEMBER AUGIER, Felipe (2014): "Lex permissiva" o contrato: crítica a la lectura rawlsiana de la doctrina del derecho de Kant". En Revista de Estudios HistóricoJurídicos, No 36, pp. 385-409

TABOADA LUGO, Noel (2017): “El consentimiento informado en la práctica asistencial e investigativa de la Genética Clínica”. En Revista Acta Médica del Centro, vol. $11, \mathrm{~N}^{\circ} 3$, pp.88-100.

SCOTTI, Luciana Beatriz (2015): "La filiación internacional en el nuevo Código Civil y Comercial de la República Argentina". En Ars Iuris Salmanticensis, vol. 3, pp. 77-104.

VALDÉS DÍAZ, Caridad del Carmen (2005): "La relación jurídica civil. Concepto y contenido". En VALDÉS DÍAZ, Caridad del Carmen. Derecho Civil Parte general (La Habana, Editorial Félix Varela), pp.77-99.

VALDÉS DÍAZ, Caridad del Carmen (2012): "Del derecho a la vida y los derechos sexuales y reproductivos, ¿configuración armónica o lucha de contrarios?”. En IUSRevista del Instituto de Ciencias Jurídicas de Puebla, México, Nueva Época, $\mathrm{N}^{\circ} 29$, pp. 216-239.

VALDÉS DÍAZ, Caridad del Carmen (2017): "El acceso a algunas técnicas de reproducción humana asistida: Crónica de una vida anunciada". En Revista del Instituto de Ciencias Jurídicas de Puebla IUS, Nueva Época, vol. 11, No 39, pp. 9-23.

VARSI ROSPIGLIOSI, Enrique (2017): "Determinación de la filiación en la procreación asistida". En IUS Revista del Instituto de Ciencias Jurídicas de Puebla, México, nueva época, año 11, No 39, pp.9-23. 


\section{Jurisprudencia citada}

Artavia Murillo y otros. vs Costa Rica (2012): Corte Interamericana de Derechos Humanos, Sentencia de 28 de noviembre de 2012.

Cámara de Familia de la Sección del centro, San Salvador, El Salvador, 13 de julio de 1995, (recurso de apelación). Disponible en: <http://www.jurisprudencia.gob.sv/ DocumentosBoveda/D/1/1990-1999/1995/07/6EB5.PDF>. [Fecha de consulta: 20 de mayo de 2018].

Corte Constitucional de Colombia, Sentencia T-1104 de 23 de agosto de 20oo. En PABÓN MANTILLAet al (2017): "El acceso a las técnicas de reproducción asistida como una garantía de los derechos sexuales y reproductivos: la jurisprudencia de la Corte Constitucional a la luz del Derecho Internacional de los Derechos Humanos". En Justicia, Universidad Simón Bolívar, Barranquilla, Colombia, No 31, Enero - Junio de 2017, pp. 171-187

Corte Suprema de Justicia de Colombia, Sala de Casación Civil, Sentencia de 28 de febrero de 2013.Disponible: https://www.icbf.gov.co/cargues/avance/docs/csj_ SCC_S-_28-02-2013_[1100131100022006-00537-01]_2013.htm. [Fecha de consulta: 17 de mayo de 2018].

Corte Suprema de Justicia Colombia, Sala de Casación Civil, Sentencia 6359 de 10 de mayo de 2017. Disponible en: <http://legal.legis.com.co/document/index?obra=j urcol\&document=jurcol_d19419719bf34f5a8863c69fdb4fb9oo >. [Fecha de consulta: 24 de mayo de 2018].

Tribunal Constitucional de España, Sentencia $N^{o} 116$ de 1999. Disponible en: <https:// www.iberley.es/jurisprudencia/sentencia-constitucional-n-116-1999-tc-plenorec-recurso-inconstitucionalidad-376-1989-17-06-1999-11997001?term=Reprodu cci\% $\mathrm{C}_{3} \% \mathrm{~B}_{3} \mathrm{n}+$ asistida + Filiaci\% $\mathrm{C}_{3} \% \mathrm{~B}_{3}$ \& \& query=Reproducci\% $\mathrm{C}_{3} \% \mathrm{~B}_{3} \mathrm{n}+$ asistida $+\mathrm{F}$ iliaci\%C3\%B3n\&noIndex>. [Fecha de consulta: 25 de mayo de 2018].

Tribunal Supremo de Justicia de Cataluña, Sala de lo Civil y Penal, Sentencia $N^{o}$ 28 de 27 de septiembre 2007. Disponible en: https://www.iberley.es/jurisprudencia/sentencia-civil-n-28-2007-tsj-cataluna-sala-civil-penal-sec-1-rec135-2006-27-09-2007-5733341?term $=$ Sentencia + Civil +N\%C2\%BA+28\%2F2o $07 \% 2 \mathrm{C}+$ Tribunal + Superior $+\mathrm{de}+\mathrm{Justicia}+\mathrm{de}+\mathrm{Catalu} \% \mathrm{C}_{3} \% \mathrm{~B} 1 \mathrm{a}{ }_{2} \mathrm{C}+\mathrm{Sala}+\mathrm{de}+$ $\mathrm{lo}+\mathrm{Civil}+\mathrm{y}+$ Penal\% $2 \mathrm{C}+\mathrm{Secci} \% \mathrm{C}_{3} \% \mathrm{~B}_{3} \mathrm{n}+1 \%{ }_{2} \mathrm{C}+\mathrm{Rec}+135 \% 2 \mathrm{~F} 2 \mathrm{Oo} 6+\mathrm{de}+27+\mathrm{de}+$ Septiembre + de $+2007 \& q u e r y=S e n t e n c i a+C i v i l+N \% C_{2} \% B A+28 \% 2 F_{2007 \%} \mathrm{C}$ + Tribunal + Superior + de + Justicia + de + Catalu $\% C_{3} \% B_{11} \% 2 \mathrm{C}+\mathrm{Sala}+\mathrm{de}+\mathrm{lo}+\mathrm{Civil}$ $+\mathrm{y}+$ Penal ${ }_{2} \mathrm{C}+\mathrm{Secci} \% \mathrm{C}_{3} \% \mathrm{~B}_{3} \mathrm{n}+1 \% 2 \mathrm{C}+\mathrm{Rec}+135 \% 2 \mathrm{~F}_{2} \mathrm{Oo} 6+\mathrm{de}+27+\mathrm{de}+$ Septiem bre+de+2007\&noIndex $>$ [Fecha de consulta: 23 de mayo de 2018]. 
Tribunal Supremo de Justicia de Cataluña, Sala de lo Civil y Penal, Sentencia $N^{o}$ 44 de 22 de diciembre de 2008. Disponible en: <https://www.iberley.es/jurisprudencia/sentencia-civil-n-44-2008-tsj-cataluna-sala-civil-penal-sec-1-rec30-2007-22-12-2008-11565341?term=Reproducci\% $\mathrm{C}_{3} \% \mathrm{~B} 3 \mathrm{n}+$ asistida + Filiaci $\% \mathrm{C}_{3} \%$ B3n\&query=Reproducci $\% \mathrm{C}_{3} \% \mathrm{~B} 3 \mathrm{n}+$ asistida + Filiaci\% $\mathrm{C}_{3} \%$ B3n\&noIndex $>$. [Fecha de consulta: 23 de mayo de 2018].

Tribunal Supremo Popular de la República de Cuba, Sala de lo Civil y de lo Administrativo, Sentencia $N^{\circ} 862$ de 30 de diciembre de 2005, (recurso de casación). En Boletín del Tribunal Supremo Popular, La Habana, 2006.

Tribunal Supremo Popular de la República de Cuba, Sala de lo Civil y de lo Administrativo, Sentencia $N^{o} 249$ de 30 de junio de 2011, (recurso de casación). En Boletín del Tribunal Supremo Popular, La Habana, 2011.

Tribunal Supremo Popular de la República de Cuba, Sala de lo Civil y de lo Administrativo, Sentencia $N^{\circ} 510$ de 31 de octubre del 2013, (recurso de casación).

Tribunal Supremo Popular de la República de Cuba, Sala de lo Civil y de lo Administrativo, Sentencia No Sentencia No. 895 de 23 de diciembre de 2014, (recurso de casación). 


\title{
Indemnización de perjuicios por infracciones a la libre competencia
}

\author{
Damages for infringements to competition law
}

\section{GABRIEl BudNiK OJEDA ${ }^{\mathbf{1}}$ \\ Universidad de Chile, Chile}

\begin{abstract}
RESUMEN El presente trabajo busca analizar las implicancias jurídicas y prácticas del artículo $30^{\circ}$ del Decreto Ley $\mathrm{N}^{\circ} 211$ de 1973, recientemente modificado por la Ley $\mathrm{N}^{\circ} 20.945$ de fecha 30 de agosto de 2016, que perfecciona el sistema de defensa de la libre competencia. Con base en la escasa jurisprudencia nacional sobre indemnización de perjuicios por infracciones a la libre competencia, así como en la Historia de la Ley $\mathrm{N}^{\circ}$ 20.945, el autor interpreta el alcance de la actual redacción del artículo $30^{\circ} \mathrm{y}$ anticipa los principales temas que deberán ser resueltos por la nueva jurisprudencia en esta materia.
\end{abstract}

PALABRAS CLAVE Indemnización de perjuicios, tipos de daños, acción followon, cálculo del daño.

ABSTRACT This paper seeks to analyze the legal and practical implications of article 30 of Decree Law $\mathrm{N}^{\circ} 211$ of 1973, amended by Law $\mathrm{N}^{\circ} 20,945$, dated August 3oth, 2016, which improves the system for the defense of competition. Based on the scarce national case law on damages due to infringements of competition law, as well as on the History of Law $\mathrm{N}^{\circ} 20,945$, the author interprets the scope of the current wording of article 30 and anticipates the main issues that must be resolved by new case law on this matter.

\footnotetext{
1. Abogado, Universidad de Chile. Diplomado en Libre Competencia, Pontificia Universidad Católica. Asociado en Philippi Prietocarrizosa Ferrero DU \& Uría. Su área de investigación es el derecho de la competencia. Mail: gabriel.budnik@ppulegal.com
} 
KEYWORDS Damages, types of damages, follow-on action, damage calculation.

\section{Introducción}

La reparación de perjuicios derivados de la infracción a un deber general de cuidado, que las personas deben observar en sus encuentros espontáneos, es una máxima que cobra vital importancia en nuestras relaciones diarias. Más allá del deber moral que pesa sobre cada uno de nosotros, la existencia de un sistema de responsabilidad extracontractual que habilite a quien sufre un daño, la reparación del mismo, nos incentiva a actuar con debida diligencia en nuestro día a día. Esta debida diligencia debe observarse en diversos campos o actividades, no estando exento de aquello, según se desarrollará infra, la libre competencia.

El presente artículo busca abordar la extensión de la responsabilidad civil derivada de infracciones a la libre competencia. Para lo anterior, este trabajo se divide en seis secciones:

La primera sección analiza el tratamiento de los daños indemnizables en materia de derecho de la libre competencia, o si se prefiere, la indemnización de perjuicios por infracciones a la libre competencia. Para lo anterior, se identifican los tipos infraccionales del Decreto Ley $\mathrm{N}^{\circ} 211$ de 1973 y sus posteriores modificaciones ("DL 211").

A continuación, sobre la base de los daños indemnizables en materia de libre competencia, se hace una revisión del tratamiento de la indemnización de perjuicios por infracciones a la libre competencia. Para lo anterior, se identifican las normas que históricamente han regulado esta materia.

La tercera sección analiza las modificaciones al artículo $30^{\circ}$ del DL 211, introducidas por la Ley $\mathrm{N}^{\circ} 20.945$ de agosto de 2016. Para facilidad de comprensión, se hace un contraste de la redacción del tipo legal antes de la modificación de agosto de 2016 versus la actual redacción de la norma, resaltando las principales similitudes y diferencias entre ambas. Luego, la cuarta sección analiza, bajo la lógica de la responsabilidad civil extracontractual, los requisitos para indemnizar perjuicios derivados de ilícitos anticompetitivos, incluyendo el análisis propio de los métodos comúnmente utilizados para calcular los daños en esta materia.

La quinta sección se refiere al único caso de indemnización de perjuicios que ha sido tramitado bajo la nueva redacción del artículo $30^{\circ}$ del DL 211, a saber, la demanda interpuesta por doña Sandra Fuentes Salazar, Julia Salazar Crane y Marcelo Hernández Sandoval, personas naturales propietarias y administradoras de los activos destinados a la explotación del giro de Buses Línea Azul ("Línea Azul”), en contra de Empresa de Transportes Rurales Limitada (“Turbus”), Servicio Pullman Bus Costa Central S.A. ("Pullman") y Transportes Cometa S.A. ("Cometa" y conjuntamente con Turbus y Pullman, las “Demandadas”) (“Demanda Línea Azul”). Al respecto, si bien 
este caso terminó por un acuerdo conciliatorio, por una parte, y por un desistimiento, por la otra, sirve como punto de partida para sacar conclusiones respecto del alcance de la nueva redacción del tipo legal.

Finalmente, el trabajo concluye con una breve referencia a la relación que existe, en materia de indemnización de perjuicios, entre libre competencia y otros cuerpos normativos.

\section{Daño indemnizable}

El artículo $3^{\circ}$ del DL 211 define al ilícito anticompetitivo como “...cualquier hecho, acto o convención, que impida, restrinja o entorpezca la libre competencia, o que tienda a producir dichos efectos" (i.e., tipo general). Tras su definición genérica, el DL 211 entrega ejemplos de ilícitos anticompetitivos, a saber²: (i) la colusión (contemplada en la letra a) del citado artículo); (ii) el abuso de posición dominante (contemplado en la letra b) y c) del referido artículo); y (iii) el interlocking (contemplado en la letra d) del mismo artículo).

2. Artículo $3^{\circ}$ del DL 211: “(...) Se considerarán, entre otros, como hechos, actos o convenciones que impiden, restringen o entorpecen la libre competencia o que tienden a producir dichos efectos, los siguientes:

a) Los acuerdos o prácticas concertadas que involucren a competidores entre sí, y que consistan en fijar precios de venta o de compra, limitar la producción, asignarse zonas o cuotas de mercado o afectar el resultado de procesos de licitación, así como los acuerdos o prácticas concertadas que, confiriéndoles poder de mercado a los competidores, consistan en determinar condiciones de comercialización o excluir a actuales o potenciales competidores.

b) La explotación abusiva por parte de un agente económico, o un conjunto de ellos, de una posición dominante en el mercado, fijando precios de compra o de venta, imponiendo a una venta la de otro producto, asignando zonas o cuotas de mercado o imponiendo a otros abusos semejantes.

c) Las prácticas predatorias, o de competencia desleal, realizadas con el objeto de alcanzar, mantener o incrementar una posición dominante.

d) La participación simultánea de una persona en cargos ejecutivos relevantes o de director en dos o más empresas competidoras entre sí, siempre que el grupo empresarial al que pertenezca cada una de las referidas empresas tenga ingresos anuales por ventas, servicios y otras actividades del giro que excedan las cien mil unidades de fomento en el último año calendario. Con todo, sólo se materializará esta infracción si transcurridos noventa días corridos, contados desde el término del año calendario en que fue superado el referido umbral, se mantuviere la participación simultánea en tales cargos". 
Además de los ilícitos indicados en las diversas letras del artículo $3^{\circ}$ del DL 211, otros ejemplos de ilícitos anticompetitivos o que importan una afectación a la libre competencia, en los términos del artículo $3^{\circ}$, inciso primero del DL 211, se encuentran consagrados en los siguientes artículos del mismo cuerpo normativo: (i) el artículo $3^{\circ}$ bis $^{3}$, relativo al gun jumping y otros ilícitos derivados de una infracción a la regulación del Título IV del DL 211 ("De las Operaciones de Concentración”); y (ii) el artículo $4^{\circ}$ bis $^{4}$, relativo a no informar la adquisición de una participación minoritaria en una empresa competidora.

La contextualización precedente no es irrelevante, sino que, por el contrario, creemos que la comprensión respecto de qué conductas son anticompetitivas es fundamental para el análisis del derecho compensatorio, toda vez que son precisamente

3. Artículo $3^{\circ}$ bis del DL 211: "Podrán también aplicarse las medidas del artículo 26, así como aquellas medidas preventivas, correctivas o prohibitivas que resulten necesarias, a quienes:

a) Infrinjan el deber de notificación que establece el artículo 48.

b) Contravengan el deber de no perfeccionar una operación de concentración notificada a la Fiscalía Nacional Económica y que se encuentre suspendida de acuerdo con lo establecido en el artículo 49. c) Incumplan las medidas con que se haya aprobado una operación de concentración, al tenor de lo dispuesto en los artículos 31 bis, 54 o 57, según sea el caso.

d) Perfeccionen una operación de concentración en contra de lo dispuesto en la resolución o sentencia que haya prohibido dicha operación, de conformidad a lo establecido en los artículos 31 bis o 57 , según corresponda.

e) Notifiquen una operación de concentración, de conformidad al Título IV, entregando información falsa".

4. Artículo $4^{\circ}$ bis: "La adquisición, por parte de una empresa o de alguna entidad integrante de su grupo empresarial, de participación, directa o indirecta, en más del 10\% del capital de una empresa competidora, considerando tanto sus participaciones propias como aquellas administradas por cuenta de terceros, deberá ser informada a la Fiscalía Nacional Económica a más tardar sesenta días después de su perfeccionamiento. El Fiscal Nacional Económico podrá instruir investigación respecto de dichos actos con el objeto de comprobar infracciones al artículo $3^{\circ}$.

La obligación de informar establecida en el inciso anterior sólo se aplicará en el evento que la empresa adquirente, o su grupo empresarial, según corresponda, y la empresa cuya participación se adquiere tengan, cada una por separado, ingresos anuales por ventas, servicios y otras actividades del giro que excedan las cien mil unidades de fomento en el último año calendario.

En caso que se infrinja la obligación de informar establecida en este artículo, podrán aplicarse las medidas del artículo 26, así como aquellas medidas preventivas, correctivas o prohibitivas que resulten necesarias". 
estas conductas las que generan daños, los cuales, según corresponda, deben ser sancionados ${ }^{5}$ (justicia retributiva), por afectar al interés general, y/o reparados (justicia correctiva $)^{6}$, por afectar un interés particular.

En tal sentido, a grandes rasgos, la doctrina clasifica los daños derivados de un ilícito anticompetitivo en: daño anticompetitivo (daño social) y daño indemnizable (daño particular) ${ }^{7}$.

El daño anticompetitivo es aquél que se traduce en una "pérdida de bienestar social o en la utilización ineficiente de los recursos en los distintos mercados" ${ }^{8}$. Este tipo de daños afecta el equilibrio entre la oferta y demanda, al generar menos bienes y servicios, de peor calidad y a un mayor precio. Es precisamente la existencia de este tipo de daños la que le "atribuye al derecho de la libre competencia su característica de norma de orden público"9.

En tal sentido, el bien jurídico protegido por el derecho de la libre competencia no apunta necesariamente a la protección de consumidores (interés privado), sino que a la promoción y defensa de la libre competencia en los mercados (interés general), entendiéndose por libre competencia ${ }^{10}$, aquel principio económico basado en la ley de la oferta y la demanda, en donde se asegura la competencia justa y la libertad de tomar decisiones tanto para el consumidor como para el productor.

Como tal, al afectar a un interés general, el daño anticompetitivo, si bien puede estar relacionado, no presupone la existencia de un daño indemnizable. En otras palabras, la afectación de un interés particular derivado de un daño anticompetitivo, si bien, según se desarrollará infra, se encuentra vinculado al daño anticompetitivo, importa un análisis propio del derecho privado.

5. La lógica de retribución íntimamente ligada con la disuasión de la conducta (prevención). En tal sentido, se busca, más allá de la sanción, amedrentar a quienes hayan realizado o estén llanos de realizar la conducta reprochable. Al efecto, la pena no atiende el daño efectivamente sufrido por el infractor.

6. Al efecto, ver BARROS (2010), pp. 40-43. En tal sentido, señala Barros que: "La idea de justicia correctiva establece un fundamento general para la responsabilidad por negligencia, porque la más elemental de las razones para que alguien sea tenido por responsable de los daños que provoca es su infracción a un deber de cuidado (...)"

7. LEWIN (2011), pp. 46-47.

8. LEWIN (2011), p. 46.

9. LEWIN (2011), p. 47.

10. En palabras de Valdés: "libre competencia significa la libertad en el ingreso, explotación y salida de los mercados relevantes, cualquiera sea la modalidad de autonomía o heteronomía empleada para competir en el cabal cumplimiento del marco de principios y garantías constitucionales, entre las cuales exhibe un rol capital el principio de subsidiariedad”. VALDÉS (2006) p. 180. 
En tal sentido, a diferencia del daño anticompetitivo, el daño indemnizable se refiere al daño reparable o indemnizable, propio del análisis de la responsabilidad civil extracontractual. En términos de Abeliuk, el daño indemnizable apunta a toda "pérdida, disminución, detrimento o menoscabo en su persona o bienes o en las ventajas o beneficios patrimoniales o extrapatrimoniales de que gozaba" ${ }^{11}$. En otras palabras, se refiere a "todo detrimento que sufre una persona, ya sea en su patrimonio material o moral"12.

Es precisamente este daño indemnizable el que es motivo del presente trabajo y será desarrollado en detalle en las siguientes secciones.

\section{Evolución chilena de la indemnización de perjuicios por infracciones a la libre competencia}

La evolución de la normativa de libre competencia en materia de indemnización de perjuicios puede separarse en tres etapas, según la regulación vigente del momento: (i) previo al año 2003, cuando no existía regulación especial para indemnización de perjuicios derivada de ilícitos anticompetitivos y, por ende, se aplicaba la regulación genérica del Código Civil, en cuanto al fondo, y del Código de Procedimiento Civil, en cuanto a la forma; (ii) entre los años 2003 y 2016, lapso de tiempo en el que preponderó la antigua redacción del artículo $30^{\circ}$ del DL 211, introducido por la Ley $\mathrm{N}^{\circ}$ 19.911; y (iii) con posterioridad a 2016, conforme al cual existe la actual redacción del artículo $30^{\circ}$ del DL 211.

A continuación se desarrollará brevemente cada una de estas etapas:

\section{A. DL 211 previo a 2003}

Como se anticipó, entre los años 1973 y 2003, el DL 211 no contemplaba una regulación especial y explícita en torno a la indemnización de perjuicios derivada de ilícitos anticompetitivos. Al no contar con regulación específica, por reglas de supletoriedad, aplicaban las reglas generales y, por tanto, procedía el procedimiento y regulación propia de la responsabilidad civil extracontractual, que en la práctica implicaba "un juicio ordinario, de lato conocimiento y de muy difícil tramitación”"13.

En ese contexto, "[p] osiblemente el primer litigio nacional en la materia, (...) involucró a Aerovías DAP y sus socios personas naturales (la familia Pivcevic) -como de

11. ALESSANDRI (1943), p. 210.

12. ABELIUK (2001), p. 730.

13. Historia de la Ley $\mathrm{N}^{\circ} 19.911$, de 2003. 
mandantes- y a Lan Chile, Ladeco y National Airlines como demandadas" ${ }^{14}$. En este juicio, el tribunal de primera instancia condenó a las demandadas a indemnizar los perjuicios ocasionados por el ilícito anticompetitivo, decisión que posteriormente fue confirmada por la Corte de Apelaciones y Corte Suprema, con la sola desestimación del daño moral por falta de prueba.

En relación a este juicio, vale la pena destacar las siguientes consideraciones: (i) la importancia de la existencia de una declaración previa de un ilícito anticompetitivo en sede infraccional; (ii) la presunción de dolo producto de la declaración anticompetitiva de la conducta en sede infraccional (i.e., el abuso del derecho a dañar es inherente a la libertad de competir, lo que exige dolo o culpa grave); y (iii) que "la responsabilidad civil emanó tanto del abuso de posición dominante como de la conspiración o colusión de las demandadas destinadas a expulsar al contrincante"15.

\section{B. DL 211 entre 2003 y 2016}

Ahora bien, fue recién en el año 2003, de la mano de la Ley $\mathrm{N}^{\circ}$ 19.911, que el legislador incorporó un mecanismo compensatorio especial para las víctimas perjudicadas por una conducta contraria a la libre competencia. Dicha incorporación "fue motivada por el envío de una nota del profesor Jorge Streeter Prieto"16, a la que se refirió el diputado Jorge Burgos en el siguiente sentido:

"La indicación recoge una cuestión muy central: que la persona que se sienta perjudicada - un empresario mediano, grande, pequeño; un ciudadano común y corriente, o un grupo de ciudadanos- en su derecho a tener libre competencia, de una competencia leal, podrá recurrir, no sólo para la sanción establecida en esta ley, sino, además, a partir de una sentencia favorable, ejercer las sanciones indemnizatorias, lo que a mi juicio, cierra el círculo de protección de la libre competencia” ${ }^{17}$.

Producto de lo anterior, la Ley $\mathrm{N}^{\circ} 19.911$ incorporó el artículo $30^{\circ}$ al DL $211^{18}$, regulando la indemnización de perjuicios derivados de ilícitos anticompetitivos.

14. BANFI (2014 a.), p. 46. En este caso, Aerovías DAP y sus socios demandaron la responsabilidad civil de las Lan Chile, Ladeco y National Airlines por haber restringido la competencia al adoptar una estrategia de precios predatorios con la finalidad de expulsar a Aerovías DAP del mercado.

15. BANFI (2014 a.), p. 48.

16. ARAYA (2005), pp. 15-16.

17. Historia de la Ley $\mathrm{N}^{\circ} 19.911$, de 2003.

18. "La acción de indemnización de perjuicios a que haya lugar, con motivo de la dictación por el Tribunal de Defensa de la Libre Competencia de una sentencia definitiva ejecutoriada, se interpondrá ante el tribunal civil competente de conformidad a las reglas generales, y se tramitará de acuerdo al procedimiento sumario, establecido en el Libro III del Título XI del Código de Procedimiento Civil. El tribunal civil competente, al resolver sobre la indemnización de perjuicios, fundará su fallo en las conductas, hechos y calificación jurídica de los mismos, establecidos en la sentencia del Tribunal de Defensa de la Libre Competencia, dictada con motivo de la aplicación de la presente ley". 
Si bien, desde su incorporación, son pocas las acciones de indemnización de perjuicio que hayan seguido el procedimiento establecido en el antiguo artículo $30^{\circ}$ del DL $211^{19}$, de los juicios tramitados bajo el antiguo tipo legal, resulta ilustrativo referirse a uno de los juicios emblemáticos en la materia, a saber, el juicio entre Philip Morris y Compañía Chilena de Tabacos.

Respecto del juicio entre Philip Morris y Compañía Chilena de Tabacos, tras la declaración en sede infraccional de la existencia de conductas por parte de Compañía Chilena de Tabacos destinadas a impedir el ingreso de Philip Morris al mercado chileno de cigarrillos, Philip Morris reclamó los perjuicios (daño emergente, lucro cesante y daño moral) derivados de dichas conductas anticompetitivas. Si bien en primera instancia se rechazó la demanda por falta de prueba en lo que dice relación al daño y a la causalidad, el tribunal de alzada acogió parcialmente la apelación de Philip Morris, condenando a Compañía Chilena de Tabacos a restituir el lucro cesante, pero limitado al período 2002-2005, ascendente a un millón ochocientos mil dólares de los Estados Unidos de América.

Esta sentencia, al igual que otras del período, permitieron adelantar interpretaciones del tipo legal que se analizarán infra. Asimismo, este fallo es útil en cuanto evidencia que la mera declaración infraccional de un ilícito anticompetitivo no es suficiente para acreditar la responsabilidad civil derivados de dichos hechos, actos o contratos, debiendo, por tanto, acreditarse los requisitos comunes a las acciones de responsabilidad civil extracontractual.

\section{DL 211 entre 2016 a la fecha}

La actual redacción del artículo 30 $0^{\circ}$ del DL 211 importa nuevos y novedosos cambios, tanto en la forma como en el fondo, en lo que se refiere a la indemnización de perjuicios por infracciones a la libre competencia. En la siguiente sección se analizarán en detalle cada una de estas modificaciones.

19. (i) Tabacaleras; (ii) Rivas v. Soc. Educacional American British; (iii) Etcom v. Telefónica; (iv) OPS Ingeniería v. Telefónica; (v) Farmacias; (vi) Pollos; y (vii) Tissues. 


\section{Análisis de la modificación al DL 211, introducida por la Ley $N^{\circ} 20.945$}

Según consta en la Historia de la Ley $\mathrm{N}^{\circ} 20.945^{20}$, la modificación del artículo $30^{\circ}$ del DL $211^{21}$ se justifica, entre otras cosas, por economía procesal, otorgando al Tribunal de Defensa de la Libre Competencia la competencia para conocer tanto de las acciones de indemnización de perjuicio privadas como colectivas ${ }^{22}$.

A continuación se presenta un análisis de las principales coincidencias y diferencias del artículo $30^{\circ}$ del DL 211, conforme a la redacción establecida por la Ley $\mathrm{N}^{\circ}$ 19.911 y a la actual redacción, incorporada por la Ley $\mathrm{N}^{\circ} 20.945$.

\section{A. Principales coincidencias respecto a la indemnización de perjuicios entre la Ley $\mathrm{N}^{\circ} 19.911$ y la Ley $\mathrm{N}^{\circ} 20.945$}

Las principales coincidencias que encontramos entre la norma introducida por la Ley $\mathrm{N}^{\circ} 19.911$ y la modificación de la Ley $\mathrm{N}^{\circ} 20.945$, son las siguientes:

20. Historia de la Ley $\mathrm{N}^{\circ}$ 20.945, de 2015.

21. "La acción de indemnización de perjuicios a que haya lugar con motivo de la dictación por el Tribunal de Defensa de la Libre Competencia de una sentencia definitiva ejecutoriada, se interpondrá ante ese mismo Tribunal y se tramitará de acuerdo al procedimiento sumario establecido en el Título XI del Libro Tercero del Código de Procedimiento Civil. Las resoluciones pronunciadas en este procedimiento, salvo la sentencia definitiva, sólo serán susceptibles del recurso de reposición, al que podrá darse tramitación incidental o ser resuelto de plano. Sólo será susceptible de recurso de reclamación, para ante la Corte Suprema, la sentencia definitiva.

Al resolver sobre la acción de indemnización de perjuicios, el Tribunal de Defensa de la Libre Competencia fundará su fallo en los hechos establecidos en su sentencia que sirvan de antecedente a la demanda. El Tribunal apreciará la prueba de acuerdo a las reglas de la sana crítica.

La indemnización de perjuicios comprenderá todos los daños causados durante el período en que se haya extendido la infracción.

La acción de indemnización de perjuicios derivados de los acuerdos sancionados en el Título V de la presente ley se sustanciará conforme a lo establecido en este artículo, y respecto de ellos no podrán interponerse acciones civiles en el procedimiento penal".

22. Al respecto, se modificó el artículo $51^{\circ} \mathrm{LPC}$, reconociendo expresamente posibilidad de iniciar juicios colectivos de indemnización de perjuicios por infracciones a la libre competencia. 


\section{a. Acción Follow-on}

$\mathrm{El}$ artículo $30^{\circ}$ del DL 211 mantiene la lógica de dependencia de la acción de indemnización de perjuicio a la existencia de una sentencia definitiva ejecutoriada por parte del Tribunal de Defensa de la Libre Competencia o de la Corte Suprema, según corresponda. Lo anterior es reforzado tanto por el artículo $20^{\circ}$, inciso final del DL $211^{23}$, como por el artículo $51^{\circ}$ de la Ley $N^{\circ} 19.496^{24}$.

Corolario de lo anterior es que la acción de indemnización de perjuicios en sede de libre competencia ${ }^{25}$ no es autónoma y, por tanto, no puede interponerse como una acción stand alone.

En la actualidad, el único caso del que tenemos conocimiento en que se intentó interponer una acción stand alone de indemnización de perjuicios es el juicio entre Sound Color S.A. y United International Pictures Chile Ltda ("UIP”). En este caso, "Sound Color accionó de responsabilidad aquiliana en contra del distribuidor UIP, alegando que este se había negado dolosamente a alquilarle cintas de estreno simultáneo para los cines que la actora administraba en Osorno y Temuco, y que además se había coludido con Andes Films, competidor de la actora. Sound Color solicitó que le fuesen indemnizados el daño emergente (debido a la disminución en las ventas de entradas y confitería), el lucro cesante (vinculado a la pérdida de las utilidades proyectadas) y el daño moral (un supuesto desprestigio ante el público causado por la indisponibilidad de películas de exhibición simultánea) ${ }^{26}$.

23. "Sin perjuicio de las disposiciones generales, las acciones civiles derivadas de un atentado a la libre competencia prescriben en el plazo de cuatro años, contado desde que se encuentre ejecutoriada la sentencia definitiva" (énfasis agregado).

24. "No obstante lo dispuesto en el artículo 30 del decreto con fuerza de ley $\mathrm{N}^{\circ} 1$, de 2004, del Ministerio de Economía, Fomento y Reconstrucción, que fija el texto refundido, coordinado y sistematizado del decreto ley $\mathrm{N}^{\circ} 211$, de 1973, y sin perjuicio de las acciones individuales que procedan, la acción de indemnización de perjuicios que se ejerza ante el Tribunal de Defensa de la Libre Competencia, con ocasión de infracciones a dicho cuerpo normativo, declaradas por una sentencia definitiva ejecutoriada, podrá tramitarse por el procedimiento establecido en este Párrafo cuando se vea afectado el interés colectivo o difuso de los consumidores" (énfasis agregado).

25. A diferencia de la Ley $\mathrm{N}^{\circ} 19.496$, que adicional a la acción indemnizatoria basada en el artículo $30^{\circ}$ del DL 211, permite el ejercicio de una acción independiente y desvinculada al razonamiento del Tribunal de Defensa de la Libre Competencia.

26. BANFI (2014 a.), p. 48. 
La demanda fue rechazada por falta de prueba, reconociendo expresamente que "para que prosperara la acción deducida por la demandante, debió haberse establecido por el H. Tribunal de Defensa de la Libre Competencia, que la demandada había incurrido en los ilícitos denunciados, cosa que en la especie no ha ocurrido, por lo que no es posible acceder a las pretensiones de la actora" ${ }^{27}$.

\section{b. Procedimiento sumario}

El juicio de indemnización de perjuicio derivado de una conducta declarada ilícita por el Tribunal de Defensa de la Libre Competencia o la Corte Suprema, según corresponda, se tramitará de acuerdo al procedimiento sumario establecido en el Título XI del Libro Tercero del Código de Procedimiento Civil.

Ahora bien, a diferencia de lo que ocurría con el antiguo artículo $30^{\circ}$ del DL 211, en donde nada se decía respecto de los recursos y, por tanto, se entendía aplicaban las normas generales para este tipo de procedimiento, el actual artículo $30^{\circ}$ del DL 211 señala que las resoluciones pronunciadas en este procedimiento sólo serán susceptibles de recurso de reposición, al que podrá darse tramitación incidental o ser resuelto de plano. La única excepción sería la sentencia definitiva, la que será susceptible de recurso de reclamación, para ante la Corte Suprema.

\section{c. Fundamentación del fallo}

Como acción follow-on, es necesario que el Tribunal de Defensa de la Libre Competencia, al dictar sentencia sobre la acción de indemnización de perjuicios, funde su fallo en los hechos establecidos en la sentencia que sirvan de antecedente a la demanda. Ahora bien, curioso resulta la modificación de esta parte del artículo, toda vez que ya no se hace referencia a la conducta y calificación jurídica del juicio previo de libre competencia.

No creemos apropiado una interpretación formalista, que apunte a que ya no es procedente la cosa juzgada respecto de estos dos aspectos, por lo que, sin perjuicio de ser un texto menos acertado, entendemos que nada ha cambiado respecto a la fundamentación del fallo.

27. BANFI (2014 a.), p. 49. Citando a: Sound Colour con United International Pictures Chile (2009): cons. $19^{\circ}$ y $20^{\circ}$, respectivamente. 


\section{d. Daños}

Si bien el actual artículo $30^{\circ}$ del DL 211 explicita que la indemnización de perjuicios comprenderá todos los daños causados durante el período en que se haya extendido la infracción, esta introducción no es más que un reconocimiento expreso a las reglas generales en materia de daños, en donde se consideran indemnizables: (i) el daño emergente; (ii) el lucro cesante; y (iii) el daño moral.

\section{e. Prescripción}

Finalmente, respecto de la prescripción, se mantiene inalterado el inciso final del artículo $20^{\circ}$ del DL 211, por lo que se ha de entender que las acciones indemnizatorias motivadas por un atentado a la libre competencia prescriben en el plazo de cuatro años contados desde que la sentencia definitiva se encuentre firme y ejecutoriada.

\section{B. Principales diferencias respecto a la indemnización de perjuicios entre la Ley No 19.911 y la Ley No 20.945}

Las principales diferencias que encontramos entre la regulación introducida por la Ley $\mathrm{N}^{\circ} 19.911$ y la modificación de la Ley $\mathrm{N}^{\circ} 20.945$, son las siguientes:

\section{a. Tribunal competente}

Tal vez el aspecto más relevante de la reforma al artículo $30^{\circ}$ del DL 211 y que más consternación ha generado, es que la Ley $\mathrm{N}^{\circ} 20.945$ modificó la competencia del tribunal llamado a conocer de la indemnización de perjuicios por infracciones a la libre competencia, pasando ésta de los tribunales ordinarios al Tribunal de Defensa de la Libre Competencia.

A favor de este cambio de competencia, encontramos los siguientes argumentos: (i) eficiencia (acciones follow-on); (ii) economía procesal; y (iii) deferencia técnica (composición del Tribunal de Defensa de la Libre Competencia -abogados y economistas- permite entender adecuadamente la cuantificación del daño).

En contra de esta modificación, encontramos los siguientes argumentos: (i) atenta al debido proceso (parcialidad del Tribunal de Defensa de la Libre Competencia al ya haber fallado sobre este tema en sede de libre competencia); (ii) falta de expertise en materias civiles; (iii) carga excesiva al Tribunal de Defensa de la Libre Competencia; y (iv) el procedimiento deberá tramitarse obligatoriamente en la ciudad de Santiago, lo que atenta contra el principio de acceso a la justicia ${ }^{28}$.

28. Historia de la Ley $\mathrm{N}^{\circ} 20.945$, de 2015. 


\section{b. Apreciación de la prueba}

Otro cambio relevante a tener en consideración dice relación con la valoración de la prueba. Al efecto, el artículo $30^{\circ}$ introducido por la Ley $\mathrm{N}^{\circ} 19.911$ no decía nada respecto a la valoración de la prueba, entendiéndose por tanto que aplicaba la regla general, esto es, la apreciación de la prueba conforme al sistema de la prueba legal o tasada.

La nueva redacción del artículo $30^{\circ}$ del DL No 211 identifica una nueva forma de valoración de la prueba: la sana crítica. Lo anterior parece acertado, considerando que el análisis de indemnización de perjuicios en sede de libre competencia es complejo y requiere la apreciación de la prueba conforme a las reglas de la lógica, las máximas de experiencias y los conocimientos científicamente afianzados.

\section{c. Legitimación activa}

El artículo $2^{\circ}$ de la Ley $\mathrm{N}^{\circ} 20.945$ modificó el artículo $51^{\circ}$ de la Ley $\mathrm{N}^{\circ} 19.496$, incorporando dos incisos que permiten accionar por los intereses colectivos o difusos de los consumidores. Si bien previo a la última modificación legal al DL 211 la discusión en torno a la legitimación activa del Servicio Nacional del Consumidor y de asociaciones de consumidores para demandar la indemnización de perjuicios por infracciones a la libre competencia no era pacífica, hoy está zanjada, siendo procedente el ejercicio de acciones colectivas para solicitar la indemnización de perjuicios.

A modo de resumen, la siguiente tabla contiene un resumen de las principales diferencias que el DL No 211 le dio a la indemnización de perjuicios.

Tabla No 1: Principales diferencias respecto a la indemnización de perjuicios entre la Ley $\mathrm{N}^{\circ} 19.911$ y la Ley $\mathrm{N}^{\circ} 20.945$

\begin{tabular}{|l|l|l|l|}
\hline & $\begin{array}{l}\text { Previo a la Ley } \mathbf{N}^{\circ} \\
\mathbf{1 9 . 9 1 1}\end{array}$ & Ley $\mathbf{N}^{\circ} \mathbf{1 9 . 9 1 1}$ & ${\text { Ley } \mathbf{N}^{\circ} \mathbf{2 0 . 9 4 5}}$ \\
\hline Artículo DL No 211 & $\begin{array}{l}\text { Juez de letra en lo } \\
\text { civil }\end{array}$ & $\begin{array}{l}\text { artículo 30 } \\
\text { Juez de letra en }\end{array}$ & $\begin{array}{l}\text { artículo 30 } \\
\text { Juezibunal de De- } \\
\text { fensa de la Libre } \\
\text { Competencia }\end{array}$ \\
\hline Efecto Positivo de la Cosa Juzgada & & Sí (Follow-on) & Sí (Follow-on) \\
\hline Valoración de la Prueba & Prueba legal o tasada & $\begin{array}{l}\text { Prueba legal o } \\
\text { tasada }\end{array}$ & Sana crítica \\
\hline $\begin{array}{l}\text { Requisitos de Responsabilidad Civil } \\
\text { Extracontractual }\end{array}$ & Todos & $\begin{array}{l}\text { Daño y causali- } \\
\text { dad }\end{array}$ & Daño y causalidad \\
\hline Procedimiento & Ordinario & Sumario & Sumario \\
\hline Acciones de Clases & No & Discutible & Sí \\
\hline Recursos & Generales & Generales & Reclamación \\
\hline
\end{tabular}




\section{Requisitos para indemnizar perjuicios derivados de ilícitos anticompetitivos}

Por regla general, los ilícitos anticompetitivos se dan en sede extracontractual ${ }^{29}$, y como tal, para que haya lugar a la responsabilidad, deben estar presentes los siguientes requisitos: (i) acción u omisión del agente; (ii) la culpa o dolo de su parte; (iii) la no concurrencia de una causal de exención de responsabilidad; (iv) la capacidad del autor del hecho ilícito; (v) el daño a la víctima; y (vi) la relación de causalidad entre la acción u omisión culpable o dolosa y el daño producido.

Tomando en consideración la naturaleza follow-on de la acción indemnizatoria, la controversia se reducirá a los daños y a la relación de causalidad entre la acción u omisión culpable o dolosa y el daño producido.

\section{A. Daño}

Como bien ha dicho la Corte de Apelaciones de Santiago, "para que un hecho culposo cause responsabilidad civil es indispensable que cause daño y se pruebe su monto"30. En otras palabras, "para que exista responsabilidad civil es menester que el hecho ilícito haya causado daño" ${ }^{31}$ y para que éste sea indemnizable, es indispensable que el mismo lesione un interés legítimo (i.e., tutelado de alguna manera por el derecho) ${ }^{32}$.

\section{a. Generalidades}

En relación a qué daño es indemnizable, es importante tener presente que en esta materia, por expresa remisión legal, "todo daño" es indemnizable. En tal sentido, es perfectamente posible demandar la reparación del daño emergente, lucro cesante y daño moral, siempre y cuando cumplan con los requisitos básicos para que éstos sean indemnizados.

En tal sentido, los siguientes requisitos rigen al daño indemnizable: (i) reparación integral del daño; (ii) certeza; (iii) relación directa con el hecho ilícito; (iv) previsible; (v) debe probarse; (vi) sólo comprenden daños personalmente sufridos por la víctima; y (vii) no debe estar indemnizado ${ }^{33}$.

29. También es posible que se de en sede contractual (v.gr., cláusulas abusivas), en cuyo caso la víctima podrá optar por el régimen de responsabilidad (contractual o extracontractual).

30. CORRAL (2004), p. 137. Citando a: C. Stgo., 5 de junio de 1997, RDJ, t. XCIV, sec. 2a. p. 67.

31. CORRAL (2004), p. 137.

32. CORRAL (2004), pp. 139 y 140.

33. Para más información, ver CORRAL (2004), pp. 141 y ss. 
De todos estos principios, el de certeza es el más complejo, toda vez que determinar la cuantía, y así la medición del excedente del consumidor, es un tema complejo, respecto del cual siempre existirá incertidumbre ${ }^{34} 35$. Por lo anterior, para que efectivamente exista indemnización de perjuicios con base en una infracción a la libre competencia, es fundamental bajar el estándar de certidumbre de los daños.

Al respecto, la Ilustrísima Corte de Apelaciones de Santiago, a propósito del fallo de ETCOM con Telefónica, señaló:

"Por consiguiente, aparece mejor informado, más imparcial, verídico y realista el proporcionado por la actora, del que estos sentenciadores extraerán la pérdida razonable probable de la demandante, aunque siempre en un escenario de razonabilidad y probabilidad, realizando una regulación, en fin, aproximada, suponiendo el curso normal de la actividad mercantil de la afectada y considerando, además, la dificultad en la prueba de lo que se trata, dificultad que, en caso alguno, puede favorecer al autor del ilícito competitivo" ${ }^{36}$.

Todo lo anteriormente dicho tiene aún más sentido si es que uno considera que los métodos de cálculo de los daños indemnizables se basan en informes periciales, presunciones y proyecciones, los cuales, por definición, importan análisis imperfectos y carentes de certeza absoluta.

Todo lo anteriormente dicho tiene aún más sentido si es que uno considera que los métodos de cálculo de los daños indemnizables se basan en informes periciales, presunciones y proyecciones, los cuales, por definición, importan análisis imperfectos y carentes de certeza absoluta.

34. En tal sentido, ETCOM Chile S.A. v. Telefónica Móviles de Chile S.A. (2016). Considerando 15: "La certidumbre del daño, que la doctrina suele señalar como condición de su reparabilidad, debe ser calificada en el caso del lucro cesante, pues rara vez habrá certeza de que el provecho se habría efectivamente producido. Exige aplicar un cálculo probabilístico de su efectiva ocurrencia. El lucro cesante será determinado usualmente por medio de presunciones e informes periciales".

35. En tal sentido, Fiscalía Nacional Económica v. Agrícola Agrosuper, Empresas Ariztía, Agrícola Don Pollo Limitada y la Asociación de Productores Avícolas de Chile A.G. (2014). Considerando 354: "Que, teniendo en cuenta los antecedentes de los tres informes recién mencionados, este Tribunal está consciente de la dificultad de estimar qué habría sucedido en el mercado de productos de pollo en Chile en ausencia de colusión; o, dicho de otra forma, de la imposibilidad de crear un escenario contrafactual satisfactorio, dado que no es posible conocer con certeza de qué manera las Empresas Avícolas Requeridas habrían competido en ausencia de colusión".

36. ETCOM Chile S.A. v. Telefónica Móviles de Chile S.A. (2016). Considerando $18^{\circ}$. En este sentido, nadie puede aprovecharse de su propio dolo. 


\section{b. Métodos de cálculo de los daños indemnizables}

La medición de los perjuicios privados derivados de infracciones a la libre competencia no es un tema sencillo, toda vez que son muchos los factores que influyen y pueden alterar los cálculos de los perjuicios (v.gr., extensión temporal, extensión geográfica, empresas involucradas, productos involucrados, número de dimensiones en colusión, valor del bien final en un componente, asimetría en demandas, etc. ${ }^{37}$. Adicionalmente, la necesidad de construir un contra-factual y la disponibilidad de datos hacen aún más difícil la labor.

A continuación, se describirán los principales métodos que se utilizan, tanto nacional como internacionalmente, para determinar la cuantía de los daños (i.e., el cálculo de los precios, utilidades, costos, etc., que hubiesen existido de no haberse concretado la infracción ${ }^{38}$ ): (i) yardstick method; (ii) before and after method; (iii) market share method; (iv) going concern method; entre otros (v.gr., basado en los costos, basado en el retorno esperado, basado en la predicción de precios y simulación de modelos teóricos).

El yardstick method (mercado de referencia) "se construye sobre la base de comparar el mercado afectado por una práctica anticompetitiva con otro mercado existente, libre de conductas atentatorias a la libre competencia, que tenga características similares al mercado afectado" 39 .

El before and after method implica una simple comparación de precios durante el periodo de la infracción con los precios en el periodo inmediatamente anterior o posterior a la misma, asumiendo que el último ofrezca una aproximación razonable de los niveles de precios en ausencia del ilícito anticompetitivo ${ }^{40}$.

El market share method combina el método yardstick con el before and after para determinar la participación de mercado que tendría la víctima en ausencia del ilícito anticompetitivo ${ }^{41}$.

El going concern method consiste en "asignar un valor a la compañía excluida del mercado, que un comprador razonable habría pagado por ésta con anterioridad a la conducta anticompetitiva. Básicamente utiliza la modalidad de traer a valor presente los flujos futuros sumando, además, el valor de sus activos" ${ }^{42}$.

37. SOTO (2017).

38. WAELBROESCK (2004), pp. 17 y ss.

39. LEWIN (2011), p. 53.

40. WAELBROESCK (2004), pp. 17 y ss.

41. LEWIN (2011), p. 55

42. LEWIN (2011), p. 56. 
Todos estos métodos, si bien no perfectos y concluyentes, permiten obtener un proxy suficiente para estimar el daño ocasionado. Al respecto, dada la especificidad técnica del asunto, si bien informes periciales podrían ser un símil en un procedimiento ante un juez de letras, creemos que el hecho que sea un tribunal especial y colegiado el que conozca de estos temas, como es el Tribunal de Defensa de la Libre Competencia, permitirá un mejor análisis y fundamentación al efecto.

\section{B. Causalidad}

Acreditada la existencia y cuantificado el daño, es necesario acreditar que el mismo se generó, necesariamente, por el ilícito anticompetitivo. En tal sentido, se ha dicho respecto de la causalidad que "[e]ntre el comportamiento voluntario e ilícito del autor y el daño sufrido por la víctima debe existir una relación o nexo. La relación es la 'causa-efecto': el hecho ilícito ha de ser considerado la causa del daño, y el daño el efecto del hecho ilícito"43. En otras palabras, se refiere a la relación directa y necesaria entre el hecho imputable y el daño (a la correspondencia fáctica y normativa del daño a la ocurrencia del ilícito).

Al respecto, en materia de causalidad, es perfectamente aplicable la conditio sine qua non (but for test), debiendo determinarse la situación contra-fáctica consistente en qué habría ocurrido de no haberse cometido la infracción anticompetitiva ${ }^{44}$.

Sin pretender ahondar al respecto, en materia de causalidad ${ }^{45}$ resultará fundamental entender la postura en torno a los siguientes temas: (i) defensa de passing-on; (ii) legitimación activa de los compradores indirectos; y (iii) el efecto paraguas en los casos de colusión.

\section{Jurisprudencia del Tribunal de Defensa de la Libre Competencia bajo la Ley $\mathbf{N}^{\circ} \mathbf{2 0 . 9 4 5}$}

A la fecha, la única demanda de indemnización de perjuicio que ha sido tramitada bajo el nuevo procedimiento es la demanda interpuesta por doña Sandra Fuentes Salazar, Julia Salazar Crane y Marcelo Hernández Sandoval, personas naturales propietarias y administradoras de los activos destinados a la explotación del giro de Línea Azul, en contra de Turbus, Pullman y Cometa.

43. CORRAL (2004), p. 179.

44. BANFI (2014 b.), p. 138.

45. Al efecto, ver BARROS (2010) 
La Demanda Línea Azul se basa en la Sentencia $N^{\circ}$ 134/2014 del Tribunal de Defensa de la Libre Competencia, en virtud de la cual dicho tribunal acoge el requerimiento interpuesto por la Fiscalía Nacional Económica en contra de las Demandadas, declarando que las Demandadas se coludieron para impedir, bloquear o retardar, según corresponda, el acceso a los terminales -y a oficinas dentro de los mismos- de Valparaíso, La Serena, Coquimbo y Carlos Oviedo Cabada de Antofagasta, a actuales o potenciales competidores del mercado de transporte interurbano de pasajeros, infringiendo de esta forma el artículo $3^{\circ}$, letra a) del DL 211.

Productos de los efectos del acuerdo colusorio referido precedentemente, Línea Azul solicitó al Tribunal de Defensa de la Libre Competencia la indemnización de los siguientes perjuicios: (i) daño emergente (i.e., inversiones ejecutadas para desarrollar la estrategia de línea de expansión de Línea Azul); (ii) lucro cesante (i.e., utilidades que, de no haber existido la colusión sancionada, los demandantes habrían percibido al ejecutar la estrategia de expansión de Línea Azul); (iii) daño patrimonial (i.e., deterioro progresivo y significativo de la situación financiera global de Línea Azul producto de la colusión); y (iv) daño moral (i.e., todas aquellas consecuencias dañosas no subsumibles en las categorías anteriores, incluyendo (a) la afectación a la reputación y honorabilidad de las demandantes en materia crediticia frente a acreedores bancarios y no bancarios; y (b) la afectación a la reputación y valor de marca de Línea Azul y a la honorabilidad de sus dueños frente a los consumidores, producto del progresivo cierre de rutas, disminución de frecuencias e imposibilidad de renovar la flota).

En cuanto a la nueva redacción del artículo $30^{\circ}$ del DL 211, fijado por la Ley $\mathrm{N}^{\circ}$ 20.945, resulta interesante resaltar la interpretación que dan los demandantes a las siguientes materias:

(i) Tribunal competente, procedimiento y régimen de recursos: Respecto a la vigencia de la Ley $\mathrm{N}^{\circ}$ 20.945, dada la naturaleza procesal y de orden público de esta norma, se ha de entender que ésta ha comenzado a regir in actum (i.e., desde su publicación en el Diario Oficial $)^{46}$, por lo que, en atención a que la demanda importa una nueva actuación judicial que dará origen a una nueva causa una vez sea notificada la resolución que provea su tramitación, la Demanda Línea Azul debe ser tramitada en conformidad al procedimiento establecido en la Ley $\mathrm{N}^{\circ} \mathbf{2 0 . 9 4 5 .}$

46. Este criterio es consistente con lo establecido en el artículo $24^{\circ}$ de la Ley sobre Efecto Retroactivo de las Leyes, en cuanto a que: "Las leyes concernientes a la substanciación y ritualidad de los juicios prevalecen sobre las anteriores desde el momento en que deben empezar a regir. Por los términos que hubiesen empezado a correr y las actuaciones y diligencias que ya estuvieren iniciadas se regirán por la ley vigente al tiempo de su iniciación". 
(ii) Efecto positivo o prejudicial de la sentencia del Tribunal de Defensa de la Libre Competencia en lo contencioso infraccional: La Historia de la Ley No 20.945 no da cuenta del sentido de suprimir "las conductas" y la "calificación jurídica de los mismos" en su nuevo texto. En tal sentido, las demandantes son de la opinión que, de no presumirse la culpa o dolo con base en la sentencia infraccional, debiendo al efecto probarse la culpa o dolo de las Demandadas, sería contrario (a) al espíritu general del legislador en la reforma al artículo $30^{\circ}$ en comento, cual fue, facilitar la posibilidad de compensación a las víctimas y (b) a la efectividad misma del derecho de la competencia aplicado por impulso privado.

(iii) Valoración de la prueba: La referencia a la sana crítica importa la manifestación del legislador de otorgar mayor libertad al Tribunal de Defensa de la Libre Competencia en la apreciación de los elementos probatorios al determinar el establecimiento de supuestos de la reparación como la causalidad, el daño indemnizable y su monto.

(iv) Extensión de la reparación: A juicio de las demandantes, lo buscado con la nueva redacción era que, independiente de la extensión de la duración de la infracción, todos los daños causados por ella habrían de ser reparados. Al efecto, hacen presente que la Historia de la Ley $\mathrm{N}^{\circ} 20.945$ no buscó limitar la extensión de la reparación en relación a lo que previamente podían reclamar los demandantes y verse los demandados obligados a responder.

(v) Acciones civiles emanadas del ilícito penal de colusión: Las demandantes indican que el legislador buscó evitar la duplicidad de procedimientos civiles indemnizatorios que tuvieran por antecedente los mismos hechos.

En las contestaciones, las Demandadas se defienden señalando, entre otras cosas, que: (i) la Demanda Línea Azul extiende artificialmente los efectos de la Sentencia $\mathrm{N}^{\circ}$ 134/2014 del Tribunal de Defensa de la Libre Competencia a circunstancias y efectos ajenos a la mismas; (ii) los daños e infortunios empresariales descritos en la Demanda Línea Azul provinieron de sus propios actos o de terceros, pero no de una conducta sancionada en la Sentencia $N^{\circ} 134 / 2014$; (iii) no concurren en la especie los requisitos de procedencia de indemnización de perjuicios por ilícitos anticompetitivos que se reclama; y (iv) las partidas indemnizatorias que se reclaman no cumplen con los requisitos de la responsabilidad extracontractual.

Si bien el citado juicio terminó por desistimiento y acuerdo conciliatorio, en el proceso se dejó constancia de las siguientes consideraciones que serán útiles para futuros juicios de indemnización de perjuicio, a saber:

(i) Según consta en la resolución de fecha 3 de diciembre de 2018, que accede a la reposición del auto de prueba, el daño debe probarse respecto de cada una de las demandantes que haya sufrido el daño que se solicita indemnizar, no constituyendo entre sí una especie de solidaridad activa; y 
(ii) Según consta en el auto de prueba, los daños reparables son aquellos comunes en materia de responsabilidad, a saber: daño emergente, lucro cesante y daño moral ${ }^{47}$. De este modo, se confirma que otros conceptos de daños, como es el daño patrimonial, no corresponden a una categoría distinta de daños.

\section{Relación entre libre competencia y otros cuerpos normativos, en materia de indemnización de perjuicios}

Finalmente, un tema relevante a considerar es el hecho de que, en la actualidad, existen diversos cuerpos normativos que regulan la indemnización de perjuicios por ilícitos anticompetitivos. Lo anterior, toda vez que dichos cuerpos normativos protegen bienes jurídicos distintos.

En primer lugar está el DL 211, que según se analizó, faculta al Tribunal de Defensa de la Libre Competencia para conocer de las acciones de indemnización de perjuicios una vez que se declare la ilicitud de una conducta y, por tanto, exista sentencia condenatoria firme y ejecutoriada ${ }^{48}$.

En segundo lugar está la Ley $\mathrm{N}^{\circ}$ 19.496, que en su artículo $3^{\circ}$, letra e) señala como derecho básico del consumidor: "El derecho a la reparación e indemnización adecuada y oportuna de todos los daños materiales y morales en caso de incumplimiento de cualquiera de las obligaciones contraídas por el proveedor, y el deber de accionar de acuerdo a los medios que la ley le franquea".

Tomando en consideración que la infracción al DL 211 no necesariamente constituye una infracción a la Ley $\mathrm{N}^{\circ} \mathbf{1 9 . 4 9 6}$, la sustancia de dichos procesos puede ser distinta, toda vez que en el segundo caso se debiese acreditar la existencia de una infracción a dicha ley.

En tal sentido, si bien podría resultar poco conveniente, nada impide que se interponga una "demanda [individual,] colectiva o acción de clases que, por unos mismos hechos, puedan ser presentadas ante [los] tribunales civiles o (luego de una sentencia condenatoria en libre competencia) ante el [Tribunal de Defensa de la Libre Competencia]" ${ }^{49}$.

Por último, la Ley $\mathrm{N}^{\circ} 20.169$, en su artículo $5^{\circ}$, letra d), reconoce el derecho de un competidor para interponer la "[a]cción de indemnización de perjuicios ocasionados por el acto, sujeta a las disposiciones del Título XXXV del Libro IV del Código Civil”. $\mathrm{Al}$ respecto, se debe tener presente que nada impide que una conducta sea calificada como un acto de competencia desleal, aunque respecto de la misma conducta resul

47. En tal sentido, el auto de prueba deja en evidencia que es necesario acreditar la efectividad de cada uno de los daños.

48. Ver supra.

49. COMISIÓN DE ESTUDIO NUEVA CODIFICACIÓN COMERCIAL (2017), pp. 20-21. 
ten procedentes acciones como las reguladas en el DL 211. En tal sentido, existe más de un tribunal competente para conocer de una pluralidad de acciones reguladas tanto en el DL 211 como en la Ley No 20.169.

Tal como señala la Comisión de Estudio para una Nueva Codificación Comercial en su informe de la Séptima Subcomisión, existen varios problemas que emanan de los vínculos y superposición entre el DL 211 y la Ley No 20.169: "Primero, no resulta claro si dichas acciones se pueden ejercer conjunta y paralelamente (...) o si pueden ejercerse secuencialmente una acción en pos de otra (...). Segundo, en el caso que se pueda ejercer sucesivamente (...) tampoco resulta claro si el ejercicio de una acción interrumpe la prescripción de las demás acciones de competencia desleal (...). Tercero, y relacionado a lo anterior, se puede generar un punto de conflicto respecto de la posibilidad de que existan decisiones contradictorias o si la declaración de un tribunal tiene fuerza de cosa juzgada respecto de otros" ${ }^{50}$.

\section{Conclusiones}

Con base en todo lo desarrollado, somos de la opinión que la modificación al artículo $30^{\circ}$ del DL 211 va a ser positiva para el régimen de indemnización de perjuicios por infracciones a la libre competencia. Si bien a la fecha existe sólo un caso, cuyo modo de término no permite sacar conclusiones definitivas en torno a la forma en que finalmente se interpretará y aplicará el artículo $30^{\circ}$ del DL 211, creemos que el Tribunal de Defensa de la Libre Competencia es un tribunal profesional y capacitado para conocer de este tipo de materia.

$\mathrm{Al}$ efecto, con base en un principio de eficiencia, propio del área en comento, el hecho que sea el Tribunal de Defensa de la Libre Competencia el que, tras un análisis previo en sede infraccional, se pronuncie en torno a la procedencia o no de una indemnización particular, es un gran avance en cuanto al procedimiento. Adicionalmente, dado el aspecto técnico de la materia y la utilización de diversos mecanismos de avaluación de daños anticompetitivos, creemos que la composición del Tribunal de Defensa de la Libre Competencia es la más adecuada para pronunciarse apropiadamente en torno al fondo del tema.

En cuanto a las críticas esbozadas durante la tramitación de la Historia de la Ley $\mathrm{N}^{\circ}$ 20.945, no vemos inconvenientes en que un tribunal técnico, como es el Tribunal de Defensa de la Libre Competencia, conozca de asuntos de derecho general, como es la indemnización de perjuicios. La composición del tribunal facilita que sea un tribunal colegiado el que conozca de la materia, entregando mayores garantías al sistema que las que hasta antes de la modificación no estaban presentes. Además, existen los recursos propios de la materia, los cuales permitirán emendar errores de las decisiones del Tribunal de Defensa de la Libre Competencia, de existir.

50. COMISIÓN DE ESTUDIO NUEVA CODIFICACIÓN COMERCIAL (2017), p. 18. 
El presente trabajo ha dejado en evidencia la forma en que probablemente ha de abordarse los nuevos temas que dejó la actual redacción del artículo 30 del DL 211. Al respecto, estamos expectantes a ver cómo la jurisprudencia interpretará y aplicará la ley.

Sin lugar a dudas el desafío es grande, pero no es de extrañar que el Tribunal de Defensa de la Libre Competencia actuará con el profesionalismo y dedicación que le ha caracterizado hasta esta fecha.

\section{Referencias bibliográficas}

ABELIUK, René (2001): Las Obligaciones (Santiago, Editorial Jurídica de Chile, Tomo II, quinta edición).

ALESSANDRI, Arturo (1943): De la responsabilidad extracontractual en el derecho chileno (Santiago, Imprenta Universitaria).

ARAYA, Fernando (2005): "Daño anticompetitivo y daño indemnizable: un ensayo de confrontación”, Revista Chilena de Derecho Privado, No 4. pp. 9-32.

BANFI, Cristián (2014 a.): “Acerca de la Imputación de Responsabilidad Civil por Ilícitos Anticompetitivos entre Rivales en Chile", Revista Chilena de Derecho. volumen 41, $\mathrm{N}^{\circ}$ 1. pp. 37-58.

BANFI, Cristián (2014 b.): "Daños por ilícitos anticompetitivos en Tabacaleras", Revista de Derecho de Valdivia, volumen 27, No 2. pp. 133-145.

BARROS, Enrique (2010): Tratado de Responsabilidad Extracontractual (Santiago, Editorial Jurídica de Chile).

COMISIÓN DE ESTUDIO NUEVA CODIFICACIÓN COMERCIAL (2017): "Informe Séptima Subcomisión: Derecho de la Competencia y Derecho del Consumidor". Disponible en: <http://codificacioncomercial.cl/wp-content/uploads/2017/o5/ Informe-Preliminar-7Subcomision.pdf. $>$. [Fecha de consulta: 02 de diciembre de 2017].

CORRAL, Hernán (2004): Lecciones de Responsabilidad Civil Extracontractual (Santiago, Editorial Jurídica de Chile).

Historia de la Ley N¹9.911 (2003). "Segundo Trámite Constitucional. Discusión en Sala. Diario de Sesión en Sesión 81. Legislatura 348”. Disponible en: <https://www. bcn.cl/historiadelaley/nc/historia-de-la-ley/5814/>. [Fecha de consulta: 02 de diciembre de 2017].

Historia de la Ley N²0.945 (2015). “Oficio 124-2015”. Disponible en: <https://www. bcn.cl/historiadelaley/nc/historia-de-la-ley/5311/>. [Fecha de consulta: 02 de diciembre de 2017]. 
Historia de la Ley $\mathrm{N}^{\circ} 20.945$ (2015). "Primer Trámite Constitucional: Cámara de Diputados. Informe Comisión Economía". Disponible en: <https://www.bcn.cl/historiadelaley/nc/historia-de-la-ley/5311/>. [Fecha de consulta: 02 de diciembre de 2017].

LEWIN, Nicolás (2011): "Indemnización de perjuicios por atentados a la libre competencia: el daño anticompetitivo, su relación con el daño civil y la determinación de los perjuicios", Revista Anales Derecho UC, No 6. pp. 43-62.

SOTO, Raimundo. XII Jornada de Libre Competencia (2017). "La indemnización de perjuicios por infracciones a la Libre Competencia. ¿Son demostrables, medibles e identificables los perjuicios privados por infracciones a la libre competencia en la prueba pericial?".

VALDÉS, Domingo (2006): Libre Competencia y Monopolio (Santiago, Editorial Jurídica de Chile).

WAELBROESCK, Denis et al. (2004). "Study on the conditions of claims for damages in case of infringement of EC competition rules". Disponible en: <http://ec.europa. eu/competition/antitrust/actionsdamages/comparative_report_clean_en.pdf $>$. [Fecha de consulta: 02 de diciembre de 2017].

\section{Jurisprudencia citada}

Demanda de Sandra Fuentes Salazar y otros contra Empresa de Transporte Rurales Limitada y otros (2017): Tribunal de Defensa de la Libre Competencia, 5 de diciembre de 2017 (demanda por indemnización de perjuicios rol CIP 1-17); y 3 de diciembre de 2018 (resolución que recibe la causa a prueba rol CIP 1-17). Disponibles en: <https://consultas.tdlc.cl/do_search?proc=8\&idCausa=42093 $>$. [Fecha de consulta 23 de marzo de 2019].

ETCOM Chile S.A. v. Telefónica Móviles de Chile S.A. (2016): Ilustrísima Corte de Apelaciones de Santiago, 7 de abril de 2016 (demanda de indemnización de perjuicios rol No 9.666-2015). Disponible en: <http://corte.poderjudicial.cl/SITCORTEPORWEB/DownloadFile.do?TIP_Documento $=3 \&$ TIP_Archivo $=1 \&$ COD_ Opcion $=1 \&$ COD_Corte $=90 \& C R R \_I d T r a m i t e=14746825 \& C R R \_I d D o c u m e n-$ to=13219099>. [Fecha de consulta: 27 de marzo de 2018].

Fiscalía Nacional Económica v. Agrícola Agrosuper, Empresas Ariztía, Agrícola Don Pollo Limitada y la Asociación de Productores Avícolas de Chile A.G (2014): Tribunal de Defensa de la Libre Competencia, 25 de septiembre de 2014 (requerimiento por infracción a la libre competencia rol C-N $\left.{ }^{\circ} 236-11\right)$. Disponible en: <http:// www.tdlc.cl/tdlc/wp-content/uploads/sentencias/Sentencia_139\%20_2014.pdf>. [Fecha de consulta: 27 de marzo de 2018]. 
Philip Morris Chile Comercializadora Limitada con Compañia Chilena de Tabacos S.A. (2013): $10^{\circ}$ Juzgado Civil de Santiago, 25 de enero de 2010 (acción indemnizatoria por infracción del DL 211 rol 19.655-2009); Corte de Apelaciones de Santiago, 8 de noviembre de 2011 (recursos de casación en la forma y de apelación rol 1.5202010); y Corte Suprema, 25 de julio de 2013 (recursos de casación en la forma y en el fondo rol 1.339-2012). Disponibles en: <www.poderjudicial.cl $>$. [Fecha de consulta 23 de marzo de 2019]. 


\title{
Los diputados chilenos y la despenalización del aborto: una aproximación desde el análisis crítico del discurso
}

\author{
The Chilean deputies and the decriminalization of abortion: an approach from \\ the critical analysis of discourse
}

\author{
Lina Maritza Camacho Lucio ${ }^{1}$ \\ Universidad de las Américas (UDLA), Quito, Ecuador
}

\begin{abstract}
RESUMEN En este artículo se analizan treinta y cuatro discursos de los diputados chilenos, durante la sesión número cincuenta, celebrada el 20 de julio de 2017 , en la cual se debatió el proyecto de ley originado en mensaje que regula la despenalización de la interrupción voluntaria del embarazo en tres causales. Las intervenciones de los legisladores se entienden como un tipo de comportamiento legislativo que es prominente para observar las posiciones ideológicas sobre los intereses de las mujeres. Por medio de una escala simple que evalúa el contenido de las intervenciones se ubica a cada diputado en un eje horizontal, el cual expresa el espectro ideológico de los partidos políticos, izquierda-derecha, y el segundo del espectro discursivo, control-autonomía de las mujeres en la decisión de abortar. Los hallazgos indican que los discursos de los legisladores son coherentes con la posición ideológica del partido al que se adscriben. El artículo también demuestra que las legisladoras chilenas a la hora de representar los intereses de género como el aborto actúan según la plataforma ideológica del partido y no por las experiencias compartidas de género.
\end{abstract}

1. Magíster en Ciencias Sociales con mención en estudios de género, Candidata a magíster de Investigación en Política Comparada, por la FLACSO- Ecuador. Docente a tiempo completo en la Facultad de Formación General, Escuela de Humanidades, Universidad de las Américas, Quito, Ecuador. Mail: lina.camacho@udla.edu.ec 
PALABRAS CLAVE Representación sustantiva, género, interrupción del embarazo, discurso, Chile.

ABSTRACT This article analyzes thirty-four speeches by Chilean deputies during the 5oth session that was celebrated on July 2oth, 2017. In that session, the topic was the decriminalization of pregnancy voluntary termination in three causes. The legislators' interventions are understood as a type of legislative behavior that it is prominent in order to observe ideological positions about woman interests. The deputies` speeches were placed in a horizontal axis through a simple scale that evaluate the content of the interventions. This axis express ideological spectrum and discursive spectrum. The findings indicate that the legislators' discourses (women and men) are consistent with the ideological position of the party which they are members. The article also proves that Chilean legislators acting according to the ideological platform of the party, but not on their own gender experiences when representing gender interests such as abortion.

KEYWORDS Substantive representation, gender, interruption of pregnancy, speech, Chile.

\section{Introducción ${ }^{2}$}

Los legisladores tienen muchas formas de representar sustantivamente los intereses de género, por ejemplo, presentar proyectos de ley vinculados a los temas que inciden en la vida de las mujeres, votar por las iniciativas que cierren las brechas de género e intervenir durante los debates en los que se discuten los proyectos de ley que incorporan preocupaciones que se derivan de la larga historia de desigualdad entre hombres y mujeres en la sociedad ${ }^{3}$. Los intereses de las mujeres corresponden a contextos específicos, varían en espacio y tiempo, pueden coincidir en otros países por efecto de difusión de ideas y son los temas que los movimientos feministas, en determinados momentos, ponen en la opinión pública ${ }^{4}$, entre esos temas se encuentra el aborto.

2. La autora agradece los comentarios de Alejandro Olivares L. y el grupo de trabajo en Mujeres y Política de la Asociación Ecuatoriana de Ciencia Política (AECIP).

3. SCHWIND-BAYER (2011).

4. SCHWINDT-BAYER (2014); CELIS (2008). 
Una parte importante de la investigación sobre la representación sustantiva de las mujeres se enfoca fundamentalmente en la presentación de iniciativas legislativas, son estudios que se interesan por observar el número de proyectos de ley que responden a los intereses de género, desagregan las características de los proponentes como el sexo y el partido político de los legisladores 5 . Otros estudios analizan cuánto de las propuestas de legislación a favor de los intereses de las mujeres son sancionadas como ley ${ }^{6}$. Igualmente, la literatura observa los temas en los que las legisladoras se interesan en comparación con sus colegas hombres ${ }^{7}$ y si la presencia de las mujeres hace una diferencia en términos de promover los derechos de las mujeres ${ }^{8}$.

La intervención de los legisladores durante los debates en los que se discuten los proyectos de ley es un tema poco estudiado en los países latinoamericanos, en comparación con el tipo de estudios mencionados anteriormente. Los estudios precedentes son aplicados al contexto de Estados Unidos y países europeos ${ }^{9}$. La investigación precedente analiza todos los discursos sobre políticas presentados por los cien senadores norteamericanos en un año y encontraron que las senadoras hablan más sobre temas de política con relevancia directa para las mujeres. En cuanto al tema del aborto en particular, el mismo estudio demostró que no existen diferencias significativas en el porcentaje de discursos pronunciados por los hombres y las mujeres en el Senado, pero sí hay diferencias en temas tales como los delitos relacionados con la mujer, problemas de salud de la mujer y problemas familiares de la mujer ${ }^{10}$.

La intervención discursiva como una forma de observar el concepto de representación sustantiva ${ }^{11}$ es una perspectiva innovadora porque este tipo de representación usualmente es observada a partir del número de proyectos de ley presentados a favor de los intereses de las mujeres. Aunque estos análisis nos han brindado conocimientos importantes sobre la actuación de los legisladores frente a los temas de género, dejan por fuera aspectos sustanciales tales como la orientación de sus discursos y la posición ideológica frente a iniciativas valóricas. El discurso es entendido como la expresión de un sistema de creencias común, que puede ser compartido por los miembros de los partidos políticos, es el principio organizador y da forma a las opiniones de los individuos sobre temas específicos. Clasificar las intervenciones de los congresistas es una herramienta analítica para ver si la ideología restringe el discurso político $^{12}$.

5. PISCOPO (2014).

6. SWERS (2002).

7. PISCOPO (2010); SWERS (2016).

8. FRANCESCHET (2011).

9. CELIS Y HOGESCHOOL (2006).

10. OSBORN Y MOREHOUSE (2010).

11. PITKIN (1967).

12. YU ET AL (2008). 
En concordancia con lo mencionado, cabe recordar que, en Chile, el aborto fue legal, con fines terapéuticos, desde las reformas al código de salud en 1931, durante el gobierno Carlos Ibáñez, hasta 1989. En la fase final de la dictadura de Augusto Pinochet, se prohibió bajo cualquier circunstancia en la ley 18.886. En los primeros años del retorno de la democracia los diputados del Partido Socialista y el Partido por la Democracia intentaron poner en el debate la despenalización, con poco éxito, pues la iniciativa legislativa fue archivada. Eso no quiere decir que el tema en cuestión haya sido ignorado por los legisladores de la primera década de la democracia. La mayor parte de la actividad legislativa sobre el aborto en Chile, fue iniciativa de los partidos políticos de derecha que buscaban, extender las penas de prisión por delitos contra la vida del no nacido ${ }^{13}$. Desde 1991 hasta 2018, se presentaron 32 iniciativas legislativas. El 59,38\% de las propuestas fueron archivadas, el 9.38\% rechazadas y el $28.23 \%$ se encuentran en tramitación. Una iniciativa, que se refiere al $3 \%$ de la legislación cuenta como ley. En cuanto a la Cámara de origen el $56,25 \%$ de los proyectos se iniciaron en la Cámara de Diputados, el 40.63\% por la Cámara del Senado y 3.12\% por el Poder Ejecutivo. En cuanto al sexo de los principales impulsores de los proyectos que abordan el tema en cuestión el $71.88 \%$ eran hombres y el $28.13 \%$ eran encabezadas por mujeres.

\section{El camino de las iniciativas legislativas en torno al aborto en Chile}

La historia legislativa de la despenalización del aborto en Chile puede concebirse en tres etapas críticas. La primera etapa es el intento de los diputados de partidos políticos de izquierda, en el primer año del retorno a la democracia, por modificar el artículo 119 Código Sanitario en lo relativo al aborto terapéutico. En ese momento se propuso despenalizar el aborto en condiciones excepcionales como riesgo para la vida de la madre o deformidad de la criatura. El proyecto fue archivado. La segunda etapa de la historia legislativa ocurrió cuando los diputados y senadores de los partidos políticos de derecha presentaron proyectos de carácter restrictivo. Desde 1994 hasta 2002 la derecha chilena se movilizó con el fin de modificar el código penal y ampliar las penas a terceros que produjeran un aborto o a la mujer que lo causare. En el contenido de las iniciativas en el segundo periodo de la historia legislativa restrictiva los legisladores se oponían a los derechos de la madre. Los diputados y senadores de la UDI sobrepusieron los derechos del no nacido como la bandera enarbolada para defender la vida desde la concepción.

En 2003, después de tres iniciativas con miras a garantizar la vida desde la concepción, se lleva de nuevo a la escena legislativa el proyecto de ley que proponía modificar el artículo 119 del Código Sanitario en lo relativo al aborto terapéutico. Sin embar

13. HTUN (2003) 
go, la acción de los miembros de partidos políticos de derecha no se hizo esperar. De la misma forma que en los años noventa, la derecha presentó iniciativas restrictivas como erigir monumentos en memoria de las víctimas de aborto. En el contenido de sus proyectos el aborto significaba un atentado a la vida humana en cualquiera de sus formas y apostaban por la defensa de la vida del que está por nacer. En esta fase, se presentaron propuestas de elevar el quorum para la despenalización del aborto $\mathrm{u}$ otras limitaciones tales como imponer la reforma constitucional como único mecanismo para derogar el delito del aborto, entendido así en esa época. En esta misma etapa, se presentaron otras iniciativas de carácter restrictivo para desincentivar la interrupción del embarazo y con la intensión de incorporar una figura penal de lesiones al feto como tipo delictivo doloso y culposo en medio o procedimiento distinto a las labores de parto.

En 2006 se propone despenalizar el aborto en tres causales: peligro para la vida de la madre, grave deterioro o malformación incompatibles para la vida del feto o violación. La iniciativa fue presentada por el senador Nelson Ávila Contreras del Partido Radical. De nuevo los partidarios de la derecha no tardaron en responder reanimando un proyecto para erigir monumentos a las víctimas inocentes de aborto (proyecto de ley 4818). Sin embargo, a partir de 2006, se da un giro en cuanto a la producción de proyectos de ley de carácter amplio. A partir del año mencionado anteriormente, numerosas iniciativas proponían despenalizar el aborto y ampliar los derechos de las mujeres. Entre los proyectos de esta fase se encuentra el de la senadora de la Renovación Nacional Evelyn Matthei y el senador del Partido Socialista Fulvio Rossi, juntos presentaron un proyecto para despenalizar la interrupción del embarazo por razones médicas, asimismo, los senadores propusieron delimitar el concepto de aborto y excluir de la definición, la muerte del feto como consecuencia de una intervención, tratamiento o administración de un fármaco para salvar la vida de la madre lo cual debía certificarse por un grupo de tres médicos.

La tercera etapa se da cuando en 2015 vía mensaje del Poder Ejecutivo se inicia el trámite del proyecto de ley número 9895 tendiente a despenalizar del aborto en tres causales, modificar del código sanitario, el código penal en lo constituyente al delito de aborto y el código procesal penal. A partir de este momento, 2015 hasta 2018, el número de iniciativas de carácter amplio se incrementaban. Se trata de una coyuntura que creó las condiciones para que los diputados de partidos políticos de izquierda y centro derecha iniciaron legislación con miras a ampliar los derechos de las mujeres. Se propuso regular la objeción de conciencia en los servicios de salud, asegurar los pagos del Ministerio de Salud a las instituciones prestadoras de este servicio por atenciones a pacientes afiliadas independientemente de la modalidad de contrato que haya suscrito el Estado con la institución de salud, ampliar el derecho de aborto después de las 14 semanadas de gestación y regular, garantizar y promover los derechos 
de la mujer en el ámbito del aborto. Todas las iniciativas presentadas después de 2015 se encuentran en trámite y durante esta etapa la UDI no ha intentado influir de manera restrictiva sobre el aborto.

A modo de resumen, en el primer periodo, la izquierda chilena se propuso ampliar los derechos de las mujeres para decidir sobre continuar o no con el proceso de gestación humana. Eso marcó el derrotero de lo que serían las ideas de los legisladores con una posición favorable a la autonomía de las mujeres para interrumpir el embarazo. Los miembros de partidos políticos de la UDI también marcaron el camino por más de dieciocho años en los que por encima de los derechos de la madre estaban los del no nacido, su objetivo primordial era promover el derecho a la vida desde la concepción. Algunos miembros de la Renovación Nacional, marcaron, durante el periodo analizado, posturas variadas con respecto a la interrupción del embarazo en caso de riesgo de vida para la madre. Los diputados Arturo Logton Guerrero, Osvaldo Palma Flores y Carmen Ibáñez Soto, apoyaron el proyecto de ley número 3197 de 2003 que modificaba el artículo 119 de Código Sanitario en lo relativo al aborto terapéutico. La Exsenadora Evelyn Matthei presentó un proyecto que daba luz verde a la interrupción del embarazo en caso del riesgo de la vida de la madre. Los diputados Francisco Chahuán y Roberto Sepúlveda en 2006 intentaron extender las penas por delito de aborto y en 2007 promovieron una iniciativa para erigir monumentos a las víctimas inocentes de aborto.

En el contexto legislativo chileno de los últimos veinte años los representantes de partidos políticos de izquierda y derecha han marcado posturas polarizadas en torno al aborto, mientras que los miembros de partidos de centro derecha como la Renovación Nacional (RN) postulan ideas variadas en torno a este tema en coherencia con las divisiones conservadoras y liberales dentro del mismo partido ${ }^{14} \mathrm{y}$ por tratarse de un partido poco estructurado ${ }^{15}$. Ocurre algo similar con la Democracia Cristiana (DC), algunos de sus miembros apoyaron iniciativas tanto de carácter restrictivo, entre ellas un proyecto que pretendía tipificar el delito de lesiones al ser humano en gestación, como de carácter amplio las cuales intentaban modificar el código penal y despenalizar el aborto en tres causales en 2013.

En el contexto regional, el camino trazado por la legislatura chilena es diferente en comparación con países que retornaron al cauce democrático. En Uruguay la legislación anterior al restablecimiento de la democracia, 1933, posibilitaba que las mujeres abortaran en las 12 semanas en condiciones de riesgo para la salud y vida de la madre, embarazo por consecuencia de una violación; penuria económica u honor; el aborto debía llevarse a cabo por un médico ${ }^{16}$. No obstante, la penalización del aborto ocurrió

14. DÍAZ (2016).

15. LUNA Y RUIZ (2014).

16. BALTAR DA ROCHA, ROSTAGNOL Y GUTIÉRREZ (2009). 
en 1938. Con el restablecimiento de la democracia, se presentaron 6 propuestas de ley entre 1985 y 2007 con el fin de despenalizar la interrupción del embarazo, la primera iniciativa estuvo en manos de miembros del Partido Colorado quienes intentaron despenalizar el aborto sin restricciones y con el consentimiento de la mujer. En el análisis del contenido de la legislación uruguaya las intenciones de los legisladores en principio eran menos restrictivas ${ }^{17}$ en comparación con el caso chileno. Los legisladores empezaron por proponer la despenalización del embarazo sin restricciones, pero a medida del desarrollo del periodo democrático los representantes uruguayos se propusieron disminuir las opciones de despenalización, se encontraron con el veto parcial del Poder Ejecutivo en 2008 y en 2012 se aprueba la interrupción del embarazo en las primeras 12 semanas de gestación. El contexto de Chile y Uruguay dan cuenta que el retorno a la democracia no constituye una inmediata condición suficiente para abrir el paso a las libertades de las mujeres, por el contrario, el aborto se enfrenta a largos debates legislativos para su consideración y puede encontrarse o no con oportunidades políticas para su aprobación.

El propósito de este artículo es ubicar los discursos de los diputados en un eje horizontal, que expresa tanto la posición ideológica del partido político y como el tipo de discurso que producen sobre el aborto. Se puede esperar que las legisladoras respondan a las estructuras partidistas y el contenido de sus discursos reforzará dicha posición. La actuación en búsqueda de los intereses de género está mediada por las características del partido político al que pertenecen los diputados, por lo tanto, la representación sustantiva o no de la agenda de género, en la cual la despenalización del aborto se encuentra, estará influenciada por las posiciones ideológicas y la evaluación de los discursos confirmará dichas posiciones. El camino que ha seguido las posturas de los legisladores de los distintos partidos chilenos enmarcadas en el contenido de los proyectos de ley, indican que el discurso de la UDI mantendrá una posición ideológica coherente con los principios del derecho a la vida del feto, mientras que los partidarios de la izquierda se ubicarán en el extremo de la autonomía de las mujeres. Los partidos de centro derecha y centro izquierda son proclives a emitir discursos que se ubican en cualquiera de los extremos.

\section{Análisis del discurso y representación sustantiva}

El discurso es una aproximación empírica a la representación sustantiva porque el debate en la sala y el discurso entre los senadores -o diputados- son una parte sustancial de la actividad legislativa que desempeñan ${ }^{18}$ y tienen el potencial de ser una forma importante de toma de decisión. En este contexto, el presente trabajo analiza los discursos de los diputados chilenos sobre la despenalización del aborto. Este caso

17. JOHNSON (2011).

18. OSBORN Y MOREHOUSE (2010). 
es relevante, por varios motivos. Primero, porque permite ver la representación sustantiva en un momento donde el porcentaje escaños de mujeres es el más alto en el sistema binominal chileno. Segundo, las intervenciones de los legisladores pueden ser un buen proxy para identificar sus posiciones sobre los temas de las mujeres. En cuanto a estas posiciones, se espera que las diputadas actúen en beneficio de las iniciativas que abordan los intereses de las mujeres por las experiencias compartidas de género, otro posible resultado es que la plataforma ideológica del partido y no el género de los legisladores media la acción a favor o en contra de las medidas que afectan la vida de las mujeres. En el desarrollo del trabajo se analiza si el discurso de los diputados y en especial el de las diputadas se sitúa en los elementos discursivos esperados de acuerdo a la ideología del partido.

En la literatura varios análisis han comprobado que los legisladores de derecha suelen promover intereses de género conservadores ${ }^{19}$. Se espera entonces que los contenidos de sus intervenciones estén orientados al tipo de discurso que restringe la autonomía de las mujeres. El control es una forma de expresión del poder que se ejerce sobre los individuos bajo la forma de vigilancia individual y continua ${ }^{20}$. Está asociada al castigo y la recompensa, es decir, de la formación y la transformación de los individuos en función de ciertas normas ${ }^{21}$. Algunos estudios también demuestran que los partidos políticos de izquierda favorecen las iniciativas de género ${ }^{22}$. Las intervenciones de los legisladores con esta ideología tienden a ubicarse en discursos que promueven la autonomía, se opone al control, deposita la decisión en el individuo o no en un agente externo que puede determinar su comportamiento o restar la posibilidad de tomar una decisión por sí mismo. Por otra parte, se plantea la expectativa de encontrar discursos que se ubican en medio de los extremos autonomía control, los cuales son considerados como intervenciones mixtas, ligadas a partidos políticos de centro.

Desde esta perspectiva, los trabajos que relacionan el discurso sobre la representación sustantiva de las mujeres con el partido político de los legisladores, se discute si el discurso de los legisladores sobre los intereses de las mujeres debe agruparse por sexo, afiliación partidista o a partir del conjunto de esas dos dimensiones. Cuando se analiza el discurso por sexo del legislador se espera que las experiencias de género faciliten una definición específica de los intereses de las mujeres, por lo tanto, las mujeres en la política se interesan en representar sustantivamente a otras mujeres por su experiencia de género compartidas ${ }^{23}$. Por otra parte, el partido político es predic

19. TAM (2017); EVANS (2012).

20. FOUCAULT (1994).

21. FOUCAULT (1994) P, 606.

22. Op. cit., p 9.

23. XYDIAS (2012), P 3-4. 
tor dominante del comportamiento y las preferencias de los legisladores, son la base ideológica sobre la cual ellos hablan. Las investigaciones tienden a tomar por separado las dimensiones sexo y partido político del legislador, sin embargo, la propuesta de Cristina Xydias demuestra que las concepciones de los legisladores están marcadas tanto por el sexo como por la afiliación partidista "es probable que las legisladoras compartan un sentido de urgencia sobre la brecha de género, pero las políticas que aprueban para abordar esa brecha son variadas" ${ }^{24}$. Por ejemplo, las mujeres demócratas son más propensas a defender los intereses de género feministas en comparación con sus colegas del partido republicano ${ }^{25}$. De esta manera, tanto las mujeres conservadoras como feministas son representantes legitimas de las mujeres, pero difieren en lo que hablan de lo mejor para las mujeres según su filiación partidista ${ }^{26}$.

La posición ideológica de los partidos políticos puede observarse a través de los electores $^{27}$, de los legisladores del partido ${ }^{28}$, a través de la definición de izquierda- derecha de los electores y los expertos en partidos políticos ${ }^{29}$, a partir de la congruencia entre la posición ideológica de los partidos y sus simpatizantes ${ }^{30}$. En el presente artículo, se retoma el posicionamiento ideológico de los legisladores y no de sus electores. La denominación ideológica de los partidos políticos ha tenido una gran discusión en la investigación reciente, porque estas organizaciones se renuevan y adaptan de forma estratégica a lo largo del tiempo. A pesar de la limitación que presenta el estudio de la ideología de los partidos políticos, los análisis que existen se enfocan sobre todo en la dimensión económica de la ideología partidista y dejan de lado la dimensión valórica. Para ubicar a los partidos políticos chilenos en el continuum izquierda derecha se recurre a los datos del Proyecto de Elites Parlamentarias de la Universidad de Salamanca.

Aunque la ideología de los partidos políticos mayoritarios en Chile presenta características especiales. La Unión Demócrata Independiente (UDI) es un partido excepcional, sus diputados se orientan fuertemente hacia el partido con un alto nivel de disciplina y homogeneidad interna en comparación con los otros partidos con presencia en el Congreso chileno. La Democracia Cristiana (DC), siguiendo a los estudios precedentes, es un partido de centro que tiene un enfoque altamente programático. La Renovación Nacional (RN) es poco estructurado. El Partido Socialista (PS),

24. Op, cit., 10.

25. SWERS (2002).

26. Op cit., 10.

27. ZECHMEISTER Y CORRAL (2010); COLOMER Y ESCATEL (2005).

28. ALCÁNTARA (2003).

29. GONZÁLEZ Y QUEIROLO (2013).

30. TRAK (2015). 
según Luna y Ruiz es un partido con un discurso tradicional de las izquierdas y opera mediante consenso ${ }^{31}$.

\section{Metodología y datos}

Los datos para este estudio fueron los discursos dados por treinta y cuatro diputados en la Cámara Baja de Chile durante la sesión número cincuenta, en la cual se discutió el proyecto de ley, iniciado por el ejecutivo, mediante el cual se despenalizó la interrupción voluntaria del embarazo en tres causales. Aunque la Cámara de Diputados está compuesta por 120 miembros, el número de observaciones corresponde a las intervenciones que se dieron durante el debate en mención. La variable dependiente son los tipos de discursos de los legisladores sobre la despenalización de la interrupción del embarazo en tres causales y las variables independientes son el género del legislador y el partido político. Para analizar los discursos se adoptó la metodología holistic grading o calificación holística, la cual se basa en una forma de análisis de contenido de la psicología educativa ${ }^{32}$. Dicha metodología, fue organizada de la siguiente manera en un estudio anterior. En primer lugar, se utilizó un concepto, en su caso el populismo, para estudiar los discursos de presidentes latinoamericanos y se creó una escala simple de tres puntos para observar empíricamente el dicho concepto.

La metodología de Hawkins requiere al menos de cinco pasos ${ }^{33}$. El primero se trata de diseñar una rúbrica o una guía para evaluar el texto que identifique las cualidades asociadas con diferentes tipos o grados de evaluación. El segundo paso es seleccionar a más de un evaluador por texto para realizar una interpretación más transparente del discurso. En el tercer paso se capacita a un grupo de graduadores en el uso de la rúbrica con la que avaluarán el contenido del discurso. En el cuarto paso, se piden a los evaluadores que lean y califiquen cada discurso. Finalmente, los evaluadores asignan un valor de acuerdo con la rúbrica.

En esta investigación se transcribieron los discursos de los diputados durante la sesión número cincuenta, se construyó la rúbrica a partir de la noción de control ${ }^{34}$ y se desarrolló una escala simple de tres puntos como medida cuantitativa sobre las cualidades del discurso, las cuales se definen en la tabla 1.

31. LUNA Y RUIZ (2006), p. 4.

32. HAWKINS (2009).

33. Op. cit., p. 11.

34. Op. cit., p. 9. 
Tabla 1. Rúbrica, escala simple para medir el discurso de los legisladores

\begin{tabular}{|l|l|l|}
\hline 2 & Control & $\begin{array}{l}\text { Un discurso en esta categoría ejerce un tipo de poder sobre los } \\
\text { individuos denominado control. Toma la forma de la vigilancia } \\
\text { individual y continua, y recurre al castigo; se centra en la pro- } \\
\text { hibición y tiene el objetivo de determinar la conducta de las per- } \\
\text { sonas. }\end{array}$ \\
\hline 1 & Mixto & $\begin{array}{l}\text { Un discurso en esta categoría es mixto, incluye elementos del } \\
\text { control, pero no los usa consistentemente o los atenúa al incluir } \\
\text { elementos de la autonomía. }\end{array}$ \\
\hline 0 & Autonomía & $\begin{array}{l}\text { Un discurso en esta categoría considera que las mujeres deben } \\
\text { decidir sobre sus cuerpos, se opone a la criminalización del abor- } \\
\text { to en condiciones extremas tales como violación, inviabilidad del } \\
\text { feto o riesgo de la madre. La autonomía también se refiere a las } \\
\text { opciones con las que cuentan las mujeres para decidir sobre el } \\
\text { embarazo inmerso en un contexto adverso, se opone al control } \\
\text { punitivo de la decisión de las mujeres sobre el aborto. }\end{array}$ \\
\hline
\end{tabular}

Fuente: Elaboración propia.

Una vez construida la rúbrica y trascritos los discursos de los diputados se enviaron una invitación a once estudiantes de la maestría de política comparada de la FLACSO- Ecuador para que participaran en la evaluación del contenido. En el correo se explicaron los pasos metodológicos y se adjuntaron los discursos trascritos al igual que la rúbrica Los evaluadores recibieron tres discursos, los mismos fueron enviados a dos personas para comparar las calificaciones y aumentar la confiabilidad en la evaluación. Los discursos fueron enviados mediante copia oculta para evitar cruces de información que pudieran influir en el resultado final. Esta medida se tomó con el fin de lograr interpretaciones más transparentes ${ }^{35}$.

Aunque en la metodología original se recomienda familiarizar a la gente con la definición discursiva del concepto operacionalizado y el uso de la rúbrica por medio de una reunión grupal, en esta investigación no se reunieron a los evaluadores de forma presencial por las implicaciones de recursos en tiempo y dinero que implicaba trasladarse a un espacio específico para la realización de la evaluación de forma grupal. En las reuniones presenciales para evaluar el discurso que realizó Hawkins para su investigación los evaluadores se tomaron entre 30-45 minutos en analizar los textos, sin embargo, para este estudio se determinó un tiempo de un día y medio para responder el correo adjuntando el discurso evaluado.

Una vez que se recibieron los discursos de parte de los evaluadores, se contrastaron las calificaciones otorgadas por cada uno de ellos, se creó una tabla con las

35. Op. cit., p. 11. 
calificaciones (véase anexo 1) y se diseñó un gráfico con un eje horizontal que indica las posiciones ideológicas de los partidos políticos (izquierda, centro, derecha) y que señala la escala básica con la que los evaluadores calificaron el discurso $(0,1,2)$ : control, mixto, autonomía. El cruce de partido político y calificación del discurso se representa de forma gráfica con el fin de posicionar a los diputados de acuerdo al eje horizontal que expresa las dos dimensiones. Es importante señalar que la definición de posición ideológica del proyecto de Elites Parlamentarias de la Universidad de Salamanca utiliza una escala ideológica de 1 a 10, en donde 1 es extrema izquierda y 10 extrema derecha, para esta investigación se homologaron las dos escalas para combinar los resultados en la ubicación del partido y tipo de discurso. Cada una de las escaladas toma los valores $0,1,2$.

Los datos sobre la posición ideológica de los partidos políticos a los que pertenecen los legisladores chilenos, se tomaron del portal de Elites Parlamentarias de la Universidad de Salamanca (PELA). La información proporcionada permite presentar una primera aproximación a la ubicación de los diputados y el comportamiento en esa posición sobre el aborto. Hasta dónde se han movido por partidos políticos con respecto a este tema valórico y si la combinación con los discursos examinados en el presente artículo, refuerza la posición ideológica o presenta diferencias.

En la tabla 2 se puede observar que a medida que los partidos se ubican en el espectro ideológico de la izquierda sus posiciones son favorables al aborto, mientras que los partidos que se van desde el centro a la derecha (PDC, RN y UDI) se oponen a la despenalización de la interrupción voluntaria del embarazo. La posición frente de la UDI y RN frente a este tema valórico fue casi la misma en 2002, 2006 y 2010, con una posición media de 6,80, 6,36 y 7,78 en los tres últimos periodos correspondientes. La DC, partido político que se ubica en el centro del espectro ideológico está muy cerca al desacuerdo frente al aborto. Estas condiciones previas permiten considerar que los discursos de los diputados tenderán a ubicarse en espacios similares. Los discursos de la UDI y RN se espera que estén orientados al control. Las intervenciones del PDC y el PPD mostrarán una tendencia mixta en el discurso y los miembros del PS tenderán a ubicarse en la autonomía de las mujeres en la interrupción del embarazo. Tanto diputadas como diputados actuarán en consecuencia de la posición ideológica del partido político y su postura frente al tema valórico del aborto. 
Tabla 2. Posición media de la ideológica de los partidos políticos en Chile 2002-2006 y $2006-2010$

\begin{tabular}{|l|c|c|c|c|c|c|}
\hline & 2002-2006 & 2002-2006 & 2006-2010 & 2006-2010 & $\mathbf{2 0 1 0 - 2 0 1 4}$ & $\mathbf{2 0 1 0 - 2 0 1 4}$ \\
\hline $\begin{array}{l}\text { Partido } \\
\text { Político }\end{array}$ & $\begin{array}{c}\text { Autou- } \\
\text { bicación } \\
\text { ideológica }\end{array}$ & $\begin{array}{c}\text { Autoubi- } \\
\text { cación legis- } \\
\text { ladores sobre } \\
\text { el aborto }\end{array}$ & $\begin{array}{c}\text { Autou- } \\
\text { bicación } \\
\text { ideológica }\end{array}$ & $\begin{array}{c}\text { Autou- } \\
\text { bicación } \\
\text { legisladores } \\
\text { sobre el } \\
\text { aborto }\end{array}$ & $\begin{array}{c}\text { autou- } \\
\text { bicación } \\
\text { ideológica }\end{array}$ & $\begin{array}{c}\text { Autou- } \\
\text { bicación } \\
\text { legisladores } \\
\text { sobre el } \\
\text { aborto }\end{array}$ \\
\hline PDC & 5.28 & $\mathbf{1 . 7 2}$ & 4.63 & $\mathbf{2 , 6 0}$ & 4,62 & 3,0 \\
\hline PPD & 3.85 & $\mathbf{5 . 5 3}$ & 3.31 & $\mathbf{5 , 0 6}$ & 3,73 & 4,31 \\
\hline PS & 2.56 & $\mathbf{5 . 7 8}$ & 2.73 & $\mathbf{7 , 0}$ & 2,60 & 5,0 \\
\hline RN & 6.80 & $\mathbf{2 . 9 4}$ & 6.36 & $\mathbf{2 , 6 4}$ & 7.78 & 1,62 \\
\hline UDI & 7.08 & $\mathbf{1 . 4 4}$ & 7.13 & $\mathbf{1 , 1 6}$ & 9,40 & $\mathbf{1 . 5 8}$ \\
\hline
\end{tabular}

Fuente: Proyecto de Elites Parlamentarias Latinoamericanas (PELA). La escala de la ubicación ideológica del partido político va de 1 a 10, donde 1 es extrema izquierda y 10 es extrema derecha. La escala para valorar la posición del aborto es 1 que significa totalmente en contra y 10 totalmente a favor. Los datos correspondientes al periodo 2002-2006 y 2006-2010 son de Alcántara 2014.

\section{Principales hallazgos}

En primer lugar, se observa que los miembros de partidos políticos de izquierda en su mayoría se posicionan en un discurso que respalda la autonomía de las mujeres, con un caso excepcional del diputado Raúl Zaldívar quien fue calificado como un diputado miembro de un partido izquierda, pero con un discurso cercano a una posición mixta sobre la despenalización de la interrupción voluntaria del embarazo en tres causales, por esta razón el caso de este diputado se encuentra alejado del bloque de diputados que se ubican a la izquierda y mantienen un discurso por la autonomía de las mujeres. En cuanto al partido de centro izquierda, Democracia Cristiana, se observar que los legisladores se ubicaron en un discurso mixto, en coherencia con su posición ideológica como partido autodenominado de centro ${ }^{36}$; dos de los seis casos que fueron observados del partido de la Democracia Cristiana, diputado Marcelo Chávez y Jorge Sabat, fueron calificados como un discurso más cercano al control de las mujeres sobre el aborto.

En cuanto a los discursos de los diputados de los partidos de derecha, los resultados señalan que la mayoría concentró sus discursos en el otro extremo de la autonomía. La figura 1 da cuenta que los diputados de partidos independientes se mueven por todo el espectro ideológico y por toda la escala discursiva. Por la ubicación de las observaciones en la figura 1 se sigue corroborando la polarización ideológica sobre el tema del aborto identificada en otros estudios ${ }^{37}$. Si bien la UDI y Renovación Nacional

36. Op. cit., p. 7.

37. ELITES PARLAMENTARIAS LATINOAMERICANAS (2008). 
(RN), según los análisis del PELA, se encuentran en la derecha del espectro político, el diputado Nicolás Monckeberg, miembro de RN, fue calificado con un discurso mixto.

Figura 1. Ubicación de los discursos sobre la despenalización de la interrupción del embarazo en tres causales en los ejes ideología del partido y espectro discursivo.

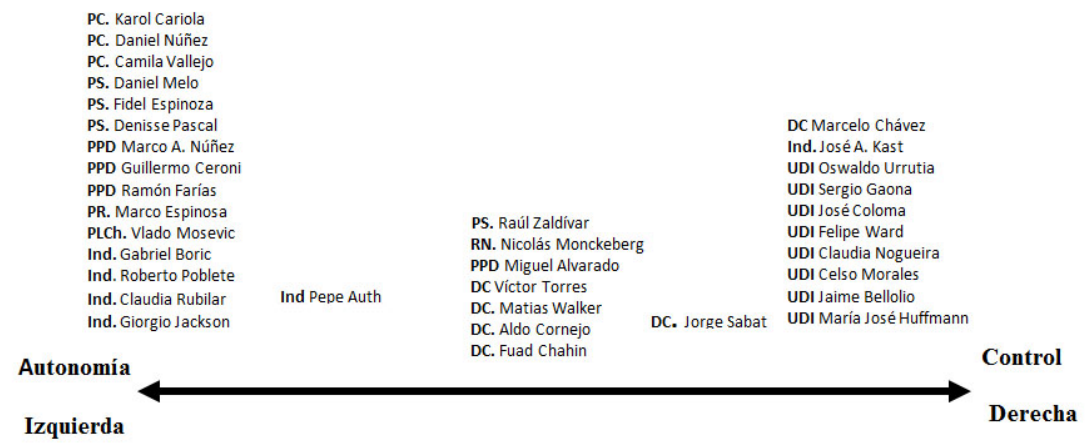

En 2006 el proyecto de Élites Parlamentarias de la Universidad de Salamanca, entrevistó a un conjunto de diputados sobre sus posiciones sobre el aborto. Los resultados comparados con la figura 1 de esta investigación, nos muestran que para los diputados del Partido Socialista "se declararon a favor del aborto en una media de 7 dentro de la escala del PELA" ${ }^{\prime 3}$. El Partido Por la Democracia presentó, para ese entonces, una posición intermedia por la despenalización del aborto mientras que en los resultados de esta investigación los diputados de éste partido, con excepción del diputado Miguel Ángel Alvarado, se manifestaron desde un discurso de autonomía y su respaldo a la iniciativa presidencial.

Con respecto a la representación sustantiva que hacen las mujeres específicamente, los resultados aseguran que las legisladoras, en la sesión observada, actúan siguiendo la posición ideológica de los partidos, sean estos de derecha o de izquierda, si una mujer hace parte de un partido político con una ideología de derecha tenderá a pronunciarse desde un discurso controlador de las decisiones de las mujeres, aunque ella comparta una identidad de género es más relevante la lealtad al partido, y las diputadas de izquierda se pronunciaron desde un discurso de autonomía de las mujeres. En las siguientes citas sobre el discurso de las legisladoras se confrontan de manera más sustancial las posiciones de autonomía y control. Esto rompe con la idea de que la simple presencia de mujeres conduce a favorecer medidas de género, podemos ver que la pertenencia al partido político influye en el modo en que las mujeres actúan frente a los intereses de género. 
Lo primero decir aquí que todos estamos con la vida. Economizar el debate entre los buenos que votan en contra y los malos que votan a favor, es una situación vergonzosa y una falta de respeto a las mujeres cuando escuchó que quienes somos creyentes no podemos hablar de libertad ante los derechos que nos lleva a ser mujer y decidir por nosotras misma en condiciones extremas, que no quisiéramos que existiera, pero existen. Es una falacia, cuando, escuchado colega al frente, como ellos llaman, hablar de derecho a la vida o el interés superior del niño es tener un cinismo total. Diputada Denisse Pascal-PS.

Creo que claramente aquí la Presienta Bachelet va a arrepentirse de un legado que solamente da muestras de que a este gobierno no le importa la vida por ciento de los niños nacidos y menos de los que están por nacer. Este es un día negro para Chile, histórico entre comillas. Como lo ha dicho la presidenta Bachelet por no mostrar nada más qué alternativas de muerte, alternativas de abandono para una mujer que lo que necesita es apoyo; vergüenza que estos diputados hayan tenido que introducir una indicación de acompañamiento y el gobierno el acompañamiento de las mujeres que sufren y que necesitará apoyo claramente no le importa hoy lejos de eso lo que hace este gobierno es desconocer lo que basa todo, todo país democrático que es el respeto a la dignidad humana, Eso es lo que desconoce y desvaloriza. Diputada Claudia Nogueira- UDI.

Como era de esperar los hallazgos confirman que en el tema del aborto las mujeres no actúan como bloque, bajo una identidad de género compartida. Esto es contrario a lo que demuestra el caso estadounidense en 1997 en donde las legisladoras republicanas y demócratas presentaron patrones de voto cohesionado como grupo, sin importar, como ya se ha dicho, la filiación partidista ${ }^{39}$.

En cuanto los hallazgos metodológicos, la evaluación externa de los contenidos discursivos permitió confrontar la asignación de un valor desde dos miradas distintas sobre el mismo contenido. Como se observa en el figura1 existen algunos casos excepcionales en donde las medidas no fueron absolutas porque un evaluador asignó un valor diferente, lo que hicimos fue calcular la media entre las dos calificaciones para ubicar la observación en el rango correspondiente. La metodología propuesta permitió convertir una medida cualitativa en una cuantitativa, al igual que ubicar aspectos sustanciales del discurso en una fotografía (figura 1) que permite observar de forma rápida las posiciones y habla de la relación entre posición ideológica y tipo de discurso, y de la posición de las mujeres legisladoras frente a los asuntos de género.

39. NORTON (1999). 


\section{Conclusiones}

Este artículo analizó los discursos de los diputados chilenos sobre la despenalización del aborto. Los hallazgos dan cuenta, en primer lugar, que en ningún caso analizado el discurso estuvo por fuera del esperado por la literatura: los partidos políticos de derecha están a favor del control y los miembros de los partidos de izquierda intervinieron a favor de la autonomía de las mujeres sobre el aborto, no obstante, el comportamiento de los partidos de centro en torno a este tema es un vacío dentro de la literatura. En segundo lugar, en ningún caso las legisladoras actúan en contra de la plataforma ideológica del partido, aunque tengan experiencias compartidas de género. Sin embargo, diputados del sexo masculino sí se movieron hacia posiciones sobre el aborto contrarias al bloque del partido político al que pertenecen, Nicolás Monckeberg se ubica en un discurso mixto, contrario al que sus colegas del partido de la Renovación Nacional manifestaron durante el debate de la ley; cabe precisar que el diputado Monckeberg cambió su discursos hacia una postura mixta lo cual resulta inesperado, pues en 2006 apoyó una iniciativa que proponía crear una figura delictiva de lesiones al ser humano en gestación. Otros diputados como Jorge Sabat y Marcelo Chávez de la Democracia Cristiana, también se posicionan por fuera de las ideas sobre el aborto promovidas por el bloque partidista al que se adhieren, se trata de diputados con discursos más cercanos al control del cuerpo de las mujeres.

Este artículo también aportó a los estudios sobre la representación sustantiva de las mujeres desde una mirada innovadora, el análisis de las intervenciones en el pleno de la Cámara de Diputados durante el debate de temas que afectan la vida de las mujeres. Los hallazgos refuerzan que, en algunos temas de género como el aborto, las legisladoras no actúan en bloque para impulsar las iniciativas legislativas valóricas, en comparación con las fusiones que se originan más allá del partido político en asuntos como las cuotas de género. Ese comportamiento deja abierta la puerta a futuras investigaciones que se pregunten en qué temas las legisladoras cruzan los limites ideológicos del partido político y forman bloques o bancadas femeninas multipartidarias para promover los intereses de género y en qué condiciones realizan alianzas con sus colegas hombres de partidos políticos ideológicamente distintos con el fin de impulsar la legislación pro derechos de las mujeres. En la actualidad, en la Cámara de Diputados de Chile se conformó la bancada feminista Julieta Kirkwood, sin embargo, reúne a una mayoría de legisladoras que se ubican a la izquierda del espectro ideológico (PC, PS, PPD y PR) y Marcela Sabat, de Renovación Nacional, es la única legisladora miembro de un partido que se ubica a la derecha del espectro ideológico.

Los discursos de los legisladores también demuestran la coherencia con las posturas ideológicas del partido y con las ideas promovidas por los legisladores desde el retorno a la democracia. Los miembros de la UDI mantuvieron una postura coherente, defender la vida desde la concepción, ningún representante se movió por fuera de 
lo esperado de acuerdo a la hipótesis planteada la cual se derivó del comportamiento histórico de los legisladores en el marco de los proyectos de ley presentados. Los miembros de los partidos de izquierda PS, PPD y los independientes cercanos con esta posición ideológica, también tuvieron el comportamiento esperado, su discurso estuvo enmarcado en la defensa de la autonomía de las mujeres. Los partidos ubicados en el centro del espectro ideológico como la DC y la Renovación Nacional también son coherentes porque se trata de un partido político poco estructurado en el que sus miembros pueden manifestar una diversidad de posiciones sobre temas valóricos. Los hallazgos del presente artículo contradicen a lo esperado por la encuesta del PELA porque los datos presentados por el proyecto de la Universidad de Salamanca presentan a la Renovación Nacional como un partido con una clara oposición al tema del aborto, pero lo que demuestra este análisis es que los legisladores de dicha afiliación partidista presentaron posturas a favor y contra de la interrupción del embarazo.

Finalmente, futuras investigaciones pueden comparar los discursos de los diputados chilenos con diputados de otros países de América Latina que abordan temas valóricos como el aborto. Este tipo de estudios permitirían examinar si los partidos políticos se diferencian o no de sus posiciones ideológicas a la hora de representar sustantivamente a las mujeres. Igualmente, pueden centrarse en análisis con un enfoque cualitativo que entrevisten a las legisladoras para establecer las causas de la actuación adscrita al partido y no como un grupo de mujeres que transcienden la ideología partidista con miras a favorecer los intereses pro autonomía de las mujeres.

\section{Referencias bibliográficas}

ALCÁNTARA, Manuel (2003): "La ideología de los partidos políticos chilenos, 19942002: rasgos constantes y peculiaridades". En Revista de Ciencia Política, año. XXIII, No 2 , Diciembre de 2002, pp. 68-87.

CÁMARA DE DIPUTADOS DE CHILE (2017): Discursos de los Diputados sobre la Despenalización de la Interrupción voluntaria del Embarazo en tres Causales, Sesión de Sala No 50/ 20 o7 2017. Disponible en https://www.youtube.com/ results?search_query $=$ sesion + de + sala $+\mathrm{No}+50+$ diputados + de + chile

CÁMARA DE DIPUTADOS DE CHILE (2017): Listado de diputados y partido politico. Disponible en https://www.camara.cl/camara/diputados.aspx\#tab

CELIS, Karen (2008): "Studying Women's Substantive Representation in Legislatures: When Representative Acts, Contexts and Women's Interests Become Important". En Representation, año XLIV, No 2, Junio de 2008, pp. 111-123. 
CELIS, Karen y HOGESCHOOL Gent (2006): "Substantive Representation of Women: The Representation of Women's interests and the Impact of descriptive Representation in the Belgian Parliament (1990-1979)". En Journal of Women, Politics E Policy, año XXVIII, $\mathrm{N}^{\circ}$ 2, Octubre de 2008, pp. 85-114.

COLOMER, Josep y ESCATEL Luis (2005): "La dimensión izquierda-derecha en América Latina". En Desarrollo Económico, No 177, abril de 2005, pp. 123-136

DÍAZ, Nicolás (2016): "Una travesía inconclusa: divisiones en Renovación Nacional Durante el Gobierno de Sebastián Piñera". En Revista de Ciencia Política, año XXXVI, No 2, agosto de 2016, pp. 481-502.

ELITES PARLAMENTARIAS LATINOAMERICANAS. Boletín $n^{\circ} 20$, Valoraciones y actitudes por partido político, Chile (2006-2010). Disponible en: http://americo. usal.es/oir/elites/Boletines_2008/boletin_20_Chile_P.pdf [Fecha de consulta: 21 de junio de 2017].

EVANS, Elizabeth (2012): "From finance to equality: the substantive representation of women's interests by men and women MPS in the house of commons" En Representation, año XLVIII, No:2, pp 183-196.

FRANCESCHET, Susan (2011): “Gendered Institutions and Women's Substantive Representation: Female Legislators in Argentina and Chile" En Gender, politics and Institutions Krook Mona Lena y Mackay Fiona (Londres: Palagrave Macmillan)

FOUCAULT, Michael. (1994): Dichos y Escritos tomo III. s/i.

GONZÁLEZ, Luis y QUEIROLO, Rosario (2013): "Izquierda y derecha: formas de definirlas, el caso latinoamericano y sus implicaciones". En América Latina Hoy, año LXV, No 65, diciembre de 2013, pp. 79-105.

HAWKINS, Kirk (2009): "Is Chávez Populist? Measuring Populist Discourse in Comparative Perspective". En Comparative Political Studies, año XLII, No 8, febrero de 2009, pp. 1040-1067.

HTUN, Mala (2003): Sex and the State: Abortion, Divorce, and the Family Under Latin American Dictatorships and Democracies. (Cambridge University Press).

JOHNSON, Niki (2011) El tratamiento de la despenalización del aborto en el ámbito político-parlamentario. En (Des) penalización del aborto en Uruguay: practicas, actores y discursos. Universidad de la República. 
LUNA, Juan y RUIZ Leticia (2014): Documento de trabajo. Relaciones entre estructuración ideológica y organización interna de los partidos: el caso chileno. Disponible en http://americo.usal.es/oir/elites/PapersELITES/lunayruiz.pdf [Fecha de consulta: 30 de junio de 2017].

NORTON, Noelle (1999): "Uncovering the Dimensionality of Gender Voting in Congress", En Legislative Studies Quarterly, año XXIV, No 1, febrero 1999, pp-65-86. Disponible en http://www.jstor.org/stable/44030o

OSBORN, Tracy y MOREHOUSE Jeanette (2010): "Speaking as Women: Women and Floor Speeches in the Senate", En Journal of Women, Politics E Policy, año XXXI, $\mathrm{N}^{\circ}$ 1, febrero 2010, pp. 1-21. No spe, Diciembre de 2014, pp. 87-110.

PITKIN Hanna (1967): The Concept of Representation. (Berkeley: University of California Press).

PISCOPO, Jennifer (2014): "Más allá del hogar: las legisladoras, el cambio feminista en las políticas y la representación sustantiva en México", En Revista Uruguaya de Ciencia Política, No spe, diciembre de 2014, pp. 87-110.

PISCOPO, Jennifer (2010): Setting Agendas for Women in the legislature: Patterns of Bill Introduction in the Argentina Congress. Disponible en https://papers.ssrn. com/sol3/papers.cfm?abstract_id $=1581150$ [Fecha de consulta: 30 de enero de 2019].

BALTAR DA ROCHA, María I, ROSTAGNOL, Susana y GUTIERREZ, María. (2009): Aborto y Parlamento un estudio sobre Brasil, Uruguay y Argentina. Disponible en http://www.scielo.br/scielo.php?pid=S0102-30982009000200005\&script=sci abstract\&tlng=es [Fecha consulta: 03 de junio de 2018].

SCHWINDT-BAYER, Leslie A (2011): "Women Who Win: Social Backgrounds, Paths to Power, and Political Ambition in Latin American Legislatures." En Politics $\mathcal{E}$ Gender, año VII, No. 1, marzo de 2011, pp. 1-33.

SCHWINDT-BAYER, Leslie A (2014): "La representación de las mujeres en la legislación latinoamericana: desafíos actuales y nuevas direcciones." En Revista Uruguaya de Ciencia Política, año XXIII, No 2, diciembre de 2014, pp. 15-35.

SWERS, Michele (2002): The difference Women Make: The Policy Impact of Women in Congress. (Chicago: The University of Chicago Press). 
SWERS, Michele (2016): "Pursuing Women's Interests in Partisian Times: Explaining Gender Differences in Legislative Activity on Health, Education, and Women's Health Issues. En Journal of Women, Politics \& Policy, $N^{\circ}$ 3, junio de 2016, pp. 249-273.

TAM, Waikeung (2017): "Do female legislators have different policy priorities than their male colleagues in an undemocratic/semi-democratic legislature? The case of Hong Kong", En The Journal of Legislative Studies, año XXIII, No 1 , febrero 2017, pp. 44-70.

TRAK, Juan Manuel (2015): La representación sustantiva en América Latina: un estudio de la congruencia entre partidos y simpatizantes en América Latina (Tesis para optar al título de Doctor en Estado de Derecho y Gobernanza Global, Universidad de Salamanca Facultad de derecho).

XYDIAS, Christina (2012): "Mapping the language of women`s interests: Sex and Party affiliation in the Busdestag". En Political Studies, No 61, septiembre de 2012, pp. 1-22.

YU, Bei, KAUFMANN, Stefan y DIERMEIER Daniel (2008): "Classifying Party Affiliation from Political Speech", En Journal of Information Technology \& Politics, año V, No ${ }_{1}$, Octubre de 2008, pp. 33-48.

ZECHMEISTER Elizabeth y CORRAL Margarita (2010). El variado significado de "izquierda" y "derecha. Disponible en https://www.vanderbilt.edu/lapop/insights/ Io838es.pdf. [Fecha de consulta: 12 de noviembre de 2018]

\section{Anexos}

\section{Anexo 1.}

Calificación de los diputados por orden de intervención durante la sesión No. 50 en la que se debatió el mensaje para la despenalización de la interrupción voluntaria del embarazo en tres causales

\begin{tabular}{|l|l|l|c|}
\hline No $^{\circ}$ & \multicolumn{1}{|c|}{$\begin{array}{c}\text { Nombre del/la } \\
\text { legislador/a }\end{array}$} & \multicolumn{1}{|c|}{ Partido Político } & Puntuación \\
\hline 1 & Roberto Poblete & Independiente & 0 \\
\hline 2 & Giorgio Jackson & Independiente & 0 \\
\hline 3 & Claudia Rubilar & Independiente & 0 \\
\hline 4 & Gabriel Boric & Independiente & 0 \\
\hline 5 & Pepe Auth & Independiente & 0,5 \\
\hline
\end{tabular}




\begin{tabular}{|c|c|c|c|}
\hline 6 & José Antonio Kast & Independiente & 2 \\
\hline 7 & Camila Vallejo & Partido Comunista & 0 \\
\hline 8 & Daniel Núñez & Partido Comunista & 0 \\
\hline 9 & Karol Cariola & Partido Comunista & 0 \\
\hline 10 & Aldo Cornejo & Partido Demócrata Cristiano & 1 \\
\hline 11 & Matías Walker & Partido Demócrata Cristiano & 1 \\
\hline 12 & Jorge Sabag & Partido Demócrata Cristiano & 1,5 \\
\hline 13 & Marcelo Chávez & Partido Demócrata Cristiano & 2 \\
\hline 14 & Fuad Chahin Valenzuela & Partido Demócrata Cristiano & 1 \\
\hline 15 & Víctor Torres & Partido Demócrata Cristiano & 1 \\
\hline 16 & Vlado Mirosevic & Partido Liberal & 0 \\
\hline 17 & Ramón Farías & Partido Por la Democracia & 0 \\
\hline 18 & Miguel Ángel Alvarado & Partido Por la Democracia & 1 \\
\hline 19 & Guillermo Ceroni & Partido Por la Democracia & 0 \\
\hline 20 & Marco Antonio Núñez & Partido Por la Democracia & 0 \\
\hline 21 & Marcos Espinosa & Partido Radical & 0 \\
\hline 22 & Denisse Pascal & Partido Socialista & 0 \\
\hline 23 & Raúl Saldívar & Partido Socialista & 1 \\
\hline 24 & Daniel Melo & Partido Socialista & 0 \\
\hline 25 & Fidel Espinoza Sandoval & Partido Socialista & 0 \\
\hline 26 & Nicolás Monckeberg & Renovación Nacional & 1 \\
\hline 27 & Juan Antonio Coloma & Unión Demócrata Independiente & 2 \\
\hline 28 & María José Hoffmann & Unión Demócrata Independiente & 2 \\
\hline 29 & Felipe Ward & Unión Demócrata Independiente & 2 \\
\hline 30 & Osvaldo Urrutia & Unión Demócrata Independiente & 2 \\
\hline 31 & Celso Morales & Unión Demócrata Independiente & 2 \\
\hline 32 & Sergio Gahona & Unión Demócrata Independiente & 2 \\
\hline 33 & Jaime Bellolio & Unión Demócrata Independiente & 2 \\
\hline 34 & Claudia Nogueira & Unión Demócrata Independiente & 2 \\
\hline
\end{tabular}




\title{
Propiedad y caridad en Locke: un análisis crítico a la propuesta interpretativa de Juliana Udi ${ }^{1}$
}

\author{
Property and charity in Locke: a critical analysis of Juliana Udi's interpretative \\ proposal
}

José Miguel González Zapata

LuCiano SimonetTi IzQUierdo

Pontificia Universidad Catolica de Chile, Chile

\begin{abstract}
RESUMEN El presente trabajo analiza críticamente la propuesta interpretativa que Juliana Udi ofrece respecto al rol que juega el deber de caridad en la teoría de la propiedad de John Locke. Para ello, en primer lugar exponemos la interpretación predominante de la teoría de la propiedad lockeana, basándonos en la obra de dos de sus principales representantes: Leo Strauss y C. B. Macpherson. En segundo lugar, exponemos los principales argumentos y características de la lectura que Udi hace de la caridad en Locke. En tercer lugar, presentamos nuestras críticas y observaciones constructivas a su propuesta. Finalizamos proponiendo una categorización que se hace cargo de manera no sintética de las tensiones existentes en el Corpus Lockeano.
\end{abstract}

PAlabras Clave Caridad, Propiedad, Derecho Natural, John Locke, C. B. Macpherson, Leo Strauss, Juliana Udi.

ABSTRACT This work presents a critical analysis of Juliana Udi's interpretation of the role that charity plays in Locke's theory of property. In order to do this, we first explain the predominant interpretation of this theory, based on the work of two of its main authors: Leo Strauss and C. B. Macpherson. Secondly,

1. José Miguel González Zapata. Licenciado en Ciencias Jurídicas, Pontificia Universidad Católica de Chile.Mail: Jmgonzalez3@uc.cl

Luciano Simonetti Izquierdo. Licenciado en Ciencias Jurídicas, Pontificia Universidad Católica de Chile. Tutor académico de derecho público, Universidad Central de Chile. Mail: lsimonetti1@uc.cl 
we expound the main arguments and characteristics of Udi's reading of charity in Locke. Thirdly, we present our criticisms and constructive observations on her proposal. We conclude by proposing a categorization that explains, nonsynthetically, the tensions existing in the Lockean Corpus.

KEYWORDS Charity, Property, Natural Law, John Locke, C. B. Macpherson, Leo Strauss, Juliana Udi.

\section{Introducción}

John Locke (1632-1704) es un pensador que no pasa desapercibido. Ya desde la agitada y reformista época en que le tocó vivir, sus ideas han permeado el debate público y determinado el curso político seguido no solo en Inglaterra sino en otras partes del globo, erigiéndose como uno de los pensadores más influyentes de los últimos siglos.

Sin embargo, aquella influencia y popularidad está lejos de significar que la interpretación de su legado esté exenta de debate. Predomina, sin duda, la postura de aquellos que ven en Locke al precursor del liberalismo clásico. Sus entonces rupturistas concepciones acerca de la propiedad y el gobierno habrían servido como sustento ideológico tanto de las revoluciones políticas del siglo XVIII como de las transformaciones sociales que a la postre originarían el surgimiento y florecimiento de las democracias liberales que predominan en el escenario político actual. En este sentido, Víctor Méndez Baiges afirma:

"La interpretación académica dominante de la teoría lockeana, que en gran medida llega incólume hasta bien entrado el siglo veinte, tiene su origen en el siglo anterior. Es una interpretación eminentemente sociopolítica, que destaca como los pilares básicos de la construcción lockeana los tres siguientes: el individualismo, como dato psicológico fundamental de la naturaleza humana, la propiedad, como relación del hombre con sus derechos y como derecho natural básico, y el contrato, como libre acuerdo de voluntades libres e iguales. Estos tres supuestos son los responsables de que su teoría política sea la fundamentación de un gobierno en esencia limitado (...) Así, desde el siglo pasado, Locke ha pasado a ser, para lo bueno y para lo malo, el teórico del ascenso de la burguesía por excelencia"2.

En opinión del autor recién mencionado, esta lectura de Locke habría predominado de manera indubitada durante todo el siglo XIX y la primera mitad del siglo XX, momento en que la teoría del Individualismo Posesivo de Macpherson -que para Méndez Baiges constituye respecto de esta corriente interpretativa su "resumen perfecto, así como su desarrollo más acabado"3- generaría distintos cuestionamientos a

2. MÉNDEZ (1995) p. 66

3. Ídem, p. 69 
la forma tradicional de entender a Locke. La relevancia de la interpretación de Macpherson está no solo en su radical propuesta, que lleva a la obra de Locke a sus más extremas consecuencias lógicas, sino también en haber abierto el debate en torno a los verdaderos alcances, tanto teóricos como prácticos, del corpus lockeano, dando pie al desarrollo de otras corrientes alternativas de interpretación.

En este contexto destaca la denominada "corriente historiográfica", que critica la exagerada vinculación entre Locke y el surgir de la democracia liberal y el capitalismo. Postulan que "respondía, en el lenguaje de su tiempo, a los problemas de su tiempo, y no a los del siglo XIX o a los nuestros" ${ }^{4}$, de manera que cualquier conexión causal entre la obra de Locke y los fenómenos ocurridos décadas después de su muerte supone un error interpretativo respecto al verdadero alcance de la misma. Nuestro autor sería, en definitiva, un pensador de su época, no de los siglos venideros. Uno de los mayores exponentes de la corriente historiográfica es John Dunn, que ve en Locke a un "teólogo natural calvinista, un teórico de la ley natural, a la cual se subordinan y en la que se inscriben los derechos naturales" ${ }^{5}$, muy distante del liberalismo capitalista moderno al que se lo intenta vincular.

La ofensiva historiográfica contra la interpretación predominante de Locke abrió la puerta a otras corrientes. Algunas caracterizan a nuestro autor como un pensador poco vinculado con el liberalismo, haciendo primar en él su herencia escolástica y adscripción a la teoría de la ley natural y el cristianismo ${ }^{6}$. Otras, intentando conciliar ambos extremos 7 , lo entienden en cuanto autor bisagra, parte de la transición entre dos maneras distintas de entender lo político. Otros como Duncan Bell ${ }^{8}$ creen que lo liberal en Locke no es más que una atribución "póstuma”. James Tully va más allá, sosteniendo que la entera interpretación de Macpherson se basa en un error de análi

\section{4. Ídem, p. 72}

5. Ibídem

6. En este sentido escriben BACIERO (2012): "El concepto de derecho subjetivo y el derecho a la propiedad privada en Suárez y Locke" y UDI (2012a): "El Derecho a la Caridad: Repercusiones de la Teología Cristiana en la teoría de la Propiedad de John Locke". El primero postula que "en realidad (a propósito de la teoría de la propiedad) Locke parece reproducir también en este caso lo esencial del pensamiento suareciano, tanto en los detalles como en el marco general de su doctrina, contexto que es típicamente escolástico."

7. En este sentido, FERNÁNDEZ (2010) dice en "La justicia como pretensión política: John Locke entre el Medioevo y la Modernidad" que "de acuerdo con este panorama, la obra de Locke puede denominarse como de transición (...) si bien Locke fundamenta la organización política de la sociedad en el consentimiento individual, es difícil sustraer sin más los elementos de tipo comunitario que incluye en su teoría para limitar la voluntad individual."

8. Sostiene BELL (2014): Locke became a liberal during the twentieth century. As part of a process of retrojection his body of work - or at least some stylised arguments stripped from it-was posthumously conscripted to an expansive new conception of the liberal tradition". 
sis, en cuanto la teoría de la propiedad lockeana sería esencialmente limitada, al estar subordinada a los mandatos de la ley natural'.

Es entre estas últimas corrientes en las que se circunscribe la obra de Udi. La autora cuestiona la lectura dominante de Locke recuperando y reinterpretando la caridad lockeana, la que debidamente entendida supondría, en su opinión, nuevos límites no previstos a la teoría propietaria de nuestro autor. Nosotros cuestionaremos los alcances que la autora busca dar a su tesis, haciendo notar algunas insuficiencias e inconsistencias en la misma que imposibilitan que la misma llegue a las conclusiones pretendidas por Udi. Lo anterior no supone que la tesis de la autora carezca de valor. Al contrario, creemos que aporta matices interesantes y abre posibilidades de interpretación sobre la institución propietaria en Locke, para lo cual urge caracterizar la propuesta de Udi dentro de sus límites y posibilidades.

La estructura de la presente obra consistirá en un primer capítulo donde exponemos las ideas de Strauss y Macpherson, en cuanto autores paradigmáticos de la corriente interpretativa mayoritaria de Locke. En el segundo capítulo sintetizamos los postulados de Udi relativos al deber de caridad lockeano. En el capítulo tercero se busca aportar ciertas apreciaciones críticas y constructivas sobre el trabajo de la autora y el cuarto finaliza proponiendo una metodología distinta de aproximación a la obra de nuestro autor.

\section{Interpretación mayoritaria de la obra de John Locke}

Para contextualizar debidamente la obra de Juliana Udi, es necesario analizar la corriente interpretativa dominante de la teoría jurídico-política de Locke, que encuentra sus principales exponentes en C. B. Macpherson y Leo Strauss, no solo por ser las obras pilares a partir de las cuales se ha desarrollado el tratamiento de la obra lockeana sino también y principalmente porque la propuesta analítica de Udi se articula como contestación a mencionados pensadores. Se procederá por tanto a enunciar y sistematizar los principales elementos de aquella interpretación.

La teoría jurídico-política de John Locke se configura y construye en torno a la institución de la propiedad privada, la cual constituye el eje paradigmático desde el cual el autor desarrolla los demás conceptos e instituciones que conforman su teoría. La hegemonía del concepto es tal, que el autor caracteriza la vida y la libertad del indi

9. Sostiene TULLY (2006): "Macpherson seems to place the wrong emphasis on labour. Labour justifies neither the accumulation of nor rights over one's goods; it provides, as I have attempted to show, a means of identifying something as naturally one's own. Justification of accumulation and use is derived from the prior duty and right to support and comfort God's workmanship. The priority of natural law renders all rights as means to this end, and therefore Locke's account is a limited rights theory", p. 131 
viduo en términos de derechos de propiedad. Lo anterior se manifiesta en el Segundo Tratado, particularmente en el apartado 47, el cual dice: "El hombre, al ser dueño de sí mismo y propietario de su persona y de las acciones y trabajos de ésta, tiene en sí mismo el gran fundamento de la propiedad"10.

En armonía con dicha afirmación, C.B. Macpherson afirma: "Locke sometimes writes as if life and liberty were valuable because they were means of getting possessions (...) because everybody has a property on his own person, one might see Locke's assumption that life is valuable as means of acquiring material possessions" ${ }^{11}$.

Para Macpherson, Locke no afirma que se tiene propiedad sobre la propia vida, libertad y posesiones exteriores adquiridas per se, consideradas en sí mismas, sino que se es dueño de ellas como consecuencia de ser éstas medios útiles para la adquisición y acumulación de nueva propiedad. Esto supone una subordinación total de la vida y la libertad a la propiedad y su consecuente adquisición, apreciadas no por el valor que podrían en sí mismas contener sino en razón de criterios utilitaristas. Si bien posteriormente el autor modera estas conclusiones, considera que el sólo hecho de poder realizar dichas inferencias a partir de la obra lockeana brinda luces respecto de sus intenciones y presupuestos. Afirma al respecto: "It is illuminating that Locke can write as if personality was an extension of possessions, rather than possessions being an extension of personality"12.

Por otra parte, los autores mencionados sostienen que Locke considera que el derecho de propiedad es pre-social; es decir, que existe en el Estado de Naturaleza, con independencia del contrato social, lo que, entre otras consecuencias, marca los límites de actuación y las funciones propias del Gobierno una vez configurada la sociedad civil. De esta manera, la propiedad lockeana es una institución anterior a la sociedad civil, tanto ontológica como cronológicamente, cuya estructuración es ajena, al menos en el mencionado estado de naturaleza, a consideración colectiva alguna. Afirma Strauss que en Locke "the natural right to property is a corollary of the fundamental right of self-preservation; it is not derivative from (...) any action of society" ${ }^{13}$.

Sostiene a su vez Casimir J. Czajkowski que "for Locke, the right of property is inherent in the people themselves. It is an inalienable right of every individual, flowing from his very nature and personality. This is the basis of Locke's theory, and throughout the eighteenth and nineteenth century authors there has been predominant tendency to conceive property in terms of the theory which founds it classic expression in Locke"14.

10. LOCKE (2005) p. 15

11. MACPHERSON (1951) p. 551

12. Ibídem

13. STRAUSS (1953) p. 235

14. CZAJKOWSKI (1941) p.2 
En la misma línea argumentativa, resulta ilustrativa la afirmación de Dania González, quien concluye que "la propiedad es, para Locke, individual, en la medida en que el trabajo es concebido sólo como la actividad individual del hombre. De esta forma no es necesario el consenso de toda la sociedad que reconozca, al estilo rousseano, la propiedad exclusiva de un sujeto sobre un objeto; sólo se necesita la actividad de sujetos aislados que produzcan [...]. La propiedad es por tanto individualista y asocial"15. Sostiene a su vez que "para Locke, y a diferencia de Hobbes, la propiedad nace en el mismo Estado de Naturaleza, y por ende, es anterior a la conformación de la sociedad y gobiernos civiles, en cuanto la propiedad nace con el hombre, de su persona"16.

Al caracterizar la propiedad como derecho natural pre-social, Locke subordina lo social a lo jurídico-económico. La propiedad pasa a ser ontológica y cronológicamente anterior al fenómeno social de modo que la existencia del mismo se justifica sólo en cuanto sirva como medio para proteger mencionada institución y favorecer su multiplicación y acumulación. La función de la sociedad queda reducida a la protección de la propiedad, y su valor es dado sólo en cuanto cumple dicha instrumentalidad. Dice Locke al respecto en el apartado 124, del Segundo Tratado que "por consiguiente, el gran y principal fin que lleva a los hombres a unirse en Estados y a ponerse bajo un gobierno, es la preservación de su propiedad" ${ }^{17}$.

Sobre lo anterior sostiene Leo Strauss que "by saying that property antedates civil society, Locke says that even civil property -the property owned on the basis of positive law- is in the decisive respect independent of society: it is not the creation of society (...) Man, the individual, has in himself the great foundation of property (...) Property is created by the individual and in different degrees by different individuals. Civil society merely creates the conditions under which the individuals can pursue their productive-acquisitive activity without obstruction" ${ }^{18}$.

En armonía con lo anterior, Diana González sostiene que "El pacto social de entrar en sociedad civil no crea nuevos derechos, sino que sólo cede a la autoridad civil los poderes que los hombres tenían en estado natural para que ésta proteja sus derechos naturales. El pacto social santifica lo ya existente: si una propiedad desigual es el resultado de un derecho poseído en el estado de naturaleza, la sociedad civil debe garantizarlo" ${ }^{19}$.

Afirma por su parte Czajkowski que "no original consent could overcome the inherent sacredness of private ownership" ${ }^{20}$. En la misma línea se encuentra María

15. GONZÁLEZ (2010) p. 30

16. Ibídem

17. Ídem p. 32

18. STRAUSS (1953) pp. 245-246

19. GONZÁLEZ (2010), p. 38

20. CZAJKOWSKI (1941) p. 77 
Dolly, quien identifica en Locke la existencia de un Estado mínimo, al afirmar que "en esta nueva dimensión política de la convivencia lockeana, el Estado es un ente de intervención mínima, sólo puede garantizar los derechos individuales, arbitrar en los conflictos y mantener la seguridad, de manera que no puede excederse en el poder que se le ha dado ${ }^{21}$. Agrega a lo anterior que "con el concepto de Propiedad, Locke justifica la existencia del Estado civil, en tanto las leyes tienen como única función la protección de lo ya establecido, como derechos naturales en las sociedades domésticas, formadas en el estado de naturaleza" ${ }^{22}$.

Caracterizada la propiedad como institución pre-social y eje temático de su propuesta, Locke a continuación afirmaría que la principal manera de obtener dicha propiedad de lo externo es por medio del trabajo. Afirma el autor inglés en el apartado 27 del Segundo Tratado que "Every man has a property in his own person; this nobody has a right to but himself. The labour of his body and the work of his hands we may say are properly his (...) Whatever a man removes of its natural state, he has mixed his labour with and by this mixing, he makes it his property" ${ }^{23}$.

Así, al ser el individuo propietario de sí mismo, lo es por extensión de su trabajo, de manera que al mezclarlo con cosas externas se supone forman un todo indivisible, comunicando la propiedad sobre el propio trabajo a aquello apropiado. Es en este razonamiento lockeano en el cual se vislumbra la relevancia de la asocialidad de la propiedad, en cuanto sólo entendida fuera de dicho fenómeno y recaída sobre el propio cuerpo y facultades es que se justifica que la misma exista en el estado de naturaleza. Sin la existencia de un derecho de propiedad sobre las propias facultades, malamente podría transmitirse cualidad alguna a lo apropiado, pertenencias éstas que constituirían meras apropiaciones fácticas sin connotación jurídica alguna. Sin este hilo conductor en la obra lockeana, lo apropiado no podría convertirse jamás en propiedad sin el reconocimiento y sanción positiva de la sociedad civil, quedando la propiedad subordinada a lo político, consecuencia lógica que Locke a toda costa busca evitar.

Sin embargo, y a pesar de caracterizar la propiedad como una relación puramente personal e individual entre el sujeto y lo apropiado, sin relación con comunidad alguna, Locke enuncia ciertas limitaciones a esta institución. Éstas han sido caracterizadas como las de "no estropeo de lo apropiado" y la de "dejar suficiente a los demás".

La primera limitación consiste en la imposibilidad de apropiarse de más de lo que se pueda usar antes de su estropeo. Esta parece ser, a primera vista, una significativa barrera a las posibilidades de apropiación, en cuanto supone una limitación física a la capacidad de consumo de relevante entidad. No obstante aquello, tanto Strauss como

21. CUARTAS (2010) p. 4

22. Ídem p. 7

23. LOCKE (2005) p. 10 
Macpherson sostienen que esta limitante es meramente formal y aparente, toda vez que es superada por el mismo Locke en su obra, "derogada" por la introducción del dinero. Sostiene Macpherson: "The introduction of money by tacit consent has removed the previous natural limitations of rightful appropriation, and in doing so has invalidated the natural provision that everyone should have as much as he can make use of ${ }^{24}$.

En efecto, en cuanto el dinero no perece, todo individuo puede apropiarse de cuanto quiera con tal que lo acumule en dinero, bien por excelencia no perecible, superando de esa manera tal obstáculo. Afirma Leo Strauss que "In civil society the right of appropriation is completely freed from shackles by which it was still under Locke's original law of nature: the introduction of money has introduced large possessions and right to they; man may now, rightfully and without injury, possess more than he himself can make use of "25.

Luego agrega, terminando de erradicar la limitación mencionada, que "According to this natural law (Locke's), man may acquire as much property of everykind in civil society; particularly as much money as he please (...) Even the natural law prohibition against waste is no longer valid in civil society" ${ }^{26}$. En el mismo sentido, Macpherson sostiene que "the spoilage limitation has disappeared thanks to money. Locke has justified the specifically capitalist appropiation" ${ }^{27}$.

Si a todo lo ya mencionado se agrega que Locke sostenía que en determinados momentos del estado de naturaleza ya existía la institución del dinero, ni siquiera era necesario el pacto social para que dicha limitación fuese superada. La propiedad elimina por sí misma dicha limitante, sin necesidad alguna de lo social para ello. Así, lo que pudo ser una subordinación de la propiedad a lo social, en cuanto requisito sine qua non sin la cual la acumulación propietaria no sería posible, es por Locke desechado con su afirmación de la presocialidad del dinero.

La segunda limitación consiste en dejar suficiente para los demás. Es decir, nadie podría apropiarse de una cantidad de bienes que suponga la insuficiencia de lo común, superando un mínimo aceptable para que el resto de la humanidad pueda proveerse de medios de preservación. Sin embargo, y a pesar de no citar directamente pasaje alguno de Locke que afirme esto, Macpherson cree encontrar en la argumentación lockeana una tácita superación de la misma. Sostiene dicho autor que "His chain of thought seems to have been that the automatic consequence of the introduction of money is the development of a commercial economy, hence the creation of markets

24. MACPHERSON (1951) pp. 555-556

25. STRAUSS (1953) p. 241

26. Ibídem

27. MACPHERSON (1951) p. 559 
for the produce of land hitherto valueless, hence the appropiation of land not hitherto worth appropriating. By implication, consent to the use of money is consent to the consequences, and as individual is therefore justified in appropiating land even when it does not leave enough and good for others" ${ }^{28}$.

En línea con dicha argumentación, cita luego un argumento de Locke agregado por éste en la tercera edición del Segundo Tratado, que en el apartado 37 reza "that he who appropiates land to himself by his labour does not lessen but increase the common stock of mankind" ${ }^{29}$. De esta manera, Macpherson sostiene que Locke justifica la apropiación ilimitada en un hipotético beneficio futuro a "la humanidad", basándose en la presunción -de pronto discutible- de que todo aquel que se apropia de bienes y los trabaja aumenta la riqueza global, y por tanto con ello no reduce sino que aumenta los bienes comunes disponibles. Dice Macpherson que "the greater productivity of the appropiated land makes up for the lack of land available for others" ${ }^{{ }^{\circ}}$. Que aquella asunción se cumpla o no en la práctica carece de relevancia en la argumentación lockeana, en la cual se han superado así las endebles limitaciones que él mismo pretendió imponer a la apropiación, dando rienda a lo que Macpherson identifica como el individualismo posesivo lockeano.

De esta manera, y en atención a la postura de los autores antes mencionados, la propiedad lockeana sería una institución pre-social, ontológicamente superior a toda consideración política y fundamento último y limitación omnipresente del actuar gubernamental, estando por tanto despojada de cualquiera limitación externa de entidad real. En efecto, afirma Macpherson: "If it is labor -a man's absolute propertywhich justifies appropiation and creates value, the individual right of appropiation overrides any moral claims of the society. The traditional view that property and labor are social functions, and that ownership of property involves social obligations, is thereby undermined" ${ }^{31}$.

El mismo autor concluye su análisis diciendo que "Property was released from the stigma of original sin, and this release carried with it release from the limitations and obligations of individual appropiation" ${ }^{32}$, de manera que "Locke made property stronger than civil society (...) civil society has only a limited jurisdiction; its power to regulate property can be exercised only to preserve property, because the purpose of the agreement to enter civil society is to preserve property" ${ }^{33}$.

A modo ilustrativo, conviene enunciar la concepción de justicia que John Locke tenía, la cual era definida en términos de derechos de propiedad. En efecto, afirma

28. MACPHERSON (1951) p. 559.

29. Ibídem

30. Ibídem

31. Ídem, p. 565

32. Ibídem

33. MACPHERSON (1951) p. 556. 
Baciero que "Locke supone que el derecho subjetivo es una propiedad del individuo, que no se le puede arrebatar sin injusticia" ${ }^{44}$. Al respecto, cita el Ensayo sobre el Entendimiento Humano, en que afirma Locke de manera contundente que "donde no hay propiedad, no hay injusticia". En efecto, asevera que "no hay injusticia donde no haya propiedad, es una proposición tan cierta como cualquier demostración de Euclides; porque la idea de propiedad es la de un "derecho a algo", y la injusticia, la violación de ese derecho" ${ }^{35}$.

Tal es la caracterización de la propiedad lockeana a la luz de la interpretación mayoritaria de su teoría jurídico-política. Sin embargo, y como se verá a continuación, Juliana Udi discrepa con este entendimiento, presentando una matización de la interpretación antedicha y una propuesta propia del corpus lockeano en torno al deber de caridad y su lugar dentro del mismo.

\section{Tesis de Juliana Udi sobre el deber de caridad en Locke}

Juliana Udi llama la atención sobre el escaso tratamiento que ha recibido el deber de caridad en la obra de John Locke ${ }^{36}$. Entre aquellos quienes se han aventurado en el estudio de esta institución, cita a Jeremy Waldron, quien señala la importancia del principio de caridad en el corpus lockeano como una condición mucho más fundamental que las limitaciones de suficiencia y no-desperdicio ${ }^{37}$ presentes en dicha obra, y a John Simmons, que dedica un breve apartado a la caridad en uno de sus textos sobre Locke, atreviéndose a desafiar programáticamente "la persistencia del punto de vista según el cual Locke está desinteresado en los derechos y deberes relativos a la caridad" ${ }^{8}$. James Tully, si bien omitido por la autora, también se remitió a la caridad lockeana, reconociendo su existencia y sosteniendo que la misma constituye un deber positivo del propietario ${ }^{39}$. En la misma línea, Dunn afirma que "charity is a right on the part of the needy and a duty on the part of the wealthy ${ }^{40}$. Sin embargo, Udi considera, con razón, que ninguno de estos autores indagó a fondo la cuestión.

34. BACIERO (2012) p. 23

35. Ibídem

36. UDI (2014) p. 150

37. WALDRON (2002) p.177

38. SIMMONS (1992) pp. 327-336

39. Dirá TULLY (2006), citando a Locke "'Charity gives every man a title to so much out of another's plenty, as will keep him from extreme want, where he has no means to subsist otherwise'. Where no means are available for a man to provide for himself, the right to the means of subsistence applies directly to another person's goods (...) A propietor who has more than enough to sustain himself is under a positive duty to sustain those who do not" (pp. 131-132).

40. DUNN (1968), pp. 81-82. 
La doctrina lockeana del deber de caridad se encuentra desperdigada a lo largo de las obras de Locke, sin un tratamiento sistemático. Cita Udi algunas menciones o alusiones indirectas en el Segundo Tratado del Gobierno Civil, específicamente en el párrafo 6, cuando Locke sostiene que "cada uno debe, cuando su propia preservación no está en juego, preservar al resto de la humanidad tanto como le sea posible" ${ }^{41}$. Agrega lo dicho en el párrafo 70 donde sostiene que todos debemos "caridad y asistencia a los menesterosos" ${ }^{42}$ y en el párrafo 93 se refiere a "la caridad que nos debemos unos a otros" ${ }^{43}$.

Además de las referencias presentes en el Segundo Tratado, existen otras obras a las que Udi denomina "menores" en que habría referencias al deber de caridad. Uno de ellos son los Ensayos sobre la ley natural, donde Locke afirma que todos tenemos el deber de "consolar a nuestro prójimo desahuciado", prestar "asistencia" a "aquellos que se encuentran en problemas" y "alimentar al hambriento" ${ }^{44}$. También en un texto breve y poco conocido de 1695, titulado "Venditio", Locke sopesa las exigencias de la justicia y las de la caridad, y sostiene que en casos de necesidad extrema esta última debe priorizarse. Asimismo, en sus Escritos Pedagógicos, Locke destaca la necesidad de enseñar a los niños la liberalidad, que define como "la disposición a compartir de buen grado lo que se tiene".

Sin embargo, y a pesar de las referencias mencionadas, Udi sostiene que el tratamiento fundamental de la caridad lockeana y su alusión más explícita se encuentra en el parágrafo 42 del Primer Tratado del Gobierno Civil. En efecto, Locke afirma en dicho texto la existencia de un deber para con las personas que se encuentran en situaciones de necesidad extrema, concediendo al necesitado un derecho sobre el excedente de sus bienes ${ }^{45}$. Juliana Udi exige no pasar por alto el estudio del deber de caridad tal como está planteado en dicha obra. Al ser el Primer Tratado una respues

\footnotetext{
41. LOCKE (2005) párrafo 6

42. Ídem, párrafo 70

43. Ídem, párrafo 94

44. LOCKE (2004) p. 123 (traducción de la autora)

45. Afirma LOCKE (2008), en el parágrafo 42: "Sabemos que Dios no dejó a ningún hombre tan a merced de otro como para que éste pueda dejarlo morir de hambre si le place. Dios, Señor y Padre de todos, no ha dado a ninguno de sus hijos tal propiedad sobre su porción particular de las cosas de este mundo, sino que ha concedido a su hermano necesitado un derecho sobre el excedente de sus bienes, de forma que, en justicia, no se le pueden negar cuando sus necesidades apremiantes los reclamen. Y, en consecuencia, ningún hombre pudo nunca tener un poder justo sobre la vida de otro, por derecho de propiedad de la tierra o de otras posesiones. Y siempre será pecado que un hombre de posición deje perecer en la necesidad a su hermano por no darle algo de lo que mucho tiene. Así como la justicia otorga a cada hombre un título sobre el producto de su honesta industria y las legítimas adquisiciones que sus antecesores le legaron, de modo análogo la caridad da a todos los hombres un título sobre lo que le sobra a los que mucho poseen, para mantenerlos alejados de la necesidad extrema, en tanto carezcan de medios para subsistir de otra manera".
} 
ta al Patriarca de Robert Filmer, Locke se empeña en refutar la justificación divina e ilimitada naturaleza del poder real, siendo este texto de relevancia no solo política y jurídica sino también teológica. Lo anterior constituiría, en concepción de Udi, indicio suficiente de la importancia que le otorgaría a la caridad, en cuanto su tratamiento más sistemático se encuentra no en uno de los textos menores del autor sino en una de sus obras epigonales. Al respecto asegura Udi que "Situar la formulación del deber de caridad en el marco de la polémica de Locke con Filmer destaca la importancia que tiene este deber, en tanto que lo hace aparecer como una exigencia que no podría ser desconocida ni siquiera por quien detentara el más absoluto de los poderes. Incluso si Dios le hubiera dado a Adán todo el mundo, igual sería injusto que éste amenazara con privar de los recursos de subsistencia a quienes se negaran a reconocer su dominio político" ${ }^{46}$.

Udi va más allá, afirmando que el deber de caridad alcanzaría el estatus de principio general. En efecto, dice respecto del Primer Tratado: "Locke va más allá: afirma que siempre es incorrecto que alguien que posee un excedente se lo niegue a los indigentes y que la caridad le otorga a todo hombre necesitado un título sobre el excedente de bienes de otro, cuyas necesidades básicas se encuentran satisfechas" ${ }^{47}$.

Tras haber establecido la ubicación del deber de caridad dentro del corpus lockeano, la autora procede a desentrañar su naturaleza, para lo cual desvincula ab initio la caridad en Locke del normal entendimiento del término. En efecto, las características asociadas comúnmente al concepto de caridad serían, según Udi, las siguientes: 1) Su cumplimiento supone una práctica supererogatoria, esto es, situada más allá de lo normativo. 2) No se puede exigir su cumplimiento por vías coercitivas. 3) Es un deber imperfecto, es decir, indeterminado en lo relativo a su contenido - no podría determinarse a priori cuánta ayuda es debida y de qué tipo- y al perfil del beneficiario, quedando ambos aspectos librados al arbitrio del benefactor. 4) Es un deber negativo, consistente en la abstención de realizar prácticas lesivas a terceros y no en la exigencia de acciones positivas ${ }^{48}$.

Para Udi, el deber de caridad lockeano asume una naturaleza radicalmente diversa. A partir del parágrafo 42, la caridad en Locke parece contradecir cada una de las características enunciadas. En efecto, sostiene la autora que "Para empezar, Locke considera que el deber de caridad sí implica un derecho correlativo. Lo dice claramente: «Dios, Señor y Padre de todos, no ha dado a ninguno de sus hijos tal propiedad sobre su porción particular de las cosas de este mundo, sino que ha concedido a su hermano necesitado un derecho sobre el excedente de sus bienes»" ${ }^{49}$. Se trataría por

\footnotetext{
46. UDI (2012b) p. 169

47. Ibídem

48. Ídem pp. $169-170$

49. Ídem, p. 170
} 
tanto de un "claim right" en sentido restringido, que en la concepción de Wesley Hohfeld es aquel que exige de otros el deber correlativo de permitir al titular del mismo el ejercicio de su derecho ${ }^{50}$.

Tampoco parece ser que para Locke sea la caridad algo tan indeterminado en cuanto a su contenido y beneficiarios. Así, Udi señala que "De acuerdo con el pasaje citado, (parágrafo 42 del Primer Tratado) el deber de caridad obliga a todos los propietarios de algún tipo de excedente. En cuanto al aspecto cuantitativo, el deber de caridad les exige ceder a todos sólo una mínima porción de su excedente, a saber, la mínima indispensable para que otros hombres no mueran de hambre. Los beneficiarios deben ser personas que, en primer lugar, se encuentren atravesando una situación de necesidad tal, que ponga en peligro su subsistencia. A este requisito Locke añade la condición adicional de que la persona necesitada «carezca de medios para subsistir de otra manera», esto es, que esté imposibilitada para trabajar, sea por una incapacidad física o intelectual, sea por falta real de empleo"51.

Lo anterior resulta también importante, en opinión de Udi, respecto de otra característica de la caridad lockeana: su exigibilidad coercitiva. Señala que el carácter imperfecto e indeterminado de los deberes de justicia suelen ser esgrimidos como excusa para denegarles su exigibilidad mediante coacción, amparados en la supuesta amenaza de prácticas arbitrarias y abusos que su aplicación práctica conllevaría. De esta manera, Udi parece estar insinuando que, quedando establecido el carácter determinado del deber de caridad para Locke, no cabría duda acerca de la posibilidad de que se exija su respeto incluso mediante la coacción. Dice en un pie de página -en concreto el número 15 en la página 170 de "Propiedad lockeana, Pobreza extrema y Caridad" - que tratará en el próximo apartado la exigibilidad por coacción, pero en dicho "siguiente apartado" se refiere a la justificación de la caridad en el derecho natural de preservación, sin tratar de manera directa el problema de su exigibilidad. Debido a lo anterior, especulamos que Udi encuentra el fundamento de la coercibilidad del deber de caridad lockeano en la ley natural a la que refiere Locke.

Finalmente, Udi asevera que la caridad lockeana es un deber positivo. Reconoce que algunos pasajes parecen insinuar un carácter meramente negativo en virtud del cual exigiría sólo una abstención o limitación del actuar en beneficio de otros, como por ejemplo cuando Locke trata la ley fundamental de la naturaleza, de la cual provienen todos los derechos y deberes naturales, que dictaría dos deberes jerarquizados: maximizar la propia preservación y, cuando esto esté garantizado, maximizar la de la humanidad en su conjunto. En dicha instancia, pareciera darse a entender que el deber de caridad mandaría tan solo no bloquear el acceso a otros. Sin embargo, Udi

50. HOHFELD (1917), pp. 716-717

51. Ibídem 
señala que en el mismo parágrafo 42 se caracteriza claramente la caridad como un hacer positivo, por el cual los propietarios de excedentes deben "darle a los indigentes algo de lo mucho que tienen" ${ }^{52}$, y cita en apoyo de la misma idea el séptimo de los Ensayos sobre la ley natural titulado ¿Es perpetua y universal la fuerza obligatoria de la ley natural? Sí, donde se indica que la caridad constituye la "realización de actos exteriores", como lo es la "provisión de alimento a los que sufren hambre" ${ }_{53}$.

Tras haber caracterizado el deber de caridad lockeano, se aboca Udi a determinar el fundamento último del mismo y su razón de ser dentro del corpus lockeano. Esta tarea resulta fundamental en el trabajo de la autora toda vez que en ella reside la originalidad y relevancia de esta nueva perspectiva que busca aportar a la comprensión de Locke y de su teoría de la propiedad. En este esfuerzo, Udi identifica como fundamento de la caridad lockeana el derecho natural de los hombres a los medios de preservación, el cual sería así sustento justificatorio no solo del derecho de propiedad, como la lectura tradicional de Locke sugiere, sino también del deber de caridad. Este constituye el eje central de la propuesta de la autora, lo cual es esencial en ella en cuanto al caracterizar a la caridad de esta manera la misma deja de considerarse una amenaza o transgresión a la propiedad privada, convirtiéndose en su necesario complemento ${ }^{54}$.

Udi redirige así el análisis hacia los fundamentos sobre los cuales Locke construye su teoría de la propiedad. Tales son la igualdad primigenia entre los hombres y la entrega "en comunidad" que Dios hace de todos los bienes y tierras a la especie humana en su totalidad, para su provecho y subsistencia. En este punto recuerda la autora que al justificar la propiedad privada o la apropiación individual desde el derecho natural Locke establece limitaciones a la misma fundados en mencionada ley. Así, la misma Ley Eterna que da sustento a la propiedad privada establece las limitaciones inherentes a ella, fundado en la necesidad de preservación y subsistencia de la humanidad como un todo. Como se vio anteriormente, varios intérpretes de Locke han visto en él un derecho natural a la apropiación privada ilimitada, propiciado en gran medida por la invención del dinero como hecho que derogaría los límites naturales a la propiedad $^{55}$. Ante esto, Udi contesta que la caridad viene a cumplir un rol equilibrador, al ser la "forma bajo la cual persiste el contenido normativo del derecho a los medios de preservación una vez iniciado el proceso histórico de apropiación privada de la tierra y de los recursos naturales en general" ${ }^{16}$. De esta manera, ante la predominancia de un

52. Ídem, p. 171

53. LOCKE (2004) p. 93

54. UDI (2012b) pp. 171-172

55. UDI (2014) p.150

56. Ídem, p. 156 
sistema propietario omnicomprensivo, la autora contribuye con estos razonamientos a redirigirlo hacia su fundamento originario -la preservación de todos los hombres-, y aquello lo hace con su vínculo con la caridad.

Por último, en cuanto a las conclusiones a las que llega con su trabajo Udi, hay diferentes ideas presentes en dos de sus publicaciones. El trabajo titulado El derecho a la caridad: repercusiones de la teología cristiana en la teoría de la propiedad de John Locke tras seguir pasos a grandes rasgos coincidentes con lo aquí expuesto, concluye postulando que la existencia para Locke de un derecho natural a la caridad se explicaría, en definitiva, por la presencia de algunos elementos de la teología cristiana en su teoría de la propiedad ${ }^{57}$. Dice Udi que, tomado aisladamente el capítulo de la propiedad, "Puede parecer dirigido a legitimar la "posesión desproporcionada y desigual de la tierra" que inevitablemente genera el trabajo una vez que se introduce el dinero. Pero la teoría del derecho natural que sirve de marco tanto a la teoría de la propiedad de Locke como a su doctrina de la caridad exige velar por la preservación de todos los hombres, aun de los "no industriosos y racionales". Y esta teoría del derecho natural tiene una dimensión teológica: la concepción de la ley natural como un conjunto de mandamientos divinos es el fundamento teológico-filosófico que anima toda la teoría política de Locke, incluida su teoría de la propiedad. Dios, que creó a todos los hombres iguales y les entregó en común los recursos naturales, lo hizo con el propósito de que todos, sin excepción, preserven su vida. Ningún estado de cosas resultante de las acciones de los hombres que se desvíe de esta pauta igualitaria mínima es compatible con este axioma teológico de partida" ${ }^{58}$.

Es así como Udi entiende a la caridad en cuanto garantía. En una sociedad monetizada que difumina tanto los límites naturales de la propiedad privada como su sentido originario justificante, la caridad viene a garantizar el cumplimiento del "designio divino de que todos los hombres dispongan de medios para preservarse" ${ }^{159}$.

Para demostrar lo anterior, Udi expone, en la misma línea que Waldron ${ }^{60}$, el interés que Locke evidencia por la doctrina cristiana a lo largo de su obra, en la cual se sustentaría la caridad como contrapeso a la propiedad. Cita al respecto La racionalidad del cristianismo, donde el autor alerta sobre la necesidad de recurrir a las enseñanzas y ejemplos de Jesús para entender la ley natural. También se refiere la autora a la finalidad de los Dos tratados sobre el gobierno civil, concebidos como respuesta polémica al Patriarca, de Robert Filmer. Tratándose esta obra de un intento de justificación, a través del derecho divino, del poder del rey, resulta decidor, en la opinión

\footnotetext{
57. Ibídem

58. Ibídem

59. Ibídem

60. WALDRON (2002) p. 12
} 
de Waldron ${ }^{61}$, que en su obra refutadora Locke destine todavía mucho más espacio que Filmer a exponer pasajes del Antiguo Testamento. No pasa el tema desapercibido para John Dunn quien hace notar que todo el argumento de los Dos tratados está "saturado de presupuestos cristianos"62, y en el mismo sentido Edward Andrew destaca la influencia religiosa en el pensamiento político de Locke haciendo ver como una "característica curiosa del pensamiento liberal contemporáneo su aceptación de la teoría política lockeana unida a un simultáneo rechazo del fundamento teológicofilosófico en el que se apoya"63. Todo esto permite entender la influencia del cristianismo en el pensamiento lockeano.

A continuación, Udi cita a Waldron para especificar los alcances de mencionada influencia cristiana en Locke. Según el autor, la misma se enmarcaría dentro de una teoría de la igualdad. En efecto, sostiene que "este postulado de la igualdad básica de los hombres no tiene el estatus de "una preferencia o una regla empírica de prudencia; tampoco el de un «dictado de la razón»", como las leyes naturales de Hobbes. En cambio, Locke confirió a la idea de igualdad básica el fundamento más poderoso que se le puede dar a un principio: la consideró un axioma de la teología, entendido como la verdad más importante sobre Dios y su relación con el mundo en lo que respecta a las implicancias sociales y políticas de su creación de la persona humana"64.

Según Waldron, esta idea de la igualdad cumpliría una doble función: ser base o premisa para la construcción de la teoría política de Locke, y ser un límite teórico que "asegure que las derivaciones que se siguen de las premisas de la teoría no se desvíen y continúen siendo plenamente consistentes con el concepto de que las criaturas racionales son iguales entre sí”65.

Esta doble función postulada por Waldron es tomada por Udi y aplicada a su obra en lo relativo a la relación entre propiedad y caridad. Lo hace recordando que la propiedad privada y el deber de caridad lockeanos comparten una misma base justificatoria: el derecho natural a los medios de preservación. Y este derecho natural a su vez proviene de la idea cristiana de igualdad y de la concepción de la ley natural como expresión de la voluntad divina ${ }^{66}$ : "Los hombres son criaturas de Dios y deben subsistir por el tiempo que Dios disponga: están obligados a preservarse a sí mismos y a preservar al resto de la humanidad tanto como les sea posible"67. De esta manera, Udi vuelve a hacer ver el carácter de garantía o reaseguro que cumple la caridad en el

61. Ídem pp. 16-17

62. DUNN (1969) p. 99 (traducción de la autora)

63. ANDREW (1988) pp. 5-6 (traducción de la autora)

64. WALDRON (2002) p. 6

65. Ídem, p. 151

66. UDI (2014) p. 158

67. LOCKE (2005) párrafo 6 
sistema de Locke, en el cual la igualdad mencionada "se encarna en el derecho natural que todos tienen a los medios de preservación, pero si las cosas se desvían de esta pauta y, por ejemplo, por ejercer diferentes grados de laboriosidad, algunos hombres llegan a apropiarse de mucho más de lo necesario mientras que otros no acceden siquiera a lo indispensable para mantenerse con vida, el ideal de igualdad reaparece como "límite teórico" bajo la forma del deber de caridad"68.

Finalmente, tenemos otras ideas conclusivas de Udi publicadas en Propiedad lockeana, pobreza extrema y caridad. Aquí se dedica a analizar la relación entre la caridad y la propiedad, para llegar específicamente a la conclusión de que la primera no es amenaza de la propiedad privada, sino su complemento necesario para que se den ciertos márgenes mínimos de redistribución.

Realizado el análisis relativo a la ubicación y justificación de la caridad en Locke, en dicha obra la autora procede a contextualizar históricamente la teoría de la propiedad lockeana, demostrando que entre los siglos XVI y XVII era una urgencia política realizar una defensa filosófica de la propiedad, lo que explicaría su aparente preeminencia respecto de otras instituciones dentro del sistema filosófico-político de nuestro autor. Esto se sustenta, según Udi, en tres factores que expondremos a continuación ${ }^{69}$.

En primer lugar, la expansión ultramarina europea habría generado disputas por el control de las colonias y las rutas comerciales, lo que suscitó interrogantes respecto a la propiedad. ¿Tenían las potencias europeas expansionistas derecho a reclamar la propiedad exclusiva de los mares descubiertos? ¿Cómo justificar las pretensiones de dichas naciones sobre tierras habitadas por pueblos -supuestamente- menos desarrollados? ¿Cómo es que los habitantes nativos de las tierras conquistadas podían llegar a convertirse en propiedad -esclavos- de los europeos $?^{70}$.

En segundo lugar, en el siglo XVII había surgido en Inglaterra la polémica entre los whigs, enemigos de la monarquía absoluta, y los tories, sus defensores. Ambos bandos se acusaban mutuamente de no poder proveer una defensa sólida de la propiedad y la desigualdad. Para los whigs, lo que amenazaba la propiedad privada era principalmente un rey católico poderoso que se consideraba el propietario último de la tierra. Para los tories, en cambio, la propiedad se veía amenazada principalmente por los whigs, que postulaban una igualdad originaria natural de los hombres ${ }^{71}$.

Finalmente, existía también un crecimiento inusitado de la pobreza, la desocupación y el vagabundeo, incremento que tuvo lugar a raíz de cambios económicos y demográficos acelerados. Aunque la pobreza no era un fenómeno nuevo, durante el siglo XVII recibió mayor atención en cuanto fenómeno de relevancia política ${ }^{72}$.

\footnotetext{
68. UDI (2014) p.158

69. UDI (2012b) p. 174

70. Ibídem

71. Ibídem

72. Ibídem
} 
A la luz de estos antecedentes contextuales, Udi explica el intenso debate existente en la época en torno a la justificación la propiedad privada. Numerosos autores como John Selden, Samuel Pufendorf, James Tyrrell y el mismo Locke concentraron sus esfuerzos en dicha empresa. Lo anterior permitiría entender a la misma como una prioridad política de la época, lo que explicaría la predominancia de la institución de la propiedad dentro de las teorías políticas de todos y cada uno de ellos. Al respecto afirma Udi que "La imagen de estos autores como «teóricos de los derechos de propiedad» muchas veces opaca el hecho de que también se abocaron a justificar derechos de subsistencia"73. En efecto, estos autores "procuraban dar cuenta de dos aspectos de los derechos de propiedad que, desde su óptica, se hallaban necesariamente interconectados: (i) el derecho a excluir, en ciertas circunstancias, a otros del control y uso de ciertos recursos; (ii) el derecho a que, en otras circunstancias, se nos incluya en el uso de los recursos necesarios para nuestra subsistencia. Así, las discusiones en torno del significado apropiado de los derechos de propiedad eran discusiones acerca del equilibrio o la proporción que debía existir entre los aspectos excluyente e inclusivo ya comprendidos en dichos derechos. Esto se vio plasmado en la justificación que desarrollaron estos autores de un «derecho de necesidad» [right of necessity], cuyas exigencias entran en vigencia toda vez que se produce una situación de necesidad extrema"74.

De esta manera, y si bien Locke no habría conceptualizado un derecho de necesidad propiamente tal, sí habría incorporado sus características fundamentales a través de otras instituciones que sí encuentran consagración en su obra. Entre ellas, la principal sería, en opinión de Udi, la institución de la caridad.

Para demostrar la relevancia que en el corpus lockeano tienen las limitaciones a la propiedad fundadas en razones de necesidad, Udi acude a lo expuesto por Locke en un reporte que elaboró con ocasión de un proyecto de Ley de Pobres. Sin entrar en detalle, pues escapa al objeto del trabajo, puede decirse a modo de resumen que Udi construye a partir de la lectura y análisis de dicho texto, la existencia de ciertos sistemas de justicia distributiva en el Corpus Lockeano, los que serían aplicaciones concretas del deber de caridad de nuestro autor.

Ya hacia el final del planteamiento de Juliana Udi, pueden resaltarse los siguientes elementos de su obra. En primer lugar, la autora aclara que la caridad no constituye en ningún caso un límite a la legítima apropiación originaria, toda vez que esta institución no permite discriminar entre lo que es con justicia de uno y de otro. El deber de caridad, por el contrario, permite establecer límites al ejercicio de la propiedad una vez adquirida, no cuestionando la titularidad de la propiedad sino estableciendo ma

73. Ídem, p. 175

74. Ibídem 
neras legítimas de ejercicio de la misma que sean compatibles con el principio último de preservación de todos los hombres.

En segundo lugar, sostiene que la toma de postura en materia distributiva -que corresponde al motivo específico que infunde este texto en particular de Udi- está íntimamente ligada a la justificación de la propiedad en Locke. La autora recuerda que el fundamento de la propiedad lockeana es el derecho natural a los medios de preservación, y no el trabajo, como comúnmente se afirma. El segundo se subordina al primero, de manera que si bien ambos son fundamentos empleados por Locke para justificar su teoría de la propiedad, sería sólo el primero el fundamento último. $\mathrm{Y}$ en este sentido afirma la autora que "La caridad no vulnera los derechos de propiedad lockeanos porque ellos son per se limitados: está en su fundamento último, del que emanan tanto los derechos de propiedad como su complemento necesario, los deberes (y derechos) de caridad"75. Así, existirían entonces algunos márgenes de redistribución connaturales a la institución de la propiedad privada, que si bien mínimos -reducidos a casos de extrema necesidad y/o pobreza-, no son por ello menos relevantes y dignos de consideración ${ }^{76}$.

Asentado lo anterior, Udi acusa a los intérpretes de Locke y “filósofos neolockeanos" de haber obviado deliberadamente los elementos distributivos de su pensamiento. Afirma la autora que "En paralelo con su teoría de la propiedad puede identificarse una teoría de la justicia distributiva. La presentación es dispersa y elíptica, pero no por ello despreciable"77.

De esta manera, Udi termina su exposición en torno al deber de caridad y su relevancia dentro del corpus lockeano. La misma sería una institución fundamental dentro del mismo que, sin embargo, ha sido ignorada por la mayoría de los intérpretes del autor inglés. Concluye así la autora que la caridad nos permite tomar conciencia de todo un sistema distributivo que, si bien disperso en distintas obras y sin un tratamiento sistemático, no es posible ignorar si el objetivo es una comprensión acabada y omnicomprensiva del sistema político de Locke.

\section{Críticas y concesiones al planteamiento de UDI}

\section{A. Críticas a Udi}

\section{Integración horizontal del Corpus Lockeano}

El primer problema que presenta el análisis de Juliana Udi se haya en su manera de abordar e integrar las distintas obras de John Locke. Al estudiar la teoría política lockeana, y en particular la institución de la propiedad, la generalidad de sus intér

75. Ídem pp. 185-186

76. Ídem p. 186

77. Ídem, p.184 
pretes consideran que la misma se encuentra condensada en el Segundo Tratado. Esto no debería sorprender debido a la naturaleza de la obra en cuestión, que, a diferencia de otras obras de Locke -connotado polímata que abordó las más diversas ramas del saber-, es de eminente naturaleza filosófica. La autora rompe con este consenso, recurriendo a escritos lockeanos "menores" y de diversas materias con el objeto de expandir los alcances de la doctrina política de nuestro autor. Esta nueva forma de integración es la que analizaremos -y cuestionaremos- a continuación.

La propuesta política presente en el Segundo Tratado es coherente y consistente. Analizada en sí misma, deja poco espacio a interpretaciones divergentes, lo cual se manifiesta en el incuestionado dominio interpretativo de las propuestas de Strauss y Macpherson ya analizadas. Quien quiera desbancar dicha doctrina no encontrará en el Segundo Tratado herramientas suficientes. Se hace necesario recurrir a otros textos del Corpus, y esa es justamente la táctica de Udi.

Udi encuentra su principal refugio en el Primer Tratado, en el que se alberga un amplio desarrollo de la caridad -ya expuesto en este trabajo-, funcional a la propuesta de la autora. Se suma al mismo ciertos textos que ella misma caracteriza como "menores", en atención a la relevancia que estos tienen dentro del corpus. Finalmente, recurre a un comentario de un proyecto de Ley de Pobres elaborado por Locke para desarrollar un detallado análisis de lo que constituiría, en opinión de la autora, la concreción práctica de la Caridad Lockeana, texto a partir del cual Udi también extrae la existencia en el corpus de sistemas de exigibilidad incluso coercitiva del deber de caridad. A partir de estos textos, Udi reinterpreta la teoría política de Locke en general y la institución de la propiedad en particular, redefiniendo así la naturaleza misma de la propuesta política lockeana.

El principal problema de esta manera de entender a Locke está en que, para que la misma sea posible, Udi realiza una integración horizontal del Corpus Lockeano. Como ya mencionamos, Locke fue un polímata que dedicó sus esfuerzos a las más diversas ramas del conocimiento, entre las que destacan la filosofía, política, psicología y medicina. Se suma a lo anterior que fue un ferviente escritor, que puso por escrito todas y cada una de sus ideas, sin mayor discriminación respecto a su profundidad, elaboración y relevancia. Afirma Carlos Peña que existe en Locke una extrema profusión en su escritura y heterogeneidad en los temas de los que se ocupó ${ }^{78}$. Agrega que "era un escritor casi maníaco, que puso en el papel con entusiasmo y con deleite prácticamente todo lo que se le ocurrió: sus libros tardíos, los debates en que participaba, las dudas que lo asaltaban, cartas, prescripciones médicas, conjeturas, análisis constitucionales"79. Era por tanto un intelectual que escribió sobre diversos temas, sin autolimitarse en atención a la relevancia de sus escritos ni pretender lograr una coherencia sistemática entre cada uno de ellos.

78. PEÑA (2004), p. 133.

79. bis 
Es por esto que decimos que Udi cae en el error de la integración horizontal. La autora recurre a textos que son o bien de menor entidad dentro de la doctrina filosófica del autor o derechamente ajenos a la materia, para luego colocarlos en el mismo nivel que el Segundo Tratado, el texto filosófico lockeano por antonomasia, y a partir de ellos refutar el razonamiento ahí vertido, desconociendo toda jerarquía existente, al menos implícitamente, entre las mismas -e incluso aferrándose, en más de algún caso, a frases y aseveraciones aisladas y poco argumentadas dentro de los textos citados-.

La obra de Locke no puede integrarse de manera horizontal. Sus diversos textos no suponen un todo orgánico, piezas dentro de un engranaje debidamente aceitado. Debido a sus características en cuanto pensador, cada uno de los textos de nuestro autor tenían un objetivo específico, tanto respecto a su elucubración teórica como también respecto a sus consecuencias prácticas. Los textos deben valorarse por lo que efectivamente dicen y no por lo que pudieron haber dicho pero no lo hicieron. En ese respecto, y en atención a la materia que nos convoca, siendo el Segundo Tratado el texto político fundamental de Locke, uno esperaría que las principales instituciones de su propuesta estuvieran al menos enunciadas en el mismo. Sin embargo, el deber de caridad brilla por su ausencia, y la remisión al Primer Tratado, cuyo principal foco era refutar la fundamentación de la legitimidad de la monarquía en el derecho natural, y no remitirse a los límites del derecho de propiedad, resulta insuficiente. Si el deber de caridad no fue caracterizado en el Segundo Tratado, y no existe remisión alguna al mismo en su Capítulo Quinto sobre la Propiedad, en el cual Locke desarrolla meticulosamente los fundamentos, características y limitaciones a mencionada institución, es porque, dentro de la teoría política de nuestro autor, la caridad no ocupaba un lugar predominante. Defender otra postura supone forzar los textos lockeanos de una manera que desvirtúa la naturaleza y finalidades de cada uno de ellos individualmente considerados.

\section{La caridad: término equívoco en Locke}

Ya mencionamos que, tras demostrar la existencia del deber de caridad dentro del Corpus, Udi se aboca a la caracterización y especificación del mismo. Al hacerlo, la autora desmarca la caridad lockeana de las características atribuidas tradicionalmente al concepto. Al contrario, identifica los que serían, en su opinión, los atributos de esta institución en la obra de Locke, a saber, que ésta 1) conlleva un derecho correlativo aparejado, 2) está suficientemente determinado en cuanto a sus sujetos y contenido, 3) es exigible coercitivamente y 4) supone un deber de actuar, y no una mera abstención ${ }^{80}$. Estas serían, según Udi, las características de la caridad lockeana, unívocamente entendida.

80. Ya expuesto en las páginas 5 y 6 del presente trabajo. 
Esta integración de la caridad lockeana es generalizadora y apresurada. De la lectura de los textos que la misma autora cita, no queda en absoluto claro que Locke maneje un concepto unívoco de caridad y, muy por el contrario, existen indicios que permiten sostener lo contrario, esto es, que la caridad lockeana es un concepto equívoco. Esto es especialmente evidente respecto de los últimos dos atributos por Udi asignados a la institución en cuestión, que serán analizados a continuación.

El deber de caridad no es siempre exigible coactivamente. En el Primer Tratado, obra en el que según la propia Udi es donde se trata de manera más general y sistemática la institución en cuestión, no se hace referencia a dicha coercibilidad -y mucho menos en un Segundo Tratado que no hace mención alguna a la caridad-. Si es el Primer Tratado el texto donde mejor se configuran los contornos de la caridad con pretensiones de generalidad, se esperaría que en el mismo se estableciera de manera explícita su exigibilidad. Sin embargo, dicha característica no se encuentra presente en este texto. La autora, para fundamentar su tesis, recurre al reporte sobre la Ley de Pobres -cayendo una vez más en la integración horizontal ya esbozada y criticada-. Sin entrar en la discusión ya esgrimida relativa a la jerarquía de cada uno de los textos lockeanos -en virtud de la cual constituiría un error asignar mayor importancia, a la hora de establecer las características de la caridad, a un texto sobre políticas públicas que a aquel sobre filosofía política-, la diferencia entre ambos textos respecto a la exigibilidad coercitiva de esta institución demuestra que en Locke no existe solo una caracterización de la caridad, no siendo posible universalizar un único concepto con características inmutables aplicable a todo el Corpus de manera uniforme.

En cuanto al carácter positivo o negativo del deber de caridad en Locke, resulta aún más evidente la falta de uniformidad. La misma Udi comenta que en el Segundo Tratado Locke parece sugerir en el tratamiento que ahí hace de la "ley fundamental de la naturaleza, de la que emanan en definitiva todos los derechos y deberes naturales" ${ }^{\prime 1}$, que el deber secundario -respecto a la propia preservación- de maximizar la preservación de la humanidad sería más bien un deber negativo, consistente en no dañar a otros hombres. Si dicho deber, tratado explícitamente en el Capítulo Quinto del Segundo Tratado como uno de los límites fundamentales del ejercicio del derecho de propiedad, no supone un actuar positivo, menos podría serlo un supuesto deber que ni siquiera ha sido tratado en mencionado texto. La referencia que hace Udi al Primer Tratado y a uno de los Ensayos sobre la ley natural ${ }^{82}$ es insatisfactoria para sus pretensiones, pues si bien sí podrían ser útiles para argumentar la existencia de una cierta clase de caridad que supone un actuar positivo, no sirve para aunar criterios y

81. UDI (2012b) p. 171

82. Todo esto comentado anteriormente al exponerse el trabajo de Udi, en p. 6 
generalizar dicha característica, más cuando en el Segundo Tratado se ha afirmado que los límites explícitos que Locke colocó a la propiedad -que, como afirma la mayoría de la doctrina, han de ser los más relevantes- son de carácter negativo. Sostener que existe un límite no tratado en el texto en cuestión y que sin embargo rompe con el principio rector de los límites sí tratados en el texto filosófico por antonomasia supone romper con toda lógica y forzar el texto más allá de lo razonable.

Es por esto que la caridad lockeana no es un concepto unívoco. Al menos dos de las cuatro características que Udi pretende asignar a dicha institución no se encuentran de manera consistente en el Corpus. Al intentar sistematizar una institución con alcances genéricos, Udi va más allá de lo que los propios textos lockeanos permiten ir. Sin desconocer las referencias a la caridad que en ellos existen, la univocidad de dicho concepto no es posible. Esto puede tener consecuencias relevantes en la propuesta interpretativa de la autora, las que sin embargo no exploraremos en detalle por escapar al objeto del presente trabajo, limitándonos a decir algo al respecto en el siguiente apartado.

\section{Imposibilidad de sistematizar la institución de la caridad en el Corpus Loc- keano}

Esta crítica es una consecuencia de las dos anteriores. Si dijimos que Udi cae en una integración horizontal que el Corpus no permite y que la caridad es un concepto equívoco en Locke, entonces se puede afirmar que no es posible realizar una sistematización de la institución en cuestión. En efecto, la propiedad lockeana recibe un tratamiento sistemático y con afanes generalizadores por parte de nuestro autor, por lo que, para intentar establecer límites a la misma, Udi se ve forzada a colocar a la caridad en el mismo nivel teórico, lo que explica en parte la integración horizontal que hace de las obras lockeanas y la univocidad que le atribuye a la caridad. Sin embargo, la caridad en Locke no permite ser sistematizada, por lo que, aún si aceptáramos la caridad con la forma y características que Udi le asigna, no podríamos atribuirle el mismo alcance que ella le concede -ser un límite a la propiedad, emanado del propio fundamento de la misma, la ley natural, en cuanto manifestación de un sistema distributivo en el corpus-, sin afectar a la propiedad lockeana en su configuración teórica. Creemos que la caridad puede ser entendida como un recordatorio de la presencia e influencia del derecho natural en la elucubración lockeana. No puede ni debe ser entendida, a la manera que pretende Udi, como una institución sistemática que materializa un cierto sistema de justicia distributiva en la obra de Locke. Una lectura imparcial de sus textos no lo permite. 


\section{B. Concesiones a Udi}

A pesar de las inconsistencias ya expuestas, la tesis de Juliana Udi posee elementos que son un aporte para una mejor lectura de Locke. Los expondremos a continuación. El principal aporte de la autora está en recuperar y reposicionar a la caridad dentro del corpus lockeano. En sus palabras, la generalidad de los autores no hacen mención alguna a este deber, y autores como Waldron o Simmons sólo la mencionan, sin un tratamiento acabado. En este contexto, la autora pone en la palestra una institución que, si bien hemos dicho no creemos tiene los alcances que ella sostiene, sí ha de ser considerada si se busca un entendimiento más integral del corpus. Que el mismo no suponga un todo armónico y coherente no significa que su estudio deba ser parcelado. Un estudio acabado de Locke requiere hacerse cargo del deber de caridad presente en su obra, si bien a través de una aproximación diversa y con fines más acotados.

Otro aporte relevante lo constituye el rendimiento que la caridad lockeana puede ofrecer en la tarea de redirigir la propiedad lockeana hacia su fundamento último. La misma Udi sostiene que la principal utilidad e importancia de la caridad está en servir como complemento a la propiedad, para así no olvidar el lugar que ésta ocupa dentro del pensamiento lockeano. Como ya mencionamos, para nuestro autor la propiedad es consecuencia de la igualdad natural entre todos los hombres, de la entrega que Dios hace de todas las cosas a la humanidad en su conjunto y del derecho natural a la preservación. La crítica de Udi contra autores como Strauss y Macpherson, quienes desconocen estos fundamentos al centrarse en una propiedad ilimitada e identificar en Locke un individualismo exacerbado, es una constante. A través de la caridad, Udi busca reinterpretar a la propiedad lockeana, para así volver a tener en miras que Locke no pensaba en la propiedad como una institución emanada del mero derecho positivo sino de la ley natural, y que en cuanto tal debía adecuarse a ciertas exigencias de igualdad y justicia emanadas de la misma -si bien criticamos, como ya dijimos, la relevancia y entidad que se le da a la caridad en dicho esfuerzo, el cual creemos no se condice con la importancia que dicha institución tiene en los textos lockeanos-.

Destacamos también algo que Udi parece recoger a $\operatorname{ratos}^{83}$, sin desarrollar acabadamente, que es ver en la caridad indicios de un sistema distributivo en Locke. Creemos, sin embargo, que una afirmación de tal envergadura supone una tarea interpretativa que no puede tener como único fundamento el deber de caridad. Elementos como la concepción de bien común, presente en pasajes de la obra lockeana, deberían ser considerados si se pretende construir un sistema de justicia distributiva en Locke.

En definitiva, es posible que Locke haya tenido en su mente elementos redistributivos a la hora de escribir su obra, lo que explicaría gran parte de sus contradicciones

83. Como aparece en la p. 11 de este trabajo, al final de la exposición de Udi, cuando hace ver la existencia de un "sistema de justicia distributiva" en Locke que ha sido obviado. 
e inconsistencias, además de la amplitud de interpretaciones que ha recibido su pensamiento, sirviendo de fundamento para el liberalismo más extremo al mismo tiempo que para colectivismos socialistas. Pero una cosa son las convicciones personales de Locke, que siembran desparramadas sus semillas a lo largo de su obra -una de ellas siendo, en nuestra opinión, la caridad- y otra muy distinta es el sistema teórico que plasmó en sus escritos. Y en este respecto, su teoría de la propiedad es tal vez una de sus propuestas más coherentes y sistemáticas, la que, en sí misma entendida, parece ser tierra fértil para extraer esas conclusiones individualistas y liberales que Udi critica. Esto no supone, por supuesto, abrazarlas irreflexivamente, siendo la tesis de la autora debidamente entendida un aporte en dicho esfuerzo de reinterpretación de la propiedad lockeana, acercándola a sus fundamentos ontológicos.

\section{Propuesta metodológica de aproximación a Locke: sistema lockeano de pro- piedad y locke-persona}

Analizada críticamente la propuesta de Udi, queda resolver cómo ha de leerse el Corpus Lockeano. ¿Debe renunciarse a toda lectura que pretenda entenderlo como un todo, o es aún posible una aproximación que se haga cargo de sus inconsistencias y tensiones? Nosotros nos inclinamos por la segunda alternativa, y ofrecemos una propuesta de aproximación a la obra de nuestro autor, en la que categorizamos los distintos elementos de la misma sin atribuirle ni presumir coherencia sistemática. Las categorías que proponemos, y que creemos son especialmente provechosas en referencia a la propiedad en Locke, son las de un Sistema Lockeano de Propiedad y Locke-Persona, que explicaremos a continuación.

Como ya expusimos en este trabajo, parte notable de la influencia del autor en cuestión se encuentra en su teoría de la propiedad del Segundo Tratado. Es considerada su aportación más importante y a la que más intensamente se han abocado sus intérpretes. A partir de ella es posible alcanzar conclusiones como las de Strauss, Macpherson u otros autores que, partiendo desde esta parte del corpus lockeano, construyen el individualismo posesivo y caracterizan a Locke como el padre del liberalismo. Creemos que dicha interpretación es sostenible. En efecto, si atendemos a la propiedad lockeana en sí misma, las conclusiones a las que llega C.B. Macpherson son coherentes. El individualismo posesivo termina siendo la consecuencia natural de este derecho de propiedad pre-social, absoluto e ilimitado, completamente ajeno a los intereses y necesidades de la comunidad. Como señala Macpherson, el efecto lógico que se sigue a partir de esas premisas es que el individuo es esencialmente propietario de su propia persona y capacidades, por lo que no debe nada a la sociedad ${ }^{84}$. Toda relación con el otro está basado en el propio interés, de manera que el individuo no es

84. MACPHERSON (1962), p. 263. 
obligado a nada para con el prójimo, a menos que voluntariamente lo decida -en atención, justamente, de su propio interés- ${ }^{85}$. Nos encontramos así ante el pilar jurídico de la sociedad de mercado, en cuanto la misma se funda sobre este derecho incondicional de propiedad ${ }^{86}$. La propiedad y el trabajo dejan de ser funciones sociales y las obligaciones sociales tradicionalmente asignadas a la propiedad resultan superadas ${ }^{87}$. Así, el derecho de propiedad moderno no está sujeto a la ejecución de una función social por parte del propietario ${ }^{88}$.

Esto no puede ser de otra forma, pues si la propiedad es un derecho natural, individual, absoluto y pre-social, y si la relación humana es contingente y movida por el propio interés, no existiendo obligación necesaria alguna asociada a este derecho, la sociedad aparece lógica y cronológicamente posterior al individuo y subordinada al interés particular de sus integrantes. En esta estructura ninguna limitación es posible, y por ello las restricciones que Locke impone a la propiedad son rápidamente superadas por una institución que, así configurada, no conoce límite a su capacidad expansiva. El sistema ya fue creado, y este crece independiente de los intereses que su creador tenía en mente al momento de instituirla.

No obstante lo anterior, esta interpretación, si bien correcta, tiene un alcance restringido en lo que al estudio de nuestro autor respecta. Si solo se considera su teoría de la propiedad, estas conclusiones aparecen irrebatibles. Sin embargo, a partir de ello no se puede afirmar que Locke buscase fundar el capitalismo. Las teorías de Macpherson y Strauss son correctas, pero sólo si se pretende hacer un análisis hermenéutico y exegético del capítulo quinto del Segundo Tratado. Sus conclusiones no son extrapolables al Corpus Lockeano como un todo ni a Locke en cuanto autor, pues supondría omitir deliberadamente demasiados pasajes e instituciones en manifiesta contraposición con mencionado capítulo.

Por ello creemos que una manera de leer el Corpus Lockeano es distinguiendo aquellos elementos y pasajes que se corresponden al Sistema Lockeano de Propiedad y aquellos que responden al Locke-Persona, los cuales, entre todos, conforman la obra total de nuestro autor. El Sistema de Propiedad Lockeano se encuentra desarrollado en el quinto capítulo del Segundo Tratado, constituyendo un todo armónico, mientras que los elementos que pueden caracterizarse como manifestaciones del Locke-Persona se encuentran desperdigados en distintas obras. Entendemos por manifestaciones de Locke-Persona aquellos pasajes e instituciones que son consecuencia

85. Ibídem.

86. RUIZ (1984), p. 6.

87. VILAJOSANA (1987), p. 471.

88. Ídem, p. 470 
directa de quién era Locke, cuál era su historia personal y los fines específicos que buscaba alcanzar con sus escritos, de manera de hacernos cargo no solo de su teoría de la propiedad sino de su obra como un todo. En este contexto, la caridad cae dentro de esta segunda categoría y constituye una de sus más importantes representaciones.

Debido a la distinción recién esbozada, consideramos que tanto los autores del individualismo posesivo como Udi llegan a sus conclusiones debido a las distintas metodologías y puntos de partida empleados, y que ambas aproximaciones son insuficientes. Strauss y Macpherson se centran en los elementos del Sistema de Propiedad Lockeano -que, como dijimos, es en sí mismo un sistema coherente-, y ello explica sus conclusiones. Sin embargo, no es posible, a partir de la parte, pretender caracterizar al todo. Que la teoría de la propiedad de Locke de pie al individualismo posesivo no permite caracterizar al Locke autor como el fundador del capitalismo o ideólogo de la sociedad de mercado. El ethos del sistema de propiedad lockeano no puede extenderse al resto de su obra.

En línea con lo anterior, Udi se centra en el Corpus, en el todo, y a partir de ahí pretende construir una nueva interpretación de la propiedad lockeana. Nuevamente, si bien en la dirección inversa, creemos que ello supone un error, pues pretende desde la integración del todo, desde la igual consideración de los elementos del Sistema de propiedad lockeano y de los de Locke-Persona, reinterpretar la teoría de propiedad. Pese a que la caridad permite arrojar luz sobre Locke en cuanto autor y sobre las finalidades que perseguía al tiempo de escribir, introducirlo casi a la fuerza dentro del esquema de la propiedad supone un error metodológico que resta validez a las conclusiones obtenidas.

Las distintas conclusiones a las que Macpherson y Udi arriban se explican por sus distintos puntos de partida, pero en ambos se incurre en el error de mezclar dos planos que consideramos deben entenderse con independencia, para una cabal comprensión de Locke y de su obra. Las conclusiones tanto de Macpherson como de Udi son coherentes siempre y cuando se circunscriban al plano teórico que les corresponde. La interpretación de Macpherson es apropiada si se considera el Sistema de propiedad lockeano, sin pretensiones de generalidad respecto del corpus ni de Locke en cuanto autor, y la de Udi es apropiada si se busca matizar la caracterización de nuestro autor como ideólogo del capitalismo, sin pretender reinterpretar un sistema de propiedad que es consistente y que ha adquirido independencia de las intenciones que su creador hubiese podido tener respecto al mismo. Por todo esto creemos que distinguir el Sistema de propiedad lockeano y los elementos que son manifestación de Locke-Persona es una beneficiosa manera de aproximarse a la obra de nuestro autor, esencialmente contradictoria y que no permite integraciones omnicomprensivas. 


\section{Conclusiones}

1. La propuesta de Juliana Udi desafía la interpretación dominante de la filosofía política de John Locke, la cual desconoce sus elementos distributivos que emanan de la ley natural, su fundamento primero. La autora identifica en el deber de caridad la posibilidad de reinterpretar el Corpus Lockeano, trayendo al debate esos elementos a través de la construcción de dicha institución.

2. Dicha construcción, sin embargo, adolece de ciertas inconsistencias. Al querer hacer del deber de caridad una institución de mayor entidad y relevancia que la que naturalmente tiene dentro de la teoría de nuestro autor, Udi formula una sistematización que no existe en su obra, cayendo en algunos saltos lógicos y extrapolaciones ya expuestos.

3. Lo anterior no significa que la propuesta de Udi adolezca de valor. Al rescatar la caridad lockeana la autora redirige la mirada hacia la esencia del deber de propiedad en Locke, esto es, su carácter de instrumento para la mejor preservación de la humanidad como un todo. Si bien no creemos que el deber de caridad sea el paradigma a partir del cual deba hacerse dicha recuperación, sí es un aporte para recaracterizar a Locke y cuestionar, al menos parcialmente, el título a él otorgado de "Padre del Liberalismo Clásico”. El esfuerzo de Udi, sumados a otros como Baciero -sobre la influencia de Suárez en la obra de Locke-, Dunn -sobre la influencia de la teología cristiana en su teoría política- y Waldron -sobre la caridad en la obra del inglés-, abren la posibilidad a un nuevo entendimiento del Corpus Lockeano.

4. Creemos que toda interpretación del Corpus Lockeano debe identificar y separar los planos del Sistema Lockeano de Propiedad y Locke-Persona, de manera que se pueda alcanzar un resultado metodológica y hermenéuticamente satisfactorio. La obra de Locke no es sistemática y en ella conviven elementos en eterna tensión. Esta distinción previa permite una mejor lectura del mismo, facilitando la debida categorización y diferenciación de dichos elementos para así evitar extrapolaciones y contradicciones.

\section{Referencias bibliográficas}

ANDREW, Edward (1988): Shylock's Rights: a Grammar of Lockian Claims (Toronto, University of Toronto Press).

BACIERO Ruiz, Francisco T. (2012): "El concepto de derecho subjetivo y el derecho a la propiedad privada en Suárez y Locke”, Anuario Filosófico, Salamanca, № 45/2, pp. 391-421.

BELL, Duncan (2014): “What is Liberalism?”, Political theory, Año 42, No. 6 (Sage Publications), pp.682-715 
CUARTAS Henao, María Dolly (2014): "El derecho a la propiedad: Locke y Kant, entre el trabajo y la ocupación”, Estudios de Derecho, Medellín, pp. 213-234.

CZAJKOWSKI, Casimir J. (1941): The theory of private property in John Locke's political philosophy (Indiana, University of Notre Dame).

DUNN, John (1968): “Justice and the interpretation of Locke's political theory”, Political Studies, No 16, I, pp. 68-87.

DUNN, John (1969): The political thought of John Locke: an historical account of the argument of the Two treatises of government (Cambridge, Cambridge University Press)

FERNÁNDEZ Peychaux, Diego (2010): “La justicia como pretensión política: John Locke entre el Medioevo y la Modernidad”, Bajo Palabra, Madrid, No 5 , pp. 239250.

GONZÁLEZ Terán, Diana Luz (2010): El derecho de propiedad privada en el liberalismo individualista (Santiago, Universidad de Chile).

HOHFELD, Wesley (1917): "Fundamental Legal Conceptions as Applied in Judicial Reasoning", The Yale Law Journal, Año 26, No. 8 (Jun., 1917), pp. 710-770.

LOCKE, John (2004): Essays on the Law of Nature, Political Essays (Cambridge, Cambridge University Press).

LOCKE, John (2005): Ensayo sobre el gobierno civil, trad. de C. Amor y P. Stafforini, Bernal, (Universidad Nacional de Quilmes-Prometeo).

LOCKE, John (2008), "First Treatise”, Two Treatises of Government. P. Laslett, (ed. Cambridge, Cambridge University Press) pp. 141-263.

MACPHERSON, Crawford Brough (1951): “Locke on Capitalist Appropriation”, The Western Political Quarterly, Año 4, No. 4, pp. 550-556.

MACPHERSON, Crawford Brough (1962): The Political Theory of Possessive Individualism: Hobbes to Locke (Oxford, The Oxford Handbook of Classics in Contemporary Political Theory).

MÉNDEZ Baiges, Víctor (1995): “QQué Locke?: tradición y cambio en la historia del liberalismo", Convivium, Barcelona, Año 7, pp. 64-80.

PEÑA, Carlos (2004): "Locke y la Filosofía Política" en Revista de Ciencia Política, Año 24, No 2, pp. 133-141.

RUIZ, Carlos (1984): "Individualismo posesivo, liberalismo y democracia liberal. Notas sobre la contribución de C.B. Macpherson a la teoría democrática”, Estudios Públicos, 1984, pp. 59-92. 
SIMMONS, John (1992): The Lockean Theory of Rights (Princeton, Princeton University Press).

STRAUSS, Leo (1953): Natural Right and History (Chicago, University of Chicago Press).

TULLY, James (2006): A Discourse on Property. Locke and his adversaries (Cambridge, Cambridge University Press).

UDI, Juliana (2012a): "El liberalismo cristiano de John Locke, una interpretación de su teoría de la propiedad a la luz del deber de caridad”, Repositorio Institucional de la Facultad de Filosofía y Letras UBA, Buenos Aires

UDI, Juliana (2012b): "Propiedad Lockeana, Pobreza Extrema y Caridad", Revista de Estudios Políticos (nueva época), Madrid, Julio - Septiembre, No 157: pp. 165-188.

UDI, Juliana (2014): "El derecho a la caridad: Repercusiones de la teología cristiana en la teoría de la propiedad de John Locke", Revista de Filosofía, Universidad de Chile, No 70: pp. 149-16o.

VILAJOSANA, Josep (1987): "El aparato conceptual de C.B. Macpherson: poder y propiedad", Anuario de Filosofía del Derecho, Barcelona, pp. 449-472.

WALDRON, Jeremy (2002): God, Locke, and Equality. Christian Foundations in Locke's Political Thought (Cambridge, Cambridge University Press). 


\title{
Comportamiento judicial estratégico: el caso del Supremo Tribunal Federal de Brasil
}

\author{
Strategic judicial behavior: the case of the Brazilian Supreme Court
}

\author{
Patrícia Perrone Campos Mello ${ }^{1}$ \\ Centro Universitário de Brasília (UniCEUB), Brasil
}

\begin{abstract}
RESUMEN El presente artículo tiene como objetivo demostrar que el material jurídico ortodoxo es apenas uno de los elementos que influencian el comportamiento judicial, y no necesariamente el más importante, sobre todo en casos emblemáticos. El trabajo presenta tres modelos principales de comportamiento judicial: el modelo legalista, el modelo ideológico y el modelo estratégico. Se profundiza en el modelo estratégico, abordando sus características principales y las críticas que se le han formulado. Propone un estudio de caso acerca de las decisiones dictadas por el Supremo Tribunal Federal de Brasil, a la luz de este último modelo. Se concluye en el sentido que los factores extrajurídicos también interfieren en el proceso decisorio de las cortes. Por ello, el Derecho no puede prescindir de un entendimiento adecuado sobre cómo las cortes efectivamente deciden en la vida real.
\end{abstract}

1. Doctora y Maestra por la Universidade do Estado do Rio de Janeiro (UERJ). Profesora del Programa de Mestrado e Doutorado do Centro Universitário de Brasília (UniCEUB). Procuradora del Estado del Rio de Janeiro (pcamposmello@uol.com.br).

El presente artículo se encuentra asociado a dos proyectos de investigación: 1. Proyecto de Investigación "Cortes Constitucionais e Democracia", del Programa de Doutorado e Mestrado da Faculdade de Direito do Centro Universitário de Brasília - UniCEUB, Brasília, Brasil. Registrado oficialmente junto al Conselho Nacional de Desenvolvimento Científico e Tecnológico - CNPQ, del Ministério da Ciência, Tecnologia, Inovações e Comunicações, Brasil. Disponible en: <http://dgp.cnpq.br/dgp/ faces/consulta/consulta_parametrizada.jsf>. 2. Proyecto de Investigación "Constitutional Courts in Times of Democratic Crisis: the Brazilian Case", desarrollado en el Max Planck Institute of Comparative Public Law and International Law, Heiderberg, Alemania, 2019. 
PALABRAS CLAVE Comportamiento judicial, Modelo legalista, Modelo ideológico, Modelo estratégico, Interacción entre poderes.

ABSTRACT The purpose of this article is to demonstrate that orthodox legal materials are just one of the factors that influence judicial behavior, and not necessarily the most important, especially in emblematic cases. The paper presents three principal models of judicial behavior: the legalistic model, the ideological model and the strategic model. It explores the strategic model, addressing its main characteristics and the principal criticisms made of it, and develops a case study of the decisions handed down by the Brazilian Supreme Court in light of this model. The work concludes that extralegal factors also interfere in the decision-making process of the courts. Therefore, an adequate understanding on how the courts actually decide in real life is essential for understanding the law itself.

KEYWORDS Judicial behavior, Legalistic model, Ideological model, Strategic model, Interaction between powers.

\section{Introducción}

La noción de que las cortes juzgan los casos que les son sometidos solo en base a los textos normativos, los precedentes y la dogmática jurídica -conjunto que se denominará, en este artículo, "material jurídico ortodoxo"- no tiene sustento en la vida real. Existe un reconocimiento creciente de que otros factores son capaces de interferir sustancialmente en el comportamiento de las cortes ${ }^{2}$. Existen, también, importantes estudios empíricos que procuraron identificar tales factores, incluso con el propósito de predecir cómo serían decididos nuevos $\operatorname{casos}^{3}$. Este será el objeto de este artículo.

De modo general, los mencionados estudios aluden a tres modelos capaces de explicar el comportamiento judicial: el legalista, el ideológico y el estratégico ${ }^{4}$. Cada uno de ellos trata de examinar la actuación de los magistrados a partir de un factor principal. El modelo legalista apuesta por la primacía del Derecho, en su concepción ortodoxa, como principal factor explicativo de las decisiones. El modelo ideológico se centra en la demostración de que la ideología del juez es el principal elemento determinante de las decisiones judiciales. El modelo estratégico concibe el proceso deciso

2. FRANK (1949b) pp. 405-415; POSNER (2008); SEGAL y SPAETH (2002); EPSTEIN y KNIGHT (1998); BAUM (2008); SUNSTEIN et al (2006); En la literatura brasileña, v. MELLO (2015).

3. ASHENFELTER et al (1995); BRENNER y WHITMEYER (2009); CROSS y NELSON (2001); PINELLO (1999).

4. Sobre los tres modelos, con énfasis variada en cada uno: CROSS y TILLER (1988); FRIEDMAN (2005); FRIEDMAN (2004); EPSTEIN y KNIGHT (1995); MARTIN (2004). 
rio de una forma más sofisticada, como resultado de la interacción de los magistrados con múltiples influencias, tales como: sus propias preferencias, las preferencias de sus colegas de corte, la de los demás poderes y de la opinión pública.

Aun cuando todos los modelos referidos son relevantes para la comprensión del funcionamiento de las cortes, optamos en este trabajo por explorar con mayor profundidad el modelo estratégico, tanto por la limitación de espacio, como, en especial, por el rol que los factores extra jurídicos alcanzan en este modelo decisorio.

El presente artículo se divide en tres secciones. La primera sección hace una presentación general de los modelos mencionados. La segunda, se dedica a un análisis en mayor profundidad del modelo estratégico de comportamiento judicial. La tercera sección tiene por objeto un estudio de caso sobre las decisiones emitidas por el $\mathrm{Su}$ premo Tribunal Federal de Brasil (STF) en materia de suspensión de parlamentarios del cargo (afastamento cautelar) ${ }^{5}$. Como se demostrará en este estudio, la Corte, en un espacio de tiempo de menos de dos años y con un único cambio en su composición, osciló sustancialmente en la jurisprudencia sobre este tema. Al respecto, sostendremos que el modelo estratégico puede ofrecer una matriz importante para la comprensión de tal oscilación.

\section{Modelos de comportamiento judicial}

Como se ha observado, la literatura adoptada sobre modelos de comportamiento judicial alude a tres modelos principales: (i) el legalista, (ii) el ideológico y (iii) el estratégico. Cada uno de esos modelos elige un elemento preponderantemente apto para explicar cómo una determinada cuestión será decidida. Esos modelos no abarcan todos los factores que pueden explicar una decisión. Tan solo identifican el elemento que consideran dominante ${ }^{6}$. La literatura reconoce otros modelos de comportamiento que no serán abordados en el presente trabajo7. Para los fines de este artículo, los tres modelos de comportamiento judicial antes mencionados son suficientes.

\footnotetext{
5. El Supremo Tribunal Federal de Brasil es una corte suprema que reúne entre sus competencias: (i) la apreciación de recurso extraordinario sobre materia constitucional y el juicio de acciones directas de inconstitucionalidad y (ii) la competencia original para juzgar a las más altas autoridades del país por delitos penales.

6. Para otros factores, v., ilustrativamente: POSNER (1993).

7. MELLO (2015) pp. 147-371.
} 


\subsection{Modelo legalista}

El modelo legalista de comportamiento judicial apuesta por el "material jurídico ortodoxo" como factor preponderante apto para explicar y prever cómo un juez o una corte decidirá un caso $^{8}$. Como fue explicado, el material jurídico ortodoxo corresponde a los textos normativos, a los precedentes judiciales, a la hermenéutica y a la dogmática jurídica tradicionalmente utilizada en la aplicación del Derecho. En la perspectiva del modelo legalista de decisión, si un texto es explícito acerca de un determinado dispositivo, si existe un precedente vinculante en algún sentido, si las reglas hermenéuticas favorecen el entendimiento, este será el tratamiento adoptado por el juicio. Tales factores constituirían el elemento determinante de cómo el juez decidirá un caso.

Una suprema corte que adopte un comportamiento legalista, en la acepción de ese modelo, se caracterizaría por dictar decisiones que pueden ser predominantemente explicadas, e incluso anticipadas, en base al texto de la Constitución, a los precedentes de la propia corte y a la dogmática sobre la interpretación constitucional, es decir, fundamentadas en el mencionado "material jurídico ortodoxo".

Como se puede deducir, el modelo legalista es insuficiente para explicar el comportamiento de los jueces en una multiplicidad de casos comúnmente enfrentados en materia constitucional. Los textos constitucionales están, de modo general, repletos de cláusulas abiertas y de conceptos jurídicos indeterminados que pueden no ofrecer nortes suficientemente claros para la solución de ciertos conflictos, en circunstancias en las que tampoco los precedentes y la dogmática ofrecerán respuestas incontestables ${ }^{9}$.

Asimismo, el modelo legalista no ofrece soluciones adecuadas en los casos en que la aplicación mecánica de un precedente arroje decisiones de injusticia fragrante. Tampoco explica la superación de precedentes o la oscilación jurisprudencial, objeto del estudio de caso que será desarrollado en este artículo más adelante. Tanto la resolución de casos en que la aplicación del modelo ortodoxo conduciría a conclusiones evidentemente no razonables, como las decisiones que implican el uso inconsistente de precedentes, evidencian que factores diversos de aquellos identificados por el modelo legalista tienen un papel relevante en la comprensión del comportamiento judicial $^{10}$.

8. La expresión "legalista" no es la más adecuada para caracterizar el comportamiento de una corte constitucional o de una suprema corte que juzgue materias constitucionales, ya que la alusión a la ley remite a la norma infra constitucional. Sin embargo, la constitución también es norma y, en virtud de eso, las reflexiones del modelo legalista pueden ser extrapoladas al análisis que se pretende desarrollar.

9. BARROSO (2009) pp. 311-338; SOUZA NETO y SARMENTO (2007) pp. 385-391, 493-531.

10. MELLO y BAQUEIRO (2018) pp. 668-690. 
El modelo legalista de comportamiento judicial tiene, con todo, su valor. La solución de una gran gama de casos que llega a las cortes constitucionales y supremas cortes, puede ser explicada por medio de este modelo. Generalmente, se trata de casos en los que el texto constitucional es explícito acerca de la solución, o cuya cuestión de fondo ya fue apreciada y no suscita conflicto actual. En estas situaciones, las cortes se ven involucradas en una actividad de corrección de errores y rectificación de las decisiones adoptadas por las demás instancias.

Entretanto, no son esas las causas que llaman la atención del público y que generan los titulares de la prensa. De modo general, los fallos que atraen miradas sobre el trabajo de las cortes son, por ejemplo, aquellos en los que una cuestión polémica, que divide la comunidad, está siendo abordada por primera vez; o casos en que las cortes se desviaron de sus precedentes anteriores u ofrecieron una interpretación menos evidente del texto de la Constitución. Esos procesos, que llamamos "casos emblemáticos" en este trabajo, producen por su propia naturaleza, una mayor indeterminación del Derecho. En dichas circunstancias, los modelos ideológico y estratégico pueden mostrar un gran potencial explicativo de cómo las decisiones son tomadas.

\subsection{Modelo ideológico}

El modelo ideológico identifica la ideología de los magistrados como el factor determinante de su comportamiento judicial. La ideología, en este caso, se concibe de forma amplia, como un conjunto de valores e ideas que integran la visión de mundo del magistrado $^{11}$. A partir de ese conjunto, se procura explicar o incluso predecir cómo determinado juez votará en un caso inédito o controvertido. Los fundamentos utilizados por el magistrado para decidir, las normas jurídicas y los argumentos invocados para justificar su decisión constituirían, en verdad, una mera racionalización producida a posteriori, después de tomada la decisión, con el fin de legitimarla ${ }^{12}$.

Los estudios empíricos enfocados en medir la participación de la ideología en los procesos decisorios de los magistrados fueron muy favorecidos por el ambiente ideológico norteamericano. Dicho ambiente es bipartito y está polarizado entre demócratas y republicanos, y sus divergencias ideológicas tienen una proyección muy

11. MELLO (2015) p. 57.

12. El modelo ideológico está inspirado en ideas oriundas del realismo jurídico. El realismo jurídico fue una corriente de pensamiento norteamericano articulada como reacción al formalismo y a la fundamentación jurídica artificial de las decisiones judiciales. Sus estudiosos defendían un cambio de enfoque en el estudio del Derecho, proponiendo el abandono de los debates teóricos sobre cómo las normas deben ser interpretadas y aplicadas, centrándose en la comprensión de lo que efectivamente ocurre en los tribunales (a semejanza de lo que se propone en este artículo). HOLMES (1897) p. 994, FRANK (1949a) pp. 146-156, LLEWELYN (1960), CARDOZO (2005). 
clara en materia constitucional. Los demócratas son generalmente más progresistas desde el punto de vista de la tutela de los derechos fundamentales y más favorables a la intervención del Estado en la economía. Los republicanos son más conservadores y, por tanto, menos garantistas en materia de derechos fundamentales y menos abiertos a la intervención estatal. En esa línea, a título ilustrativo, en relación con el derecho de igualdad, los demócratas son asociados a posiciones más protectoras de grupos minoritarios, como los negros, las mujeres, los hispanos y las minorías sexuales ${ }^{13}$. En materia económica, generalmente se manifiestan a favor de la mantención de normas regulatorias, la tutela del medio ambiente y los sindicatos, cuando sus derechos entran en conflicto con los intereses de empresas privadas ${ }^{14}$. Los republicanos son asociados al posicionamiento opuesto.

En dicho contexto, los estudios empíricos sobre el comportamiento judicial ideológico emplearon el siguiente método: (i) buscaron identificar ideológicamente al magistrado como predominantemente progresista/demócrata o conservador/republicano; (ii) reunieron un conjunto de casos y procuraron anticipar cómo tales casos serían decididos por cada juez, de acuerdo con su perfil ideológico; (iii) por último, verificaron cómo fueron efectivamente decididos en la práctica y, basándose en esta confrontación, evaluaron la precisión del modelo en la previsión del comportamiento del magistrado.

Dichos estudios desarrollaron dos métodos principales para la identificación ideológica de los jueces. El primer método, se centró en explicar el comportamiento de los magistrados de la Corte Suprema norteamericana. En su origen, fue desarrollado por Segal y Cover, quienes produjeron una indexación ideológica de tales jueces, con base en editoriales de periódico ${ }^{15}$. A partir de cómo los jueces fueron descritos y evaluados por los periódicos, los estudiosos los escalonaron entre más o menos conservadores o progresistas.

Con este criterio, los autores del estudio obtuvieron una medida independiente de la ideología de los magistrados (que no tenía como base sus propios votos). A continuación, examinaron cómo votaron los magistrados en determinados casos con proyecciones ideológicas claras y verificaron el nivel de acierto del modelo. Es decir, en qué medida el índice ideológico atribuido al juez era capaz de indicar cómo él votaría

13. SEGAL y COVER (1989); SEGAL et al (1995); SOLBERG (2006).

14. SEGAL et al (1995); REVESZ (1997); SUNSTEIN y MILES (2006) p. 823.

15. La indexación original, producida por Segal y Cover, fue posteriormente actualizada por Segal y Spaeth, ampliándose incluso el universo de los periódicos examinados con ese objetivo. SEGAL y COVER (1989); SEGAL y SPAETH (2002) p. 322. 
en determinada cuestión. Este primer modelo reveló un alto potencial predictivo de la forma de decidir de los magistrados ${ }^{16}$.

El segundo método empírico de estudio del comportamiento ideológico fue utilizado para el estudio de la actuación de los jueces federales norteamericanos. Este método asociaba la orientación ideológica del juez al Presidente que lo nombró. En los Estados Unidos, los jueces federales son nominados por el jefe del Poder Ejecutivo y confirmados por el Senado Federal. Se asumió que el Presidente, al nominar a un magistrado, buscaba candidatos que fuesen mínimamente convergentes con sus propias convicciones, en una tentativa de influenciar el rumbo del Derecho. Por ello, fue utilizado como criterio objetivo para determinar las inclinaciones ideológicas de cada juez el partido al cual pertenecía el Presidente que lo designó. A partir de ese criterio, se procuraba identificar cómo votaría el magistrado en los diferentes casos que le serían sometidos a decisión, en base a la misma lógica anteriormente descrita: las decisiones más progresistas serían producto de jueces nombrados por demócratas, a la par que las decisiones más conservadoras serían tomadas por los jueces designados por republicanos ${ }^{17}$.

Tales estudios empíricos demostraron que algunas materias eran más propensas a votaciones ideológicas que otras, aunque, de forma general, confirmaron la hipótesis de la votación ideológica. En esa línea, se constató que los jueces demócratas fallaban más favorablemente a grupos minoritarios, en casos de acciones afirmativas, de discriminación sexual y acoso sexual; que producían más decisiones reconociendo la incidencia de segregación racial; que juzgaban favorablemente a las personas discapacitadas, en casos de argumentación de violación de sus derechos de igualdad; que se manifestaban más a favor del derecho de comercializar materiales pornográficos, invocando la libertad de expresión; y que validaban más normas restrictivas sobre la financiación de campañas electorales ${ }^{18}$.

16. En un conjunto de casos sobre derechos fundamentales decididos entre los años 1953 y 1999 , se constató una convergencia de 76\% (setenta y seis por ciento) entre las decisiones de los magistrados y sus inclinaciones ideológicas. En otro estudio que reunió casos de búsqueda policial, entre 1962 y 1998, el porcentaje de acierto fue de 71\% (setenta y un por ciento) de los votos. SEGAL y SPAETH (2002) pp. 320-323; MELLO (2015) pp. 67-68.

17. SISK y HEISE (2005); SUNSTEIN et al (2006).

18. SEGAL y SPAETH (2002) pp. 320-326; FRIEDMAN (2005) p. 273. Ver, también, sobre el tema, MILES y SUNSTEIN (2006) p. 823; BENESH y SPAETH (2003) pp. 20-22; SUNSTEIN et al (2006) pp. 17-40. 
La importación de la metodología utilizada por el modelo de comportamiento ideológico norteamericano para países en que no existe un universo ideológico tan definido, con proyección en materia constitucional, no es viable. Por tanto, aunque la metodología desarrollada por los norteamericanos haya producido resultados bastante impresionantes en Estados Unidos, no es replicable para otros países que no presentan la misma realidad política.

A pesar de ello, los hallazgos del modelo ideológico son importantes para la comprensión del comportamiento judicial de modo general. La influencia de la ideología en el proceso decisorio manifiesta, en realidad, que este proceso es permeable a la subjetividad del magistrado. Dicha subjetividad abarca un conjunto amplio de experiencias, valores, pre-comprensiones, que componen el bagaje (background) de un juez y que es fuertemente responsable de sus inclinaciones ideológicas ${ }^{19}$.

Por esa razón, aun no siendo posible desarrollar un análisis del comportamiento de un ministro con base en la metodología descrita arriba, existen otros elementos que pueden funcionar como buenos indicadores de sus inclinaciones ideológicas. La identidad de las personas, por regla general, se construye mediante la interacción con el otro y, por consiguiente, los grupos de identificación de un magistrado influencian sus concepciones de mundo y revelan tendencias decisorias. La familia, la crianza, los amigos, la religión y la vinculación con movimientos sociales, son algunos elementos que pueden funcionar como indicadores de dichas tendencias ${ }^{20}$. En esa medida, identificar el background de los jueces e intentar asociarlos a un patrón decisorio en determinadas materias puede ayudar a comprender sus inclinaciones. Puede, además, orientar la argumentación de las partes y, eventualmente, permitirá prever la forma en que se manifestará sobre determinada materia o, incluso, el tipo de argumento al cual se mostrará más sensible.

\subsection{Modelo estratégico}

El modelo estratégico corresponde al tercer modelo de comportamiento judicial tradicionalmente referenciado por la literatura. Es compatible, al menos en parte, con las ideas del modelo ideológico. Tanto en el modelo ideológico como en el modelo estratégico, se cree que los jueces tienden a decidir buscando influenciar en el desarrollo del Derecho, en el sentido -extrajurídico- que ellos consideran más adecuado. En el modelo ideológico, con todo, los magistrados tan solo votan de acuerdo con sus preferencias, mientras que en el modelo estratégico presentan un comportamiento más sofisticado.

19. GROSSMAN (1966); BAUM (2008) pp. 26-28; ASHENFELTER et al (1995).

20. SISK et al (1998) p. 1457; PERESIE (2005) pp. 1786-1787; COX y MILES (2008); MELLO (2015) pp. 127-144. 


\subsubsection{Características y elementos del modelo estratégico}

En la actuación estratégica, el hecho de que la decisión de un juez depende del comportamiento de otros agentes para lograr prevalecer o influenciar el desarrollo del Derecho en un determinado sentido, interfiere sobre sus opciones. En un órgano colegiado, el juez que desea influenciar el resultado de un caso necesita tener en consideración que su entendimiento de este necesitará la adhesión de la mayoría para prevalecer. Si su propósito es producir un determinado resultado, que considera el más adecuado, necesitará considerar el pensamiento de los demás miembros colegiados y evaluar si sus preferencias personales contarán con el apoyo de ellos.

En dichas circunstancias, es posible que el juez procure identificar cómo se comportarán los otros miembros de la Corte en determinado juzgamiento y que opte por votar, no propiamente conforme sus convicciones, sino de acuerdo con un entendimiento más moderado que sea capaz de conquistar la adhesión de la mayoría -lo que el modelo estratégico ha convenido en llamar second best decisión-. Entre votar como desea y ser vencido o proferir un voto que no considera ideal, mas tiene la oportunidad de ser aprobado por la mayoría, es posible que el juez opte por esa segunda alternativa. En ese caso, el magistrado estará actuando estratégicamente.

Los estudiosos del modelo estratégico recurren a dos teorías para explicar este fenómeno: la "teoría de la elección racional" y la "teoría de los juegos". De acuerdo con la teoría de la elección racional, los agentes y, por tanto, también los jueces, tienen determinados objetivos y optan por las actitudes que creen que serán más aptas para alcanzarlos. Para que la actuación estratégica logre un buen resultado se deben cumplir algunas condiciones, a saber: (i) en primer lugar, el comportamiento adoptado debe posibilitar la maximización del beneficio pretendido; (ii) en segundo lugar, la percepción de la actitud que cumple esa función precisa tener una base sólida; y, por lo tanto, (iii) el agente debe hacer un esfuerzo óptimo para la obtención de información sobre el comportamiento que puede esperar de los demás agentes ${ }^{21}$. Desde la perspectiva del modelo estratégico, el beneficio que debe ser maximizado por los jueces es la adopción de una decisión convergente con sus expectativas. Para alcanzar dicha finalidad, es necesario obtener información sobre como sus demás colegas pretenden votar, con el fin de evaluar si conseguirán construir una mayoría que apoye sus preferencias.

La teoría de juegos, a su vez, explica la acción humana justamente cuando la consecución de un objetivo depende del comportamiento de terceros, demostrando que, en esas condiciones, el agente definirá su conducta basándose en las actitudes que espera de los demás. Por eso, si un juez piensa que sus preferencias sinceras no ob

21. ELSTER (1986) pp. 1-33; EPSTEIN y KNIGHT (1995) p. 2; PETTIT (1996) pp. 62-89. 
tendrán el apoyo de la mayoría, él tenderá a moderar su entendimiento, con el fin de producir un voto que pueda ser apoyado por los demás, optando así por una second best decision ${ }^{22}$.

\subsubsection{Críticas al modelo estratégico:}

La principal crítica dirigida al modelo estratégico corresponde a la alegación de que su comprobación empírica es inviable, una vez que un mismo comportamiento puede ser explicado por justificaciones concurrentes. Se alega que, en realidad, la caracterización de ciertas actitudes como estratégicas ocurre a posteriori, como consecuencia de interpretaciones elaboradas para explicar eventos que ya ocurrieron y que esa particularidad hace que el propio observador pierda la imparcialidad en la comprensión de los fenómenos y genere involuntariamente percepciones confirmadoras de su hipótesis. Es por eso que el modelo estratégico sería cuestionable desde el punto de vista científico ${ }^{23}$.

Se trata de una crítica importante. De hecho, la comprobación del modelo estratégico por medio de estudios empíricos cuantitativos, como aquellos que evidenciaron el comportamiento ideológico, es de difícil viabilidad. Esto no significa, sin embargo, que el modelo estratégico no pueda ofrecer explicaciones importantes acerca del comportamiento judicial. Tampoco impide que estudios cualitativos sean desarrollados.

Una segunda crítica a ese modelo tiene en cuenta que la vida real presenta situaciones de gran asimetría de información, en las cuales a un juez o una corte no les resulta posible conocer cómo se comportarán los demás agentes con los que interactúan. En tales circunstancias -se alega- la actuación estratégica estaría comprometida. De hecho, por un lado, puede ser difícil conocer cómo se comportará cada agente. Sin embargo, la experiencia demuestra que el juez que integra un tribunal colegiado procura verificar anticipadamente las elecciones de sus demás colegas de corte cuando el caso es relevante y la decisión final depende de ellos. En casos con semejante importancia, la mera amenaza de una mayoría divergente o del incumplimiento de una decisión por otro Poder puede ser suficiente - dada la gravedad de las consecuencias- para provocar una conducta estratégica del magistrado.

La tercera crítica al modelo en examen pondera, justamente, que este modelo parte desde la teoría de la elección racional, pero que diversos estudios de la economía del comportamiento ya demostraron que no siempre la conducta humana es racional. $\mathrm{Al}$ optar por un determinado comportamiento, el juez puede estar siendo motivado

22. CORAM (1995) p. 92; ELSTER (1986) pp. 1-33.

23. ELSTER (2007) p. 19. 
por mero temor a ciertas consecuencias, y no propiamente por amenazas reales ${ }^{24}$ En esas condiciones, el modelo estratégico solo explicaría el comportamiento de los magistrados, si fuese posible tener acceso al estado psíquico de cada juez en los momentos que precedieran a su voto. Sin embargo, en lo que respecta a este argumento, se alega que, aunque las personas, por norma general, no sean plenamente racionales, desean serlo. Por consiguiente, el modelo tendría un buen potencial explicativo, a pesar de la existencia de los límites ya mencionados.

La próxima sección está dedicada a una mirada más profunda sobre el modelo estratégico de conducta judicial.

\section{El modelo estratégico: dimensiones interna y externa}

El comportamiento judicial estratégico puede ser pensado en dos ámbitos: interno y externo a las cortes. El estudio del comportamiento estratégico interno dice relación a la comprensión de la interacción entre jueces de un mismo órgano colegiado. Como ya ha sido esclarecido, cada juez depende de la adhesión de la mayoría para hacer prevalecer su punto de vista. El juez actuará estratégicamente cuando: (i) pueda anticipar cómo votarán el resto de sus colegas de corte; y (ii) optar por formular su voto de modo que obtenga el apoyo de la mayoría, sacrificando el entendimiento que considera ideal, para defender la decisión más próxima a sus preferencias capaz de lograr el respaldo de los demás (second best decision) $)^{25}$.

La actuación estratégica puede, además, hacer que los miembros de una corte opten por actuar en bloque, en el intento de firmar los precedentes que entienden más adecuados. En esas circunstancias, es posible que algunos jueces renuncien a la presentación de votos divergentes, a cambio del apoyo de los demás jueces que integran su bloque o de la moderación de la decisión a la que se va a adherir.

El estudio del comportamiento estratégico externo tiene como objetivo la interacción entre las cortes e instituciones que le son externas, tales como: el Poder Ejecutivo, el Poder Legislativo, la opinión pública y la prensa. Es cierto que el Poder Judicial y sus miembros están rodeados de garantías cuyo propósito es asegurar la independencia de sus decisiones. Se cree, a pesar de ello, que, en ciertas circunstancias, las cortes pueden ser sensibles a cómo ciertos agentes responderán a sus juzgamientos y, si fueren capaces de prever una gran reacción negativa en su contra, posiblemente moderarán su actuación de forma de minimizar tales posibles reacciones. La interacción entre las cortes y dichos agentes externos puede ser sintetizada en los términos que se indica en los párrafos siguientes.

24. TVERSKY Y KAHNEMAN (1986) pp. 123-141.

25. EPSTEIN y KNIGHT (1998) pp. 79-98; CALDEIRA y WRIGHT (1988) pp. 1120-1121; EPSTEIN y KNIGHT (1995); SEGAL y SPAETH (2002) pp. 358-406. 
i) Cortes v. Poder Ejecutivo y Poder Legislativo: las cortes constitucionales y supremas cortes dependen del apoyo del resto de los poderes para ejercer su autoridad. Deben contar con el Poder Ejecutivo para el uso de la fuerza, si fuere necesario para imponer el cumplimiento de sus decisiones. Necesitan el Poder Legislativo para aprobar sus presupuestos. En caso de conflicto con esos poderes, se pueden ver sujetas a represalias importantes. Sus decisiones pueden ser manifiestamente incumplidas o superadas por medio de enmienda constitucional. Asimismo, su composición puede ser ampliada, para viabilizar la selección de jueces convergentes con los intereses del Ejecutivo o del Legislativo; o bien, el criterio de selección de sus jueces puede ser modificado para favorecer su captura ideológica, entre otras medidas tendientes a reducir su independencia o a ejercer presión sobre sus decisiones. Este conjunto de acciones suele ser denominado, según la literatura, como court packing plans.

Ocurre justamente que la credibilidad de una corte está íntimamente relacionada al cumplimiento de sus decisiones y la preservación del régimen jurídico que asegura su independencia. Cuando esos elementos están en riesgo, las cortes, en condición de agentes estratégicos, posiblemente renunciarán a las decisiones que creen ideales para preservar su estabilidad institucional y evitar ataques de los demás poderes. Ya que, en esas condiciones, sería de poca utilidad dictar una decisión que, además de no ser cumplida acabará comprometiendo el poder de la Corte para influenciar el desarrollo del Derecho a largo plazo ${ }^{26}$.

ii) Cortes v. opinión pública: de modo general, la doctrina atribuye a las cortes que ejercen una jurisdicción constitucional un papel contra-mayoritario, cuando su decisión tenga por objeto la protección de los derechos fundamentales o el adecuado funcionamiento del proceso democrático. Sin embargo, estudios empíricos demuestran que las decisiones contra-mayoritarias de las cortes son menos comunes de lo que se imagina y que, en muchas ocasiones, dichas cortes atienden a la voluntad de la mayoría que no encontró acogida en los poderes Ejecutivo y Legislativo ${ }^{27}$.

Existen diversas explicaciones para ese fenómeno. En primer lugar, en muchos sistemas, los jueces constitucionales son seleccionados por un proceso que es de carácter político y, por consiguiente, son sensibles a las expectativas populares. Es lo que ocurre en el sistema norteamericano y en el brasileño. En estos ordenamientos los jueces de la Corte Suprema son escogidos por el Presidente de la República y aprobados por el Senado. En segundo lugar, dichos jueces están sujetos a las mismas influencias que los demás ciudadanos. Son miembros de su comunidad y comparten

26. POSNER (2008) pp. 69-70, 198; CROSS y NELSON (2001) pp. 1437-1467; SPILLER et al (1996) p. 503; WHITTINGTON (2003) pp. 448-474.

27. MARSHALL (1989) p. 97; MARSHALL (2008) p. 5; KLARMAN (1994); LAIN (2012). 
valores con ellos. Además de esto, una corte necesita presentar algún nivel de convergencia con la percepción social de lo que es justo para tener legitimidad. Necesita, además, evitar decisiones que no serán obedecidas, ya que tal incumplimiento genera daños a su autoridad ${ }^{28}$.

El apoyo popular es un bien muy importante para las cortes constitucionales y supremas cortes. Ese apoyo puede ser medido desde dos perspectivas diferentes. Existe, por una parte, el "apoyo popular específico", que trata de la adhesión de la mayoría de la comunidad a una decisión con la cual está de acuerdo. Por otra, también existe el concepto más complejo de "apoyo popular difuso", el cual corresponde al respaldo popular del que goza una corte como institución, incluso cuando se toman decisiones impopulares.

El apoyo popular difuso es producto de la historia de la Corte, de la credibilidad que construyó a lo largo del tiempo y de la forma (confiada o no) en la que los ciudadanos aprendieron a pensar respecto de la Corte $^{29}$. El apoyo popular difuso es el mayor capital político del que dispone una corte y, por ello, debe ser utilizado con prudencia. Una corte con gran apoyo popular difuso es una corte fuerte, que puede afirmarse frente a los demás poderes y enfrentarse a intereses poderosos. Una corte sin apoyo popular es una corte frágil. Por ese motivo, las cortes son sensibles a las expectativas de la opinión pública ${ }^{30}$.

Por otro lado, las cortes no pueden simplemente someterse ante las opiniones de la comunidad en la que operan. Hay situaciones en que su papel es justamente invalidar deliberaciones mayoritarias, para proteger a las minorías o a la propia democracia. Por eso, la decisión de atender u oponerse a la voluntad de la mayoría envuelve cálculos políticos. Para ese cálculo, es importante conocer las preferencias y reacciones de los demás poderes. Cuando los demás poderes están alineados con la opinión pública, los costes de una decisión impopular pueden ser insostenibles.

iii) Cortes v. prensa: los ciudadanos saben muy poco acerca de lo que sucede en la esfera pública o en las propias cortes. Dependen de intermediarios que recolectan ese tipo de información y se la reportan, de forma que la comunidad tenga un conocimiento mínimo de lo que ocurre. Muchos tampoco son capaces de comprender el significado y las implicaciones de ciertas decisiones judiciales. El papel de seleccionar los hechos relevantes que serán divulgados y de ofrecer una interpretación sobre sus aspectos positivos y negativos es llevado a cabo por los medios de comunicación. La prensa es, por eso, un poderoso intermediario entre las cortes y el pueblo. Ella le

28. DAHL (1957) pp. 6563-583; FRIEDMAN (2009) p. 375; FRIEDMAN (2003) p. 2596; BAUM (2008) pp. 66-72.

29. EASTON (1975) p. 435.

30. CRITIN y EGAN (2009). 
presenta no solo los hechos que ocurren en la esfera pública (aquellos que juzga que deben ser reportados), mas igualmente una primera interpretación de tales hechos. En esas condiciones, los medios de comunicación pueden construir o destruir la reputación de una corte y de sus miembros, seleccionando informaciones y ofreciendo interpretaciones a su respecto ${ }^{31}$.

En ese sentido, debe reconocerse que la percepción popular sobre una corte o sobre sus miembros no emerge de forma espontánea necesariamente. Es el producto de un proceso de animación social en el cual la prensa tiene un papel muy importante. Por esa razón, es relevante no solo tener una prensa libre, sino también plural, medios de comunicación que puedan ofrecer a la comunidad diferentes interpretaciones y versiones sobre lo que pasa en la esfera pública. En cualquier caso, si la prensa es capaz de interferir en la percepción de la comunidad sobre el desempeño de la Corte y de sus miembros, y si el apoyo popular es fundamental para su estabilidad institucional, los medios de comunicación serán capaces de influenciar el comportamiento de las cortes, en cierta medida. Los tribunales, por lo general, son conscientes de que una reacción muy negativa por parte de los medios puede costarles un enorme capital político.

\section{Estudio de caso}

Como ya ha sido reconocido arriba, el modelo estratégico de comportamiento judicial es difícil de comprobar con base en estudios empíricos cuantitativos. Es difícil construir una ecuación según la cual, estando presentes determinados elementos y otros ausentes, se pueda afirmar que una corte decidirá en un sentido específico, tal y como se logró hacer en la comprobación del modelo ideológico de comportamiento judicial en el sistema norteamericano. Sin embargo, ello no impide que se desarrollen estudios de caso que demuestren buenos indicios de actuación estratégica. En esta medida, el estudio de caso que se desarrolla a continuación puede ofrecer explicaciones importantes para la comprensión del comportamiento judicial.

\subsection{El contexto}

El Supremo Tribunal Federal es el órgano judicial brasileño de más alta jerarquía, que reúne, entre sus competencias: (i) la decisión de recursos extraordinarios y de acciones directas de inconstitucionalidad; y (ii) el juzgamiento de las más altas autoridades de la República en materia penal, entre otras atribuciones. Se trata, por lo tanto, de un tribunal que actúa en temas de máxima sensibilidad. Además de eso, algunas de las explicaciones adicionales sobre el contexto en que ha operado en los últimos años parecen relevantes. 
En 2014, comenzó en Brasil la fase visible (ostensiva) de investigaciones de la "Operación Lava Jato" ${ }^{2}$. La "Operación Lava Jato" es una investigación de la Policía Federal brasileña que tiene por objeto pesquisar un gran esquema de corrupción y de desvío de recursos públicos, involucrando a Petrobrás (empresa estatal que actúa en el segmento del petróleo, gas natural y sus derivados), empresas de infraestructura contratadas por el poder público, partidos políticos y altas autoridades de la Repúbli$\mathrm{ca}^{33}$. Mediante esta operación, se identificó el que probablemente sea el mayor esquema de corrupción jamás elucidado en el país. Esta fase de la operación comprendió la ejecución de múltiples órdenes de búsqueda y captura de documentos y de prisión cautelar de altos empresarios, autoridades y exautoridades.

En 2015, las investigaciones de la "Operación Lava Jato" alcanzaron autoridades con "fuero especial" en el STF ${ }^{34}$, tales como diputados, senadores y ministros de estado, y dejaron aún más en evidencia que el esquema de corrupción sistémica revelado por la operación alcanzaba una parcela sustancial del medio político. Por ese motivo, parte de dichas investigaciones pasó a ser tramitada por el Supremo Tribunal Federal. En ese mismo año, se inició el proceso de impeachment ${ }^{35}$ de la presidente Dilma Rousseff, concluido con su inhabilitación en $2016^{36}$.

El ambiente de desconfianza, denuncia y conflagración que se instaló en el país colocó el STF en una posición institucional bastante delicada. Acciones y recursos pertinentes al proceso de impeachment, a la "Operación Lava Jato" y a otros casos que envolvían políticos relevantes llegaron a la Corte y despertaron la atención de la prensa. Pasó a exigírsele al Tribunal un reiterado escrutinio de los actos de los demás poderes. Diversos miembros de poderes se convirtieron en foco de investigaciones y pasaron a ser alcanzados por decisiones del STF. Escándalos sucesivos y una inestabilidad política, económica e institucional sin precedentes se instaló en el país.

En ese contexto, entre mayo de 2016 y diciembre de 2017, el Supremo Tribunal Federal fue llamado a considerar cinco casos que trataban sobre suspensión provisional de la función pública (afastamento cautelar) de parlamentarios en ejercicio, envueltos en procesos penales ${ }^{37}$. En estos casos, el Tribunal presentó una oscilación

32. Caso Lava Jato, Ministério Público Federal. Brasil.

33. Caso Lava Jato, Ministério Público Federal. Brasil.

34. El "fuero especial" está contemplado en el art. 102, I, "b" y "c", de la Constitución. Las autoridades beneficiarias de este instituto procesal deben ser juzgadas directamente por el STF.

35. Conforme el art. 52, I, de la Constitución, corresponde al Senado Federal juzgar al Presidente de la República por crímenes de responsabilidad. El proceso de impeachment está regulado en la Ley 1079/1950 y puede arrojar la pérdida del cargo.

36. GARCIA et al (2016). Vale decir que, aun así, el proceso de impeachment no tuvo relación directa con los resultados de la Operación Lava Jato, pero sí con la imputación de delitos contables. 37. Decreto-Lei n. 3689, de 1941 (Código de Proceso Penal Brasileño), art. 319. 
jurisprudencial difícil de explicar con base en el modelo legalista o en el modelo ideológico de comportamiento judicial. Esto es lo que se pasa a demostrar a continuación.

\subsection{La oscilación jurisprudencial del Supremo Tribunal Federal en materia de suspensión provisional de la función pública de parlamentarios}

En mayo de 2016, el plenario del Supremo Tribunal Federal decidió alejar al Presidente de la Cámara de los Diputados del ejercicio de la Presidencia de la Casa y de su mandato, por medio de una decisión cautelar. La decisión se basó en dos fundamentos principales. En primer lugar, un proceso penal había sido instruido contra la autoridad. Ocurre que el Presidente de la Cámara formaba parte de la línea de sucesión del Presidente de la República, y que no podría desempeñar esa atribución en condición de reo en un proceso penal. Asimismo, había indicios de que el diputado podría valerse de su posición para interferir en el curso del proceso penal, poniendo en riesgo la efectividad de la jurisdicción criminal. Basándose en esos fundamentos, el STF decidió, por unanimidad (11 a o), apartarlo de la Cámara de Diputados ${ }^{38}$.

Meses después, el Presidente del Senado fue denunciado por peculato (apropiación de fondos y bienes públicos ${ }^{39}$ ), y le correspondió al STF considerar la petición de alejamiento cautelar dirigida contra esta alta autoridad. Se alegaba, a favor de esta suspensión del cargo, que también esta autoridad integraba la línea de sucesión de la Presidencia de la República, como en el caso anterior, y que no podría estar acusada en un proceso penal y permanecer en condición de jefe de un poder. Aunque no hubo alegación de intento de obstrucción del proceso penal, como en el caso del Presidente de la Cámara, hubo rumores de que el Senado podía no cumplir la decisión del STF si este determinase la suspensión de su Presidente de sus funciones. El Supremo denegó la suspensión del Presidente del Senado, pero advirtió que dicha autoridad estaba impedida para substituir al Presidente de la República ${ }^{40}$.

A continuación, otro senador y un miembro de su familia fueron grabados mientras conversaban. En dichas conversaciones, se alegó que estarían solicitando dinero a un empresario privado, aparentemente, a cambio de beneficios públicos. Hubo, in

38. Procurador-Geral da República con E.C.D.C. (2016): Supremo Tribunal Federal. Ação Cautelar 4070 (AC 4070), relator Ministro Teori Zavasci. Diário de Justiça Eletrônico (DJe) de 21 de octubre de 2016.

39. Decreto-lei n. 2848 de1940 (Código Penal Brasileño), art. 312.

40. Rede Sustentabilidade con Presidente da Câmara dos Deputados (2017): Supremo Tribunal Federal, Arguição de Descumprimento de Preceito Fundamental 402 (ADPF 402), redactor Ministro Celso de Mello. Diário de Justiça Eletrônico (DJe) de 01 de febrero de 2017. 
cluso, imágenes filmadas de un intermediario recibiendo el dinero. El Supremo Tribunal Federal determinó la suspensión provisional de la autoridad de su mandato. La decisión generó, con todo, nuevas reacciones en el Senado y amenazas de incumplimiento ${ }^{41}$.

Semanas más tarde, el Supremo Tribunal Federal dio inicio al juicio de una acción directa de inconstitucionalidad relacionada a la interpretación del art. 53, par. $2^{\circ}$, de la Constitución de 1988. Este dispositivo prevé que los miembros del Legislativo no pueden ser apresados, salvo en delito flagrante, por crimen sin fianza, hipótesis en la cual la cárcel debería ser confirmada por la respectiva casa legislativa, en un plazo de 24 (veinticuatro) horas ${ }^{42}$. El autor de la acción alegó que la finalidad del dispositivo era evitar la interferencia judicial indebida sobre los mandatos de los miembros del Legislativo, en relación al principio de separación de poderes. Por esa razón, requirió al STF que reconociese que la norma constitucional, en realidad, determinaba que cualquier medida judicial que interfiriese con el mandato de un miembro del Legislativo -incluyendo el afastamiento cautelar- debería ser confirmada por el Poder Legislativo.

Sorprendentemente, el mismo STF que alejó provisionalmente al Presidente de la Cámara de Diputados del cargo, en el primer caso descrito, acogió la petición sostenida en esta nueva acción y afirmó, por una mayoría de 6 a 5, que los alejamientos cautelares de parlamentarios de sus mandatos deberían pasar a ser confirmados por el Legislativo. Con eso, el STF dejó de tener la última palabra sobre la cuestión ${ }^{43}$. Acto seguido, el Senado rechazó la cautelar que permitía el alejamiento del senador en el tercer caso narrado arriba, por una decisión de 44 a $26 \operatorname{votos}^{44}$.

41. Ministério Público Federal con Aécio Neves da Cunha (2017). Supremo Tribunal Federal, Agravo Regimental no Terceiro Agravo Regimental na Ação Cautelar 4327 (AgR no Terceiro no AgR AC 4327), redactor Ministro Luís Roberto Barroso. Diário de Justiça Eletrônico (DJe) de 27 de octubre de 2017.

42. Constitución Brasileña de 1988, art. 53: "Los diputados y senadores son inviolables, civil y penalmente, por cualesquiera que sean sus opiniones, palabras y votos. [...] $2^{\circ}$ Desde la expedición del diploma, los miembros del Congreso Nacional no podrán ser apresados, salvo en flagrante de crimen sin fianza. En ese caso, los autos serán remitidos dentro de veinticuatro horas a la Casa respectiva, para que, mediante el voto de la mayoría de sus miembros, se resuelva sobre la cárcel".

43. Partido Progressista y Partido Social Cristão (2017): Supremo Tribunal Federal. Ação Direta de Inconstitucionalidade 5526 (ADI 5526), redactor Ministro Alexandre de Moraes. Diário de Justiça Eletrônico (DJe) de 11 de octubre de 2017.

44. AGÊNCIA SENADO (2017). 
Basándose en esta nueva decisión del Supremo Tribunal Federal, los poderes legislativos de los estados -Brasil es una federación compuesta por 27 unidades federativas $^{45}$ - pasaron a rechazar las decisiones judiciales que apartaban diputados estaduales de sus respectivos mandatos y comenzaron a determinar su retorno a sus funciones. De hecho, la Constitución brasileña (art. 27, par. $1^{\circ}$ ) determina que los diputados estaduales se someten al mismo régimen que los diputados federales, incluso en lo que respecta a inmunidades ${ }^{46}$. Por lo tanto, si era necesaria una confirmación del Legislativo para el alejamiento de diputados federales, parecía lógico que también fuese necesaria para el alejamiento de diputados estaduales.

Por consiguiente, la decisión dictada en el caso anterior presentaba un importante efecto sistémico. Todo indicaba que la necesidad de alejamiento cautelar de diputados estaduales y su rechazo por los legislativos estaduales podrían ser bastante amplios. Después de eso, tres nuevas acciones directas de inconstitucionalidad fueron interpuestas ante el STF, para discutir el tema en lo que se refiere al Legislativo estadual. Esta vez, en la primera sesión de juzgamiento, cinco ministros votaron contra la necesidad de confirmación de las cautelares por el Legislativo, entre ellos un ministro que, anteriormente, había votado a favor de la necesidad de confirmación en el caso de parlamentarios federales ${ }^{47}$.

En ese nuevo caso, el mencionado ministro defendió una interpretación según la cual el poder de dar la palabra final sobre la prisión (y, por lo tanto, también sobre la cautelar de alejamiento del mandato), previsto en el art. 53, parr. $2^{\circ}$ de la CF, se aplicaría, única y exclusivamente, a los miembros del Congreso Nacional. Propuso, por lo tanto, una distinción entre el régimen de los miembros del Legislativo federal y estadual. Cuatro ministros votaron a favor de la necesidad de confirmación de cautelares

45. Las mencionadas veintisiete unidades federativas corresponden a veintiséis estados y a un distrito federal, este último con competencias y estructura política equivalentes a las de los estados, además de otras especificadas en la Constitución (CF/1988, art. 32).

46. Constitución Brasileña de 1988, art. 27, par. 1: "Será de cuatro años el mandato de los diputados estaduales, aplicándoseles las reglas de esta constitución sobre sistema electoral, inviolabilidad, inmunidad, remuneración, pérdida de mandato, permisos, impedimentos e incorporación a las Fuerzas Armadas."

47. El Ministro Dias Toffoli defendió una interpretación específica en este nuevo caso, según la cual la prohibición de prisión prevista en el art. 53, par. $2^{\circ}$ de la CF (y, por lo tanto, también de cautelar de alejamiento del mandato) estaría restringida, única y exclusivamente, a los miembros del Congreso Nacional. V. Supremo Tribunal Federal (2017): "Informativo 887 del STF". 
en cualquier caso, incluso para los diputados estaduales ${ }^{48}$. Así, con los nueve votos ya mencionados, se formó, en esa primera sesión, una mayoría provisional de cinco votos que se opuso a la necesidad de confirmación de las cautelares, contra cuatro votos a favor de dicha confirmación.

A continuación, el juzgamiento fue suspendido, con el fin de esperar los votos de los otros dos ministros que no asistieron a la sesión. En mayo de 2019, el juicio fue reanudado para recoger el voto de esos dos últimos ministros. Uno de ellos votó contra la necesidad de confirmación de las cautelares y el otro a favor de la necesidad de confirmación (los dos de forma coherente con sus votos anteriores). Así, después del voto de los once ministros que componían la Corte, en esa segunda sesión, había una mayoría de seis votos contra la necesidad de confirmación de las cautelares por las Casas Legislativas estaduales. Por lo tanto, la Corte parecía haber decidido dar un trato distinto a diputados federales y estaduales en su jurisprudencia, aunque el texto de la Constitución no pareciera disponer en ese sentido, al menos no expresamente.

Sin embargo, el juicio no se terminó. El mismo ministro que propuso el trato distinto para congresistas federales y estaduales anteriormente (en la primera sesión) cambió de entendimiento (en la segunda sesión) y reformuló su voto para afirmar la necesidad de confirmación también en el caso de los Estados. Con ello, se concluyó que tanto en el caso de parlamentarios federales, cuanto en el caso de diputados estaduales, habría necesidad de confirmación de las cautelares por las casas legislativas, siempre que tales cautelares interfiriesen en el ejercicio del mandato.

\subsection{Análisis}

En el primer caso narrado, el Supremo Tribunal Federal suspendió al Presidente de la Cámara de Diputados del cargo por decisión unánime de sus once ministros. La decisión tuvo por fundamentos: (i) el hecho de que la autoridad era reo en un proceso penal e integraba la línea sucesoria de la Presidencia de la República y (ii) los indicios alegados de que estaría valiéndose de su cargo para crear obstáculos a la prosecución del proceso criminal. No se consideró la necesidad de confirmación de la cautelar por la Casa Legislativa. Tampoco se tuvo noticia de rumores de incumplimiento de la decisión por la Cámara de Diputados.

48. Associação dos Magistrados Brasileiros con Assembleia Legislativa do Estado do Rio Grande do Norte: Supremo Tribunal Federal. Ação Direta de Inconstitucionalidade 5823 Medida Cautelar (ADI 5823 MC), relator Ministro Marco Aurélio; Associação dos Magistrados Brasileiros con Assembleia Legislativa do Estado do Rio de Janeiro; Associação dos Magistrados Brasileiros con Assembleia Legislativa do Estado do Mato Grosso: Supremo Tribunal Federal. Ações Diretas de Inconstitucionalidade 5824 y 5825 Medidas Cautelares (ADIs 5824 y 5825 MC), relator Ministro Edson Fachin. 
En el segundo caso, el STF no alejó al Presidente del Senado, determinando únicamente que, siendo procesado penalmente, no podría sustituir al Presidente. Es cierto que no había indicios de obstrucción del proceso penal, como en el caso anterior. Por otro lado, había rumores de que el Senado podría incumplir la eventual decisión que determinase el alejamiento cautelar.

En el tercer caso, el Supremo Tribunal Federal determinó la suspensión del senador de sus funciones. No se consideró la necesidad de confirmación a través del Senado. Al mismo tiempo, había rumores de que habría una gran resistencia entre los senadores a su cumplimiento.

En el cuarto caso, juzgado pocas semanas más tarde, el Supremo Tribunal Federal decidió, entonces, que cualquier decisión que implicase suspensión del mandato (aun siendo cautelar), debería ser confirmada por el Legislativo. Esa decisión, en la práctica, posibilitó la reversión por el Senado del alejamiento determinado en el tercer caso narrado arriba, sin un incumplimiento manifiesto y abierto de la decisión del STF, es decir, dentro de los límites trazados por el propio STF acerca de las posibilidades de actuación del Senado.

En el quinto caso, el entendimiento firmado en el cuarto caso fue nuevamente puesto en cuestión. Se trataba del alejamiento cautelar de diputados estaduales, y no de diputados federales, pero la Constitución determinaría la aplicación a ambos del mismo régimen jurídico, incluso en lo relativo a inmunidad (art. 27, par. $1^{\circ}$ ). Sin embargo, el Tribunal casi decretó una distinción entre diputados federales y estaduales, donde la literalidad del texto de la Constitución parecía determinar la aplicación del mismo régimen. No bastara eso, en el curso del juicio, un mismo ministro cambió dos veces de posición, invirtiendo el resultado final de la decisión.

Las diferentes decisiones descritas arriba difícilmente serían explicables solo en base al modelo legalista. El Tribunal se manifestó de forma considerablemente distinta en el primer y cuarto caso, y volvió a oscilar en el quinto. Tales decisiones tampoco parecen explicables basándose en el modelo ideológico. Entre la decisión del primer caso y la resolución del cuarto transcurrieron menos de dos años. Tan solo un miembro del Tribunal fue substituido. Es difícil sostener un cambio de convicción política en lo que respecta al alcance de separación de poderes en un periodo tan corto. Y, el mismo objeto de la decisión -separación de funciones legislativas por encausamiento criminal- no dice relación a una disputa valórica o ideológica.

El modelo de comportamiento estratégico, en cambio, puede ofrecer algunas explicaciones. El Supremo Tribunal Federal venía siendo, progresivamente, sometido a una fuerte presión. El impeachment de la Presidenta de la República, los hallazgos de la "Operación Lava Jato" y de otras investigaciones de altas autoridades llevaron todos los grandes debates al Tribunal. La opinión pública y la prensa presionaban al STF para que actuase con rigor en relación a tales delitos. Es posible que los miembros de 
los demás poderes, gran parte de ellos objeto de dichas investigaciones, se sintieran amenazados por la actuación de la Corte y que se hayan pretendido movilizar contra ella. El hecho es que rumores de que las decisiones del Tribunal serían incumplidas se hicieron muy fuertes. En este escenario, el cuarto caso tal vez haya constituido una especie de "salida honrosa" que permitía al Tribunal evitar el abierto incumplimiento de su decisión y otras posibles represalias.

La actuación estratégica encuentra dificultades en situaciones de asimetría de información ${ }^{49}$, como ya fue anticipado. Saber de antemano si la decisión del Tribunal será incumplida y si habrá represalias a la Corte puede ser difícil. Sin embargo, la credibilidad de la amenaza (de incumplimiento) y la gravedad de sus consecuencias para la autoridad del Tribunal pueden ser suficientes para llevar a una parte de sus miembros a optar por una second best decision.

El hecho es que, en los casos ya narrados, la inmunidad reconocida a los parlamentarios federales fue aplicada por los legislativos estaduales. Las asambleas legislativas pasaron a entender, por simetría, que también les cabía dar la última palabra acerca de prisiones y de cautelares de alejamiento del mandato contra sus miembros. Tener veintisiete Legislativos locales con poderes de rechazo de cautelares judiciales contra sus propios miembros era un efecto sistémico grave de la decisión dictada en el cuarto caso. Ante ese nuevo cuadro la Corte buscó una interpretación que pudiese distinguir entre la esfera federal y la estadual, hasta porque el riesgo de incumplimiento de decisiones del Tribunal por el Legislativo estadual era menor. Sin embargo, ni el texto constitucional ni el contexto político - de fuerte presión por parte de las elites locales - favorecieron esta salida.

\section{Conclusión}

Pensar en una corte constitucional o en una suprema corte simplemente como un órgano que actúa en la defensa de los derechos fundamentales y en el funcionamiento adecuado del proceso democrático, simplemente en base a principios y al mejor argumento, significa idealizar el papel desempeñado por tales cortes. Aunque el comportamiento judicial legalista tenga su valor para explicar el proceso decisorio de las cortes en un gran conjunto de casos, posiblemente tendrá un bajo potencial explicativo en las decisiones de casos emblemáticos, en que el material jurídico ortodoxo ofrece luces incompletas para la decisión, o en virtud de una situación de conflagración entre poderes.

A pesar de que los teóricos del Derecho hayan producido muchas obras sobre cómo deben ser tomadas las decisiones, aún se cuida poco de la investigación sobre cómo efectivamente ocurren o cuáles son los factores extrajurídicos que interfieren

49. Hay asimetría de información cuando no es posible conocer con precisión las preferencias o el comportamiento que un determinado agente adoptará ante ciertas circunstancias. 
en el proceso decisorio de las cortes. El resultado arroja teorías normativas desconectadas de la realidad; idealizaciones sobre el papel que debe ser desempeñado por los magistrados, que desconsideran las condiciones bajo las cuales trabajan o los límites a los que están sujetos, y una incomprensión generalizada sobre cómo argumentar, sostener un punto de vista o defender un caso con posibilidades de éxito en un juicio.

Les corresponde a los tribunales interpretar las normas y decidir los conflictos de interés, y a las cortes constitucionales y supremas cortes dictar decisiones finales sobre un conjunto muy importante de temas. La comprensión de lo que es el Derecho depende de un entendimiento adecuado sobre cómo deciden dichas cortes, de los factores y argumentos capaces de influenciar sus decisiones. Los elementos jurídicos son apenas una parte de ellos y, eventualmente, en situaciones muy conflictivas, la parte menos relevante. Es tiempo, por tanto, de que el Derecho se ocupe de lo que efectivamente ocurre en las cortes.

\section{Referencias bibliográficas}

AGÊNCIA SENADO (2017): Plenário rejeita medidas cautelares contra Aécio Neves e senador retoma mandato. 17 out. 2017. Disponible en: <https://www12.senado. leg.br/noticias/materias/2017/10/17/senado-derruba-decisao-do-stf-contra-aecio $>$. [Fecha de consulta: 15 abril 2018.]

ASHENFELTER, Orley; EISENBERG, Theodore; y SCHWAB, Stewart (1995): "Politics and the Judiciary: the influence of judicial background on case outcomes". Journal of Legal Studies, Cornell Law Faculty, Año 24, № 2, junio de 1995, pp. 257281, jun. 1995. Disponible en: <http://scholarship.law.cornell.edu/cgi/viewcontent. cgi? article=1411 \&context=facpub $>$. [Fecha de consulta: 15 marzo 2018].

BARROSO, Luís Roberto (2009): Curso de Direito Constitucional Contemporâneo: os conceitos fundamentais e a construção de um novo modelo (São Paulo, Saraiva).

BAUM, Lawrence (2008): Judges and their audiences: a perspective on judicial behavior (Nova Jersey, Princeton University).

BENESH, Sara C. y SPAETH, Harold J (2003): The Supreme Court justice-centered judicial databases: the Warren, Burger, and Rehnquist Courts 1953-20oo (East Lansing, Michigan State University). Disponible en: <http://artsandsciences.sc.edu/ poli/juri/flpdcodebk.pdf $>$. [Fecha de consulta: 15 de marzo de 2018].

BIKHCHANDANI, S.; HIRSHLEIFER, D. y WELCH, I. (1998): "Learning from the behavior of others". En Journal of Economic Perspectives, Año $\mathrm{N}^{\circ}$ 12, verano de 1998, pp. 151-170. 
BRASIL. Ministério Publico Federal. "Caso Lava Jato". Disponible en: <http://www. mpf.mp.br/para-o-cidadao/caso-lava-jato/atuacao-na-1a-instancia/investigacao/ historico $>$. [Fecha de consulta: o7 de mayo 2018].

BRASIL. Ministério Publico Federal. "Caso Lava Jato". Disponible en: <http://www. mpf.mp.br/para-o-cidadao/caso-lava-jato/entenda-o-caso $>$. [Fecha de consulta: o7 de mayo 2018].

BRASIL. Supremo Tribunal Federal (2017): Informativo 887 del STF. Disponible en: <http://www.stf.jus.br/portal/informativo/verInformativo.asp?s1=5823\&numero $=887$ \&pagina $=1 \&$ base $=$ INFO $>$. [Fecha de consulta: 14 de abril 2019].

BRENNER, Saul y WHITMEYER, Joseph M (2009): Strategy on the United States Supreme Court (Nova York, Cambridge University).

CALDEIRA, Gregory A. y WRIGHT, John R (1988): "Organized interest and agenda setting in the U.S. Supreme Court". En American Political Science Review, Washington, No 82 , pp. 1109-1127.

CARDOZO, Benjamin N (2005): The nature of the judicial process (Nova York, Dover Publications).

Código Penal, Decreto-Lei n. 2.848/1940 (Código Penal Brasileño).

Código de Processo Penal, Decreto-Lei n. 3.689/1941 (Código Proceso Penal Brasileño).

Constituição da República Federativa do Brasil de 1988 (Constitución de la República Federativa del Brasil o Constitución Brasileña).

CORAM, Bruce Talbot (1995): "Second best theories and the implications for institutional design". En GOODIN, Robert E. The theory of institutional design (Cambridge, Cambridge University Press), pp. 90-102.

COX, Adam y MILES, Thomas (2008): "Judging the Voting Rights Act". En Chicago Unbound, University of Chicago Law School, Año 108, No. 1, enero de 2008, pp 1-54. Disponible en: <https://chicagounbound.uchicago.edu/cgi/viewcontent.cgi? article $=8033 \&$ context $=$ journal_articles $>$. [Fecha de consulta: 30 de junio de 2018].

CRITIN, J. y EGAN, P. J. (2009): "Opinion leadership, backlash, and delegitimation: Supreme Court rulings and public opinion". En Social Science Research Network, agosto 2009. Disponible en: <https://papers.ssrn.com/sol3/papers.cfm?abstract_ $\mathrm{id}=1443631>$. [Fecha de consulta: 17 de octubre de 2018].

CROSS, Frank B. y NELSON, Blake J. (2001): "Strategic institutional effects on Supreme Court decision making". En Northwestern University Lae Review, Año 95, pp. 1437-1493. 
CROSS, Frank P. y TILLER, Emerson H (1998): "Judicial partisanship and obedience to legal doctrine: whistleblowing on the Federal Courts of Appeals". En Yale Law Journal, Yale University, Año 7, No107, pp. 2155-2176.

DAHL, Robert (1957): "Decision-making in a democracy: the Supreme Court as a national policy-maker". En Journal of Public Law, Año 6, pp. 279-295.

EASTON, David (1975): "A re-assessment of the concept of popular support". En British Journal of The Politics Science, West Nyack, Año 5 No 4 (oct., 1975),, pp. 435457.

EGAN, Patrick J. y CITRIN, Jack (2009): "Opinion leadership, backlash, and delegitimation: supreme court rulings and public opinion". En Social Science Research Network, Rochester, agosto de 2009. Disponible en: <http://ssrn.com/abstract $=1443631>$. [Fecha de consulta: 15 de marzo de 2018.

ELSTER, Jon (2007): Explaining social behavior: more nuts and bolts for the social sciences (Nova York, Cambridge University).

ELSTER, Jon (1986): "Introduction". En ELSTER, Jon. Rational choice (Nova York, New York University), pp. 1-33.

EPSTEIN, Lee y KNIGHT, Jack (1995): "Documenting strategic interaction on the U.S.Supreme Court". En Political Science Paper, n. 275. Disponible en: <http:// epstein.wustl.edu/research/conferencepapers.1995APSA.pdf $>$. [Fecha de consulta: 30 de junio de 2018].

EPSTEIN, Lee y KNIGHT, Jack (1998): The choices justices make (Washington, CQ Press).

FRANK, Jerome (1949a): "Are judges human?". En FRANK, Jerome. Courts on trial: myth and reality in American justice (Nova Jersey, Princeton University Press).

FRANK, Jerome (1949b): "Justice and emotions". En FRANK, Jerome. Courts on trial: myth and reality in American justice (Nova Jersey, Princeton University).

FRIEDMAN, Barry (2003): "Mediated popular constitutionalism". En Michigan Law Review, No. 101, pp. 2596-2636.

FRIEDMAN, Barry (2004): "The importance of being positive: the nature and function of judicial review". En University of Cincinnati Law Review, Cincinnati, No 72 , pp. 1257-1305.

FRIEDMAN, Barry (2005): "The politics of judicial review". En Texas Law Review, Austin, No. 84, pp. 257-339. 
FRIEDMAN, Barry (2009): The will of the people: how public opinion has influenced the Supreme Court and shaped the meaning of the Constitution (Nova York, Farrar, Strauss e Giroux).

GARCIA, Gustavo; CALGARO, Fernanda; MATOSO, Filipe; LIS, Laís y RODRIGUES, Mateus (2016): "Senado aprova impeachment, Dilma perde mandato e Temer assume". En G1, Política, agosto de 2016. Disponible en: <http://g1.globo.com/ politica/processo-de-impeachment-de-dilma/noticia/2016/o8/senado-aprovaimpeachment-dilma-perde-mandato-e-temer-assume.html $>$. [Fecha de consulta: 15 de mayo 2018].

GREENHOUSE, L (2005): Becoming Justice Blackmun: Harry's Blackmun's Supreme Court Journey (New York, Times Books).

GROSSMAN, Joel B (1966): "Social backgrounds and judicial decision-making". En Harvard Law Review, Cambridge, No 79, pp. 1551-1564.

HOLMES, Oliver Wendell Jr. (1897): "The path of the law". En Harvard Law Review, Cambridge, Año 10, p. 457-478.

KLARMAN, M. J. (1994): "How Brown changed race relations: the backlash thesis". En The Journal of American History, Oxford University, Año $81 \mathrm{~N}^{\circ} 1$ (jun., 1994), pp. 81-118.

LAIN, Corinna Barrett (2012): "Upside-down judicial review". En Social Science Research Network, Rochester, enero de 2012. Disponible en: <http://ssrn.com/abstract $=1984060>$. [Fecha de consulta: 15 de marzo de 2018].

LIPPMAN, W (2008): Opinião pública (Petrópolis, Editora Vozes).

LLEWELYN, Karl N (1960): The common law tradition: deciding appeals (Boston, Little, Brown and Company).

MARSHALL, T. R. (1989): Public opinion and the Supreme Court (Boston, Unwin Hyman).

MARSHALL, T. R. (2008): Public opinion and the Rehnquist Court (New York, University of New York Press).

MARTIN, Andrew D. et al (2004): "Competing approaches to predicting Supreme Court decision-making". En Perspectives on Politics, New York, Año $2 \mathrm{~N}^{\circ} 4$, pp. 761-767.

MELLO, Patrícia Perrone Campos (2015): Nos bastidores do Supremo Tribunal Federal (Rio de Janeiro, Forense). 
MELlO, Patrícia Perrone Campos y BAQUEIRO, Paula Andrade (2018): "Distinção inconsistente e superação de precedentes no Supremo Tribunal Federal". En $R e$ vista Brasileira de Políticas Públicas, Centro Universitário de Brasília, Año 8, № 1, abril de 2018, pp. 668-690.

MILES, Thomas J. y SUNSTEIN, Cass R (2006): "Do judges make regulatory policy? An empirical investigation of Chevron". En University of Chicago Law Review, Chicago, Año 73, pp. 823-878.

MORETZOHN, S (2002): Jornalismo em tempo real: O fetiche da velocidade (Rio de Janeiro, Revan).

PERESIE, Jennifer (2005): "Female judges matter: gender and collegial decision-making in the Federal Appellate Courts". En Yale Law Journal, New Haven, № 114, Vol. 7,mayo de 2005, pp. 1759-179o. Disponible en: <https://www.yalelawjournal. org/note/female-judges-matter-gender-and-collegial-decisionmaking-in-the-federal-appellate-courts $>$. [Fecha de consulta: 26 de marzo de 2018].

PETTIT, Philip (1996): "Institutional design and rational choice". En GOODIN, Robert E. The theory of institutional design (New York, Cambridge University), pp. 54-89.

PINELLO, Daniel R (1999): "Linking party to judicial ideology in American courts: a meta-analysis". En The Justice System Journal, Denver, Año $20 \mathrm{~N}^{\circ} 3$, pp. 219-254.

POSNER, Richard (1993): "What do judges maximize? (the same thing everybody else does)". En Supreme Court Economic Review, New York, No 3, pp. 1-41.

POSNER, Richard (2008): How judges think (Cambridge, Harvard University).

REVESZ, Richard L (1997): "Environmental regulation, ideology, and the D.C. circuit". En Virginia Law Review, Charlottesville, Año 83, No8, pp. 1717-1772.

SEGAL, Jeffrey A. y COVER, Albert D (1989): "Ideological values and the votes of U. S. Supreme Court Justices". En American Political Science Review, Washington, Año 83, Nº2 (jun., 1989), pp. 557-565.

SEGAL, Jeffrey A. y EPSTEIN, Lee; CAMERON, Charles M.; SPAETH, Harold J. (1995): "Ideological values and the votes of U.S. Supreme Court justices revisited". En Journal of Politics, West Nyack, Año 57, No 3 (Agosto 1995), pp. 812-823.

SEGAL, Jeffrey A. y SPAETH, Harold J. (2002): The Supreme Court and the attitudinal model revisited (Nova York, Cambridge University).

SISK, Gregory C. y HEISE, Michael (2005): "Judges and ideology: public and academic debates about statistical measures". En Northwestern University Law Review, Chicago, Año 99, $\mathrm{N}^{\circ} 2$, pp. 743-804. 
SISK, Gregory C. y HEISE, Michael; MORRISS, Andrew P (1998): "Charting the influences on the judicial mind: an empirical study of judicial reasoning". En New York University Law Review, New York, Año 73, Nº5, pp. 1377-150o.

SOLBERG, Rorie Spill (2006): "Activism, Ideology and Federalism: Judicial behavior in constitutional challenges before the Rehnquist Court". En Journal of Empirical Legal Studies, Oxford, Año 3, No 2, p. 237-261.

SOUZA NETO, Cláudio Pereira y SARMENTO, Daniel (2007): A constitucionalização do direito: fundamentos teóricos e aplicações específicas (Rio de Janeiro, Lumen Juris).

SPILLER, P. T.; TILLER, E. H. y EMERSON, H. (1996):"Invitations to override: congressional reversals of Supreme Court decisions”. En International Review of Law and Economics, Año 16, pp. 503-521.

SUNSTEIN, C. R.; SAWICKI, A.; ELLMAN, L. M. y SCHKADE, D. (2006): Are judges political? An empirical analysis of the federal Judiciary (Washington, Brookings Institution).

SUNSTEIN, Cass R y MILES, Thomas J. (2006): "Do judges make regulatory policy? An empirical investigation of Chevron". En University of Chicago Law Review, Chicago, Año. 73, pp. 823-848.

TVERSKY, Amos; KAHNEMAN, Daniel (1986): "The framing of decisions and the psychology of choice". En ELSTER, Jon. Rational choice (New York, New York University Press).

WHITTINGTON, Keith (2003): "Legislative sanctions and the strategic environment of judicial review". I.CON, Oxford University Press and New York University School of Law, Año 1, No 3, pp. 446-474. Disponible en:<http://www.princeton. edu/ kewhitt/strategic_context.pdf $>$. [Fecha de consulta: 17 de octubre de 2018].

\section{Jurisprudencia Citada}

Associação dos Magistrados Brasileiros con Assembleia Legislativa do Estado do Rio Grande do Norte (juicio no concluido): Supremo Tribunal Federal. Ação Direta de Inconstitucionalidade 5823 Medida Cautelar (ADI $5823 \mathrm{MC}$ ), relator Ministro Marco Aurélio. Disponible en: <http://portal.stf.jus.br/processos/detalhe. asp? incidente $=5316137>$. [Fecha de consulta: 13 de abril de 2019].

Associação dos Magistrados Brasileiros con Assembleia Legislativa do Estado do Rio de Janeiro (juicio no concluido): Supremo Tribunal Federal. Ação Direta de Inconstitucionalidade 5824. Medida Cautelar (ADI 5824 MC), relator Ministro Edson Fachin. Disponible en: <http://portal.stf.jus.br/processos/detalhe. asp? incidente $=5316137>$. [Fecha de consulta: 13 de abril de 2019]. 
Associação dos Magistrados Brasileiros con Assembleia Legislativa do Estado do Mato Grosso (juicio no concluido): Supremo Tribunal Federal. Ação Direta de Inconstitucionalidade 5825 Medida Cautelar (ADI $5825 \mathrm{MC}$ ), relator Ministro Edson Fachin. Disponible en: <http://portal.stf.jus.br/processos/detalhe. asp?incidente $=5316137>$. [Fecha de consulta: 13 de abril de 2019].

Ministério Público Federal con Aécio Neves da Cunha (2017). Supremo Tribunal Federal, Agravo Regimental no Terceiro Agravo Regimental na Ação Cautelar 4327 (AgR no Terceiro no AgR AC 4327), redactor Ministro Luís Roberto Barroso. Diário de Justiça Eletrônico (DJe) de 27 de octubre de 2017.

Partido Progressista y Partido Social Cristão (2017): Supremo Tribunal Federal. Ação Direta de Inconstitucionalidade 5526 (ADI 5526), redactor Ministro Alexandre de Moraes. Diário de Justiça Eletrônico (DJe) de 11 de octubre de 2017.

Procurador-Geral da República con E.C.D.C. (2016): Supremo Tribunal Federal. Ação Cautelar 4070 (AC 4070), relator Ministro Teori Zavasci. Diário de Justiça Eletrônico (DJe) de 21 de octubre de 2016.

Rede Sustentabilidade con Presidente da Câmara dos Deputados (2017): Supremo Tribunal Federal, Arguição de Descumprimento de Preceito Fundamental 402 (ADPF 402), redactor Ministro Celso de Mello. Diário de Justiça Eletrônico (DJe) de 01 de febrero de 2017. 


\title{
Vale o quanto Custa? Um Estudo sobre a Relação entre a Capacidade Institucional dos Tribunais de Contas Subnacionais Brasileiros e a Qualidade das Políticas Públicas de seus Respectivos Estados
}

\author{
Worth What It Costs? A Study on the Relationship between the Institutional \\ Capacity of the Brazilian Subnational Accounts Courts and the Quality of Public \\ Policies of their Respective States
}

\section{Thiago Augusto de Oliveira Marinho Ferreira ${ }^{1}$ \\ Universidade Federal de Pernambuco, Brasil}

\begin{abstract}
RESUMO O controle é um ato ou momento político central de um ciclo mais amplo da representação democrática. Para assegurar que os representantes, uma vez à frente de seus cargos, pautem sua conduta pelo "melhor interesse de seus representados", é necessário haver instrumentos efetivos e continuados de controle. No Brasil, a Constituição Federal conferiu aos Tribunais de Contas o desafio de controlar suas contas públicas. Mas qual é a relação entre o fortalecimento do controle dos gastos públicos - a partir de uma maior capacidade institucional destes órgãos de controle - e a qualidade das políticas públicas oferecidas aos cidadãos? O presente artigo se propõe a investigá-la. Para tanto, o desenho de pesquisa combina estatística descritiva e multivariada para analisar um banco de dados original elaborado com informações obtidas de diferentes fontes. Em particular, operacionaliza-se a capacidade institucional dos
\end{abstract}

1. Doutor e Mestre em Ciência Política, Universidade Federal de Pernambuco - UFPE. Email: thiago.aomf@hotmail.com. O autor agradece as valiosas ponderações dos professores da UFPE e, em especial, às significativas sugestões e recomendações propostas pelos avaliadores anônimos. Quaisquer incorreções remanescentes são de sua total responsabilidade. 
Tribunais de Contas subnacionais brasileiros a partir das seguintes variáveis: orçamento, pessoal e contas julgadas irregulares. Não obstante, utiliza-se a análise fatorial para definir os indicadores relativos à qualidade das políticas públicas de saúde e educação de seus respectivos Estados, no ano de 2010. Dentre as variáveis analisadas, os resultados preliminares sugerem que o fortalecimento do controle dos gastos públicos está positivamente correlacionado com a qualidade das políticas públicas oferecidas aos cidadãos.

Palavras-Clave Tribunais de Contas, Capacidade Institucional, Políticas Públicas.

ABSTRACT Control is a central political act or moment of a broader cycle of democratic representation. To ensure that representatives, once at the head of their positions, conduct themselves in the "best interests of their constituencies", there must be effective and continuous instruments of control. In Brazil, the Federal Constitution gave the Audit Courts the challenge of controlling their public accounts. But what is the relationship between strengthening public spending control - based on a greater institutional capacity of these control bodies - and the quality of public policies offered to citizens? This article proposes to investigate it. To do so, the research design combines descriptive and multivariate statistics to analyze an original database prepared with information obtained from different sources. In particular, the institutional capacity of the Brazilian subnational Accounts Courts is operationalized based on the following variables: budget, personnel and accounts judged to be irregular. $\mathrm{Ne}-$ vertheless, the factorial analysis is used to define the indicators related to the quality of the public health and education policies of their respective States, in 2010. Among the variables analyzed, the preliminary results suggest that the strengthening of the control of public expenditures is positively correlated with the quality of public policies offered to citizens.

KEYWORDS Courts of Accounts, Institutional Capacity, Public policy.

\section{Introdução}

O debate sobre instituições de controle tornou-se mais presente nas últimas décadas - principalmente - em razão da consolidação das democracias. Afinal, o controle sobre a Administração Pública é dimensão crucial de uma ordem democrática² ${ }^{2}$.

2. ARANTES et al. (2011). 
No Brasil, a população é confrontada quase que diariamente com temas relacionados ao controle dos gastos públicos que tem ocupado grande espaço na mídia e no debate público ao longo dos últimos anos. De um lado, há denúncias de escândalos envolvendo agentes públicos e do poder privado - é cotidiano aparecerem casos de grandes "esquemas" que desviaram sistematicamente recursos milionários dos cofres públicos. De outro, a preocupação com o bom uso dos recursos públicos também é oriunda da inquietação do poder público com o tema - o esgotamento fiscal do Estado brasileiro forçou os governos a redirecionarem os seus esforços de desenvolvimento para o horizonte da eficiência, da eficácia e da efetividade, de modo a compeli-los a fazer melhor aquilo que fazem com os recursos já existentes, ou até com menos do que isso.

E é nesse contexto em que se observa a grande razão para este crescente interesse pelo estudo das instituições de controle. Notadamente pelo papel que podem desempenhar não só no combate à corrupção, mas também na redução de desperdícios e na melhoria da responsabilização dos governos, que são objetivos-chave da governança democrática ${ }^{3}$.

Com efeito, os instrumentos de controle da Administração Pública desenvolvidos pelo Brasil pós-1988 envolvem desde o controle parlamentar, exercido pelo Legislativo sobre o Executivo, os controles judiciais, os controles administrativos e financeiros e diferentes formas de controle social. Dentre estes, importa destacar os controles administrativos e financeiros exercidos pelos Tribunais de Contas, que possuem a função de verificar se o poder público efetuou as despesas da maneira como fora determinado pelo orçamento e pelas normas legais mais gerais (tais como: os limites para endividamento, a vinculação orçamentária a determinadas áreas, etc). O ponto central dessa fiscalização é a probidade, tendo como finalidade não permitir o mau uso dos recursos públicos ${ }^{4}$.

Os Tribunais de Contas surgiram historicamente com a República, sendo concebidos como órgãos de assessoria técnica do Legislativo em sua atividade de controle das contas públicas - hoje, existem 33 Tribunais de Contas em funcionamento no país. A Constituição de 1988 assegurou a eles uma série de avanços institucionais, ao passo que a Lei de Responsabilidade Fiscal (Lei Complementar $n^{\circ}$ 101/2000) ampliou suas funções fiscalizatórias, materializando a preocupação do legislador com a qualidade da gestão fiscal dos recursos públicos ${ }^{5}$ e, mais recentemente, a Lei da Ficha Limpa (Lei Complementar $n^{\circ}$ 135/2010) conferiu um peso maior às suas decisões.

3. MELO et al. (2009).

4. Idem.

5. ARANTES et al. (2005); ROCHA et al. (2014). 
Contudo, embora se tratem de instituições de longa data e que passaram por importantes avanços pós-1988, carecem de visibilidade e têem sofrido críticas severas quanto ao não desempenho de seu papel como guardiões-mor dos recursos públi$\cos ^{6}$. Diante disso, cabe indagar: os Tribunais de Contas são capazes de reduzir as irregularidades na execução orçamentária, na celebração de contratos com entidades privadas, na contratação e aposentadoria de pessoal e nos demais atos da Administração Pública? Ademais, após dez anos de vigência da Lei de Responsabilidade Fiscal, é possível estabelecer algum tipo de relação entre essa capacidade institucional dos Tribunais de Contas subnacionais brasileiros e a qualidade das políticas públicas de saúde e educação de seus respectivos Estados? O presente artigo se propõe a investigar esta relação, em busca de evidências empíricas que sinalizem nesta direção.

O controle constitui importante instrumento de governança pública, encarado como mecanismo que possibilita à sociedade acompanhar e fiscalizar os atos públicos, atendendo aos princípios da Administração Pública e da gestão voltada para os cidadãos. Pode, além da essência fiscalizadora, permitir o uso de suas ferramentas para o aprimoramento da gestão e dos serviços públicos ${ }^{7}$. Ao fornecer suporte à gestão e segurança aos cidadãos quanto aos resultados das políticas públicas, o controle pode aumentar a transparência e a accountability, que são pilares da governança ${ }^{8}$.

A formulação e a implementação de políticas públicas, em qualquer esfera de governo, requer o entendimento da realidade, a identificação das causas críticas e as formulações sobre produtos e resultados que permitam a otimização do uso dos recursos públicos escassos disponíveis. Nesse sentido, a governança está relacionada com a capacidade e as condições internas às instituições, para exercício de suas competências e alcance de seus objetivos. Diz respeito aos recursos técnicos, tecnológicos, de infraestrutura, de pessoal, entre outros de que dispõem as estruturas governamentais para formular, planejar e implantar as políticas públicas, assim como acompanhar, avaliar e fiscalizar a sua execução e resultados obtidos ${ }^{9}$.

Razão pela qual, analisar a capacidade institucional dos Tribunais de Contas subnacionais brasileiros se apresenta como um caminho viável para a compreensão de sua relação com a qualidade das políticas públicas. Para tanto, o argumento desenvolvido no presente artigo é o de que: existe uma relação entre a capacidade institucional dos Tribunais de Contas subnacionais brasileiros e a qualidade das políticas públicas de saúde e educação de seus respectivos Estados.

\footnotetext{
6. SPECK (2000); Idem.

7. FARACO et al. (2016).

8. CAVALCANTE et al. (2012); OLIVEIRA (2015).

9. MPOG (2014).
} 
Nesse sentido, adota-se a abordagem da accountability horizontal, identificandose como objetivo dos Tribunais de Contas dispor de capacidade para realizar ações efetivas de controle da Administração Pública - que vão desde a supervisão de rotina a sanções legais contra ações ou omissões de outros agentes ou agências do Estado, que possam ser qualificadas como delituosas ${ }^{10}$.

Para tanto, operacionaliza-se a capacidade institucional dos Tribunais de Contas subnacionais brasileiros a partir das seguintes variáveis: orçamento, pessoal e contas julgadas irregulares. Não obstante, utiliza-se a análise fatorial para definir os indicadores relativos à qualidade das políticas públicas de saúde e educação de seus respectivos Estados.

É importante destacar que a pesquisa se concentra em instituições de controle externo localizadas dentro de um mesmo país. Metodologicamente, o desenho de pesquisa combina estatística descritiva e multivariada para analisar um banco de dados original elaborado com informações obtidas de diferentes fontes. O período analisado corresponde ao ano de 2010, o qual tem por base a disponibilidade dos dados que serão analisados. Trata-se, também, do ano em que a Lei de Responsabilidade Fiscal completa a sua primeira década de vigência.

Bem se sabe que não basta apenas analisar a atuação dos Tribunais de Contas - de forma isolada - para que se possa avaliar com precisão a sua relação com a qualidade das políticas públicas. Afinal, a fiscalização dos gastos públicos demanda uma ampla rede de controle atuante - e disposta a atuar ${ }^{11}$. De todo modo, o presente trabalho se constitui em esforço para demonstrar que os Tribunais de Contas figuram como importantes instituições de controle, logo, funcionam como checks and balances e, por conseguinte, impactam a qualidade das políticas públicas.

Por fim, estrutura-se o artigo da seguinte forma: a primeira seção resgata o debate sobre controles democráticos e como os Tribunais de Contas subnacionais brasileiros se inserem nesse contexto, sobretudo, com o fim de evidenciar a importância de sua capacidade de fiscalização em relação à qualidade das políticas públicas. A próxima seção se dedica a discutir a metodologia utilizada para responder a questão de pesquisa e testar a hipótese formulada. A seção seguinte traz a lume as análises e os resultados apurados sobre as variáveis propostas. Por fim, a última seção sumariza as considerações finais do artigo.

\section{Os Tribunais de Contas no Contexto dos Controles Democráticos}

O controle se constitui em um ato ou momento político central de um ciclo mais amplo da representação democrática. Essa noção de ciclo completo de representação implica que o momento eleitoral é apenas o começo do processo democrático, que

10. O’DONNELL (1998).

11. Idem. 
deve ter continuidade durante o mandato do governante. De sorte que, para assegurar que os representantes, uma vez a frente de seus cargos públicos, pautem sua conduta pelo melhor interesse de seus representados, é necessário haver instrumentos efetivos e continuados de controle. Por fim, o ciclo da representação se completa quando o povo, a partir dos efeitos gerados pelos atos de controle, é capaz de avaliar se os governantes agiram (ou não) como seus representantes de fato, decidindo-se por sua recondução ou destituição do cargo ${ }^{12}$.

Mas, como os governantes são controlados? A resposta a essa questão nos remete à discussão das diferentes formas de accountability democrática, ou seja, a existência de um aparato institucional que garanta a responsabilização política ininterrupta do poder público diante da sociedade. O controle é, portanto, momento constitutivo do processo mais amplo de accountability ou responsabilização política dos governantes para garantir (ou tentar garantir) que eles atuem, de fato, como representantes do povo. A primeira forma de accountability diz respeito ao processo eleitoral, por meio do qual os eleitores podem recompensar ou punir seus representantes. A segunda forma de accountability passou a ser destacada na literatura justamente pela insatisfação diante dos ínfimos resultados obtidos pelas eleições. Trata-se do conjunto de instituições de controle intraestatal que fornecem os mecanismos de fiscalização contínua dos representantes eleitos - durante o exercício de seus mandatos - e da alta burocracia com responsabilidade decisória. Por fim, a terceira forma de accountability democrática se relaciona à criação de regras estatais intertemporais, pelas quais o poder governamental é limitado em seu escopo de atuação, a fim de se garantir os direitos dos indivíduos e da coletividade que não podem simplesmente ser alterados pelo governo de ocasião ${ }^{13}$.

Essa classificação não diverge daquela construída por O'Donnell ${ }^{14}$, segundo a qual a responsabilidade democrática procura aliar dois mecanismos: de um lado, os relacionados à accountability vertical, na qual os cidadãos controlam de forma direta os governantes, por meio do voto para escolher seus representantes, em plebiscitos sobre matérias substantivas ou ainda pelo controle exercido, por exemplo, em conselhos de usuários de serviços públicos; e, de outro, os vinculados à accountability horizontal, que se efetivam mediante a fiscalização mútua entre os poderes ou por meio de outras agências governamentais que monitoram e fiscalizam o poder público.

\footnotetext{
12. Ibidem.

13. ABRUCIO y LOUREIRO (2004).

14. Ibidem.
} 
Quais seriam estas instituições secundárias, capazes de realizar esse controle horizontal? A accountability horizontal é exercida por dois tipos de agências: (1) os Poderes clássicos - Executivo, Legislativo e Judiciário - representando o mecanismo de freios e contrapesos (checks and balances); e (2) agências designadas para este fim, a exemplo das ouvidorias e das Entidades Fiscalizadoras Superiores ${ }^{15}$, tais como: as controladorias, auditorias, tribunais de contas, e similares ${ }^{16}$. Estas últimas atuam no controle administrativo e financeiro dos recursos públicos. Para tanto, qual o desenho institucional destes mecanismos de controle desenvolvido pelo sistema político no plano internacional?

Não há um modelo institucional ideal de instituição secundária de controle que possa ser discutido como parâmetro universal, uma vez que há uma variabilidade nos desenhos institucionais que têm sido adotados com êxito em contextos e tradições históricas distintas. Pode-se identificar, no entanto, três modelos de atuação de instituições de controle no plano internacional que correspondem a três tipos distintos de desenho institucional ${ }^{17}$.

Segundo Rick Stapenhurst e Jack Titsworth ${ }^{18}$, os órgãos de controle se dividem nos seguintes sistemas: Napoleônico, Westminster e Board System. No sistema Napoleônico, aplicado aos países da América Latina e Europa Continental, os órgãos de controle têm autoridade judiciária e administrativa, além de serem autônomos ao legislativo. São chamados também de cour des comptes, termo francês que significa Cortes de Contas, ou ainda, de Tribunais de Contas. No caso do julgamento de contas de chefes do Executivo, tal atribuição fica a cargo do Legislativo, sendo que as contas individuais dos gestores ainda ficam sob a responsabilidade destes Tribunais ${ }^{19}$.

No sistema Westminster - também conhecido como modelo de Auditor Geral encontrado, sobretudo, nos países de origem anglo-saxã, o Auditor-geral é um corpo independente que se reporta ao parlamento e não tem atribuições judiciais, mas pode exercer certos tipos de ações legais, tais como "a liberdade ampla de recrutar pessoal para o serviço e de organizar os trabalhos de auditoria como bem lhe aprouver" ${ }^{20}$. A articulação com o Parlamento se dá através das Comissões de Contas Públicas, ou Public Accounts Comites ${ }^{21}$. A despeito da autonomia que lhe é concedida, o auditor é, em muitos casos, estatutariamente funcionário do Legislativo ${ }^{22}$.

15. Denominação atribuída pela Organização Internacional de Entidades Fiscalizadoras Superiores (INTOSAI, em inglês) aos órgãos encarregados do controle externo das contas públicas.

16. Ibidem.

17. MELO (2008).

18. STAPENHURST y TITSWORTH (2001).

19. CRUZ JUNIOR (2015).

20. Idem, p. 07.

21. STAPENHURST (2004).

22. Ibidem. 
Já o Board System (encontrado em países asiáticos e outros dispersos, como Alemanha, Argentina e Países Baixos), ou Conselho de Contas, se assemelha ao Westminster, mas se diferencia por ter em sua composição um colegiado de auditores, ao invés da figura do Auditor Geral. Tal colegiado pode ser nomeado pelo Presidente ou indicado por ele e aprovado pelo Legislativo. Ainda variam muito os focos e os tipos de auditoria, não possuindo assim um padrão identificável desse sistema.

Dentre os três modelos apresentados acima, o de Tribunal de Contas é o adotado pelo sistema político brasileiro para fazer frente ao desafio de controlar suas contas públicas, os quais surgem no país durante a transição da Monarquia para a República, período em que as instituições estatais se ampliam e se reformulam para se adequarem ao novo regime político.

Organizacionalmente, os tribunais seguiram parcialmente o modelo federativo. O Tribunal de Contas da União (TCU) fiscaliza os recursos da União, incluindo os repasses a Estados, Municípios e Entidades não governamentais. Por sua vez, o Tribunal de Contas do Distrito Federal (TCDF) é responsável pela fiscalização dos recursos distritais e os Tribunais de Contas estaduais (TCEs) são responsáveis pela fiscalização dos recursos estaduais e municipais. Além disso, Cearáe ${ }^{23}$, Bahia, Pará e Goiás criaram, no âmbito estadual, Tribunais de Contas dos municípios (TCMs). Não obstante, Rio de Janeiro e São Paulo possuem Tribunais de Contas municipais autônomos, escolhidos e financiados com recursos municipais ${ }^{24}$.

Vale dizer que, em relação aos Tribunais de Contas subnacionais (TCDF, TCEs e TCMs), estes reproduzem o modelo do TCU tanto em atribuições como em organização interna com algumas pequenas adequações. A organização, o funcionamento e as atribuições dos Tribunais de Contas são estabelecidos pela respectiva legislação distrital, estadual e municipal. Além disso, cada tribunal dispõe de sua própria lei orgânica ou regulamento interno específico. Outra adequação em relação ao modelo do TCU é quanto ao número de membros do seu Colegiado Superior: o colegiado do TCU é composto por o9 (nove) membros - denominados Ministros, ao passo que o colegiado dos Tribunais de Contas subnacionais é formado por 07 (sete) membros denominados Conselheiros, ressalvando-se apenas o colegiado do Tribunal de Contas do Município de São Paulo, que é composto por 05 (cinco) membros ${ }^{25}$.

Ao longo da história republicana brasileira, as atribuições constitucionais dos Tribunais de Contas se ampliaram. Sendo que o ápice dessas transformações veio com a promulgação da Constituição de 1988. Entre elas, cabe citar: a ampliação das funções das Cortes de Contas, abrangendo também o controle de desempenho; a indicação da maioria de seus dirigentes pelo Poder Legislativo e a atribuição à população de poder de denúncia de irregularidades.

23. O TCM-CE foi extinto em 2017, por meio da Emenda Constitucional no 92, de 21/08/2017.

24. SPECK (2013).

25. MORAES (2006). 
No que tange às suas funções, destacam-se a definição e a ampliação de suas competências exclusivas como os maiores ganhos para estes órgãos dentro da estrutura de poder. Além da prerrogativa de elaborar parecer técnico sobre a tomada de contas do Executivo, eles também assumiram a função de realizar auditorias de desempenho das políticas públicas, superando assim a atividade de cunho estritamente legalista, que sempre os caracterizou. Isso significa verificar não apenas se o gasto foi realizado segundo as normas legais, mas também se ele produziu o resultado esperado. Inclui-se, ainda, no rol das atribuições, a apreciação da legalidade dos contratos, da admissão de pessoal, concessão de aposentadorias, reformas e pensões, além de se manifestar acerca da legalidade das licitações em caráter prévio, evitando, assim, benefícios a determinados grupos econômicos ${ }^{26}$.

O Quadro 1 sintetiza as principais competências constitucionais dos Tribunais de Contas:

\section{Quadro 1. Competências Constitucionais dos Tribunais de Contas}

\begin{tabular}{|l|}
\hline \multicolumn{1}{|c|}{ ROL DE COMPETÊNCIAS } \\
\hline 1. Emitir parecer sobre as contas anuais prestadas pelo chefe do Poder Executivo. \\
\hline 2. Julgar as contas dos responsáveis por recursos públicos. \\
\hline 3. Apreciar a legalidade de atos relacionados à admissão e à aposentadoria de pessoal. \\
\hline $\begin{array}{l}\text { 4. Fiscalizar o uso dos recursos públicos, por meio de auditorias e inspeções de iniciativa } \\
\text { própria ou do Legislativo. }\end{array}$ \\
\hline $\begin{array}{l}\text { 5. Aplicar sanções e determinar a correção de ilegalidades e irregularidades em atos e } \\
\text { contratos. }\end{array}$ \\
\hline $\begin{array}{l}\text { 6. Apurar representações e denúncias apresentadas por qualquer cidadão, partido político, } \\
\text { associação ou sindicato sobre irregularidades ou ilegalidades na aplicação dos recursos } \\
\text { públicos. }\end{array}$ \\
\hline
\end{tabular}

Fonte: Elaboração própria, a partir de Constituição Federal (1988).

Não obstante, o Quadro 2 abaixo traça as principais características dos Tribunais de Contas no Brasil: 


\section{Quadro 2. Principais Características dos Tribunais de Contas no Brasil}

\begin{tabular}{|c|c|}
\hline FUNÇÕES & $\begin{array}{l}\text { As funções básicas dos Tribunais de Contas podem ser agrupadas em oito } \\
\text { grandes categorias: fiscalizadora (auditam/fiscalizam, apreciam atos), ju- } \\
\text { dicante (julgam contas), sancionadora (aplicam sanções/penalidades), } \\
\text { consultiva (respondem consultas/emitem parecer prévio), informativa } \\
\text { (prestam informações ao Legislativo e ao Ministério Público), corretiva } \\
\text { (determinam, fixam prazos, sustam atos), normativa (expedem normativos, } \\
\text { fixam coeficientes) e de ouvidoria (examinam denúncias e representações). }\end{array}$ \\
\hline $\begin{array}{l}\text { PROCEDIMENTOS } \\
\text { O P E R A C I O N A I S } \\
\text { BÁSICOS DE FISCAL- } \\
\text { IZAÇÃO }\end{array}$ & $\begin{array}{l}\text { Para desempenhar suas atribuições, os Tribunais empregam quatro pro- } \\
\text { cedimentos básicos: tomadas e prestações de contas, tomadas de contas } \\
\text { especiais, fiscalizações e monitoramentos. }\end{array}$ \\
\hline $\begin{array}{l}\text { FOCO DE CON- } \\
\text { TROLE }\end{array}$ & $\begin{array}{l}\text { O foco da auditoria de conformidade se concentra em examinar a legali- } \\
\text { dade e a legitimidade dos atos de gestão dos responsáveis sujeitos a sua } \\
\text { jurisdição, quanto ao aspecto contábil, financeiro, orçamentário e patrimo- } \\
\text { nial. Ao passo que o foco da auditoria de natureza operacional se destina a } \\
\text { avaliar o desempenho dos órgãos e entidades jurisdicionados, assim como } \\
\text { dos sistemas, programas, projetos e atividades governamentais, quanto aos } \\
\text { aspectos da economicidade, eficiência e eficácia dos atos praticados. }\end{array}$ \\
\hline $\begin{array}{l}\text { SUJEITOS PASSIVOS } \\
\text { DO CONTROLE }\end{array}$ & $\begin{array}{l}\text { Nos termos da Constituição, encontram-se sob jurisdição dos Tribunais - } \\
\text { e, portanto, figuram como sujeitos passivos do controle - qualquer pessoa } \\
\text { física ou jurídica, pública ou privada, que utilize, arrecade, guarde, gerencie, } \\
\text { aplique ou administre dinheiros, bens e valores públicos. }\end{array}$ \\
\hline $\begin{array}{l}\text { VINCULAÇÃO } \quad \text { IN- } \\
\text { STITUCIONAL }\end{array}$ & $\begin{array}{l}\text { O entendimento majoritário é no sentido de que os Tribunais de Contas são } \\
\text { órgãos de extração constitucional, independentes e autônomos, que auxil- } \\
\text { iam o Poder Legislativo no exercício do controle externo. }\end{array}$ \\
\hline $\begin{array}{l}\text { NATUREZA JU- } \\
\text { RÍDICA DA INSTI- } \\
\text { TUIÇÃO }\end{array}$ & $\begin{array}{l}\text { A maior parte da doutrina e a jurisprudência quase unânime dos tribunais } \\
\text { superiores, inclusive do próprio Supremo Tribunal Federal, têm reconhe- } \\
\text { cido os Tribunais de Contas como uma Corte administrativa, autônoma, } \\
\text { com competência para julgar contas dos administradores e responsáveis } \\
\text { por bens e valores públicos, e dotada de jurisdição própria, peculiar e es- } \\
\text { pecífica, distinta da jurisdição em sentido estrito. }\end{array}$ \\
\hline $\begin{array}{l}\text { NATUREZA JURÍDI- } \\
\text { CA DAS DECISÕES }\end{array}$ & $\begin{array}{l}\text { Para a maior parte dos estudiosos e dos juristas, as deliberações das Cortes } \\
\text { de Contas consistem em juízos acerca da exatidão de contas e de atos sub- } \\
\text { metidos a seu exame. Elas fazem coisa julgada administrativa, o que impede } \\
\text { sua revisão e torna seu cumprimento obrigatório nessa esfera, e não po- } \\
\text { dem ser questionadas senão por mandado de segurança junto aos Tribunais } \\
\text { Superiores. Além disso, a jurisprudência do Supremo Tribunal Federal e a } \\
\text { doutrina majoritária, ao reconhecerem os Tribunais de Contas como juiz } \\
\text { natural das matérias inseridas em sua competência, têm entendido que suas } \\
\text { deliberações restringem parcialmente a atuação do Judiciário, que somente } \\
\text { pode examinar erros de procedimento, sem possibilidade de manifestação } \\
\text { sobre eventual erro de julgamento. }\end{array}$ \\
\hline
\end{tabular}

Fonte: Elaboração própria, a partir de Ferreira (2013). 
Sano y Montenegro Filho ${ }^{27}$ afirmam que as Entidades de Fiscalização Superior, como os Tribunais de Contas, estão a ser cada vez mais demandadas para realizar trabalhos qualitativos, abrangendo os critérios de eficiência, eficácia e efetividade em suas ações de controle. No mesmo sentido, Ferreira ${ }^{28}$ - ao analisar o papel do Tribunal de Contas da União como órgão de avaliação de políticas públicas - afirma que a apreciação das contas anualmente prestadas pelo Presidente da República, por exemplo, exige do Tribunal um extraordinário trabalho de avaliação de políticas públicas, sendo talvez a competência onde mais amplamente o Tribunal esmiúça as atividades governamentais. Ademais, no exercício de sua missão fiscalizadora, o Tribunal observa não apenas o aspecto da legalidade, mas também o da legitimidade e economicidade, o que alarga em muito a possibilidade de conduzir avaliações de amplo alcance, especialmente no caso das fiscalizações de natureza operacional.

Levando-se em conta que estas atividades de controle possuem um custo financeiro considerável (remuneração e qualificação de servidores, manutenção de estrutura adequada, auditorias in loco, manutenção de sistemas, entre diversas outras questões), espera-se que o fortalecimento da capacidade institucional dos Tribunais de Contas - a partir de investimentos em sua estrutura - é determinante para o seu ativismo, contribuindo positivamente com a qualidade das políticas públicas. Para tanto, considera-se o argumento de Fukuyama ${ }^{29}$, segundo o qual, instituições que dispõem de recursos suficientes para o desempenho de suas atividades funcionam melhor em todos os níveis.

Mas analisar a relação entre a capacidade institucional dos Tribunais de Contas e a qualidade das políticas públicas não se constitui em uma tarefa fácil. Muito embora o sistema Napoleônico de controle não seja restrito apenas ao Brasil - visto que o modelo de Tribunais de Contas se aplica a vários países da América Latina e Europa Continental $^{30}$, pouco se sabe sobre seu desempenho e efetividade ${ }^{31}$.

Ademais, embora se tratem de instituições de longa data e que passaram por importantes avanços pós-1988, carecem de visibilidade e tem sofrido críticas severas quanto ao não desempenho de seu papel como guardiões-mor dos recursos públicos, sobretudo, porque têm convivido com práticas tradicionais de nepotismo e corrupção ${ }^{32}$. Diante disso, cabe indagar: os Tribunais de Contas são capazes de exercer suas funções de modo efetivo e, por via de consequência, vindo a contribuir com qualidade das políticas públicas?

\section{SANO Y MONTENEGRO FILHO (2013).}

28. FERREIRA (2012).

29. FUKUYAMA (2005).

30. Idem; Idem.

31. Ibidem; FIGUEIREDO (2007); TEIXEIRA y ALVES (2011).

32. Op. cit.; Ibidem; Op. cit. 
Speck $^{33}$ afirma que as sugestões para medir o desempenho dos Tribunais de Contas estão relacionadas ao cálculo da economia resultante de suas atividades, englobando três possibilidades, quais sejam: os ganhos por antecipação, por economia imediata ou a longo prazo. Contudo, segundo o autor, essa forma de avaliação dos resultados dos Tribunais de Contas é questionável. Porque ela é, ao mesmo tempo, estreita e ampla demais. Estreita porque não leva em conta os ganhos que vão além do caso individual corrigido, ao eliminar-se erros sistêmicos. Ademais, a economia alcançada com o cancelamento de um contrato sem licitação em andamento somente poderá ser calculada em termos monetários, caso as ofertas realizadas nessas condições possam ser comparadas com ofertas reais, por ocasião da licitação. Não obstante, outro caso complicado é a economia conseguida com a correção de um regulamento de contratação, que potencialmente atinja todos os contratos a serem estimados no futuro. Esses efeitos a longo prazo são praticamente impossíveis de serem estimados em termos econômicos.

Nesse sentido, trabalhos sobre capacidade institucional trazem grandes contribuições e insights importantes para pensar a efetividade dos Tribunais de Contas. Afinal, análises sobre o fortalecimento da capacidade institucional do Estado a evidenciam como uma condição necessária para a adequada implementação de mecanismos de governança pública, com vistas a sua maior efetividade.

Tanto que a partir da promulgação da Lei de Responsabilidade Fiscal (LRF), o Governo Federal percebeu que precisaria montar uma estrutura para fiscalizar o cumprimento desse novo marco regulatório. Chegou-se até a discutir sobre a contratação de auditorias independentes, mas, questionou-se o porquê de gastar dinheiro com empresas privadas se já existiam estruturas públicas específicas para o controle das contas públicas governamentais. A partir de então, o Governo Federal passou a considerar os Tribunais de Contas subnacionais como uma peça imprescindível para o sucesso da LRF, confiando a esses órgãos a responsabilidade de garantir a fiel observância de todos os impositivos da Lei pelos gestores públicos ${ }^{34}$.

Todavia, observou-se que a capacidade institucional dos Tribunais de Contas precisaria ser reforçada em diversos aspectos: primeiro tecnologicamente, criando sistemas informatizados para recebimento de informações por parte dos estados e municípios. Segundo, em termos de capacitação dos funcionários que precisariam de treinamento para saber lidar com esse novo marco regulatório. E terceiro, em termos de integração técnica e política, pois era necessária uma padronização dos procedimentos e conceitos aplicados para que a Lei fosse implementada de forma uniforme. Foi a partir desse quadro de grandes deficiências na estrutura dos Tribunais de Contas subnacionais brasileiros que surgiu o Programa de Modernização do Sistema de Controle Externo dos Estados e Municípios Brasileiros - PROMOEX ${ }^{35}$.

\section{Ibidem.}

34. Idem.

35. Ibidem. 
O principal escopo do programa consistia em "fortalecer o sistema de controle externo como instrumento da cidadania, incluindo a intensificação das relações intergovernamentais e interinstitucionais, com vistas ao cumprimento da Lei de Responsabilidade Fiscal". Para tanto, em 14 de setembro de 2005 foi assinado o Contrato de Empréstimo $n^{\circ}$ 1628/OC-BR entre o Governo Federal e o Banco Interamericano de Desenvolvimento - BID para apoiar o referido Programa ${ }^{36}$. Este contrato teve a sua execução finalizada em 14 de setembro de 2013. Dentro dos US\$ 64,4 milhões previstos em contrato, $78,88 \%$ foram utilizados, ou seja, US\$ 50,8 milhões - sendo US\$ 27,5 milhões da fonte BID (equivalente a $71,24 \%$ do montante contratado junto ao banco - US\$ 38,6 milhões) e mais US\$ 23,3 milhões em contrapartida (equivalente a 90,31\% do ofertado - US\$ 25,8 milhões) ${ }^{37}$.

Assim, é possível concluir que, de fato, o fortalecimento da capacidade institucional dos Tribunais de Contas subnacionais brasileiros é uma condição necessária para sua maior efetividade. Entretanto, como os trabalhos específicos sobre essas instituições de controle vêm incorporando essas discussões?

Melo et al..$^{38}$ buscam explicar o desempenho dos Tribunais de Contas estaduais brasileiros pela rotatividade das elites políticas que controlam os governos estaduais; pela volatilidade eleitoral dos eleitores; e por seus arranjos institucionais internos (incluindo, entre outros, as regras para o recrutamento dos conselheiros). Para tanto, quatro classes de exercícios econométricos são aplicadas pelos autores: duas para estimar os determinantes do ativismo institucional de um Tribunal de Contas (ativismo geral e auto-iniciativa); uma para estimar os determinantes da escolha do governador ao nomear um conselheiro; e, finalmente, um teste para avaliar os determinantes da "propensão a rejeitar ou aprovar" um relatório de contas submetido por governadores, prefeitos ou legislaturas. As variáveis utilizadas são: (1) o número de auditorias realizadas pelo tribunal; (2) o número de unidades administrativas sob jurisdição; (3) o orçamento executado pelo tribunal em 2004; (4) o total de equipamentos; (5) o total de funcionários; (6) a idade do tribunal; (7) a presença de conselheiros oriundos das carreiras de auditor ou procurador de contas; (8) a presença do Ministério Público junto ao Tribunal de Contas (9) a volatilidade eleitoral no Estado; e (10) a rotatividade do governo estadual.

Os principais resultados apontados pela pesquisa são: (a) a rotatividade do governo estadual e a presença de conselheiros oriundos das carreiras de auditor ou procurador de contas melhoram o desempenho dos Tribunais de Contas subnacionais; (b) quanto maior a capacidade institucional do tribunal, mais ativo ele tende a ser; (c) a

36. MPOG (2015).

37. MPOG (2013).

38. Idem. 
presença do Ministério Público junto ao Tribunal de Contas é crucial para sancionar os maus comportamentos dos políticos; e, por fim, (d) há uma correlação inversa entre os recursos disponíveis para os tribunais e sua propensão a infligir sanções aos políticos eleitos ${ }^{39}$.

É possível notar que o trabalho de Melo et al. ${ }^{40}$ se concentra em avaliar o desempenho dos Tribunais de Contas estaduais sem, contudo, analisar o efeito desta performance sobre o contexto em que se inserem. Restando prejudicada, portanto, a análise de sua relação com a qualidade das políticas públicas. Com efeito, Rocha et al.$^{41}$ oferecem uma importante contribuição nessa direção. Objetivando analisar a relação entre a capacidade institucional dos 27 Tribunais de Contas Estaduais brasileiros e a corrupção, eles combinam estatística descritiva e multivariada para analisar um banco de dados elaborado a partir de Melo et al. ${ }^{42}$ e Ferraz y Finan ${ }^{43}$. Em particular, os autores utilizam análise de componentes principais para estimar um indicador de capacidade institucional, a partir das seguintes variáveis: (1) o percentual do orçamento estadual, (2) a transparência orçamentária e (3) a antiguidade de cada tribunal. Empregam também um modelo linear de mínimos quadrados ordinários para estimar o efeito da capacidade institucional sobre incidência de corrupção - corrupção tratada por eles como os casos de improbidade administrativa ${ }^{44}$ detectados nos respectivos Estados.

39. Ibidem.

40. Op. cit.

41. Idem.

42. Op. cit.

43. FERRAZ y FINAN (2010); para detalhes da metodologia, conferir Rocha et al. (2014).

44. De acordo com Rocha et al. (2014), a previsão legal dos atos de improbidade administrativa foi consubstanciada pela Lei n $8.429 / 1992$, que dispõe sobre as sanções aplicáveis aos agentes públicos nos casos de enriquecimento ilícito no exercício de mandato, cargo, emprego ou função na administração pública direta, indireta ou fundacional e dá outras providências. Sendo que o Art. $9^{\circ}$ estabelece que: constitui ato de improbidade administrativa importando enriquecimento ilícito auferir qualquer tipo de vantagem patrimonial indevida em razão do exercício de cargo, mandato, função, emprego ou atividade nas entidades mencionadas no art. $1^{\circ}$ da Lei no 8.429/1992; o Art. 10 estabelece que: constitui ato de improbidade administrativa que causa lesão ao erário qualquer ação ou omissão, dolosa ou culposa, que enseje perda patrimonial, desvio, apropriação, malbaratamento ou dilapidação dos bens ou haveres das entidades referidas no art. $1^{\circ}$ da Lei $n^{\circ}$ 8.429/1992; o Art. 10-A determina que: constitui ato de improbidade administrativa qualquer ação ou omissão para conceder, aplicar ou manter benefício financeiro ou tributário contrário ao que dispõem o caput e o $\mathbb{S} 1^{\circ}$ do art. $8^{\circ}$-A da Lei Complementar $n^{\circ} 116$, de 31 de julho de 2003; e o Art. 11 assevera que: constitui ato de improbidade administrativa que atenta contra os princípios da administração pública qualquer ação ou omissão que viole os deveres de honestidade, imparcialidade, legalidade, e lealdade às instituições. 
De acordo com o referido desenho de pesquisa, os autores constatam que: (a) comparativamente, o Estado de São Paulo apresenta o Tribunal com maior capacidade institucional, enquanto o Estado de Mato Grosso do Sul apresenta o pior desempenho; (b) em média, quanto maior o orçamento do tribunal, menor é o seu nível de transparência e (c) quanto maior a capacidade institucional do tribunal, maior é a probabilidade de detectar casos de improbidade administrativa.

O trabalho de Rocha et al..$^{45}$, a exemplo do trabalho de Melo et al. ${ }^{46}$, reafirma a relevância da capacidade institucional dos Tribunais de Contas para a efetividade de sua atuação. E é nesse contexto em que se insere esta pesquisa. Partindo-se da premissa de que a capacidade institucional de uma organização está associada à sua aptidão de viabilizar o cumprimento de suas competências, objetivos e metas ${ }^{47}$, este trabalho se propõe a analisar a relação entre a capacidade institucional dos Tribunais de Contas subnacionais brasileiros e a qualidade das políticas de saúde e educação de seus respectivos Estados.

Para a consecução deste objetivo, as variáveis eleitas para medir a capacidade institucional dos Tribunais de Contas são: orçamento, pessoal e contas julgadas irregulares. O orçamento e o quantitativo de pessoal dos Tribunais de Contas subnacionais afeta positivamente a sua capacidade institucional ${ }^{48}$. Ao passo que as contas julgadas irregulares pelos Tribunais de Contas subnacionais possuem o condão de gerar um impacto direto na boa gestão dos recursos e das políticas públicas. Na medida em que tais julgamentos além de coibirem o mau uso do dinheiro público, podem vir a configurar ato doloso de improbidade administrativa que, por sua vez, podem gerar responsabilização na esfera judicial por meio da ação civil de improbidade administrativa $^{49}$. Os referidos dados se encontram disponíveis na Tabela 1 abaixo:

45. Ibidem.

46. Op. cit.

47. FERNANDES (2016).

48. Op. cit.; Op. cit.

49. Op. cit. 
Tabela 1. Variáveis Selecionadas para o Cálculo da Capacidade Institucional dos Tribunais de Contas Subnacionais Brasileiros.

\begin{tabular}{|c|c|c|c|}
\hline TRIBUNAL & ORÇAMENTO (2010) & PESSOAL (2010) & $\begin{array}{l}\text { CONTAS JULGADAS } \\
\text { IRREGULARES (2010) }\end{array}$ \\
\hline TCE-AC & $\mathrm{R} \$ 29.649 .000,00$ & 153 & 33 \\
\hline TCE-AL & $\mathrm{R} \$ 56.744 .000,00$ & 731 & 03 \\
\hline TCE-AM & $\mathrm{R} \$ 91.390 .000,00$ & NA & 37 \\
\hline TCE-AP & $\mathrm{R} \$ 78.026 .000,00$ & 85 & 17 \\
\hline TCE-BA & $\mathrm{R} \$ 127.247 .000,00$ & NA & 15 \\
\hline TCM-BA & $\mathrm{R} \$ 100.433 .000,00$ & NA & 39 \\
\hline TCE-CE & $\mathrm{R} \$ 27.025 .000,00$ & NA & NA \\
\hline TCM-CE & $\mathrm{R} \$ 41.207 .000,00$ & NA & NA \\
\hline TC-DF & R\$ 194.994.000,00 & 528 & 29 \\
\hline TCE-ES & $\mathrm{R} \$ 82.591 .000,00$ & 493 & 40 \\
\hline TCE-GO & $\mathrm{R} \$ 165.471 .000,00$ & NA & 01 \\
\hline TCM-GO & $\mathrm{R} \$ 71.968 .000,00$ & 385 & 12 \\
\hline TCE-MA & $\mathrm{R} \$ 60.106 .000,00$ & NA & NA \\
\hline TCE-MG & $\mathrm{R} \$ 295.557 .000,00$ & 1321 & 89 \\
\hline TCE-MS & $\mathrm{R} \$ 108.760 .000,00$ & 499 & 9 \\
\hline TCE-MT & $\mathrm{R} \$ 125.464 .000,00$ & 575 & 45 \\
\hline TCE-PA & R\$ 81.951.000,00 & 303 & 9 \\
\hline TCM-PA & $\mathrm{R} \$ 75.924 .000,00$ & NA & NA \\
\hline TCE-PB & $\mathrm{R} \$ 82.323 .000,00$ & 445 & 08 \\
\hline TCE-PE & $\mathrm{R} \$ 202.276 .000,00$ & 775 & 85 \\
\hline TCE-PI & $\mathrm{R} \$ 47.827 .000,00$ & 396 & 129 \\
\hline TCE-PR & $\mathrm{R} \$ 177.392 .000,00$ & 668 & 11 \\
\hline TCE-RJ & $\mathrm{R} \$ 423.515 .000,00$ & 1438 & 16 \\
\hline TCM-RJ & $\mathrm{R} \$ 117.662 .000,00$ & 536 & 15 \\
\hline TCE-RN & $\mathrm{R} \$ 37.395 .000,00$ & 232 & 08 \\
\hline TCE-RO & $\mathrm{R} \$ 65.607 .000,00$ & 389 & 04 \\
\hline TCE-RR & $\mathrm{R} \$ 37.295 .000,00$ & 257 & 04 \\
\hline TCE-RS & $\mathrm{R} \$ 254.694 .000,00$ & 822 & 52 \\
\hline TCE-SC & $\mathrm{R} \$ 114.416 .000,00$ & 509 & 02 \\
\hline TCE-SE & R\$ 87.685.000,00 & NA & $\mathrm{NA}$ \\
\hline TCE-SP & $\mathrm{R} \$ 455.187 .000,00$ & 2141 & 09 \\
\hline TCM-SP & $\mathrm{R} \$ 178.934 .000,00$ & 443 & 16 \\
\hline TCE-TO & $\mathrm{R} \$ 59.935 .000,00$ & 478 & 10 \\
\hline
\end{tabular}

Obs. 1: Pessoal $=$ Total de Conselheiros + Total de Conselheiros Substitutos + Total de Servidores Concursados + Total de Servidores Comissionados, cujos dados foram obtidos a partir de Tribunais de Contas subnacionais (via Lei de Acesso à Informação).

Obs. 2: NA = Not Available (Não Disponível).

Fonte: Elaboração própria, a partir da Lei Orçamentária Anual - LOA de cada um dos respectivos Estados / Tribunais de Contas Subnacionais (via Lei de Acesso à Informação) / Secretaria do Tesouro Nacional (STN) / Instituto Brasileiro de Geografia e Estatística (IBGE) / Tribunais Regionais 
Para a escolha das variáveis de qualidade das políticas públicas de saúde e educação de seus respectivos Estados, adotam-se os critérios de que se valeram Lopes y Toyoshima ${ }^{50}$, segundo os quais a Análise Fatorial (AF) orienta a escolha dos indicadores. É importante destacar que a escolha das políticas públicas de saúde e educação tem por justificativa o fato de que estas duas pastas figuram entre as mais cobiçadas entre os políticos, sobretudo, em função da visibilidade e do volume de recursos que recebem ${ }^{51}$.

A Análise Fatorial ${ }^{52}$ é uma técnica estatística multivariada de redução de dados que objetiva gerar fatores/componentes não observados a partir das variáveis observadas, com base no padrão de correlação verificado entre as variáveis originais ${ }^{53}$. Com efeito, o modelo utilizado neste estudo possui as seguintes características: (1) análise via matriz de correlação; (2) autovalores maiores que um; (3) método de extração de Fatoração pelo Eixo Principal; (4) rotação ortogonal Varimax com normalização de Kaiser; e (5) casos ausentes substituídos pela média.

Para o emprego da AF, foram selecionados inicialmente 15 indicadores de educação e de saúde, constantes da Tabela 2 abaixo:

Tabela 2. Indicadores Utilizados na Análise Fatorial.

\begin{tabular}{|l|c|}
\hline \multicolumn{1}{|c|}{ INDICADOR } & ANO \\
\hline Taxa de analfabetismo - 11 a 14 anos & 2010 \\
\hline Taxa de analfabetismo - 15 anos ou mais & 2010 \\
\hline Taxa de analfabetismo - 18 a 24 anos & 2010 \\
\hline$\%$ de crianças de 0 a 5 anos na escola & 2010 \\
\hline \% de crianças de 5 a 6 anos na escola & 2010 \\
\hline$\%$ de crianças de 6 a 14 anos na escola & 2010 \\
\hline$\%$ de adolescentes de 15 a 17 anos na escola & 2010 \\
\hline \% de jovens de 18 a 24 anos na escola & 2010 \\
\hline$\%$ de adolescentes de 15 a 17 anos com fundamental completo & 2010 \\
\hline$\%$ de jovens de 18 a 20 anos com médio completo & 2010 \\
\hline Esperança de vida ao nascer & 2010 \\
\hline Probabilidade de sobrevivência até 60 anos & 2010 \\
\hline \% da população em domićlios com banheiro e água encanada & 2010 \\
\hline$\%$ da população em domicílios com coleta de lixo & 2010 \\
\hline \% da população em domićlios com energia elétrica & 2010 \\
\hline
\end{tabular}

Fonte: Elaboração própria, a partir de Atlas do Desenvolvimento Humano no Brasil (2010).

50. LOPES y TOYOSHIMA (2013); para detalhes da metodologia, conferir Lopes y Toyoshima (2013).

51. PASSARINHO (2018).

52. Para detalhes sobre a análise fatorial, conferir Figueiredo Filho et al. (2014).

53. FIGUEIREDO FILHO et al. (2014). 
De sorte que, após a aplicação da Análise Fatorial, foram selecionados os quatro indicadores de maior peso pertencentes ao primeiro fator, conforme Tabela 3 abaixo: Tabela 3. Cargas Fatoriais das Variáveis Utilizadas no Modelo.

\begin{tabular}{|l|c|c|c|}
\hline \multicolumn{1}{|c|}{ INDICADOR } & \multicolumn{2}{c|}{ Cargas Fatoriais } \\
\cline { 2 - 4 } & $\mathbf{1}$ & $\mathbf{2}$ & $\mathbf{3}$ \\
\hline Taxa de analfabetismo - 11 a 14 anos & $-0,943$ & 0,211 & 0,030 \\
\hline Taxa de analfabetismo - 15 anos ou mais & $-0,807$ & 0,494 & $-0,148$ \\
\hline Taxa de analfabetismo - 18 a 24 anos & $-0,892$ & 0,347 & $-0,056$ \\
\hline \% de crianças de 0 a 5 anos na escola & 0,315 & 0,778 & $-0,034$ \\
\hline \% de crianças de 5 a 6 anos na escola & 0,147 & 0,941 & 0,061 \\
\hline \% de crianças de 6 a 14 anos na escola & 0,564 & 0,646 & $-0,055$ \\
\hline \% de adolescentes de 15 a 17 anos na escola & 0,267 & 0,422 & 0,680 \\
\hline \% de jovens de 18 a 24 anos na escola & $-0,251$ & 0,008 & 0,872 \\
\hline \% de adolescentes de 15 a 17 anos com fundamental completo & 0,857 & $-0,158$ & $-0,084$ \\
\hline \% de jovens de 18 a 20 anos com médio completo & 0,932 & $-0,074$ & 0,049 \\
\hline Esperança de vida ao nascer & 0,919 & $-0,225$ & 0,178 \\
\hline Probabilidade de sobrevivência até 60 anos & $-0,223$ & $-0,308$ & 0,284 \\
\hline \% da população em domicílios com banheiro e água encanada & 0,907 & 0,202 & $-0,045$ \\
\hline \% da população em domicílios com coleta de lixo & 0,660 & $-0,145$ & 0,004 \\
\hline \% da população em domicílios com energia elétrica & 0,649 & 0,468 & $-0,161$ \\
\hline
\end{tabular}

Fonte: Elaboração própria, a partir de Atlas do Desenvolvimento Humano no Brasil (2010).

Em termos práticos, estes indicadores têm o maior poder de explicação da estrutura total de variância dos dados. Assim, os quatro indicadores eleitos para figurarem como indicadores de qualidade das políticas de educação e saúde são: (a) o percetual de jovens de 18 a 20 anos com ensino médio completo; (b) a taxa de analfabetismo na faixa etária de 11 a 14 anos; (c) a esperança de vida ao nascer; e (d) o percentual de pessoas que vivem em domicílios com banheiro e água encanada.

Os dois primeiros indicadores - "a" e "b" - podem ser entendidos como medidas de qualidade do ensino nos Estados. O indicador "a” mede a razão entre a população de 18 a 20 anos de idade que já concluiu o ensino médio em quaisquer de suas modalidades (regular seriado, não seriado, educação de jovens e adultos ou supletivo) e o total de pessoas nesta faixa etária multiplicado por 100. Ao passo que o indicador "b" calcula a razão entre a população de 11 a 14 anos de idade que não sabe ler nem escrever um bilhete simples e o total de pessoas nesta faixa etária, multiplicada por 100.

Os dois últimos indicadores - "c" e "d", por sua vez, podem ser entendidos como medidas de boas condições de saúde nos Estados. O indicador "c" trata do número médio de anos que as pessoas deverão viver a partir do nascimento, se permanecerem constantes ao longo da vida o nível e o padrão de mortalidade por idade, prevalecen 
tes no ano do Censo. Enquanto o indicador "d" calcula a razão entre a população que vive em domicílios particulares permanentes com água encanada em, pelo menos, um de seus cômodos e com banheiro exclusivo e a população total residente em domicílios particulares permanentes, multiplicada por 100. Os referidos dados se encontram disponíveis no Quadro 3 abaixo:

Quadro 3. Indicadores de Qualidade das Políticas de Educação e Saúde Selecionados.

\begin{tabular}{|c|c|c|c|c|}
\hline UF & $\begin{array}{l}\text { Percentual de jovens de } 18 \\
\text { a } 20 \text { anos com ensino mé- } \\
\text { dio completo (2010) }\end{array}$ & $\begin{array}{c}\text { Taxa de analfabetismo } \\
\text { na faixa etária de } 11 \text { a } \\
14(2010)\end{array}$ & $\begin{array}{l}\text { Esperança re de } \\
\text { vida ao nascer } \\
(2010)\end{array}$ & $\begin{array}{l}\text { Percentual de pes- } \\
\text { soas que vivem em } \\
\text { domicílios com } \\
\text { banheiro e água } \\
\text { encanada (2010) }\end{array}$ \\
\hline $\mathrm{AC}$ & 31,98 & 6,64 & 71,63 & 47,42 \\
\hline AL & 25,86 & 8,96 & 70,32 & 75,64 \\
\hline AP & 35,73 & 3,81 & 73,8 & 66,38 \\
\hline AM & 28,76 & 6,54 & 73,3 & 62,16 \\
\hline BA & 29,49 & 5,01 & 71,97 & 77,6 \\
\hline CE & 37,39 & 4,65 & 72,6 & 76,28 \\
\hline DF & 53,48 & 1,1 & 77,35 & 96,01 \\
\hline ES & 44,93 & 1,76 & 75,1 & 96,89 \\
\hline GO & 44,62 & 1,57 & 74,6 & 93,66 \\
\hline MA & 29,6 & 7,59 & 70,4 & 51,79 \\
\hline MT & 42,36 & 2 & 74,25 & 90,37 \\
\hline MS & 40,43 & 1,55 & 74,96 & 93,76 \\
\hline MG & 42,82 & 1,52 & 75,3 & 94,91 \\
\hline PA & 24,1 & 6,32 & 72,36 & 57,5 \\
\hline PB & 32,88 & 5,39 & 72 & 78,91 \\
\hline $\mathrm{PR}$ & 48,05 & 1,14 & 74,8 & 96,69 \\
\hline $\mathrm{PE}$ & 32,64 & 5,66 & 72,32 & 78,22 \\
\hline PI & 29,44 & 6,5 & 71,62 & 67,12 \\
\hline RJ & 42,93 & 1,76 & 75,1 & 94,73 \\
\hline $\mathrm{RN}$ & 36,11 & 6,63 & 72,52 & 85,06 \\
\hline RS & 43,79 & 1,29 & 75,38 & 96,46 \\
\hline RO & 36,47 & 1,59 & 72,97 & 79,62 \\
\hline RR & 40,53 & 5,13 & 73,51 & 74,04 \\
\hline $\mathrm{SC}$ & 51,8 & 1,05 & 76,61 & 97 \\
\hline SP & 52,33 & 1,49 & 75,69 & 97,12 \\
\hline SE & 30,55 & 5,52 & 71,84 & 82,24 \\
\hline TO & 40,73 & 2,9 & 72,56 & 80,41 \\
\hline
\end{tabular}

Fonte: Elaboração própria, a partir de Atlas do Desenvolvimento Humano no Brasil (2010). 
Registre-se que as variáveis em questão são reportadas por unidade da federação a fim de que seja possível relacioná-las aos indicadores dos Tribunais de Contas subnacionais.

\section{Desenho de Pesquisa}

Segundo King ${ }^{54}$, o padrão de replicabilidade requer a disponibilização de informações suficientes que permitam: compreender, avaliar e replicar os resultados de um determinado trabalho sem informação adicional do autor do estudo. Em outras palavras, o componente básico do padrão de replicabilidade é que o pesquisador deixe claro o passo a passo de como os dados foram coletados e analisados. O Quadro 4 abaixo resume as características essenciais deste trabalho, a saber:

Quadro 4. Desenho de Pesquisa

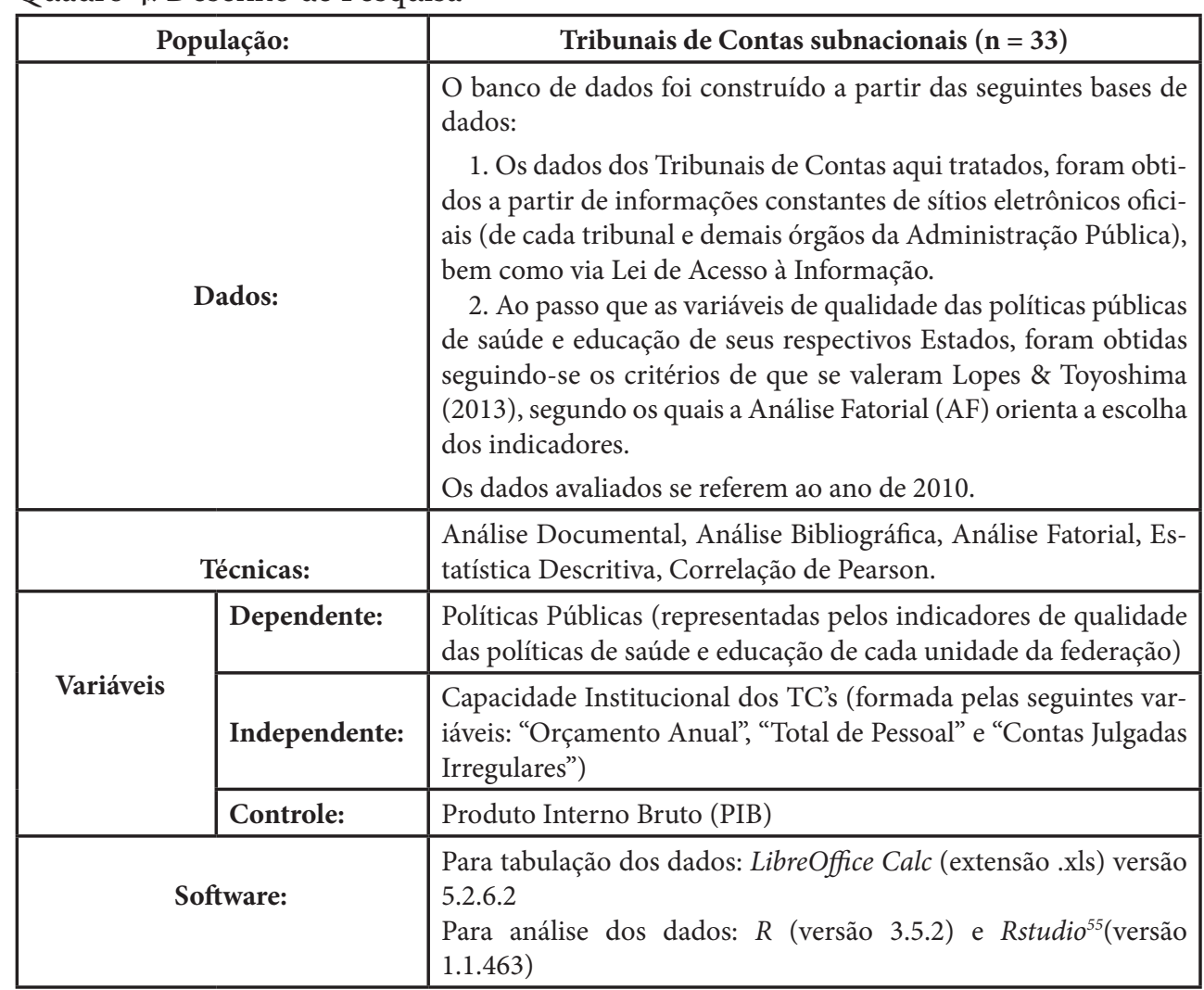

Fonte: Elaboração própria.

54. KING (2005).

55. Destaque-se aqui os principais pacotes utilizados para a análise dos dados, quais sejam: pastecs, lmtest, readxl, UsingR (além dos demais pacotes básicos para utilização do software). 
Os dados utilizados nesta pesquisa foram obtidos por meio do levantamento de informações disponíveis nos sítios eletrônicos oficiais dos órgãos da Administração Pública, bem como por meio do requerimento de informações via Lei de Acesso à Informação - LAI (Lei n $\left.{ }^{\circ} 12.527 / 2011\right)$. A partir de então, construiu-se um banco de dados original composto por 21 (vinte e uma) variáveis, cujas principais informações sobre cada uma delas são sumarizadas no Quadro 5 abaixo:

Quadro 5. Especificações das Variáveis Constantes do Banco de Dados.

\begin{tabular}{|c|c|c|}
\hline VARIÁVEL & $\begin{array}{l}\text { N O M E N - } \\
\text { CLATURA NO } \\
\text { BANCO DE } \\
\text { DADOS }\end{array}$ & DESCRIÇÃO \\
\hline Identificação & id & $\begin{array}{l}\text { Variável que indica as instituições pesquisadas (os Tribunais de Contas sub- } \\
\text { nacionais). }\end{array}$ \\
\hline $\begin{array}{l}\text { Contas } \\
\text { Irregulares }^{56}\end{array}$ & irraccounts & $\begin{array}{l}\text { Variável que indica o total de contas julgadas irregulares pelas instituições } \\
\text { pesquisadas, no ano de } 2010 \text {. }\end{array}$ \\
\hline $\begin{array}{l}\text { Recursos sob } \\
\text { Fiscalização }\end{array}$ & recfisc & $\begin{array}{l}\text { Variável que indica o volume total de recursos (R\$) sob fiscalização das in- } \\
\text { stituições pesquisadas, no ano de } 2010 \text {. }\end{array}$ \\
\hline $\begin{array}{l}\text { Contas Irregu- } \\
\text { lares por volume } \\
\text { Recursos sob } \\
\text { Fiscalização }\end{array}$ & IRACREFI & $\begin{array}{l}\text { Variável obtida a partir divisão entre as variáveis "irraccounts" e "recfisc" } \\
\text { (IRACREFI = irraccounts / recfisc). }\end{array}$ \\
\hline Pessoal $^{58}$ & staff & $\begin{array}{l}\text { Variável que indica o número total de pessoal de cada uma das instituições } \\
\text { pesquisadas, no ano de } 2010 \text {. }\end{array}$ \\
\hline Orçamento ${ }^{59}$ & orc & $\begin{array}{l}\text { Variável que indica o valor total do orçamento }(\mathrm{R} \$) \text { aprovado na Lei Orça- } \\
\text { mentária Anual (LOA) para cada uma das instituições pesquisadas, no ano } \\
\text { de } 2010 \text {. }\end{array}$ \\
\hline $\begin{array}{l}\text { Produto Interno } \\
\text { Bruto }^{60}\end{array}$ & PIB & $\begin{array}{l}\text { Variável que indica o valor total do Produto Interno Bruto (PIB) da Unidade } \\
\text { da Federação onde se situa cada uma das instituições pesquisadas, no ano } \\
\text { de } 2010 \text {. }\end{array}$ \\
\hline $\begin{array}{l}\text { Percentual de } \\
\text { Pessoas que } \\
\text { Vivem em } \\
\text { Domicílios com } \\
\text { Banheiro e Água } \\
\text { Encanada }^{61}\end{array}$ & DomicBanh & $\begin{array}{l}\text { Variável que calcula a razão entre a população que vive em domicílios par- } \\
\text { ticulares permanentes com água encanada em, pelo menos, um de seus } \\
\text { cômodos e com banheiro exclusivo e a população total residente em dom- } \\
\text { icílios particulares permanentes, multiplicada por } 100 \text {, no ano de } 2010 \text {. }\end{array}$ \\
\hline $\begin{array}{l}\text { Esperança de } \\
\text { Vida ao Nascer }{ }^{62}\end{array}$ & EsperVida & $\begin{array}{l}\text { Variável que indica o número médio de anos que as pessoas deverão viver a } \\
\text { partir do nascimento, se permanecerem constantes ao longo da vida o nível } \\
\text { e o padrão de mortalidade por idade, prevalecentes no ano do Censo. }\end{array}$ \\
\hline $\begin{array}{l}\text { Taxa de Analfa- } \\
\text { betismo na } \\
\text { Faixa Etária de } \\
11 \text { a } 14 \text { anos }^{63}\end{array}$ & Analf_11_14 & $\begin{array}{l}\text { Variável que calcula a razão entre a população de } 11 \text { a } 14 \text { anos de idade que } \\
\text { não sabe ler nem escrever um bilhete simples e o total de pessoas nesta faixa } \\
\text { etária, multiplicada por } 100 \text {, no ano de } 2010 \text {. }\end{array}$ \\
\hline $\begin{array}{l}\text { Percetual de } \\
\text { Jovens de } 18 \text { a } \\
20 \text { Anos com } \\
\text { Ensino Médio } \\
\text { Completo }^{64}\end{array}$ & MdCmpl18_20 & $\begin{array}{l}\text { Variável que mede a razão entre a população de } 18 \text { a } 20 \text { anos de idade que } \\
\text { já concluiu o ensino médio em quaisquer de suas modalidades (regular se- } \\
\text { riado, não seriado, educação de jovens e adultos ou supletivo) e o total de } \\
\text { pessoas nesta faixa etária multiplicado por } 100 \text {, no ano de } 2010 \text {. }\end{array}$ \\
\hline
\end{tabular}

Fonte: Elaboração própria. 
A hipótese a ser testada - então - será a existência (ou não) de uma relação (ou associação) entre a capacidade institucional dos Tribunais de Contas subnacionais brasileiros e a qualidade das políticas públicas de saúde e educação de seus respectivos Estados.

\section{Métodos e Resultados}

A partir de agora, reportar-se-ão os principais resultados empíricos desta pesquisa. Primeiramente, apresenta-se a estatística descritiva da qualidade das políticas com educação e saúde. As Tabelas 4 e 5 sintetizam a estatística descritiva dos indicadores de qualidade das políticas públicas apuradas:

Tabela 4. Estatística Descritiva - Qualidade das Políticas com Educação e Saúde.

\begin{tabular}{|c|c|c|c|c|}
\hline \multicolumn{1}{|c|}{ Variáveis } & Mínimo & Máximo & Média & Desvio Padrão \\
\hline $\begin{array}{l}\text { Percentual de } \\
\text { Pessoas que } \\
\text { Vivem em Dom- } \\
\text { ićlios com Ban- } \\
\text { heiro é Água En- } \\
\text { canada (2010) }\end{array}$ & 47,42 & 97,12 & 81,04 & 14,819 \\
\hline $\begin{array}{l}\text { Esperança de } \\
\text { Vida ao Nascer } \\
\text { (2010) }\end{array}$ & 70,32 & 77,35 & 73,51 & 1,825 \\
\hline $\begin{array}{l}\text { Taxa de Analfa- } \\
\text { betismo na Faixa } \\
\text { Etária de 11 a 14 } \\
\text { anos (2010) }\end{array}$ & 1,05 & 8,96 & 3,89 & 2,457 \\
\hline $\begin{array}{l}\text { Percetual de } \\
\text { Jovens de 18 a 20 } \\
\text { Anos com Ensino } \\
\text { Médio Completo } \\
(2010)\end{array}$ & 24,10 & 53,48 & 38,14 & 8,199 \\
\hline
\end{tabular}

Fonte: Elaboração Própria, a partir de Atlas do Desenvolvimento Humano no Brasil (2010).

56. Os dados relativos a esta variável foram obtidos a partir de consulta ao sítio oficial dos Tribunais Regionais Eleitorais - TREs dos Estados em que se situam cada um dos Tribunais de Contas aqui pesquisados (a partir das informações fornecidas por estes últimos aos TREs).

57. Os dados relativos a esta variável foram obtidos a partir de consulta ao sítio oficial da Secretaria do Tesouro Nacional - STN (<http://www.tesouro.fazenda.gov.br/>).

58. Os dados relativos a esta variável foram obtidos por meio de requerimento de informação junto a cada um dos Tribunais de Contas aqui pesquisados, via Lei de Acesso à Informação.

59. Os dados relativos a esta variável foram obtidos a partir de consulta às Leis Orçamentárias Anuais disponíveis no sítio oficial das Assembleias Legislativas dos Estados em que se situam cada um dos Tribunais de Contas aqui pesquisados (e da Câmara de Vereadores do Rio de Janeiro e de São Paulo). 
Tabela 5. Qualidade das Políticas com Saúde e Educação por Estado.

\begin{tabular}{|c|c|c|c|c|c|c|c|}
\hline \multirow[t]{2}{*}{ Estado } & \multirow[t]{2}{*}{ Região } & \multirow{2}{*}{$\begin{array}{l}\text { Popu- } \\
\text { lação } \\
2010 \\
\text { (mil } \\
\text { habit.) }\end{array}$} & \multirow{2}{*}{$\begin{array}{l}\text { Porcent. } \\
\text { Popu- } \\
\text { lação }\end{array}$} & \multicolumn{2}{|c|}{$\begin{array}{l}\text { Qualidade das Políti- } \\
\text { cas com Saúde }\end{array}$} & \multicolumn{2}{|c|}{$\begin{array}{l}\text { Qualidade das Políti- } \\
\text { cas com Educação }\end{array}$} \\
\hline & & & & $\begin{array}{l}\text { Percent. } \\
\text { pessoas } \\
\text { em dom. } \\
\text { c/ ban- } \\
\text { heiro e } \\
\text { água enc. } \\
(2010)\end{array}$ & $\begin{array}{l}\text { Esper- } \\
\text { ança vida } \\
\text { ao nascer } \\
(2010)\end{array}$ & $\begin{array}{l}\text { Tx. } \\
\text { analfab. } \\
\text { faixa } \\
\text { etária } \\
11 \text { a } 14 \\
(2010)\end{array}$ & $\begin{array}{l}\text { Percent. } \\
\text { Jovens } 18 \\
\text { a } 20 \text { anos } \\
\text { c/ ens. } \\
\text { médio } \\
\text { completo } \\
(2010)\end{array}$ \\
\hline DF & $\mathrm{CO}$ & 2570,20 & 1,30 & 96,01 & 77,35 & 1,10 & 53,48 \\
\hline SC & $S$ & 6248,40 & 3,20 & 97,00 & 76,61 & 1,05 & 51,80 \\
\hline SP & SE & 41262,20 & 21,00 & 97,12 & 75,69 & 1,49 & 52,33 \\
\hline RS & $S$ & 10693,90 & 5,40 & 96,46 & 75,38 & 1,29 & 43,79 \\
\hline MG & SE & 19597,30 & 10,00 & 94,91 & 75,30 & 1,52 & 42,82 \\
\hline ES & SE & 3515,00 & 1,80 & 96,89 & 75,10 & 1,76 & 44,93 \\
\hline $\mathrm{RJ}$ & SE & 15989,90 & 8,10 & 94,73 & 75,10 & 1,76 & 42,93 \\
\hline MS & $\mathrm{CO}$ & 2449,00 & 1,20 & 93,76 & 74,96 & 1,55 & 40,43 \\
\hline $\mathrm{PR}$ & $S$ & 10444,50 & 5,30 & 96,69 & 74,80 & 1,14 & 48,05 \\
\hline GO & $\mathrm{CO}$ & 6003,80 & 3,10 & 93,66 & 74,60 & 1,57 & 44,62 \\
\hline MT & $\mathrm{CO}$ & 3035,10 & 1,50 & 90,37 & 74,25 & 2,00 & 42,36 \\
\hline AP & $\mathrm{N}$ & 669,50 & 0,30 & 66,38 & 73,80 & 3,81 & 35,73 \\
\hline $\mathrm{RR}$ & $\mathrm{N}$ & 450,50 & 0,20 & 74,04 & 73,51 & 5,13 & 40,53 \\
\hline TO & $\mathrm{N}$ & 1383,40 & 0,70 & 80,41 & 72,56 & 2,90 & 40,73 \\
\hline $\mathrm{RO}$ & $\mathrm{N}$ & 1562,40 & 0,80 & 79,62 & 72,97 & 1,59 & 36,47 \\
\hline $\mathrm{RN}$ & $\mathrm{NE}$ & 3168,00 & 1,60 & 85,06 & 72,52 & 6,63 & 36,11 \\
\hline SE & NE & 2068,00 & 1,10 & 82,24 & 71,84 & 5,52 & 30,55 \\
\hline $\mathrm{AM}$ & $\mathrm{N}$ & 3484,00 & 1,80 & 62,16 & 73,30 & 6,54 & 28,76 \\
\hline $\mathrm{CE}$ & $\mathrm{NE}$ & 8452,40 & 4,30 & 76,28 & 72,60 & 4,65 & 37,39 \\
\hline $\mathrm{PA}$ & $\mathrm{N}$ & 7581,10 & 3,90 & 57,50 & 72,36 & 6,32 & 24,10 \\
\hline $\mathrm{PE}$ & $\mathrm{NE}$ & 8796,40 & 4,50 & 78,22 & 72,32 & 5,66 & 32,64 \\
\hline $\mathrm{PB}$ & $\mathrm{NE}$ & 3766,50 & 1,90 & 78,91 & 72,00 & 5,39 & 32,88 \\
\hline $\mathrm{BA}$ & $\mathrm{NE}$ & 14016,90 & 7,10 & 77,60 & 71,97 & 5,01 & 29,49 \\
\hline $\mathrm{AC}$ & $\mathrm{N}$ & 733,60 & 0,40 & 47,42 & 71,63 & 6,64 & 31,98 \\
\hline PI & $\mathrm{NE}$ & 3118,40 & 1,60 & 67,12 & 71,62 & 6,50 & 29,44 \\
\hline MA & $\mathrm{NE}$ & 6574,80 & 3,30 & 51,79 & 70,40 & 7,59 & 29,60 \\
\hline $\mathrm{AL}$ & $\mathrm{NE}$ & 8796,40 & 4,50 & 75,64 & 70,32 & 8,96 & 25,86 \\
\hline
\end{tabular}

Fonte: Elaboração Própria, a partir de Instituto Brasileiro de Geografia e Estatística (IBGE) / Atlas do Desenvolvimento Humano no Brasil (2010). 
Dos 27 Estados, 11 (40\% deles) apresentaram todos os indicadores de qualidade das políticas com saúde e educação acima da média, são eles (em ordem alfabética): Distrito Federal, Espírito Santo, Goiás, Minas Gerais, Mato Grosso, Mato Grosso do Sul, Paraná, Rio de Janeiro, Rio Grande do Sul, Santa Catarina e São Paulo. É possível notar que neste grupo não há nenhum representante das regiões Norte e Nordeste do país. A porcentagem da população anexada por estes estados é de 61,90\%, mais da metade da população total, um fato positivo.

Por outro lado, 10 dos 27 Estados, apresentaram todos os indicadores de saúde e educação abaixo da média, são eles (em ordem alfabética): Acre, Alagoas, Amazonas, Bahia, Ceará, Maranhão, Pará, Paraíba, Pernambuco e Piauí. Todos os Estados deste grupo são das regiões Norte e, principalmente, Nordeste do país. Estes estados concentram uma parcela considerável da população, 33,30\%, porcentagem que não pode ser desconsiderada na formulação de políticas públicas.

Passa-se, neste momento, a analisar os indicadores de capacidade institucional dos Tribunais de Contas subnacionais brasileiros. Para tanto, a Tabela 6 ilustra a estatística descritiva das variáveis.

Tabela 6. Estatística Descritiva - Capacidade Institucional dos Tribunais de Contas Subnacionais.

\begin{tabular}{|l|c|c|c|c|}
\hline \multicolumn{1}{|c|}{ Variável } & Mínimo & Máximo & Média & Desvio Padrão \\
\hline Orçamento (2010) & $27.024 .800,00$ & $455.187 .100,00$ & $125.959 .100,00$ & $103.426 .300,00$ \\
\hline Pessoal (2010) & 85,00 & $2.141,00$ & 608,41 & 453,91 \\
\hline $\begin{array}{l}\text { Contas Irregulares por } \\
\text { Volume de Recursos } \\
\text { sob Fiscalização (2010) }\end{array}$ & 0,0000000001 & 0,0000000392 & 0,0000000064 & 0,0000000104 \\
\hline
\end{tabular}

Fonte: Elaboração própria, a partir da Lei Orçamentária Anual - LOA de cada um dos respectivos Estados / Tribunais de Contas Subnacionais (via Lei de Acesso à Informação) / Secretaria do Tesouro Nacional (STN) / Instituto Brasileiro de Geografia e Estatística (IBGE) / Tribunais Regionais Eleitorais (TREs).

60. Os dados relativos a esta variável foram obtidos a partir de consulta ao sítio oficial do Instituto Brasileiro de Geografia e Estatística - IBGE (<https://www.ibge.gov.br/>).

61. Os dados relativos a esta variável foram obtidos a partir de consulta ao sítio oficial do Atlas do Desenvolvimento Humano no Brasil (<http://atlasbrasil.org.br/>).

62. Os dados relativos a esta variável foram obtidos a partir de consulta ao sítio oficial do Atlas do Desenvolvimento Humano no Brasil (<http://atlasbrasil.org.br/>).

63. Os dados relativos a esta variável foram obtidos a partir de consulta ao sítio oficial do Atlas do Desenvolvimento Humano no Brasil (<http://atlasbrasil.org.br/>).

64. Os dados relativos a esta variável foram obtidos a partir de consulta ao sítio oficial do Atlas do Desenvolvimento Humano no Brasil (<http://atlasbrasil.org.br/>). 
Quanto ao orçamento dos tribunais, a média é de R\$ 125.959.100,oo, com um desvio padrão de 103.426.300,oo. No ano de 2010, o Tribunal de Contas do Estado do Ceará apresentou o menor orçamento, ao passo que o Tribunal de Contas do Estado de São Paulo apresentou o maior orçamento.

Com relação ao quantitativo de pessoal, a média é de 608,41, com um desvio padrão de 453,91. Comparativamente, o Tribunal de Contas do Estado do Amapá apresenta o menor quantitativo de pessoal e o Tribunal de Contas do Estado de São Paulo, por sua vez, possui o maior quantitativo.

É possível notar ainda que, no ano de 2010, a média de contas julgadas irregulares pelos Tribunais de Contas subnacionais foi de aproximadamente 6 para cada R\$ 1.000.000.000,oo sob sua fiscalização, com desvio padrão de o,00oooo0104. O Tribunal de Contas com o maior quantitativo de contas julgadas irregulares por volume de recursos sob sua fiscalização foi o TCE do Acre. Por sua vez, o menor quantitativo de contas julgadas irregulares por volume de recursos sob sua fiscalização foi apresentado pelo TCE de São Paulo.

O próximo procedimento analítico consiste em avaliar a relação entre a capacidade institucional dos Tribunais de Contas subnacionais brasileiros e os indicadores de qualidade das políticas públicas de saúde e educação de seus respectivos Estados. Para tanto, o Gráfico 1 abaixo ilustra o padrão de correlação entre essas variáveis:

\section{Gráfico 1. Correlação entre as Variáveis}



Fonte: Elaboração Própria.

Observa-se uma forte correlação negativa $(r=-0,75)$ e estatisticamente significativa ( $p$-valor $<0,01$ ) entre contas irregulares por volume de recursos sob fiscalização e percentual de pessoas que vivem em domicílios com banheiro e água encanada. Verifica-se, também, uma correlação muito forte, positiva e estatisticamente significativa 
( $p$-valor $<0,01)$ entre pessoal e orçamento $(r=0,91)$ e uma forte correlação positiva e estatisticamente significativa ( $\mathrm{p}$-valor $<0,01)$ entre pessoal e PIB $(\mathrm{r}=\mathrm{o}, 82)$.

Quanto à variável orçamento, é possível notar uma forte correlação positiva e estatisticamente significativa ( $p$-valor $<0,01)$ com a variável PIB $(r=0,82)$. Verifica-se ainda uma moderada correlação positiva e estatisticamente significativa ( $\mathrm{p}$-valor $<0,01$ ) com as seguintes variáveis: percentual de pessoas que vivem em domicílios com banheiro e água encanada $(r=0,54)$, esperança de vida ao nascer $(r=0,57)$ e percetual de jovens de 18 a 20 anos com ensino médio completo $(\mathrm{r}=0,50)$. Por fim, verifica-se uma moderada correlação negativa e estatisticamente significativa ( $\mathrm{p}$-valor $<0,01)$ com a variável taxa de analfabetismo na faixa etária de 11 a 14 anos $(r=-0,52)$.

A variável PIB possui uma moderada correlação positiva e estatisticamente significativa ( $\mathrm{p}$-valor $<0,01)$ com as seguintes variáveis: esperança de vida ao nascer $(\mathrm{r}$ $=0,52)$ e percetual de jovens de 18 a 20 anos com ensino médio completo $(\mathrm{r}=0,55)$. Verifica-se ainda uma fraca correlação positiva e estatisticamente significativa (p-valor $<0,01$ ) com a variável percentual de pessoas que vivem em domicílios com banheiro e água encanada $(r=0,49)$. Observar-se - também - uma fraca correlação negativa e estatisticamente significativa ( $\mathrm{p}$-valor $<\mathrm{O}, \mathrm{O} 1$ ) com a variável taxa de analfabetismo na faixa etária de 11 a 14 anos $(r=-0,47)$.

Com relação à variável percentual de pessoas que vivem em domicílios com banheiro e água encanada, é possível notar que ela possui uma forte correlação positiva e estatisticamente significativa ( $\mathrm{p}$-valor $<0,01$ ) com as seguintes variáveis: esperança de vida ao nascer $(\mathrm{r}=0,78)$ e percetual de jovens de 18 a 20 anos com ensino médio completo $(r=0,82)$. Verifica-se ainda uma forte correlação negativa e estatisticamente significativa $(\mathrm{p}$-valor $<0,01)$ com a variável taxa de analfabetismo na faixa etária de 11 a 14 anos $(r=-0,83)$.

A variável esperança de vida ao nascer, por sua vez, possui uma forte correlação positiva e estatisticamente significativa ( $\mathrm{p}$-valor $<0,01)$ com a variável percetual de jovens de 18 a 20 anos com ensino médio completo $(\mathrm{r}=0,89)$ e uma forte correlação negativa e estatisticamente significativa ( $\mathrm{p}$-valor $<\mathrm{O}, 01)$ com a variável taxa de analfabetismo na faixa etária de 11 a 14 anos $(\mathrm{r}=-0,89)$. Ao passo que a variável taxa de analfabetismo na faixa etária de 11 a 14 anos possui uma forte correlação negativa e estatisticamente significativa ( $\mathrm{p}$-valor $<0,01)$ com a variável percetual de jovens de 18 a 20 anos com ensino médio completo $(r=-0,87)$. As demais correlações constantes do Gráfico 1 não apresentaram significância estatística (p-valor $>0,01$ ) e, portanto, figuram com um " $\mathrm{X}$ " sobre os seus valores.

Em outras palavras, os resultados aqui reportados sugerem que: o fortalecimento do controle dos gastos públicos está positivamente correlacionado com a qualidade das políticas públicas oferecidas aos cidadãos. Tais resultados sinalizam haver apoio empírico para a hipótese testada neste estudo, isto é, existe uma associação entre a ca 
pacidade institucional dos Tribunais de Contas subnacionais brasileiros e a qualidade das políticas públicas de saúde e educação de seus respectivos Estados, como destaca Melo et $a l .{ }^{65}$ e Rocha et $a l .{ }^{66} \mathrm{O}$ que reforça a necessidade de um aprofundamento de estudos nessa direção, a fim de ressaltar a importância da atuação dos Tribunais de Contas subnacionais brasileiros em prol da qualidade das políticas públicas.

Contudo, embora esta constatação atenda aos fins a que se destinou o presente artigo, qual seja, encontrar evidências empíricas que sinalizassem na direção da hipótese testada, é importante ressaltar que ela não esgota o assunto. Pelo contrário, ela apenas abre o caminho para novas e aprofundadas discussões sobre o tema, nas quais sejam incluídas análises inferenciais mais robustas e com novas variáveis.

\section{Considerações Finais}

O principal objetivo deste artigo foi analisar a relação entre a capacidade institucional dos Tribunais de Contas subnacionais brasileiros e a qualidade das políticas públicas de seus respectivos Estados.

Metodologicamente, o desenho de pesquisa combinou estatística descritiva e multivariada para analisar um banco de dados original elaborado com informações obtidas de diferentes fontes. Em particular, operacionalizou-se a capacidade institucional dos Tribunais de Contas subnacionais brasileiros a partir das seguintes variáveis: orçamento, pessoal e contas julgadas irregulares. Não obstante, utilizou-se a análise fatorial para definir os indicadores relativos à qualidade das políticas públicas de saúde e educação de seus respectivos Estados, no ano de 2010.

Os resultados preliminares sinalizam haver apoio empírico para a hipótese testada neste estudo: existe uma associação entre a capacidade institucional dos Tribunais de Contas subnacionais brasileiros e a qualidade das políticas públicas de saúde e educação de seus respectivos Estados. Sobretudo porque, analisando os resultados desagregados por variáveis empregadas, observa-se que essa relação é estatisticamente significativa em relação a todas as variáveis empregadas, corroborando a necessidade de novos trabalhos nesta direção que incluam mais variáveis às bases dos indicadores de capacidade institucional dos Tribunais de Contas, permitindo-se assim pesquisas mais robustas e abrangentes.

65. MELO et al. (2009).

66. ROCHA et. al. (2014). 
Em relação às limitações, a principal é a disponibilidade de informações referentes ao tema estudado. Além disso, a análise cross-section diminui a robustez dos resultados em relação a um modelo de dados em painel (por exemplo), que controlaria por variâncias temporais e tornaria a análise menos suscetível a dados fora da média de cada Estado. Por fim, apesar das limitações, o presente trabalho se constitui em esforço para demonstrar que os Tribunais de Contas figuram como importantes instituições de controle, logo, funcionam como checks and balances e, por conseguinte, impactam a qualidade das políticas públicas.

\section{Referencias bibliográficas}

ABRUCIO, Fernando L. y LOUREIRO, Maria R (2004): "Finanças públicas, democracia e accountability: debate teórico e o caso brasileiro". En ARVATE, Paulo R.; BIDERMAN, Ciro. Economia do setor público no Brasil (Rio de Janeiro, Elsevier) pp. 75-102.

ARANTES, Rogério Bastos; ABRUCIO, Fernando Luiz; TEIXEIRA, Marco Antonio Carvalho (2005): "A imagem dos Tribunais de Contas subnacionais". En Revista do Serviço Público, Ano 56, № 1, jan-mar: pp. 57-83.

ARANTES, Rogério; LOUREIRO, Maria Rita; COUTO, Cláudio; TEIXEIRA, Marco Antonio (2011): "Controles democráticos sobre a administração pública no Brasil: Legislativo, Tribunais de Contas, Judiciário e Ministério Público”. En.: LOUREIRO, Maria Rita; ABRUCIO, Fernando; PACHECO, Regina. Burocracia e Política no Brasil Contemporâneo (Rio de Janeiro, Ed. FGV).

BRASIL. Constituição (1988): “Constituição da República Federativa do Brasil”. Brasília, DF, 1988. Disponível em: <http://www.planalto.gov.br>. [Data da pesquisa: 18 de março de 2018].

BRASIL. Ministério do Planejamento, Orçamento e Gestão. Secretaria de Gestão Pública (2014): "Programa GESPÚBLICA, Modelo de Excelência em Gestão Pública" (Brasília, MP, SEGEP).

BRASIL.(2013): "Contrato de Empréstimo 1628/OC-BR_PROMOEX; Relatório Final” (Brasília, MPOG, SEGEP).

BRASIL.(2015): "Programa de Modernização do Sistema de Controle Externo dos Estados e Municípios Brasileiros - PROMOEX” (Brasília, MPOG, SEGEP). 
CAVALCANTE, Mônica Clark Nunes; PETER, Maria da Glória Arrais; MACHADO, Marcus Vinicius Veras (2012): “Controle como Dimensão da Governança Pública: Princípios e Melhores Práticas definidos pelos Órgãos Internacionais”. En VI Congresso de Costos Del MERCOSUR, 2012, Uruguai. Disponível em: <http://website. acep.org.br/2011/wp-content/uploads/2014/10/teste1.pdf $>$. [Data da pesquisa: 18 de agosto de 2018].

CRUZ JUNIOR, Brauner Geraldo (2015): “A Efetividade dos Tribunais de Contas na Fiscalização de Recursos Estaduais e Municipais: Uma Análise dos Tribunais de Contas com base nas irregularidades relatadas em gestões municipais auditadas pela CGU”. 2015. 91 Páginas. Relatório Final projeto de Iniciação Científica - PIBIC Escola de Administração de Empresas de São Paulo (São Paulo, Fundação Getúlio Vargas).

FARACO, Bruno Pereira; NIWA, Tiago Hideki; VICENTIN, Ivan Carlos (2016): "Controle na Administração Pública”. En OLIVEIRA, Antonio Gonçalves; PISA, Beatriz Jackiu; AUGUSTINHO, Sonia Maria (Org.). Gestão e governança pública: aspectos essenciais (Curitiba, Ed. UTFPR).

FERNANDES, Fabiana Silva (2016): "Capacidade institucional: uma revisão de conceitos e programas federais de governo para o fortalecimento da administração pública”. En Cad. EBAPE.BR, Ano 14, No3, Artigo 2, Rio de Janeiro, Jul./Set.

FERREIRA, Thiago Augusto de O. M (2012): “O papel do Tribunal de Contas da União como órgão de avaliação de políticas públicas”. En Revista Jus Navigandi, ISSN 1518-4862, Teresina, ano 17, n. 3136, 1 fev. Disponível em: <https://jus.com. br/artigos/20989>. [Data da pesquisa: 18 de março de 2018].

FERREIRA, Thiago Augusto de O. M (2013): "Arranjos institucionais dos tribunais de contas da União e de Portugal”. 2013. 83 Páginas. Dissertação (Mestrado em Ciência Política) - Programa de Pós-Graduação em Ciência Política (Recife, Universidade Federal de Pernambuco - UFPE).

FIGUEIRÊDO, Carlos Maurício Cabral (2007): "Prestação de contas e responsabilização: uma oportunidade de interação entre os tribunais de contas e o cidadão". En V CONFERÊNCIA EUROSAI-OLACEFS, Lisboa.

FIGUEIREDO FILHO, Dalson Brito et al. (2014): "Análise fatorial garantida ou o seu dinheiro de volta: uma introdução à redução de dados". En Revista Eletrônica de Ciência Política, Ano 5, No 2.

FUKUYAMA, Francis (2005): "Construção de Estados: governo e organização mundial no século XXI” (Rio de Janeiro, Rocco). 
GIL, Antônio Carlos (1999): "Métodos e técnicas de pesquisa social”. 5.ed. (São Paulo, Atlas).

KING, Gary (1995): “Replication, Replication”. En Political Science and Politics, Cambridge, UK, No 28 , set, pp. 443-499.

LOPES, Luckas Sabioni y TOYOSHIMA, Silvia Harumi (2013): "Evidências do Impacto da Corrupção sobre a Eficiência das Políticas de Saúde e Educação nos Estados Brasileiros". En Planejamento e Políticas Públicas, № 41 jul-dez: pp. 209-238.

LOUREIRO, Maria Rita, TEIXEIRA, Marco Antonio Carvalho, MORAES, Tiago Cacique (2009): "Democratização e reforma do Estado: o desenvolvimento institucional dos tribunais de contas no Brasil recente". En Revista de Administração Pública, Ano $43 \mathrm{~N}^{\circ} 4$, jul-ago: pp. 739-772.

MELO, Marcus André (2008): "O controle externo na América Latina”. (São Paulo, Instituto Fernando Henrique Cardoso; Santiago do Chile, Corporación de Estudios para Latinoamérica - Cieplan), 56 p. Contribuição ao projeto: Uma Nova Agenda Econômica e Social para a América Latina. Disponível em: $<$ http://www. ifhc.org.b r/>. [Data da pesquisa: 18 de março de 2018].

MELO, Marcus André; PEREIRA, Carlos; FIGUEIREDO, Carlos Maurício Cabral (2009): "Political and Institutional Checks on Corruption: Explaining the Performance of Brazilian Audit Institutions". En Comparative Political Studies, Ano 42, $\mathrm{N}^{\circ}$ 9, Michigan, Set.

MORAES, Tiago Cacique (2006): "O Processo de Modernização dos Tribunais de Contas no Contexto da Reforma do Estado no Brasil”. 113 páginas. Mestrado em Administração Pública e Governo. Escola de Administração de Empresas de São Paulo (São Paulo, Fundação Getúlio Vargas).

O'DONNELL, Guillermo (1998): "Accountability horizontal e novas poliarquias". En Lua Nova, São Paulo, n. 44. Disponível em <http://www.scielo.br/scielo.php? script $=$ sci_arttext\&pid $=$ So102 $-64451998000200003 \& \ln g=$ pt\&nrm $=$ iso $>$.[Data da pesquisa: 18 de março de 2018].

OLIVEIRA, Alden Mangueira de (2015): "Governança no Setor Público sob o Prisma do Controle Externo: a experiência do Tribunal de Contas da União (TCU) na avaliação das políticas públicas e na indução do seu aperfeiçoamento como alavanca ao Desenvolvimento Nacional". 2015. pp. 178. Curso de Altos Estudos de Política e Estratégia. Departamento de Estudos (Rio de Janeiro, Escola Superior de Guerra). 
PASSARINHO, Nathalia (2018): “Os ministérios mais cobiçados pelos políticos do Brasil, segundo pesquisa inédita de Oxford”. En BBC Brasil. Disponível em: <http://www.bbc.com/portuguese/brasil-43218087>. [Data da pesquisa: $18 \mathrm{de}$ março de 2018].

ROCHA, Enivaldo Carvalho da et al. (2014): "Capacidade institucional e corrupção: Tribunais de Contas Estaduais em perspectiva comparada”. En Revista Debates, Porto Alegre, Ano 8, No 3, set.-dez, pp. 181-204.

SANO, Hironobu y MONTENEGRO FILHO, Mário Jorge França (2013): “As Técnicas de Avaliação da Eficiência, Eficácia e Efetividade na Gestão Pública e sua Relevância para o Desenvolvimento Social e das Ações Públicas". En Desenvolvimento em Questão, Editora Unijuí, Ano 11, No 22, jan./abr.

SPECK, Bruno Wilhelm (200o): "Inovação e rotina no Tribunal de Contas da União: o papel da instituição superior de controle financeiro no sistema político-administrativo do Brasil”. (São Paulo, Função Konrad Adenauer).

SPECK, Bruno Wilhelm (2013): “Tribunais de Contas”. En Revista Gestão e Controle, No 1, pp. 211-219.

STAPENHURST, Rick y TITSWORTH, Jack (2001): "Features and functions of supreme audit institutions: Supreme audit institutions can curb corruption by reinforcing legal, financial, and institutional frameworks and by reducing the arbitrary application of rules and laws". En Notes Public Sector, No 59 , World Bank.

TEIXEIRA, Marco Antônio Carvalho y ALVES, Márcio Aquino (2011): "Ethos organizacional e controle da corrupção: o TCU sob uma ótica organizacional”. En Cadernos Adenauer, Fundação Konrad Adenauer, Rio de Janeiro, Ano 12, No 3, pp. 75-109. 


\title{
RESE N A
}

\section{How Democracies Die ${ }^{1}$}

\author{
Camilo Garber Fuentes ${ }^{2}$ \\ Universidad Diego Portales, Chile
}

Steven Levitsky y Daniel Ziblatt, profesores de Harvard, nos presentan una obra extremadamente atingente para nuestros tiempos. Y es que How Democracies Die se origina desde la preocupación política de los autores al observar la creciente fragilidad contemporánea de la democracia. A esta preocupación se le añade, y esto es muy notorio, un profundo conocimiento sobre los quiebres democráticos y los autoritarismos que ambos autores han construido a lo largo de muchos años de estudio.

El libro pretende responder una pregunta de formulación simple pero de respuesta compleja: ¿están nuestras democracias en peligro? Un adelanto: sí, lo están. Pero las formas que toma la amenaza son distintas a las que clásicamente conocíamos en la ciencia política. Y es en este punto en donde radica la riqueza histórica, política y conceptual de este trabajo.

Sirviéndose de un vasto y profundo conocimiento de una plétora de casos a través del mundo y del tiempo, entre los que encontramos a varios países latinoamericanos como ejemplos de las amenazas que toman formas viejas y nuevas, los autores comienzan a trazar el nuevo rumbo y esquema de agonía de las democracias. En la actualidad ya no son necesarias las conjuras militares, los bombardeos a las casas de Estado ni las matanzas y exilios masivos. Son otras las armas utilizadas para provocar la muerte de la democracia, las que, paradojalmente, son provistas por ella misma. Tal como anotan los autores, estas formas "son menos dramáticas, pero igualmente destructivas. Las democracias pueden morir a manos no de generales, sino de líderes electos, presidentes o primeros ministros que subvierten el mismo proceso que los llevó al poder" ${ }^{\prime 3}$.

1. LEVISTKY Y ZIBLATT (2018).

2. Estudiante del pregrado de Ciencia Política y minor en Ciencias Sociales de la Universidad Diego Portales. Ayudante de cátedra y asistente de investigación. Correo electrónico: camilo.garber@mail. udp.cl

3. LEVISTKY Y ZIBLATT (2018), p.3. 
Las 312 páginas que componen el libro se distribuyen en 9 capítulos. El primero trabaja una serie de ejemplos históricos que dan cuenta del riesgo de abrir las puertas de la democracia a líderes extremistas y demagogos, entre los que se destacan Chávez, Hitler y Mussolini. Siguiendo el aporte seminal de Linz y Stepan en su libro The Breakdown of democratic regimes (1978) los autores presentan la principal herramienta teórica para diagnosticar crisis democráticas. Se trata de un modelo analítico compuesto de cuatro indicadores que buscan responder si acaso las democracias se encuentran expuestas a dinámicas autoritarias. El primer elemento pregunta si existe un rechazo abierto o un compromiso débil hacia las reglas democráticas. El segundo busca establecer si los oponentes políticos son considerados legítimos. El tercero evalúa si el clima político tolera el estímulo a la violencia. El modelo se cierra preguntándose si los actores políticos están dispuestos a reducir las libertades civiles de los oponentes políticos, especialmente en lo referido al acceso a los medios de comunicación ${ }^{4}$.

Como se puede apreciar, este modelo de alta parsimonia hace un guiño a la Poliarquía de Robert Dahl ${ }^{5}$. Sin embargo, ya no se trata de aspirar a la democracia, sino que identificar a la autocracia. Esto se agradece, pues no son necesarias ni formulaciones teóricas enrevesadas ni modelos estadísticos de alta complejidad. Al contrario, cada elemento analítico contiene una serie de preguntas que orientan su respuesta. En este sentido, a pesar del interés politológico que lo anima, esta dimensión es una que facilita la lectura a un público más amplio. Punto de radical importancia, pues el libro trata sobre un asunto que nos debiese importar a todos.

Los siguientes dos capítulos se dedican a aplicar el modelo propuesto al caso estadounidense. Analizando la figura de Donald Trump ${ }^{6}$, los autores dan cuenta de la utilidad del modelo, pues en todos los indicadores se aprecia un grado de amenaza a la democracia. El riesgo de las figuras como el actual presidente de Estados Unidos estriba en que el sistema político se cree (o creía) inoculado en contra de ellas, en tanto la solidez de la trayectoria democrática y el equilibrio de poderes le impediría su ascenso. Se trata de un desafío al enfoque del Path Dependence ${ }^{7}$, pues las condiciones políticas, sociales, económicas y culturales ya no bastan para preservar la democracia. Serán la actitud de celo democrático por parte de la ciudadanía y los principales líderes políticos el punto clave a la hora de preservarla.

\footnotetext{
4. LEVISTKY Y ZIBLATT (2018), p. 23.

5. DAHL (2001).

6. LEVISTKY Y ZIBLATT (2018), p. 53.

7. PIERSON Y SKOCPOL (2002).
} 
El cuarto capítulo trata sobre las estrategias de los líderes políticos para subvertir la democracia. Ellas son, a grosso modo, la politización del sistema judicial; la captura de agentes políticos claves, como los principales financistas, los medios de comunicación y la intelligentsia; y, finalmente, el cambio de las reglas del juego político. El ejemplo clásico de esto último es el cambio constitucional. Es de esta forma que los líderes autocráticos consolidan su poder, pues como advierten Levitsky y Ziblatt, "las instituciones se transforman en armas políticas, forzosamente manejadas por quienes controlan el poder en contra de quienes no lo tienen"».

El ejemplo de Chávez en Venezuela resulta especialmente ilustrador. No obstante de haber intentado hacerse del poder a través de un Golpe de Estado en febrero de 1992, su mensaje político de inspiración bolivariana logró penetrar a la sociedad, haciendo que el esmirriado sistema de partidos venezolano, a raíz de una crisis económica, abrazara sus ideas. El sistema político se plegó a su mensaje y lo sindicó como el salvador de la crisis. Es decir, a pesar de su pasado manifiestamente autoritario, el régimen democrático depositó sus esperanzas de supervivencias en él, bajo la ilusión de poder ejercer control sobre su mandato. Una vez que encabezó el país, dirigió una serie de políticas destinadas a suprimir la libertad de los opositores, dirigir los medios de comunicación y consagrar todo ello en las instituciones ${ }^{9}$. Un ejemplo de manual de cómo mueren las democracias modernas.

Los capítulos quinto y sexto tratan de una materia muy interesante: las reglas no escritas que sostienen la democracia. Se trata de principios, actitudes y comportamientos por parte de la población que fortalecen el régimen democrático. Son dos las principales, que los autores pesquisan en el caso estadounidense. La primera es la tolerancia mutua, definida como el entendimiento de los partidos competidores de sus rivales como actores legítimos en el sistema político. La segunda corresponde al dominio de los políticos sobre sí mismos a la hora de ejercer sus prerrogativas institucionales ${ }^{10}$.

Los restantes capítulos se dedican al análisis de los posibles escenarios post-Trump, cuyos extremos se marcan por la lenta recuperación democrática, en el más optimista, hasta la profundización de la muerte de la democracia, en la menos auspiciosa, con Trump y los Republicanos manteniéndose en el poder, reproduciendo y exacerbando las lógicas autocráticas e iliberales ${ }^{11}$.

La obra, en su conjunto, representa una valiosa contribución al entendimiento del declive democrático. Ello, por varias razones. En primer término, dibuja un pano

8. LEVISTKY Y ZIBLATT (2018), p. 7.

9. LEVISTKY Y ZIBLATT (2018), p. 20.

10. LEVISTKY Y ZIBLATT (2018), p. 134.

11. LEVISTKY Y ZIBLATT (2018), p. 193. 
rama bastante acertado respecto a la situación mundial actual de los regímenes democráticos y sus riesgos. Además, da cuenta de las nuevas formas de erosión de la democracia, las que son contenidas dentro del mismo régimen. Es decir, ya no son amenazas externas, sino que procesos desatados por los mismos modelos democráticos liberales los que contienen a su némesis autocrática.

Luego, porque advierte sobre el carácter ilusorio del control democrático sobre los componentes autoritarios y la capacidad de este último de utilizar las herramientas de la democracia liberal en su contra. También hecha luz sobre la consecuencia de esta configuración, en donde al no existir un evento traumático que separe a la democracia de un autoritarismo, el análisis debe ser mucho más atento y fino para ser capaz de distinguir el momento del proceso de degeneración en que la democracia deviene en autocracia. En este sentido, los analistas ven cómo su labor se dificulta en la medida en que las formas autocráticas se depuran y tornan más sutiles, aunque igualmente perniciosas.

En términos metodológicos, la parsimonia del modelo resulta muy valorable. Y ello se ve incrementado en tanto se sustenta de un robusto análisis histórico sobre varios casos. Con recaudos, el modelo propuesto puede ser exportado a otras realidades nacionales, pues el caso basal, el estadounidense, ha sido un referente mundial para el desarrollo institucional de las democracias.

Ahora bien, si se pudiesen señalar críticas, ellas serían dos. La primera, de carácter teórico, refiere a la escaza atención prestada a los problemas económicos que subyacen a la quiebra de las democracias. Se trata de un asunto crecientemente trabajado en la literatura politológica y que pone en entredicho la capacidad de las democracias de resistir en contextos económicos de crisis y de alta desigualdad.

La segunda es de carácter metodológico. El modelo de análisis propuesto puede verse fortalecido con un mayor desarrollo conceptual respecto a las causas suficientes y necesarias para hablar de la muerte de la democracia. Creemos que el modelo INUS ${ }^{12}$ tiene mucho que ofrecer a modo de complemento para la herramienta heurística que proponen los autores, volviéndola más precisa y extrapolable.

Sin perjuicio de lo anterior, How Democracies Die es un trabajo de gran importancia intelectual y política para la actualidad. Se trata de responder a una pregunta simple, a través de un modelo simple, al que es, en opinión de los expertos, el problema más complejo y acuciante de nuestros tiempos.

12. PÉREZ-LIÑÁN (2007) 


\section{Referencias bibliográficas}

DAHL, Robert (2001): "La poliarquía”. En BATLLE, ALBERT. Diez textos básicos de ciencia política (Barcelona, Ariel) pp. 77-92.

LINZ, Juan José y STEPAN, Alfred (1978): The Breakdown of Democratic Regimes: Crisis, Breakdown and Reequilibration (Baltimore, The Johns Hopkins University Press).

PÉREZ LIÑÁN, Aníbal (2007): "El método comparativo: fundamentos y desarrollos recientes". Documento de trabajo.

PIERSON, Paul y SKOCPOL, Theda (2002): "Historical Institutionalism in Contemporary Political Science”. En KATZNELSON, I. y MILNER, H.V. (New York, W.W. Norton) pp. 693-721. 


\section{REVISTA CHILENA DE DERECHO Y CIENCIA POLÍTICA}

La Revista Chilena de Derecho y Ciencia Política es una publicación científica editada por la Facultad de Ciencias Jurídicas, Económicas y Administrativas, fundada en el año 2010. Su sello distintivo se basa en la existencia de dos secciones permanentes sobre el Derecho y la Ciencia Política entendidas como campos interdisciplinares. Su objetivo principal es la creación de espacios especializado que se beneficie de las sinergias que pueden y deben establecerse entre ambas especialidades.

\section{DIRECTOR EDITOR}

Dr. David Almagro Castro

COORDINADORA EDITORIAL

Claudia Campos Letelier, Universidad Católica de Temuco, Chile

\section{ASISTENTE DE COORDINACIÓN}

Hernán Sandoval Alarcón, Universidad Católica de Temuco, Chile

\section{CORRECTOR DE ESTILO Y DISEÑADOR}

Angélica Vera Sagredo, Universidad Católica de Temuco, Chile 
